JOSE CARLOS TEIXEIRA DE BARROS MORAES

SISTEMA DE CIRCULAÇAO EXTRACORPOREA DE
ACORDO COM O CONCEITO INTEGRADO DE
SEGURANÇA DE EQUIPAMENTO ELETRO-MEDICO

Tese apresentada à

Escola Politécnica da Universidade de São Paulo para obtenção do título de Doutor em Engenharia Elétrica.

\title{
$F T-186$
}

FT -218

SAO PAULO, 1986 
JOSE CARLOS TEIXEIRA DE BARROS MORAES

Engenheiro Eletricista, Faculdade de Engenharia Industrial, 1969 Mestre em Engenharia, Escola Politēcnica da USP, 1976

\begin{abstract}
SISTENA DE CIRCULAÇATO EXTRACORPOREA DE ACORDO COM O CONCEITO INTEGRADO DE SEGURANÇA DE EQUIPAMENTO ELETRO-MEDICO
\end{abstract}

Tese apresentada à ESCOLA POLITECNICA DA UNIVERSIDADE DE SATO PAULO para obtenção do título de "DOUTOR" em Engenharia Elëtrica

Orientador:

Prof.Dr. LUIZ DE QUEIROZ ORSINI

Professor Catedrātico do Depar

tamento de Engenharia Elétrica

da EPUSP. 
Ao meu irmão, Nélson Luis

A minha esposa Tânia

Aos meus filhos

caroline, clāudia e Daniel 
AGRADECIMENTOS

Ao meu orientador, Prof. Dr. LUIZ DE QUEIROZ ORSINI, tanto pela orientação precisa e rigorosa como pela contribuição à minha formação profissional.

Ao Prof. Dr. Andrë Fábio Kohn, pelos permanentes in centivos e contribuições.

A todos que atuam no Sistema Nacional de Metrologia, Normalização e Qualidade Industrial em nosso país, representa dos pelo Eng: Giocondo Mário Vita, pelo serviço prestado às nos sas comunidades científica e empresarial.

A Luzia do Carmo Namiki, pelo atento e esmerado traba tho de datilografia.

Ao Marcelo de Albuquerque, pela cuidadosa feitura de desenhos e tabelas.

A minha esposa, pelo apoio e colaboração prestados em todo o decorrer deste trabalho.

A todos que direta ou indiretamente possibilitaram o desenvolvimento desta pesquisa. 
RESUMO

O objetivo da pesquisa foi o desenvolvimento de um abrangente Sistema de Circulação Extracorpórea usando o conce to integrado de segurança para equipamentos eletro-médicos. A necessidade inicial de determinação das especificações necessạ rias ao Sistema propiciou a definição de uma máquina coraçãopulmão artificial ideal, com várias inovações e modificações.

O projeto do Sistema de Circulação Extracorpórea con siderando aspectos de funcionalidade, qualidade, confiabilida de e segurança, tanto do próprio aparelho como da instalação e do ambiente de paciente, conduziu ao estabelecimento de um mo delo de concepção para equipamentos eletro-mëdicos, possibili tando inclusive a minimização dos problemas de manutenção e má utilização.

A implementação e os ensaios realizados demonstraram a viabilidade do projeto e as dificuldades de desenvolvimento e construção de aparelhos para fins médicos. Estas dificuldades decorreram da inexistência de implementos e dispositivos produ zidos em linhas normais de fabricação com as características exigidas pela aplicação médica.

A exigência da definição precisa de diretrizes rela tivas à segurança de aparelhos eletro-médicos motivou uma rea tivação e aceleração ao processo normativo do setor. 


\section{ABSTRACT}

The purpose of the research was the development of an Extracorporea1 Circulation System using the integrated con cept of electromedical equipment safety. The inicial need to determine the necessary specifications for the System lead to the definition of an ideal artificial heart-1ung machine. Several novel ideas and concepts were developed. Modifications of accepted industry procedures were proposed.

The design of the Extracorporeal Circulation System with the contraints of safety, quality, functionality and re liability lead to the development of a general model for the dcsign of electromedical equipment. In the design process other issues were also considered, such as ease of maintenance, mi nimization of hazardous consequences due to equipment misuse or the existence of harsh environments. Finally, special needs required by the installation and the patient environment were pointed out.

The implementation and testing of the machine confir med the appropriateness of the design model that was develo ped. It also pointed to the difficulties in the development and full scale production of medical equipment. These diffi culties were related to the lack of parts and devices produ ced locally with the required specifications for medical appli cations.

A by-product of all these research and development activities was the renewal of much needed work on normaliza tion of electromedical equipment in this country. 
CAPITULO I - INTRODUÇÃO

1.1 - A Engenharia Médica e o Conceito Integrado de Segu rança de Equipamento Eletro-médico............ 1.1

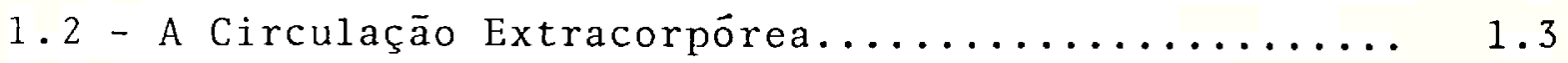

1.3 - Histórico da Mãquina Coração-Pulmão............. 1.6

1.4 - Sistema de Circulação Extracorpórea Proposto...... 1.9

1.5 - Objetivos da Pesquisa................... 1.12

CAPITULO II - A MÅQUINA CORAÇĀO-PULMAOO ARTIFICIAL IDEAL

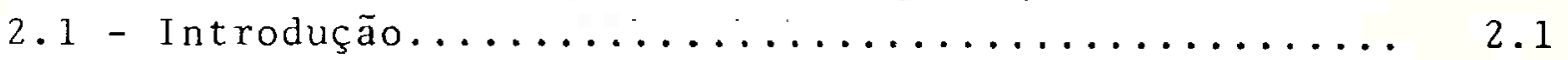

2.2 - A Perfusão Extracorpōrea e a Máquina Coração-Pulmão Artificial...................... 2.2

2.3 - Características Bäsicas da Função Cardiovascular Humana......................... 2.8

2.4 - Bases Fisiológicas da Circulação Extracorpórea e Características Hemodinâmicas da Perfusão....... 2.16

2.4 .1 - Função cardíaca.................. 2.16

2.4 .2 - Função pulmonar................... 2.21

2.5 - Características Desejāveis de Uma Máquina Coração Pulmão Artificial.................... 2.21

2.6 - A Máquina Coração-Pulmão Artificial Ideal....... 2.31

CAPÍTULO III - CONCEPÇÃO DO SISTEMA DE CIRCULAÇÃO EXTRACORPOREA DE ACORDO COM O CONCEITO INTEGRA DO DE SEGURANÇA DE EQUIPAMENTO ELETROMEDI $\mathrm{CO}$

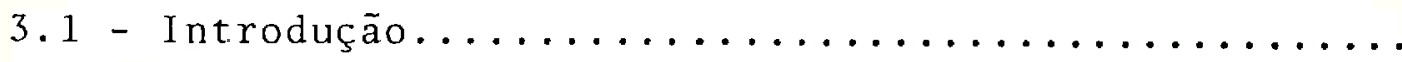

3.2 - O Conceito Integrado de Segurança para Equipamento

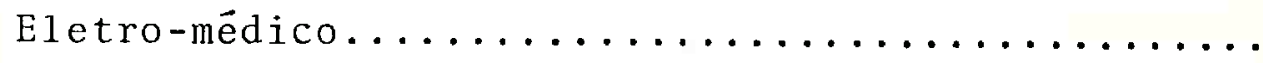

3.3 - Agentes de Risco Associados à Utilização de Equipa

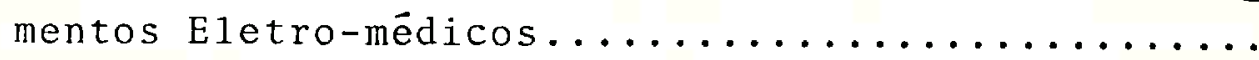


3.4 - o Sistema de Circulação Extracorpörea.........

3.4 .1 - Sub-Sistemas Motores............ 3.8

3.4 .2 - Sub-Sistema Detetor de Bolha.......... 3.11

3.4.3 - Sub-Sistema Detetor de Niveis de Sangue no

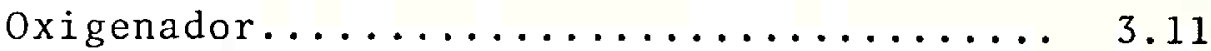

3.4 .4 - Sub-Sistema de Segurança............ 3.11

3.4 .5 - Sub-Sistema Hidráulico............. 3.12

3.4 .6 - Sub-Sistema Termométrico........... 3.14

3.4 .7 - Sub-Sistema Temporizador........... 3.15

3.4 .8 - Sub-Sistema de Alarmes............. 3.18

3.4 .9 - Sub-Sistema de Bases de Tempo......... 3.18

3.4 .10 - Sub-Sistema de Teste.............. 3.19

3.4.11 - Sub-Sistema de Alimentação........... 3.19

3.4 .12 - Sub-Sistema de Emergência............ 3.19

3.5 - Especificações Particulares das Partes .Essenciais do S.C.E. .......................... 3.20

3.5 .1 - Sub-Sistemas Motores............. 3.20

3.5 .2 - Sub-Sistema Hidräulico............. 3.28

3.5.2.1 - Bomba Hidräulica.......... 3.28

3.5 .2 .2 - Vālvulas Solenoides........ 3.29

3.5 .2 .3 - Mini-refrigerador......... 3.30

3.5.2.4 - Resistência de Aquecimento..... 3.30

3.5.2.5 - Termostato de Aquecimento..... 3.31

3.5 .2 .6 - Consideração Adicionais...... 3.32

3.5 .3 - Sub-Sistema Temporizador........... 3.32

3.5 .4 - Sub-Sistema Termométrico........... 3.32

3.5 .5 - Sub-Sistema de Alimentação.......... 3..33

3.5 .6 - Sub-Sistema de Emergência........... 3.38

3.6 - Prescrições Gerais e Ensaios do Sistema de Circula ção Extracorpōrea....................... 3.39

3.7 - Documentação e Código de Aplicação............ 3.40

3.8 - Condições Ambientais, Instalação e Manutenção.... 3.41

3.9 - Controle de Qualidade e Confiabilidade......... 3.42

CAPTTULO IV - IMPLEMENTAÇAOO E ENSAIOS DO SISTEMA DE CIR CULAÇAO EXTRACORPÓREA 
4.1 - Introdução.......................... 4.1

4.2 - Implementação do Sistema de Circulação Extracorpórea. 4.1 4.2 .1 - Partes Eletro-Eletrônicas............ 4.3 4.2 .1 .1 - Sub-Sistemas Motores......... 4.4 4.2.1.2 - Sub-Sistemas Detetores de Bolha e e de Niveis de Sangue no Oxigenador.................... 4.9

4.2.1.3 - Sub-Sistema de Segurança...... 4.13

4.2.1.4 - Sub-Sistema Hidräulico....... 4.16

4.2.1.5 - Sub-Sistema Termométrico...... 4.20

4.2.1.6 - Sub-Sistema Temporizador....... 4.24

4.2.1.7 - Sub-Sistema de Alarmes Sonoros... 4.32

4.2.1.8 - Sub-Sistema de Bases de Tempo... 4.32

4.2.1.9 - Sub-Sistema de Teste........ 4.32

4.2.1.10 - Sub-Sistema de Alimentação..... 4.36

4.2.1.11-Sub-Sistema de Emergência...... 4.36

4.2 .2 - Partẹs Mecânicas................... 4.40

4.2 .3 - Refrigeração..................... 4.40

4.2 .4 - Revestimento..................... 4.40

4.3 - Ensaios Realizados no Sistema de Circulação Extracorpörea......................... 4.42

4.3 .1 - Condições Ambientaís dos Ensaios......... 4.42

4.3 .2 - Condições de Alimentação Elētrica........ 4.44

4.3 .3 - Ensaio de Correntes de Fuga............ 4.46

4.3 .4 - Ensaio de Rigidez Dielétrica........... 4.52

4.3.5 - Ensaio nos Transformadores de Alimentação.. 4.58

4.3.6 - Ensaio da Potência Aparente Absorvida na En trada........................ 4.61

4.3.7 - Ensaio para Verificação de Partes Sob Tensão 4.61

4.3 .8 - Ensaio da Resistência Elétrica de Condutores de Proteção...................... 4.64

4.3 .9 - Ensaio de Impacto................. 4.65

4.3.10 - Ensaio de Estabilidade Posicional........ 4.66

4.3.11 - Ensaio Contra Riscos por Temperatura Excessiva....................... 4.66 
4.3 .12 - Ensaio contra Transbordamento.........4 4.67

4.3 .13 - Ensaio para Prova de Pingos...........44.67

4.3 .14 - Ensaio Funciona $1 \ldots \ldots \ldots \ldots \ldots \ldots \ldots \ldots \ldots . \ldots \ldots$

4.4 - Análise dos Resultados Obtidos nos Ensaios do Siste ma de Circulação Extracorpōrea............ 4.70

CAPITULO $v-$ CONCLUSAO ..................... 5.1

APENDICE A - FUNCIONAMENTOS DO SISTEMA VASCULAR SANGUINEO. BASES ANATÔMICAS E FISIOLOGICAS.......... A.l

APENDICE B - RELATÓRIO DESCRITIVO, REIVINDICAÇŌES E RESUMO DA PATENTE DE INVENÇAOO "APERFEIÇOAMENTOS EM BOMBAS"..................... B. 1

APENDICE C - RELATÓRIO DESCRITIVO, REIVINDICAÇOES E RESUMO DA PATENTE DE INVENÇÃO "REFRIGERADOR" ... C. 1

APENDICE D - DOCUMENTOS ACOMPANHANTES. CODIGO DE APLICA-

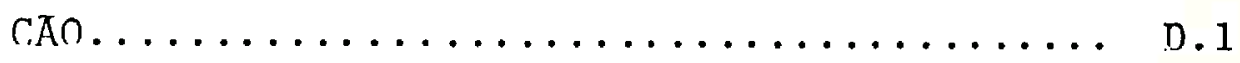

REFERENCIAS BIBLIOGRAFICAS .................. R. 1 


\section{LISTA DE SIMBOLOS}

$c$ : calor específico da água

g : aceleração gravitacional local

$\mathrm{H}_{\mathrm{Bu}}$ : altura ütil da bomba

$h_{e}$ : cota do centro de gravidade do elemento de entrada, em re lação a um plano de referência

$\mathrm{h}_{\mathrm{s}}$ : cota do centro de gravidade do elemento de saída, em rela ção a um plano de referência

m : massa da água

$\mathrm{P}_{B}$ : potência mecânica da bomba

$\mathrm{P}_{\mathrm{Bu}}$ : potência útil da bomba

$\mathrm{P}_{\mathrm{e}}$ : pressão no elemento de entrada

$\mathrm{P}_{\mathrm{S}}$ : pressão no elemento de saída

Q : quantidade de calor

R1 : resistência do enrolamento do transformador no início do ensaio

R2 : resistência do enrolamento do transformador no final do ensaio

$\mathrm{T}$ : torque do rotor

T1 : temperatura da sala no início do ensaio

T2 : temperatura da sala no final do ensaio

$v_{e}$ : velocidade média na secção do elemento de entrada

$\mathrm{v}_{\mathrm{s}}$ : velocidade média na secção do elemento de saída

$w$ : velocidade angular do rotor

$\alpha_{e}$ : fator de correção de Coriollis no elemento de entrada

$\alpha_{s}$ : fator de correção de Coriollis no elemento de saída

$\gamma$ : peso específico do sangue

$\Delta \mathrm{T}:$ diferença de temperatura

$\phi \quad$ : fluxo sanguíneo 


\section{LISTA DE FIGURAS}

Fig. 2.1. Princípio da circulação extracorpórea.

Fig. 2.2. A circulação normal e a circulação extracorpórea

Fig. 2.3. Princípio do oxigenador de membrana

Fig. 2.4. Princípio do oxigenador de bolhas

Fig. 2.5. Diagrama das modificações da pressão e da velocidade do fluxo que sofre o sangue na sua passagem pela cir culação sistêmica.

Fig. 2.6. Descrição compreensiva da função ventricular esquerda.

Fig. 2.7. Adaptações ventriculares durante atividade espontânea

Fig. 2.8. Fatores determinantes da pressão arterial sistêmica

Fig. 2.9. Uma bomba sanguinea de roletes

Fig. 2.10. A bomba de roletes usada no experimento de Head e co laboradores, 1960.

Fig. 3.1. Diagrama esquemático do Sistema de Circulação Extra corpórea.

Fig. 3.2. Vista frontal do Sistema de Circulação Extracorpórea

Fig. 3.3. Painel dos módulos motores

Fig. 3.4. Painel do sub-sistema hidrāulico

Fig. 3.5. Painel do sub-sistema termométrico

Fig. 3.6. Painel do sub-sistema temporizador

Fig. 3.7. Bomba sanguínea

Fig. 3.8. Carcaça do módulo venoso

Fig. 3.9. Carcaça do módulo arterial

Fig. 3.10. Rotor da bomba sanguínea

Fig. 3,11. Esquema do enrolamento secundārio do transformador de rede indicando os terminais $S_{1}$ e $S_{2}$.

Fig. 3.12. Sistema de Controle Total de Qualidade 
Fig. 4.1. Diagrama esquemätico do Sistema de Circulação Extra corpörea

Fig. 4.2. Circuito de controle da velocidade angular de rota ção do eixo do motor elétrico de cada bomba sanguí nea, indicando-se o próprio motor.

Fig. 4.3. Circuito de medição do fluxo sanguíneo, da velocida de angular do rotor e da abertura do lúmen.

Fig. 4.4. Diagramas de circuito e de tempo do medidor de flu xo sanguíneo e da velocidade angular do rotor.

Fig. 4.5. Diagrama de circuito e de tempo do medidor de 1 úmen

Fig. 4.6. Circuito do detetor de bolha

Fig. 4.7. Circuito detetor de níveis de sangue no oxigenador

Fig. 4.8. Circuito do sub-sistema de segurança

Fig. 4.9. Elementos principais dos circuitos de aquecimento, refrigeração e fluxos de água quente e àgua fria do sub-sistema hidráulico

Fig. 4.10. Circuito de comando dos fluxos das äguas quente e fria

Fig. 4.11. Circuitos de alimentação do mini-refrigerador e da resistência de aquecimento.

Fig. 4.12. Circuitos dos detetores de niveis nos reservatórios de äguas quente e fria.

Fig. 4.13. Visão de conjunto do sub-sistema hidrāulico.

Fig. 4.14. Circuito eletrônico do sub-sistema termométrico

Fig. 4.15. Circuito do temporizador de anóxia

Fig. 4.16. Circuito do temporizador de heparina

Fig. 4.17. Diagrama de tempo do temporizador de anóxia

Fig: 4.18. Diagrama de tempo do temporizador de heparina

Fig. 4.19. Circuito do cronômetro de perfusão

Fig: 4.20. Diagrama de tempo do cronômetro de perfusão 
Fig. 4.21. Circuito do sub-sistema de alarmes sonoros

Fig. 4.22. Circuito do sub-sistema de bases de tempo

Fig. 4.23. Diagrama de tempo do sub-sistema de base de tempo

Fig. 4.24. Circuito do sub-sistema de teste

Fig. 4.25. Circuito do sub-sistema de alimentação

Fig. 4.26. Circuito do sub-sistema de emergència

Fig. 4.27. Painel frontal do Sistema de Circulaçāo Extracorpórea

Fig. 4.28. Circuito de alimentação para medição, com um lado da rede de alimentação aproximadamente ao potencial de terra

Fig. 4.29. Circuito de alimentação para medição, com uma rede de alimentação aproximadamente simétrica em relação à terra

Fig. 4.30. Circuito de alimentação para medição, com uma fonte de alimentação monofásica especificada para equipa mento de Classe I

Fig. 4.31. Dispositivo de medição

[íg. 4.32. Circuito de mediçăo para a corrente de fuga para terra de um equipamento de Classe I com ou sem par te aplicada

Fig. 4.33. Circuito de medição para a corrente de fuga para terra de um equipamento de Classe I com ou sem par te aplicada, especificada para uso em uma rede con forme a Fig. 4.30 .

Fig. 4.34. Circuito de medição para a corrente de fuga através do invólucro de um equipamento de Classe I

Fig. 4.35. Circuito de medição para a corrente de fuga através do invólucro de um equipamento de Classe I com ou sem parte aplicada, especificado para uso em rede conforme a Fig. 4.30

Fig. 4.36. Circuito de medição para a corrente de fuga através do paciente, da parte aplicada para terra, de equi pamento de Classe I 
Fig. 4.37. Circuito de medição para a corrente de fuga através do paciente, via uma parte aplicada isolada tipo $F$ (flutuante) nara o corpo do equipamento, possuidor de fonte de alimentação elétrica interna

Fig. 4.38. Circuito de medição para a corrente de fuga atravês do paciente via uma parte aplicada isolada tipo F (flutuante) de equipamento Classe I para a terra, causada por uma tensão externa na parte aplicada.

Fig. 4.39. Caminhos de isolação e circuitos para ensaio da ri gidez dielētrica

Fig. 4.40. Dedo de prova normalizado

Fig. 4.41. Aparelho para ensaio de um equipamento à prova de proteção de 1 íquidos 


\section{LISTA DE TABELAS}

Tabela 4.1. Resultados do ensaio de correntes de fuga para a terra

Tabela 4.2. Resultados do ensaio de correntes de fuga através dó invölucro

Tabela 4.3. Resultados do ensaio de correntes de fuga através do paciente

Tabela 4.4. Tensōes para ensaio de rigidez dielétrica, em Volts. 
CAPITULO I

INTRODUÇAO

1.1. A Engenharia Médica e o Conceito Integrado de Segurança de Equipamento Eletro-médico

A utilização da ciência e da tecnologia para solucio nar problemas de relacionamento do homem com o universo mate rial constitue uma das contribuições mais relevantes que a ver dadeira Engenharia pode e deve dar à Medicina. Este emprego, contudo, deve consolidar-se de maneira otimizada e envolvendo economicamente os recursos disponiveis, de forma a resultar em um processo tanto eficiente quanto eficaz. Por outro lado, no caso específico do desenvolvimento, produção e avaliação de dispositivos e equipamentos de auxílio no atendimento médicohospitalar e na pesquisa biomédica, estes fatores devem ser considerados em igualdade de importância com as considerações relativas a controle de qualidade, segurança, confiabilidade e funcionalidade. O termo segurança, vastamente empregado em En genharia Mëdica, deve inclusive ser considerado conforme seu conceito integrado, onde estabelece-se que a segurança somente é assegurada pela combinação de medidas abrangendo o prōprio equipamento, a instalação elétrica do edifício, a manutenção e a aplicação correspondente. Justamente por não considerarem es 
ta conceituação, tanto as equipes que atuam em Engenharia Bio médica como as empresas brasileìras do setor, não conseguiram até o momento estabelecer um mercado interno com a significân cia desejada. Esta consolidação de mercado dependerá do desen volvimento de equipamentos eletro-médicos com qualidade e segu rança, decorrendo nos consequentes aumentos de produtividade e diversificaçāo de produtos e na desejada diminuição das impor tações.

No início desta década, Moraes e Vita (1981) jả enfa tizavam que qualidade, funcionalidade e complexidade dos produ tos para atendimento mêdico são consequências do desenvolvimen to científico-tecnolögico existente na ärea e, na medida que nosso país for deficiente nesse desenvolvimento, resultará uma correspondente falha na excelência dos serviços médicos. Ou, pelo menos, um ônus maior para mantê-los em bom nível, com tec nologia importada. Aliado a essa necessidade, o caräcter críti co dos produtos para a área médica, peculiaridade evidente por destinarem-se à preservação ou recuperação da saúde humana, im põe o estabelecimento de Normas Tëcnicas rigorosas para esses produtos. A não observâncìa de preceitos de segurança e confia bilidade poderá acarretar perigo da própria vida do paciente, - mesmo resultando se forem utilizados equipamentos de mä qua lidade, inadequados, sem manutenção ou não apropriadamente ins talados.

Apesar da quase totalidade das equipes que atuam em Engenharia Biomédica se dedicarem à Engenharia Médica (Secreta ria do Planejamento/Conselho Nacional de Pesquisa e Desenvolvi mento, 1983 e Panerai, 1985), especialmente no desenvolvimento 
de instrumentạ̧ão eletrônica-mẻdica, a atividade industrial de implementos nessa ảrea continua carente. o objetivo principal deste trabalho consiste no desenvolvimento de um Sistema de Cir culação Extracorpórea considerando inümeros aspectos inovado res referentes à concepção, funcionalidade e segurança. Devido ao particular campo de aplicação a que este equipamento se des tina, as considerações mencionadas são absolutamente necessá rias. O seu projeto respeitara as diretrizes estabelecidas pe la filosofia de concepção de equipamentos eletro-mëdicos de acor do com o conceito integrado de segurança, pretendendo-se inclü sive determinar um modelo para idealização de equipamento ele tro-mëdico, o qual poderā eventualmente servir de referência fú tura na definição de normas para a implementação adequada de equipamentos para a área.

1.2. A Circulação Extracorpórea

A descoberta da heparina, um anticoagulante, por Ho well e Holt (1918), tornou viāvel o conceito de perfusão san guínea artificial, proposto por Legallois (1813). Entretanto, a idêia de uma mäquina coração-pulmão artificial só surgiu com Gibbon (1937 e 1939), sendo o próprio Gibbon o primeiro a em pregar uma bomba de circulação extracorpórea com sucesso quan do, em 06 de maio de 1953, corrigiu cirúrgicamente uma cardio patia congênita em uma jovem de dezoito anos (Gibbon e colabo radores, 1953; Gibbon, 1954). Dennis e colaboradores (1951) ha viam tentado o procedimento anteriormente, mas o paciente só 
resistiu 40 minutos de cirurgia.

O conceito de parada cardíaca não significa necessa riamente a morte. A parada cardíaca induzida só é aplicável nos casos em que a vida é compatível e muitas vezes é utilizada co mo um meio auxiliar e mesmo indispensável na correção cirūrgi ca de determinadas patologias cardiacas. Muitas vezes tais cor reções necessitam que o coração e pulmões estejam em completa inatividade mecânica, sendo realizadas então com o auxílio de circulação extracorpórea, executada por um equipamento denomi nado coração-pulmão artificial, ou māquina de circulação extra corpórea. Este aparelho tem a finalidade de bombear o sangue e oxigenä-lo substituindo, respectivamente, as funções do cora ção e do pulmão. A oxigenação artificial ocorre em uma parte do conjunto denominada oxigenador e a propulsão do sangue é es tabelecida por uma bomba sanguínea. Os aspectos básicos anatô micos e fisiológicos do sistema vascular sanguíneo humano são apresentados no Apêndice A.

Há vārias técnicas de perfusão empregadas de acôrdo coll a patologia e o plano cirúrgico traçado (Conceição c Gomes, 1973). Os dois tipos de perfusão mais empregados são a perfú são total e a perfusão parcial, tambēm denominada circulação as sistida. A perfusão total resulta na completa exclusão das fun ções cárdio-respiratōrias do paciente, enquanto na perfusão par cial apenas parte do fluxo sanguíneo é assegurada pela circula ção extracorpórea, mantendo-se em atividade o coração e o pul mão.

No circuito convencional de perfusão total o sangue 
venoso é retirado do organismo pelas veias cavas, na desemboca dura atrial ou através do próprio átrio direito, nor meio de tu bos plásticos atóxicos, sendo drenado pela ação da gravidade até o oxigenador. Uma vez oxigenado é impulsionado pela bomba sanguínea e reinjetado na circulação orgānica atravēs de uma cânula metálica ou de teflon inserida na raíz da aorta ou na artēria femoral comum. Observe-se que desta forma tenta-se s $\underline{i}$ mular o comportamento do sistema cardiovascular desempenhado pelo corpo humano onde, de maneira simplificada,podemos cons $\underline{i}$ derar que o sangue rico em oxigênio é enviado por meio da at vidade cardíaca, desde os pulmōes atē os vārios órgãos, oxige nando os tecidos. O sangue pobre em oxigênio retorna então ao coração sendo enviado aos pulmōes, ainda pela ação cardíaca,on de efetua as trocas gasosas, captando o oxigênio do ar inspira do e se livrando do dióxido de carbono pelo ar expirado. oxi genado, o sangue retorna ao çoração onde é novamente bombeado atê os órgãos e tecidos, reiniciando o ciclo. Considerando que o deslocamento contínuo de um fluído no interior de um sistema tubular fechado exige um componente bombeador, constata-se que este papel è desempenhado pelo próprio coração, que realmente funciona como uma bomba dupla.

As consideraçōes para a perfusão parcial, muito menos frequente, são praticamente equivalentes. Por exemplo, em ci rurgias dos aneurismas da aorta descendente, o circuito é cons tituído pelo ảtrio direito-reservatório-bomba sanguínea-artéria femoral. 
1.3. Histórico da Máquina Coração-Pulmão

Em 1813 Legallois postulou que se fosse possível substituir o coração por uma bomba artificial de sangue, obti do natural ou artificialmente, não seria difícil manter viva por tempo indeterminado qualquer parte do organismo. Os traba 1hos de Howell e Holt, publicados em 1918, identificando a he parina-anticoagulante colocaram um marco histórico em uma lon ga sequência de pesquisas na ärea, passando por Loebell em 1845 que tentou perfundir um rim sem sucesso, por Brown - Sé quard em 1858, perfundindo cabeças isoladas de cães e chaman do a atençāo para a importância da irrigação cerebral, por Bidder em 1862 realizando experiências de perfusão renal, por Ludwig em 1865 , construtor do primeiro oxigenador mecânico, por Bunge e Schmiedbergen em 1876 com novas experimentaçōes com rins, por Schroeder em 1882 iniciando a era dos oxigenado res de bolhas, por Frey e Gruber em 1885 iniciando o uso de oxigenadores de películas. Jacoby em 1890 e Brodie em 1903 conseguiram bons resultados com o processo de borbulhamento de ar, sendo Brodie (1903) o primeiro pesquisador a tornar o san gue incoagulável pelo citrato de sódio.

Apesar dos sucessos parciais obtidos pelos oxigena dores de bolhas de Newbauer e Gross (1910) solucionando o pro blema da embolia aérea, de Issekutz (1927) construindo seu oxigenador de bolhas contendo um depósito de hidróxido de só dio e de Von Euler (1932), construindo um oxigenador que neb $\underline{u}$ lizava o sangue junto com $\mathrm{O}_{2}$, apenas em 1934 surgiu a idéia de uma máquina coração-pulmão artificial com Gibbon, em Massa 
chusetts, concretizada efetivamente só em 1953. Ainda em 1934 , DeBakey (1934) instituiu a bomba de roletes para injeção arte rial, apresentando dois ou mais roletes que comprimiam um tubo plástico, impulsionando sucessivamente o sangue. Em 1937 o mes mo Gibbon (1937) emprega com sucesso um oxigenador de telas em cirurgia experimental. Posteriormente, Bjork (1948, 1960) empre ga um oxigenador de discos, modificado por Kay e colaboradores (1956) transformando os discos anteriormente planos em discos ondulados para aumentar a ārea da superfície de oxigenação.

Em 1949, Saltzmann (1949) apresentou a bomba injeto ra Sigmamotor, impulsionando o sangue por intermédio de "dedos metālicos" que comprimiam un tubo de borracha sucessivamente e sempre no mesmo sentido, contra uma placa de aço e mantendo sem pre um "dedo" oclusivo para evitar refluxo sanguíneo.

As bases do oxigenador de bolhas foram estabelecidas por Clark e colaboradores (1950), empregado e aperfeiçoado pos teriormente por vários pesquisadores. Em 1952 Gollan e colabo radores (1952) demonstraram a possibilidade de associação en tre a hipotermia e a circulação extracorpórea, com um oxigena dor possuindo um permutador têrmico dentro da coluna de oxige nação. Em 1955, Dewal1 e Lillehei (1956, 1957, 1959, 1961,1962) empregam com sucesso um oxigenador de bolhas com reservatório helicoidal e Zuhdi $(1952,1960,1961,1962)$ em 1960 descreve um oxigenador do mesmo tipo mas contendo um tubo metálico tor cido no mesmo.sentido, por meio do qual circulava água quente ou fria. Anteriormente, em 1956, Clowes e Hopkins (1956a,1956b, $1958,1969)$ construiram o primeiro oxigenador de membranas e em 1957, Gott e colaboradores (1957) constroem um oxigenador de bo 
1has, em plástico e descartāvel, posteriormente aperfeiçoado. o desenvolvimento de oxigenadores seguiu em ritmo acelerado até que em 1976 Berry e colaboradores (1976), Beall e associados (1976), Solis e colaboradores (1975), Heimbecker e outros(1976) e Liddicoat e colaboradores (1975) demonstram as definitivas vantagens do oxigenador de membranas. No Brasil, os oxigenado res de bolhas foram modificados por Magalhaes e Jatene (1966), Jazbik e colab. (1967) e Gomes e colaboradores $(1970,1971)$, construindo modelos mais compactos. O estágio atual dos oxige nadores de bolhas em nosso país é compatível com o existente nos países desenvolvidos, propiciando produtos de alta qualida de, injetados em plästico e descartáveis, isto è, de uso único.

Pode-se facilmente verificar pela prōpria evolução dos oxigenadores, o grande desenvolvimento e a intensa diversi ficação da parte oxigenadora da mäquina de circulação extracor pórea. O mesmo não se pode afirmar quanto à parte motora. Du rante as três décadas que se seguiram à cirurgia de Gibbon em 1953, muitos tipos e modelos de bombas sanguíneas surgiram com relativo sucesso na utilização clínica, porëm, após um certo avanço inicial, os projetos de desenvolvimento da parte propul sora do aparelho praticamente se estagnaram. O princípio da pro pulsão do sangue hoje mundialmente aceito como o mais eficaz por acarretar pouco traumatismo ao sangue, apesar de sem dúv $\underline{i}$ da não ser o ideal, è o mesmo proposto por DeBakey em 1934:uma bomba peristáltica movida por dois roletes deslizantes sobre um tubo plástico ou de latex. Esta versão é no momento univer salmente adotada, em detrimento do modelo Sigmamotor, devido à maior facilidade de regulagem, manutenção, transporte e, prin 
cipalmente, por produzir menos hemólise. Ocasionalmente, uma bomba de pistão ou diafragma é empregada em circulação assisti da, contendo uma câmara com um diafragma e duas vālvulas que orientam o sentido do fluxo. A compressão da câmara é determi nada pela pressão do ar ou líquido injetado entre o diafragma e o arcabouço rígido que o envolve.

Em 1979, Moraes e Barros Moraes (1979a,1979b) concluí ram que uma māquina de circulação extracorpórea deveria apre sentar, no mínimo, características compatíveis com o estágio momentâneo de desenvolvimento da técnica cirúrgica, inclusive no tocante à correção de patologias cardíacas mais complexas. Entretanto, o fator limitante na época para o sucesso das in tervenções cirürgicas, utilizando-se parada cardíaca total e o emprego de circulação-oxigenação artificiais, era o prōprio equipamento de circulação extracorpörea com suas técnicas e dispositivos empregados, pois o alto estágio. de desenvolvimen to atingido pelas técnicas cirürgicas era apenas 1imitado, jä em nível bioquímico, pela proteção miocārdica. O autor conce beu então um novo Sistema de Circulação Extracorpörea, apresen tado em 1981. (Moraes e Barros Moraes, 1981). A posterior imple mentação e otimização, constituem um dos objetivos deste trab a 1 ho.

1.4. Sistema de Circulação Extracorpórea Proposto

Devé-se inicialmente enfatizar que qualquer māquina coração-pulmão artificial pertence à categoria tipo CF, defin 
da na norma da International Electrotechnical Commission (IEC) 601-1(1977) e correspondente a um alto grau de proteção contra choque elétrico.

Esta proteção exige, por exemplo, correntes de fuga muito baixas através do invólucro e do paciente. O equipamento tipo CF comporta uma parte aplicada separada tipo F (flutuante) e é concebido para aplicação intracardíaca. Dessa forma, as exigências referentes à segurança tornam-se fundamentais na própria concepção do equipamento. Ressalte-se, mais uma vez, que a segurança deve ser considerada de acordo com o seu con ceito integrado.

Além do aspecto anteriormente citado, as bombas de circulação extracorpórea devem apresentar grande confiabilida de e funcionalidade devido à alta periculosidade de seu campo de aplicação. Estudos realizados pelo autor nos equipamentos coração-pul mão artificiais fabricados em nosso país no final da década passada, demonstraram a produção de produtos sem segurança, ine ficientes e destituidos de vários implementos necessários para uma assistência segura, confiável e completa à equipe cirúrgi ca. Vảrias inovaçōes foram propostas, resultando inicialmente em duas patentes, apresentadas nos Apêndices B e C. A primeira (Moraes e Barros Moraes, 1979a) estabelecia um aperfeiçoamento na regulagem do curso axial dos roletes e a segunda (Moraes e Barros Moraes, 1979b) determinava um aperfeiçoamento de tal monta que resultava em um verdadeiro sistema, que se convencio nou denominar Sistema de Circulação Extracorpórea (S.C.E.).

Propunha-se inicialmente a incorporação de um minirefrigerador em um sub-sistema hidrăulico completo, composto 
por circuitos de aquecimento e refrigeração contendo controles automáticos, bem como circuitos de controle das vazões de águas quente e fria e de sinalização com alarmes áudio-visuais. Além de outras contribuições secundárias, estabelecia-se ainda a in clusão de módulos temporizadores, termométrico e de emergência. Os primeiros possibilitavam um auxílio importante na adminis tração de heparina e no controle e medição das durações da anó xia e da prōpria perfusão. O sub-sistema termométrico permitia a indicação no painel do equipamento tanto da temperatura do paciente como dos líquidos existentes nos reservatórios de àgua quente ou fria, alternativamente, e, finalmente, o módulo de emergência era constituído por uma unidade recarregável ge radora de tensão elétrica e lâmpadas para iluminação do oxige nador: Este ủltimo sub-sistema deveria ser acionado automatica mente no caso de interrupção no fornecimento pela rede elétri ca local. O Sistema de Circulação Extracorpoórea serä detalhada mente apresentado no capítulo quarto e os aspectos de sua concepção, de acordo com o conceito integrado de segurança, se rāo expostos no Capítulo III.

A quantidade substancial de inovaçōes incorporadas às mäquinas coração-pulmão artificial existentes, è imediatamente perceptível. Estas inovaçōes não eram encontradas nem mesmo em equipamentos estrangeiros. A primeira vista, algumas das inova çóes podem parecer supérfluas e desnecessārias porém, analisa das com o rigor e a responsabilidade indispensäveis a esta ca tegoria de equipamentos eletro-médicos, verificam-se fundamen tais para as exigências de qualidade, segurança, confiabilida de e funcionalidade. 
A apresentação do novo Sistema de Circulação Extra corpórea em Congressos Brasileiros de Cardiologia, bem como em Congressos Nacionais de Cirurgia Cardíaca e de Circulação Ex́ tracorpórea, recebeu da classe médica e dos técnicos em perfú são, a aceitação e aprovação que comprovavam a conveniència das inovaçōes apresentadas e as reais vantagens dos adendos incor porados, referentes aos modelos existentes na época.

Os resultados präticos obtidos nos primeiros protót pos foram muito animadores, iniciando-se então a implementação do Sistema de acordo com a concepção do sistema integrado de segurança. Nessa ocasião verificou-se a necessidade de acele rar-se a produção de textos normativos nacionais na área, o que acabou resultando em um sub-produto extremamente ütil do presente trabalho, na tentativa de suprir a lacuna existente em matéria de normalização e controle de qualidade de equipa mentos e dispositivos a serem utilizados em Engenharia Biomédi ca.

1.5. Objetivos da Pesquisa

os objetivos estabelecidos para a presente pesquisa podem ser divididos em quatro partes distintas, a saber:

a) Determinação das características necessárias a uma mãquina coração-pulmão artificial ideal;

b) Concepção e desenvolvimento da māquina de circula ção extracorpórea estabelecida no item anterior, de acordo com 
o conceito integrado de segurança de equipamento eletro-médico;

c) Determinação de um modelo de concepção para equi pamentos eletro-médicos, servindo eventualmente de referência futura para desenvolvimentos dos produtos na ärea sob o ponto de vista de uma idealização sistêmica de qualificação;

d) Implementaçāo de uma máquina de circulaçāo extrạ corpórea tão próxima quanto possível da concepção estabelecida no item b.

Observe-se que não se objetiva apenas a construção de um simples equipamento eletro-médico, mas estabelecer toda uma filosofia de concepção, desde sua idealização até a respeć tiva implantação, considerando aspectos de implementação, docu mentação e manutenção do aparelho, além de exigências concer nentes às instalações elétricas relacionadas com o mesmo. 0 próprio equipamento, pertencente à categoria tipo CF, corres ponde à situação mais delicada e com maiores riscos envolvidos. Pretende-se enfatizar a necessidade de proteção tanto do pa ciente como do operador e do meio ambiente contra os riscos ine rentes à utilização de instrumentos biomédicos na prätica médi ca, exigindo-se a criteriosa implementação desde a concepção do equipamento, com características de segurança, qualidade, confiabilidade e funcionalidade compatíveis com a responsabili dade de suas aplicações. Considera-se ainda o projeto e a im plantaçāo da instalação elétrica para fins médicos, com aspec tos significativamente diferentes das instalações elétricas pa ra outras finalidades, bem como a manutenção cuidadosa, indub $\underline{i}$ tavelmente a maior preocupação dos responsáveis por complexos hospitalares. O desenvolvimento apresentado visa contribuir ainda 
com os esforços existentes no setor formativo e educacional da ärea de Engenharia Biomédica, e com projetos de normas que per mitirão a substituição e a própria competição com os atuais apa relhos estrangeiros. Estes objetivos atendem às exigências e recomendaçōes estabelecidos nos vários relatổios e documentos resultantes de atividades isoladas e/ou individuais de vários setores de nossas comunidades científica e empresarial, além de órgãos governamentais (Conselho Nacional de Desenvolvimento Científico e Tecnológico, 1981; Moraes e Vita, 1981; Moraes e Barros Moraes, 1981; Vita, 1982; Secretaria do Planejamento/ Conselho Nacional de Desenvolvimento Científico e Tecnológico, 1983; Presidência da República/Conselho de Segurança Nacional/ Secretaria Especial de Informática, 1983a, 1983b; Moraes, 1983; Secretaria do Planejamento/Conselho Nacional de Desenvolvimen to Científico e Tecnológico, 1985; Moraes, 1985; Panerai, 1985; Conselho Nacional de Desenvolvimento Científico Tecnológico / Centro Tecnológico para Informática/ Sociedade Brasileira de Automática, 1985; Moraes, 1986; Anais do VII, VIII e IX Con gressos Brasileiros de Engenharia Biomédica). 


\section{CAPITULO II}

A MÅQUINA CORAÇĀO-PULMAOO ARTIFICIAL IDEAL

\subsection{Introdução}

O estágio atual das complexas técnicas cirúrgicas car diovasculares é limitado praticamente nela mäq̣uina de circulação ex tracorpórea, pois até mesmo o problema da proteção miocārdica, em nível bioquímico, hoje está praticamente solucionado pelo emprego de soluções cardioplégicas. O desenvolvimento de uma má quina coração-pulmão artificial com funcionalidade, qualidade, segurança e confiabilidade compatíveis com este estágio de pro cedimento cirürgico torna-se então imperativo, mobilizando re cursos científicos e tecnológicos da Engenharia para contribuir com o progresso da Medicina no campo de cirurgias cardíacas.

Durante a perfusão extracorpórea, o coração do pa ciente não pode manter a circulação sistêmica natural e tanto este örgão como os pulmões tem seus metabolismos reduzidos a um minimo vital (Netter, 1971). Decorre que os critérios de concepção e implementação do equipamento eletro-mëdico que bom bearâ e oxigenarà artificialmente o sangue, tornam-se críticos devido a esta particular aplicação em cirurgias com o coração aberto e exposto completamente, consequentemente em sua cond $\underline{i}$ 
ção de vulnerabilidade máxima.

Para compatibilizar o estágio de desenvolvimento dos equipamentos para circulação extracorpórea com o nível médico atualmente atingido nas cirurgias cardíacas é necessário deter minarem-se, inicialmente, as especificações da māquina hipoté tica ideal a ser usada no auxílio à perfusão extracorpórea. Es ta é a primeira contribuição do autor proposta como objetivo da pesquisa, e serā apresentada neste capítulo. As informações re lativas à concepção e implementação de um Sistema de Circulação Extracorpoórea, definido com base nesse modelo ideal, serão for necidas nos Capítulos 3 e 4 .

2.2. A Perfusão Extracorpórea e a Máquina Coração-Pulmão Artị ficial

A cirurgia cardíaca de médio ou grande porte exige que o coração seja operado sob visão direta e em estado de per fusão extracorpórea, isto $\vec{e}$, com um desvio total ou parcial do fluxo sanguíneo através do coração. Embora seja possível subs tituir apenas a porção do lado direito do coração, a prática usual è desativar todo o órgão e, nessas condições, è impossí vel manter a circulação pulmonar propiciando a oxigenação do sangue e removendo o dióxido de carbono. A necessāria circula ção extracorpórea é provida então pela máquina coração-pulmão artificial.

O Sistema de Circulação Extracorpōrea apresentado nes te trabalho pode ser usado em qualquer um dos tipos de perfu 
são, apesar da sistemática referência ao emprego de circulação extracorpórea total, normalmente hipotêrmica.

Durante a perfusão total, todo o sangue venoso prove niente das veias cavas que normalmente adentra o átrio direito é desviado para o circuito extracorpóreo, passando então pelo pulmão artificial-oxigenador e pelo coração artificial-bomba sanguínea, retornando então ao paciente através da artéria femoral ou da raiz da aorta. O circuito é completado pela cír culação sistêmica orgânica, constituído pelos ramos correspon dentes às artérias, arteríolas e veias, até retornar às veias cavas, conforme a Fig. 2.1.

Após a toracotomia e a pericardiotomia, as veias ca vas são cateterizadas usando catēteres plästicos de diâmetros variados de acordo com o paciente. Duas cânulas plästicas pas sam do ätrio direito para as veias cavas e cadarços de algodão enlaçam essas veias. Antes desses cadarços serem apertados o sangue ainda flue pelas cânulas e através do coração e do pul mão no paciente porém, após serem firmemente tensionados todo o sangue venoso sistêmico é desviado para o circuito extracor póreo. O sangue venoso é drenado por gravidade atē o oxigenador, onde recebe oxigênio e libera dióxido de carbono. Durante a ci $\underline{r}$ culação extracorpórea o coração e os pulmões não contêm sangue, exceto uma quantidade mínima que entra nos vasos pulmonares através das artérias brônquicas e no coração através das arté rias coronarianas. Com o coração aberto, este sangue é suave e continuamente aspirado através de aspiradores sanguíneos espe ciais conectados aos módulos venosos da mäquina de circulação extracorpórea, sendo enviado ao oxigenador onde se mistura com o san gue proveniente das veias cavas. 


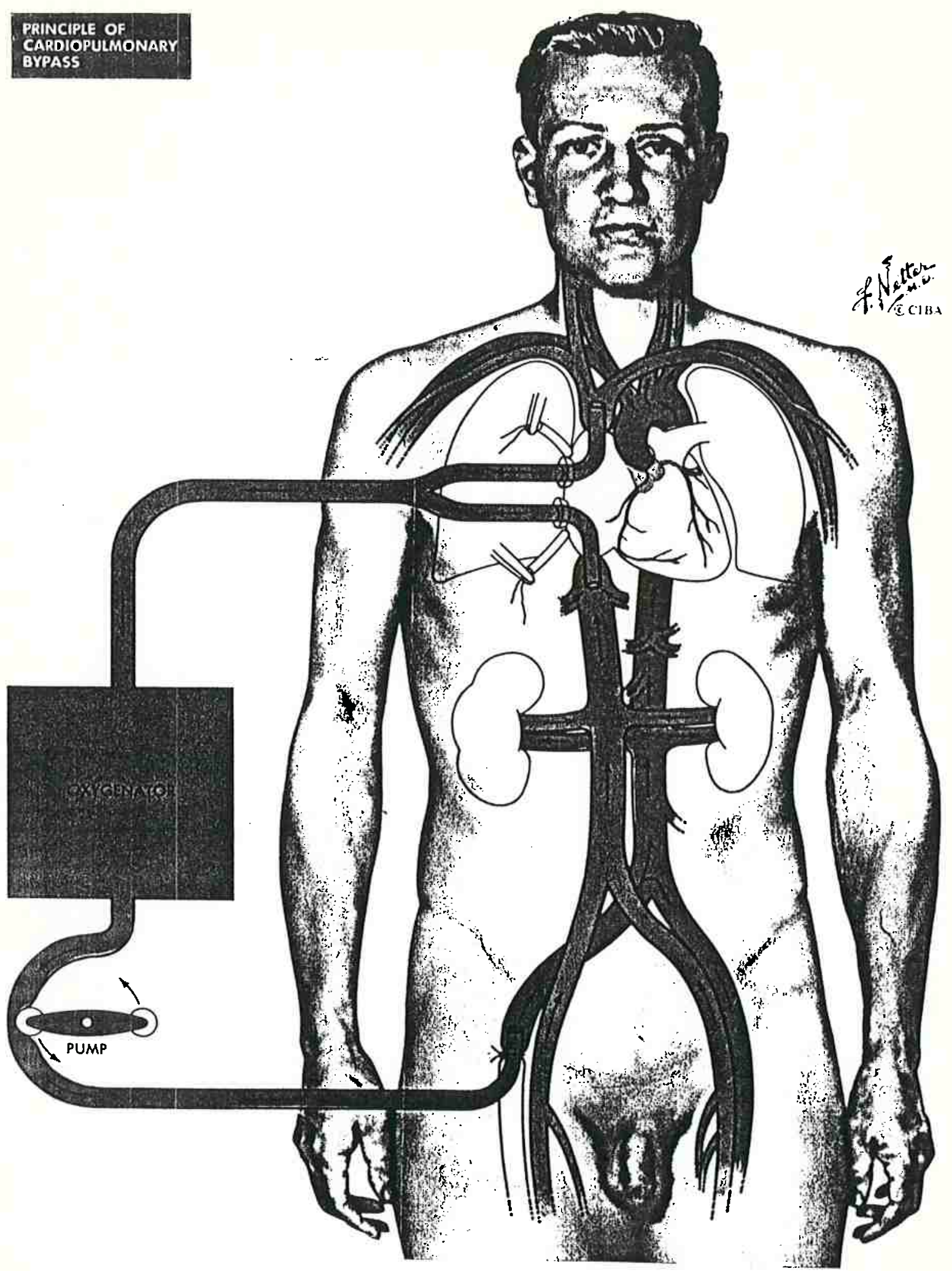

Fig. 2.1. Princípio da circulação extracorpórea. Reproduzido de Netter (1971). 
Apös passar pelo oxigenador, o sangue arterializado è impelido pela bomba sanguínea-arterial sendo reintroduzido no organismo do paciente através de uma dentre as artérias perifé ricas de grande calibre, comumente a femoral ou a ilíaca exter na, por meio de uma cânula metálica ou de teflon. Ocasionalmen te, a cânula pode ser inserida no arco ascendente da aorta ou na artêria sub-clavíaca esquerda proximal. Os tubos plästicos das linhas arterial e venosa são constituídos de polivinil com aproximadamente $10 \mathrm{~mm}$ de diâmetro interno.

As mãquinas coração-pulmão artificiais devem substí tuir o coração e os pulmões durante a cirurgia e, tanto quanto possível, devem apresentar um desempenho igual às característí cas fisiológicas desses örgãos. A Fig. 2.2 possibilita uma com paração entre as circulações normal e extracorpōrea.
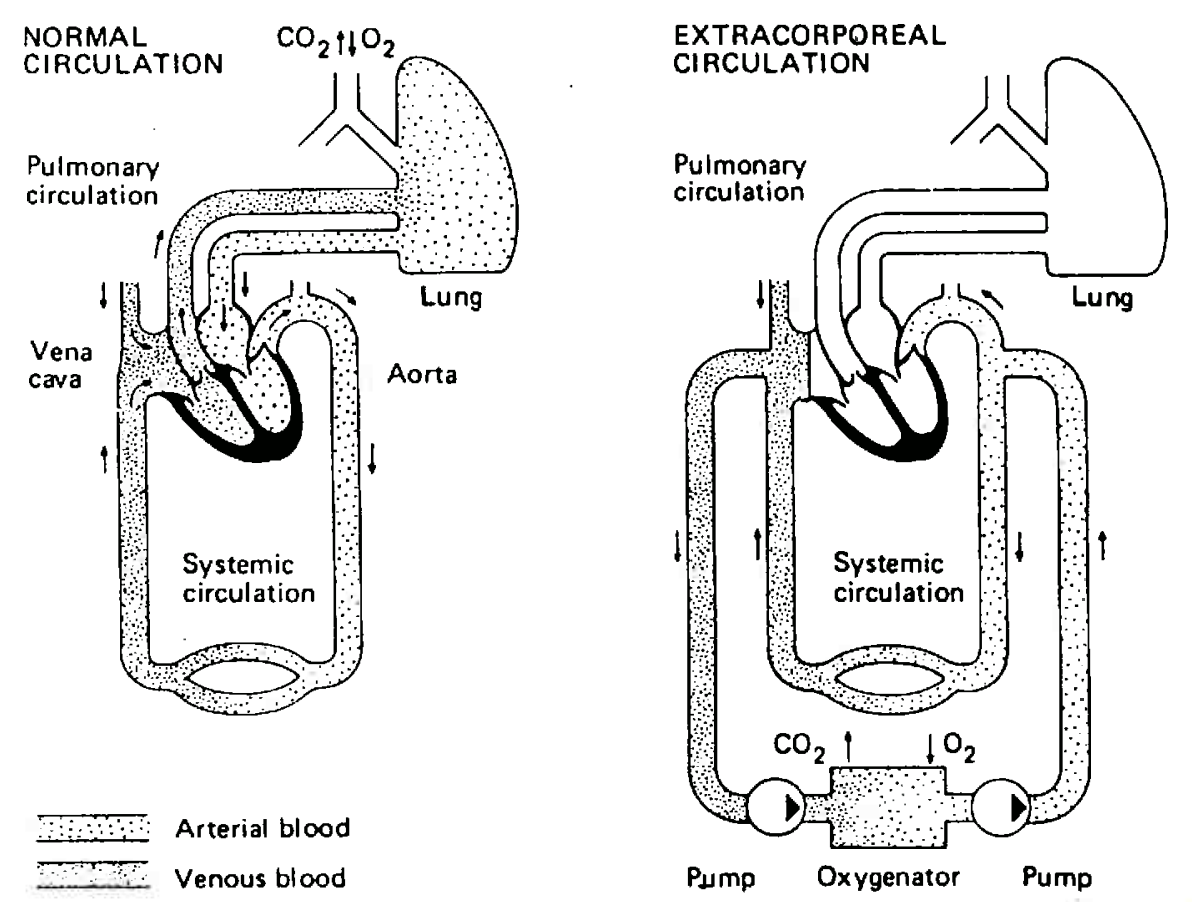

Fig. 2.2. A circulação normal e a circulação extracorpórea. Reproduzido de Ja cobson e Webster (1977). 
A parte oxigenadora da máquina de circulação extracor pórea pode ser desempenhada por vārios tipos de oxigenadores, sendo atualmente os mais empregados aqueles que utilizam o prin cípio da oxigenação e liberação de $\mathrm{CO}_{2}$ por meio de membranas (Clowes e Hopkins, 1956; Lefrak e colab., 1973; Trudell e cola boradores, 1972), conforme a Fig. 2.3, ou por meio de bolhas misturadas com o sangue numa coluna vertical (Clark, Gollan e Gupta, 1950), conforme a Fig. 2.4. Os oxigenadores de bolhas são os mais usados em nosso meio enquanto os oxigenadores de membranas são extensivamente usados nos Estados Unidos da Amé rica do Norte e em vārios países europeus.

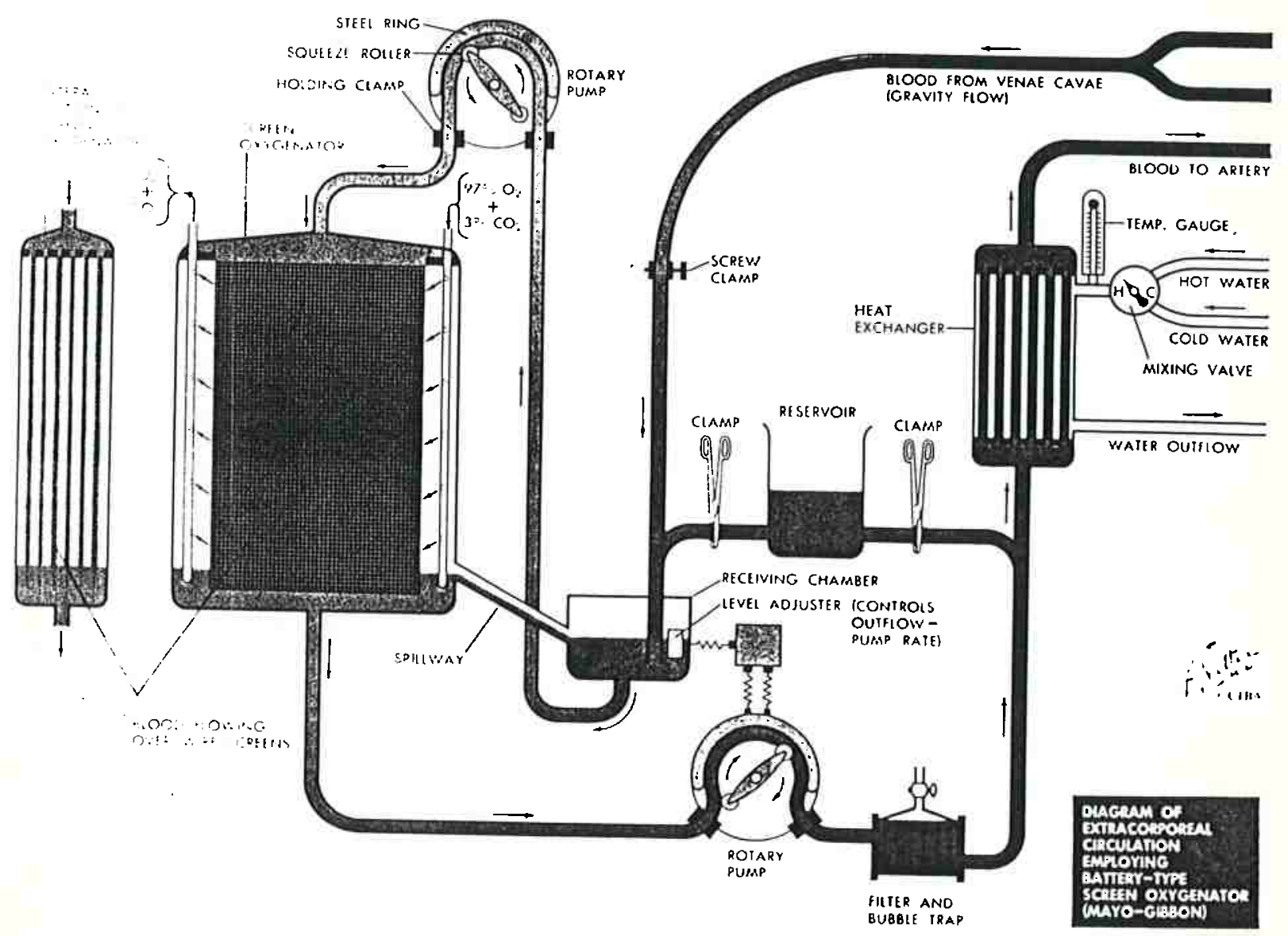

Fig. 2.3. Princípio do oxigenador de membrana (Reproduzido de Netter (1971). 


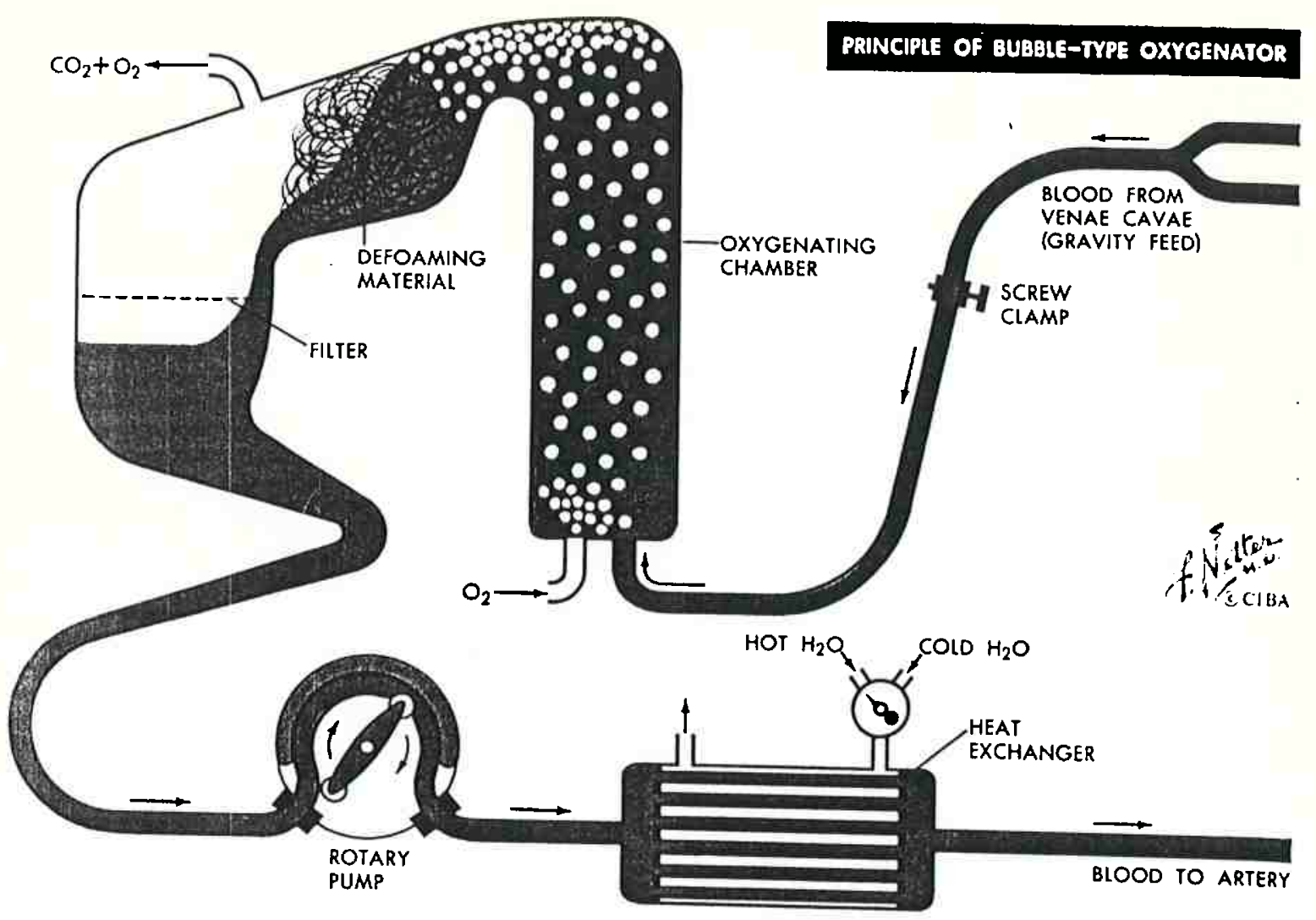

Fig. 2.4: Princípio do oxigenador de bolhas. Reproduzido de Netter (1971).

Qualquer um dos tipos de oxigenadores usados possue um permutador térmico, possibilitando a perfusão sob condição dẹ hipotermia, já que é sabido que o músculo cardíaco suporta no mäximo dez minutos desprovido de sangue, sob temperatura cor pórea normal. Entretanto, a duração da perfusão pode ser signi ficativamente aumentada para várias horas se a taxa metabölica for diminuída pelo resfriamento do corpo ou, se possível, só mente do coração. A $30^{\circ} \mathrm{C}$ a taxa metabólica é reduzida en cin coenta por cento (Jacobson e Webster, 1977) e o coração tolera aproximadamente 20 minutos sem fluxo sanguíneo. Temperaturas consideravelmente mais baixas também são usadas porēm apenas 
para cirurgias no próprio coração pois a temperaturas abaixo de $20^{\circ} \mathrm{C}$ pode ocorrer fibrilação ventricular. Entretanto, em operações cardíacas a fibrilação não interfere, podendo até mesmo constituir uma vantagem, desde que não ocorram movimen tos por bombeamento. A hipotermia pode ser geral ou seletiva, por indução interna ou externa e moderada $\left(28-30^{\circ} \mathrm{C}\right)$ ou profun da $\left(<20^{\circ} \mathrm{C}\right)$. A hipotermia por indução interna è obtida interca lando-se no circuito de circulação extracorpörea o permutador térmico no oxigenador, conforme mencionado anteriormente (Figs. 2.3 e 2.4). Iniciada a perfusão em normotermia e uma vez estạ bilizada a situação hemodinâmica, circula-se água a baixa tem peratura pelo oxigenador até atingir-se o grau de hipotermia desejado. Deve-se ter o cuidado de não ultrapassar a diferença de dez graus Celsius entre as temperaturas do paciente e do re frigerante no permutador, a fim de evitar o desprendimento de bolhas, principalmente quando o sangue estiver muito oxigenado Conceição e Gomes, 1973; Edmonds, 1981; Balderman e Col, 1983 e Kaijser e Col, 1985. Deve-se ressaltar que apesar da hipotermia possibili tar um aumento substancial na duração da perfusão extracorpōrea, atualmente esta circulação está limitada a algumas horas devi do à hemólise dos glóbulos vermelhos do sangue, inevitável nes ta prática cirúrgica.

2.3. Características Básicas da Função Cardiovascular Humana

A determinação das bases fisiológicas da circulação extracorpórea e das características hemodinâmicas da perfusão 
exige o conhecimento das propriedades bảsicas da função cardio vascular humana. Nesta secção serão apresentados os valores tí picos das grandezas hemodinâmicas mais importantes envolvidas em nosso sistema vascular. Maiores detalhes sobre os resulta dos podem ser obtidos em Rushmer (1976), Ganong (1972) e Winton e Lippold (1970), de onde foram retirados os valores adota dos.

Desde que Harvey provou, em 1628, que o sangue circu la dentro do corpo humano, a determinação das características hemodinâmicas da circulação cardiovascular constitue objeto de inümeras pesquisas. Pode-se considerar que atualmentè a grande maioria das grandezas físicas envolvidas com essa dinâmica es tão medidas com razoāvel precisão.

Os värios níveis de pressão ao longo do sistema car diovascular constituem os dados mais importantes do sistema, conjuntamente com o fluxo sanguíneo. Basicamente, considera-se que a pressão sistólica (māxima) é da ordem de $120 \mathrm{~mm} \mathrm{Hg}$ enquan to a pressão diastólica (mínima) è aproximadamente $70 \mathrm{~mm} \mathrm{Hg}$. Re sulta uma pressão de pulso de $50 \mathrm{~mm} \mathrm{Hg}$. Por outro lado, a pres são nas veias cavas $\vec{e}$ de $0-5 \mathrm{~mm} H$. Enquanto a pressão arterial varia muito, por exemplo devido a fatores psíquicos, a pressão venosa é praticamente constante. Deve-se levar em conta, entre tanto, o efeito da idade sobre esses valores pois enquanto uma criança de 5 anos apresenta uma pressão sistólica média de 80$100 \mathrm{~mm} \mathrm{Hg}$, durante a puberdade este valor se eleva até $120 \mathrm{~mm} \mathrm{Hg}$, atingindo $140 \mathrm{~mm} \mathrm{Hg}$ em um indivíduo com 60 anos e $180 \mathrm{~mm} \mathrm{Hg}$ com 70 anos. Outro fator que afeta nos resultados anteriores $\vec{e}$ o efeito da força da gravidade. Os valores anteriormente apresen 
tados referem-se a vasos sanguíneos ao nível do coração (linha manubrial) pois considerando-se um valor de referência de 100 mm Hg para a pressão arterial nesse plano horizontal, uma arté ria grande da cabeça ( $50 \mathrm{~cm}$ acima do coração) apresenta una pres são de $62 \mathrm{~mm} \mathrm{Hg}$ e uma artëria grande do pé $(105 \mathrm{~cm}$ abaixo do co ração) uma pressão de $180 \mathrm{~mm} \mathrm{Hg}$. Para a pressão venosa o efeito é semelhante. Finalmente, não se deve esquecer também da exis tência de uma pressão crítica de oclusão em qualquer vaso do sistema cardiovascular, a qual depende do seu fluxo sanguíneo.

Para o circuito pulmonar, a pressão no ventrículo di reito durante a sistole é de aproximadamente $22 \mathrm{~mm} \mathrm{Hg}$ e a pres são na saída do circuito ē de $7 \mathrm{~mm} \mathrm{Hg}$, resultando uma pressão ar terial pulmonar média de $14,5 \mathrm{~mm} \mathrm{Hg}$.

o fluxo sanguíneo na entrada da aorta (débito cardía co ou volume minuto) é outro parâmetro fundamental da hemodinâa mica cardiovascular. Calculado a partir do produto do volume de sangue impulsionado pelo coração durante um ciclo cardíaco (volume diastólico final - volume sistólico final) pela fre quência cardíca, apresenta um valor típico de $5,51 / \mathrm{min}$ para seres humanos masculinos em repouso $(80 \mathrm{ml} / \mathrm{min} \times 69 \mathrm{cpm})$, po rẻm, como depende da ārea lateral da superfície corpórea pode ser melhor representado por $3,21 / \mathrm{min} \times \mathrm{m}^{2}$ sup.corp. Entretan to, deve-se considerar que pode variar desde $-30 \%$ at $\overrightarrow{\mathrm{e}}+700 \%$ de pendendo de vários fatores, entre os quais exercícios físicos e mudanças na posição do corpo.

A velocidade mêdia correspondente a estes valores de fluxo sanguíneo varia desde $40-50 \mathrm{~cm} / \mathrm{s}$ na aorta at $\vec{e} 0,07 \mathrm{~cm} / \mathrm{s}$ 
nos vasos capilares. Porém, deve-se considerar que o fluxo é fásico pois na sístole a velocidade na aorta pode atingir 120 $\mathrm{cm} / \mathrm{s}$, havendo um ligeiro refluxo no início da diástole. Nas veias grandes a velocidade média é aproximadamente um quinto daquela existente na aorta, ou seja, 8-10 cm/s. A Fig. 2.5 a presenta um diagrama das modificações da pressão e da veloci dade do fluxo sanguíneo durante a circulação sistêmica.

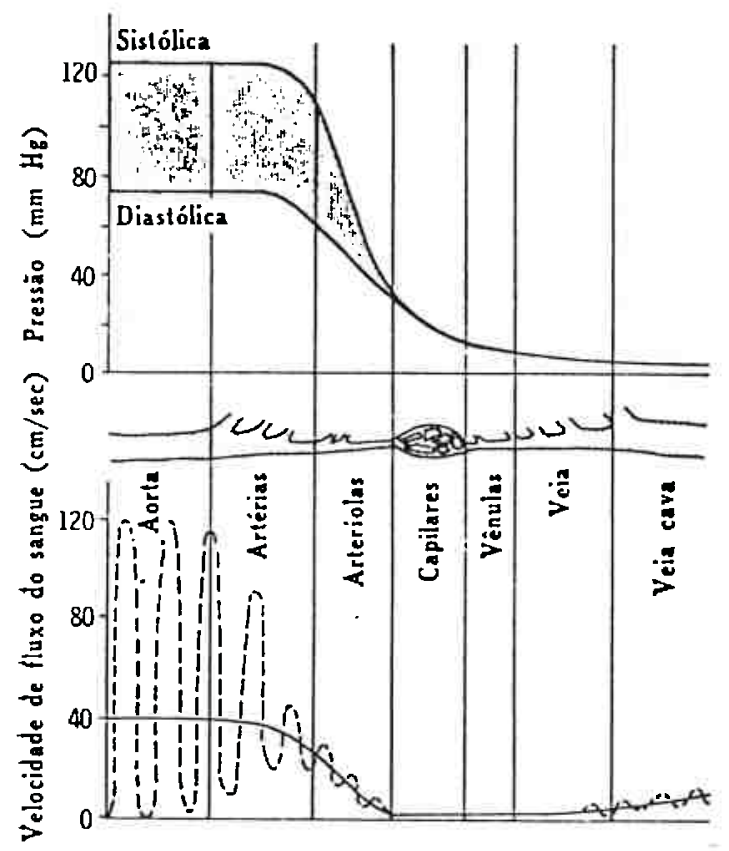

Fig. 2.5. Diagrama das modificações da pressāo e da velocidade do fluxo que sofre o sangue na sua passagem pela circulação sistêmica. A linha sólida, no de senho acima, significa a velocidade média. A linha interrompida apresenta as variações da velocidade duran te a sístole e a diästole. Reproduzi do de Ganong (1972).

A viscosidade relativa do sangue normalmente $\vec{e}$ da 
ordem de 4,5 porém atinge um valor acima de 40 em velocidades muito altas. Depende tambēm da temperatura, diminuindo de apro ximadamente $15^{\circ}$ a $44^{\circ} \mathrm{C}$ (mais alta temperatura compatível com a vida humana) e pode aumentar $40 \%$ a $23^{\circ} \mathrm{C}$ (mais baixa temperatu ra compativel com a vida humana).

A frequência cardíaca por sua vez è extremamente va riävel, desde $55 \mathrm{bpm}$ em repouso absoluto até $230 \mathrm{bpm}$ durante taquicardia paroxismal dos ventrículos. Valores típicos para humanos normais em repouso ocorrem em torno de 60-80 bpm.

A tensão nas paredes dos vasos depende de seus cal $\underline{i}$ bres. Valores típicos são de 170.000 dina $x_{\mathrm{cm}^{-1}}$ para a aorta, $21.000 \mathrm{din} \times \mathrm{cm}^{-1}$ para as veias cavas e $16 \mathrm{din}^{\mathrm{x}} \mathrm{cm}^{-1}$ para ca pilares.

Uma descriçāo mais precisa da função ventricular pọ de ser obtida através de registros das formas de onda corres pondentes às grandezas físicas mais expressivas da dinâmica car diovascular. Na Fig. 2.6 são apresentados resultados típicos dessas grandezas no homem e na Fig. 2.7 indicam-se as adapta ções ventriculares durante a atividade espontânea em experimen tos com cachorros.

Observe-se que hä um complexo sistema de controle pa ra estabelecer as características fisiológicas necessárias à dinâmica cardiovascular. Por exemplo, a distribuição do fluxo sanguíneo através dos värios ramos vasculares periféricos é controlada principalmente pelas variações de calibre nos vasos constituintes dos capilares. Este controle do fluxo depende da manutençào, em todos os instantes, de uma adequada pressão no 

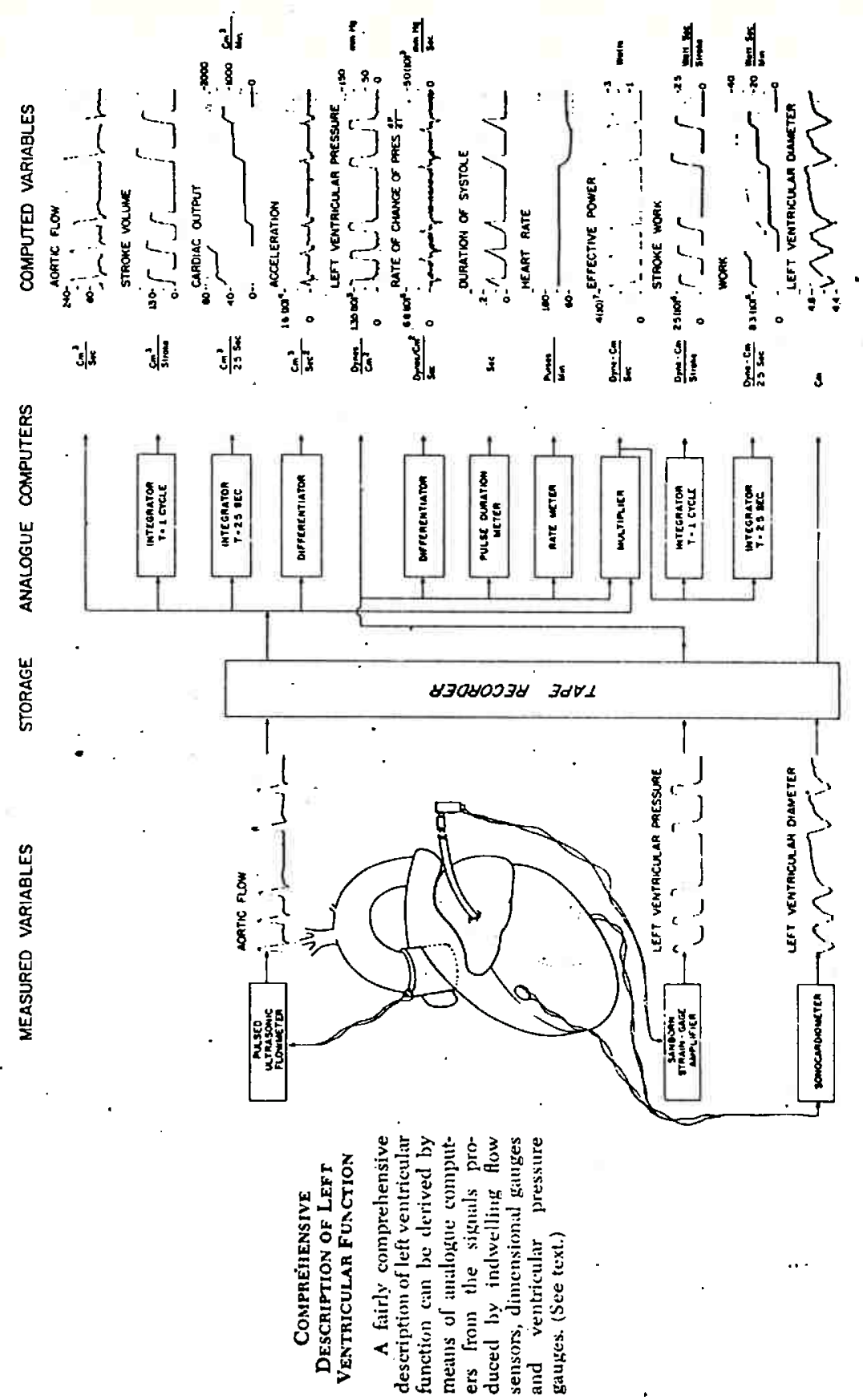

Fig. 2.6. Descrição compreensiva da função ventricular esquerda. Reoroduzi do de Rushmer (1976). 

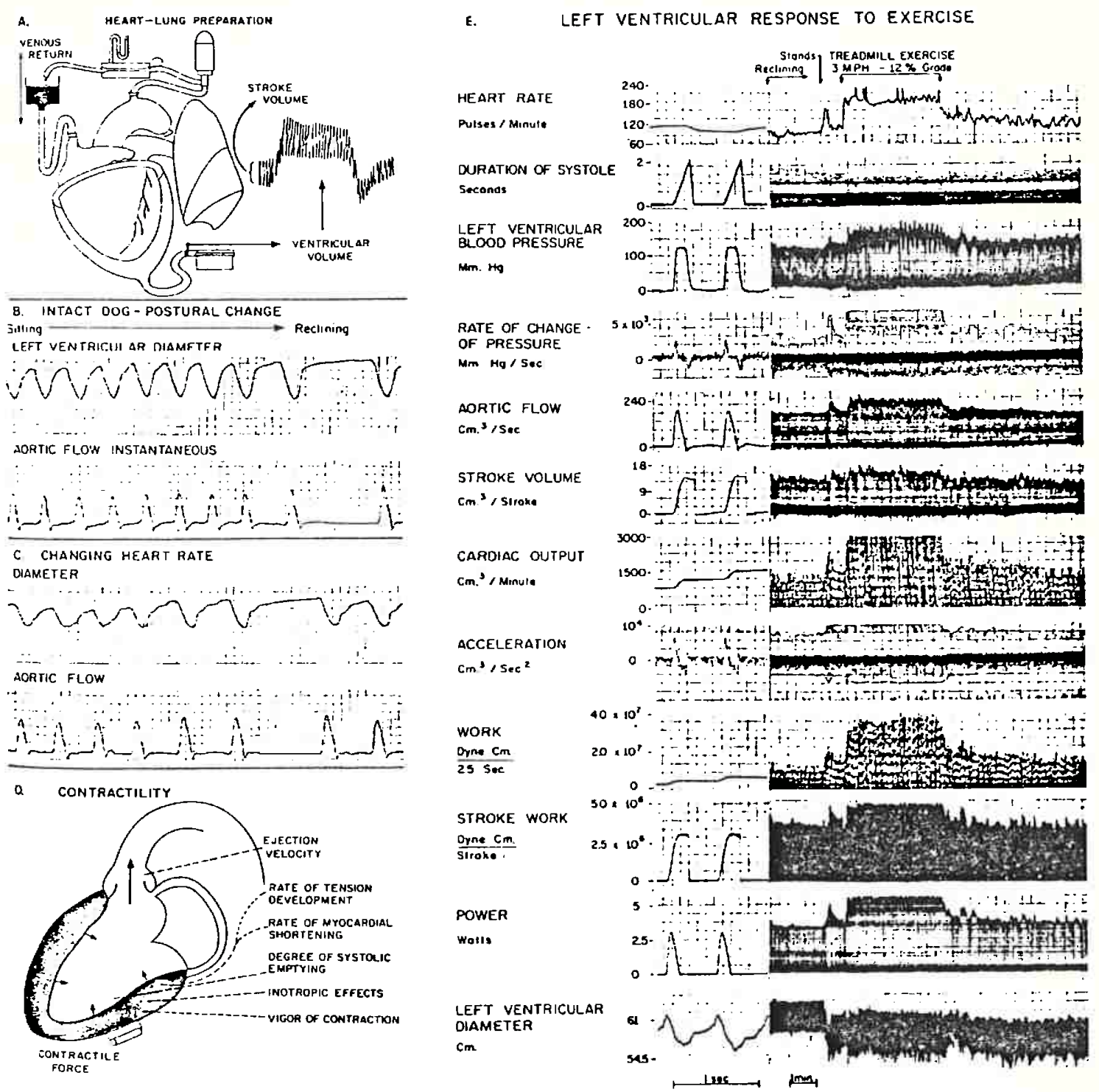

Ventmicular dDaptations DURING: Spontaneous activity

$A$, In the heart-lung preparation, the ventricle responds to an increase in either volume load or pressure load by diastolic distention and increased energy release (Frank-Starling mechanism).

$B$. In intact dogs, the Frank-Starling mechanism is readily demonstrable in the increase in energy releatse associated with increased diastolic distention as the animal reclines.

$C$. This mechanism also occurs during spontaneous changes in heart rate (i.e., sinus arrhythmia) which represent variations in vagal discharge.

$D$. Changes in veutricular performance which do not conform to the Frank-Starling mechanism are commonly attributed to changes in "contractility," a term which has so many connotations that it is relitively meituingless.

$E$. The ventricular responses to exercise by healthy active dogs correspond to the changes induced by svmpathetic stimulation. (From Rushmer et al., Circulation, 17:118-1+1, 1963.)

\author{
Fig. 2.7. Adaptações ventriculares durante \\ atividade espontânea. Reproduzi \\ do de Rushmer (1976) .
}


sistema arterial sistêmico. Os vários fatores determinantes des sa pressão estão indicados na Fig. 2.8. Observe-se que cada pon to da rede representa uma posição potencial de controle ou com pensação para qualquer perturbação do sistema.

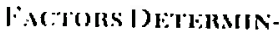

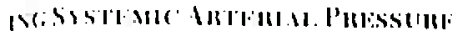

lihe malus inlorinding fiactors

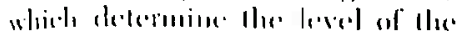

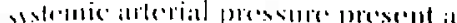

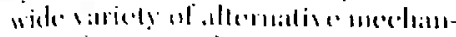

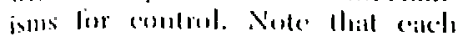
hrameh point represends a potem-

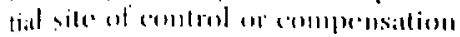

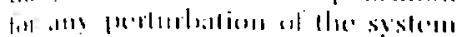
ser laxt).

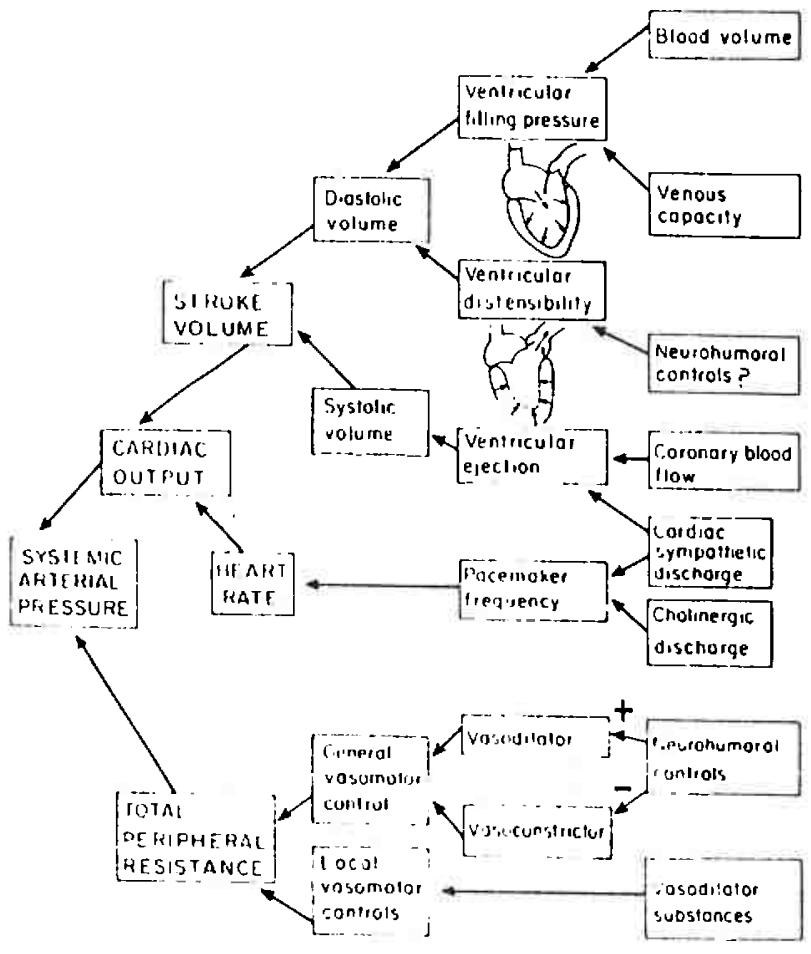

Fig. 2.8. Fatores determinantes da pressão arterial sistêmica. Reoroduzido de Rushmer (1976). 
2.4. Bases Fisiológicas da Circulação Extracorpórea e Características Hemodinâmincas da Perfusão.

A determinação das características da máquina coração-nulmão ar tificial ideal, a serem definidas nas secçōes seguintes, exige o conhecimen to das bases fisiológicas da circulação extracornórea, ap̣resentadas sucinta mente a seguir. Alpumas técnicas de medição e monitoração de parâmetros vitais durante a circulação extracorp̣órea são descritas em Kinmich, 1981, Shaw e Lewis, 1981, Kolfe, 1982 e Alexander e col., 1982.

\subsubsection{Função Cardíaca}

A primeira questão a ser solucionada quando se deter mina o conjunto de especificaçōes necessārias a uma māquina de circulação extracorpoōrea refere-se ao fluxo sanguíneo necessá rio para a cirurgia e à pressão de carga a ser vencida.

Para responder a esta pergunta deve-se considerar in cialmente que o débito cardíaco sob condições basais varia en tre 4 e 7 litros nor minuto no adulto normal (Conceição e Gomes, 1973 e Allen, 1958). Em condiçōes de nerfusäo extracorpōrea, en tretanto, värios asp̣ectos diferem da circulação normal, ressa $\underline{1}$ tando-se entre outros os seguintes:

1) O nível de oxigenação na circulação extracornoórea do indivíduo em renouso não exige o fluxo basal (Andreasen e Watson, 1952 e Lillehei e outros, 1957) sendo, a princípio, sú ficientes apenas 3 a 4 vezes o fluxo das veias ảzigos, ou 0,2 litros $/ \mathrm{m}^{2}$ de superfície corpörea/minuto.

2) Para evitar acidose grave e alterações cerebrais, resultantes comuns das perfusões com baixos fluxos, verificou- 
se a necessidade de perfusão com fluxos maiores. Vãrias pesqui sas demonstraram que um fluxo de $0,51 / \mathrm{m}^{2}$ sup. corp./min. sú priria o consumo total de oxigenação do coração e do cẻrebro en quanto as necessidades teciduais do sistema de drenagem da veia cava inferior só foram compensadas com um fluxo de $1,21 / \mathrm{m}^{2}$ sup corp./min. (Paneth e outros, 1957).

3) Deve-se considerar que a circulação extracorpórea estabelece um fluxo sanguíneo retrógrado em uma parte do orga nismo do paciente e um fluxo de perfusão adequado deve estabe lecer uma pressão arterial conveniente. Durante a perfusão to tal a manutenção da pressão arterial depende ainda dos mecanis mos naturais de controle da resistência arterial periférica.De fato, a diferença de pressão entre a aorta e as veias cavas $\vec{e}$ igual ao produto do fluxo sanguíneo pela resistência total da linha de circulação sistêmica, envolvendo os ramos arteriais e venosos. Lembrando que a resistência dos vasos venosos é baixa, proporcionalmente àquela apresentada pela parte arterial peri férica, conclui-se que a manutenção da pressão arterial cont nua depende dos mecanismos naturais de controle desta resistên cia arterial periférica. Esta resistência é não linear e depen de do fluxo sanguíneo pela ação dos baroreceptores, sendo mui to elevada para fluxos abaixo de $0,61 / \mathrm{m}^{2}$ sup.corp./min. Este resultado sugere um valor acima desse nível para o fluxo san guíneo conveniente para a perfusão total. Observe-se, entretan to, que a pressão arterial isoladamente é pouco significativa para o controle do fluxo sanguíneo devido à variação da resis tência periférica pelos vários fatores atuantes.

Atualmente considera-se que um fluxo de aproximada 
mente $2400 \mathrm{~m} 1 / \mathrm{m}^{2}$ sup.corp./min. oferece uma oxigenação adequa da a um adulto que esteja em condições basais e anestesiado.As crianças requerem um fluxo um pouco mais elevado, em $\mathrm{m} 1 / \mathrm{m}^{2}$ sup. corp./min., devido ao metabolismo basal mais elevado. Na präti ca, uma bomba sanguínea que possibilite até $6000 \mathrm{ml} / \mathrm{min}$ para aplicaçōes em adultos e $3000 \mathrm{ml} / \mathrm{min}$ para aplicaçōes pediátricas é considerada suficiente.

Outra questão a ser resolvida na circulação extracor pórea refere-se ao volume extracorpöreo. Este volume pode ser constituído por sangue total, plasma, soluções eletrolíticas ou substitutos do plasma. Varia de acordo com o tipo e o tamanho do oxigenador usado, correspondendo a 2000-4000 ml nos oxigena dores de disco, 700-1000 ml nos oxigenadores de bolhas e 300$1000 \mathrm{ml}$ nos oxigenadores de membranas. Desses resultados decor re a melhor eficiência da hemodiluição nos oxigenadores de mem branas (Heimbecker e outros, 1976; Sólis e outros, 1975; Berry e outros, 1977 e Liddicoat e outros, 1975). Na administração suplementar de volume, menos de um por cento se distribui no sistema arterial (sistema de alta pressão), estando todo o res tante nas veias sistêmicas, circulaçāo pulmonar e cavidades car díacas (sistema de baixa pressão). Consequentemente, é muito importante manter o equilíbrio da massa circulante durante a perfusão, o que se consegue facilmente anotando o nível do vo lume inicial no oxigenador e impedindo uma significativa dimi nuição ou oscilação do mesmo. o leito vascular se adapta a de terminada massa sanguínea imprimida pela bomba arterial. Varia ções bruscas de volume prejudicam essa adaptação, exigindo o controle rigoroso do fluxo sanguíneo. Todavia, mesmo com todos 
os cuidados para a realização de uma perfusão hemodinâmicamen te satisfatōria, com o passar do tempo, em geral após duas ho ras, surgem alterações de microcirculação que determinam dimi nuição do volume circulante, exigindo a reposição da massa san guinea para manutençāo do equilíbrio.

Finalmente, deve-se considerar que o retorno venoso na circulação sistêmica normal do corpo humano è devido, prin cipalmente, à diferença de pressāo entre as extremidades arte rial e venosa, à compressão das veias profundas pela contração muscular, à pressão por desnível (hidrăụlica) negativa intrato ráxica, à dinâmica inspiratória, às válvulas nos segmentos ve nosos que impedem o refluxo sanguíneo e aos baroreceptores que controlam o reflexo do retorno venoso. Entretanto, em condiçōes de perfusão total, este retorno venoso relaciona-se internamen te com a pressão venosa do paciente e, externamente, com o diâa metro dos catéteres e com a pressão negativa aplicada pelo desnível entre as veias cavas do paciente e o oxigenador (Conceição e Gomes,1973). Em uma dada perfusão, o fluxo sanguíneo pode ser variado atravēs de ca da um desses fatores, porëm, como o diâmetro dos catéteres e o desnível törax do paciente-oxigenador são fixados durante todo o procedimento cirürgico, o retorno venoso altera-se pelas va riações de volemia e pelas alterações vasomotoras do sistema venoso, sem possibilidade de controle pelos operadores. Obser ve-se que o reflexo deste retorno venoso, normalmente mediado pelos baroreceptores de capacitāncia, torna-se menos ativo quan do as câmaras cardíacas e os grandes vasos estão vazios e sub metidos à pressão atmosférica. Pesquisas demonstraram ser sufí ciente a drenagem venosa obtida por simples sifonagem (Paneth 
e outros, 1957). A diferença de pressão necessāria é obtida man tendo-se um desnivel de 30 a $50 \mathrm{~cm}$ entre o átrio direito e o oxigenador. Este resultado mostrou-se extremamente conveniente, desde que as tentativas de uso de bombas aspiradoras na linha venosa, inicialmente usadas para facilitar o escoamento sanguí neo e aumentā-lo quando necessārio, malograram devido ao cola bamento das paredes venosas aspiradas. E obvio que o retorno venoso depende diretamente do fluxo de perfusão, podendo este fluxo ser aumentado ou pela elevação da pressão venosa interna, sistêmica, do paciente ou pela mudança do desnivel paciente-oxi. genador.

Praticamente, pode-se considerar que as exigências mínimas para uma perfusão adequada são as seguintes:

1) Possibilidade de um fluxo sanguíneo suficiente pa ra estabelecer uma pressão arterial mëdia acima de $60 \mathrm{mmH}$. Fí cando a favor da segurança, exige-se a superação de pressões de carga da ordem de $180 \mathrm{mmHg}$ nas bombas sanguíneas.

2) Manutenção de uma pressão venosa central nos limi. tes normais para cada paciente.

3) Determinação de diurese não inferior a $30 \mathrm{ml} /$ hora.

4) Estabelecimento de boa perfusão capilar avaliada no leito ungueal ou na polpa digital, lembrando-se que crian ças possuem metabolismo basal mais elevado.

os principais problemas técnicos apresentados pela circulaçāo extracorpórea consistem em evitar a hemólise e a coagulação sanguínea durante seu bombeamento, bem como oxige nar convenientemente o sangue perfundido, em condições absolu 
tamente estéreis e regulando a temperatura do paciente (Jacob son e Webster, 1977). Além dessas necessidades básicas, a má quina deve manter o fluxo sanguíneo praticamente constante e em volume compatível com as necessidades orgânicas do paciente. A duração da perfusão deve ser a mínima oossível, porém a hipotermia e a cardioplegia possibilitam cirurgias de várias horas.

Muitas outras informações sobre técnicas de verfusão, preparo de material, cuidados cirürgicos e inúneras outras condições teóricas e prâa ticas sobre circulação extracorpórea, podem ser obtidas nas referências bibliográficas apresentadas no fim deste trabalho, e, em particular na referência Conceição e Gomes, 1973, de onde retiorou-se a maioria dos dados apresentados neste texto. Os efeitos da perfusão retrögrada da solução cardioplégica foram estudados por Jutta e co1. em 1985. Informações detalhadas e comparativas sobre fluxos pulsātil e não pulsātil são fornecidas em Lunda e col., 1985, Wright e Furness, 1985, Grossi, 1985 e Grossi e col., 1985.

2.4.2. Função pulmonar

Durante a circulação extracorpórea a função vulmonar $\vec{e}$ desempenhada pelo oxigenador. Como este iten é disponível co mercialmente com alta qualidade, sendo ainda descartável, não o abordaremos apesar de ser obrigatoriamente incorporado ao Si tema de Circulação Extracorpórea proposto.

2.5. Características Desejáveis de uma Máquina Coraçāo-Pulmão Artificial.

A preocupação com a determinação das especificações 
de uma máquina coração-pulmão artificial que pudesse auxiliar as circulações assistidas e extracorpóreas de maneira ideal, da ta do próprio início dos procedimentos cirürgicos cardíacos usando esta técnica. Dessa forma, as características do equipa mento ideal foram paulatinamente estabelecidas atravēs de inū meras pesquisas e debates entre especialistas em reuniões cien tíficas e médicas ao. longo destas três ültimas décadas. Nesta secção serão apresentadas as características especificadas pa ra esse aparelho até o final da ültima década. Na secção se guinte serä definida a mäquina ideal, conforme a proposta do autor deste trabalho.

Em setembro de 1957, vārios pesquisadores e cirur giōes atuantes na ärea de circulação extracorpórea reuniram-se em un Congresso patrocinado pelo National Heart Institute na cidade de Chicago (U.S.A.). O objetivo deste evento consistia em analisar os mais diferentes aspectos relacionados com o de senvolvimento desta técnica cirürgica para operações cardíacas (A11en, 1958). Uma de suas Secçōes de Estudos destinava-se a discutir as características de uma bomba sanguínea hipotética İdeal para uso em circulação extracorpórea. Do estabelecimento de uma Secção com tal finalidade, depreende-se facilmente a im portância na determinação criteriosa e precisa dessas especif $\underline{i}$ caçōes. As caracteristicas desejāveis e seus fatores limitantes foram discutidos, dividindo-se o trabalho em quatro partes: 1) a influência dos orifícios de restrição; 2) o trauma sanguíneo do bombeamento extracorpöreo; 3) a necessidade de fluxo variá vel e do seu controle automático; e 4) a medição da saída da homba, ou seja, do fluxo de sangue perfundido. 
Concluiram os especialistas, nessa ëpoca, que os co nectores deveriam ter a maior secçāo e o menor comprimento pos siveis, compatíveis com as técnicas disponíveis de canulação na época. Sugeria-se aspiração na linha venosa, o que se mostrou inconveniente nos anos seguintes, conforme exposto na secção anterior. Salientava-se tambëm que apesar da canulaçāo da aor ta ser possivel, muito mais fäcil seria a inserção em vasos me nores como as artērias femoral e subclaviana, apesar do orifí cio ser mais restritivo. Consequentemente, a pressão na linha arterial deveria exceder aquela do ventrículo normal e corres ponder mais à de uma válvula semi-lunar estenosada. 0 efeito desta pressão na saída da bomba deveria ser considerado, partí cularmente em relação à calibração do fluxo sanguíneo. Por ou tro lado, deveria ser pequeno qualquer trauma sanguíneo, tanto físico quanto químico, a começar pela turbulência que consti tuia a principal causadora da hemölise. Vālvulas internas e va riações abruptas nos diâmetros da tubulação deveriam ser evitá das, assim como abalos e ondas intensas de pressão, acarretan do pressões positivas e negativas súbitas. Essas considerações favoreciam as bombas de roletes(Fig. 2.9) contra as populares bombas Sigmamotor existentes na êpoca.

$\mathrm{Na}$ bomba de roletes um tubo elástico extremamente fle xível é comprimido sequencialmente por dois ou mais roletes, acarretando um fluxo unidirecional. O refluxo è impedido nois partes diferentes do tubo são comprimidas por diferentes role tes. Assim sendo, a bomba de roletes não precisa de válvulas.

Ressaltavam ainda que materiais em contacto com o sangue deveriam causar a mínima variação química, sendo a in $\underline{i}$ 


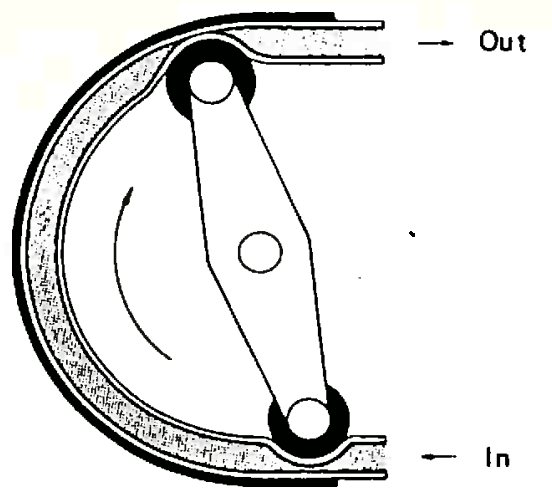

Fig. 2.9. Uma bomba sanguínea de roletes. Reproduzido de Jacobson e Web $\underline{s}$ ter, 1977).

ciação da trombose a mais óbvia evidência deste ataque químico. Materiais sintéticos eram sugeridos. Dificuldades na limpeza do sangue e da proteína de partes plásticas e metálicas exí giam que a câmara de circulação sanguínea fosse descartável.

O problema mais complexo associado com a bomba jā era o controle do fluxo sanguíneo. Era exigido um fluxo unifor memente variável desde zero ate $51 / \mathrm{min}$. Este fluxo deveria ser controlado, se possível automaticamente, mantendo-se o vo lume de sangue no sistema extracorpoóreo ou, ainda melhor, as pressões arterial e venosa do paciente. Finalmente, estabele cia-se a necessidade da medida do fluxo sanguíneo perfundido, exigindo-se uma calibração precisa, sob condições reprodutiveis

Finalizou aquela Secçāo de. Estudos deixando importan tes questōes a serem respondidas no futuro: 1) Qual o parâme tro fisiológico mais conveniente para controlar a saída da bom 
ba?; 2) Deve-se preferir o fluxo pulsátil ou o não pulsâtil? ; 3) Quão automático deve ser o equipamento?. Almejava-se que pú dessem ser respondidas nos anos seguintes, tanto quanto outras porventuras levantadas como decorrência do avanço das cirur gias cardiovasculares.

Não apenas essas düvidas, mas inümeras outras de na tureza hemodinamica foram dirimidas em importante trabalho rea lizado por Head e colaboradores em 1960, estudando experimenta 1 mente os diferentes aspectos hemodinâmicos do mecanismo de bom beamento em um circuito de circulação extracorpórea usando bom ba de roletes (Fig. 2.10). Nesta pesquisa foram tambëm estabe lecidos os principios bäsicos a serem usados na perfusão total.

Os principais resultados obtidos nesse trabalho po dem ser sumarizados em oito itens, descritos a seguir:

1) Quanto maior a oclusão do lümen pelos roletes, maior é a destruição das células sanguíneas. Por outro lado, o ajuste dos roletes em sìtuações não oclusivas acarreta um flu xo retrógrado, com a consequente diminuiçāo do volume sanguí neo impelido e a necessidade de velocidade angulares de rota ção dos roletes muito grandes a fim de fornecer o fluxo norma 1 mente desejado. Neste caso, a resistência da linha fluídica afe ta significativamente no fluxo sanguíneo. Dessas considerações decorre a necessidade de um ajuste intermediário entre a oclu são completa e a oclusão nula, por meio de compromisso entre a hemólise resultante e o fluxo retrógrado. Exige-se ainda uma calibração da oclusão do lümen com uma resistência fluídica sí mulada, considerando-se inclusive que hả uma perda no volume 


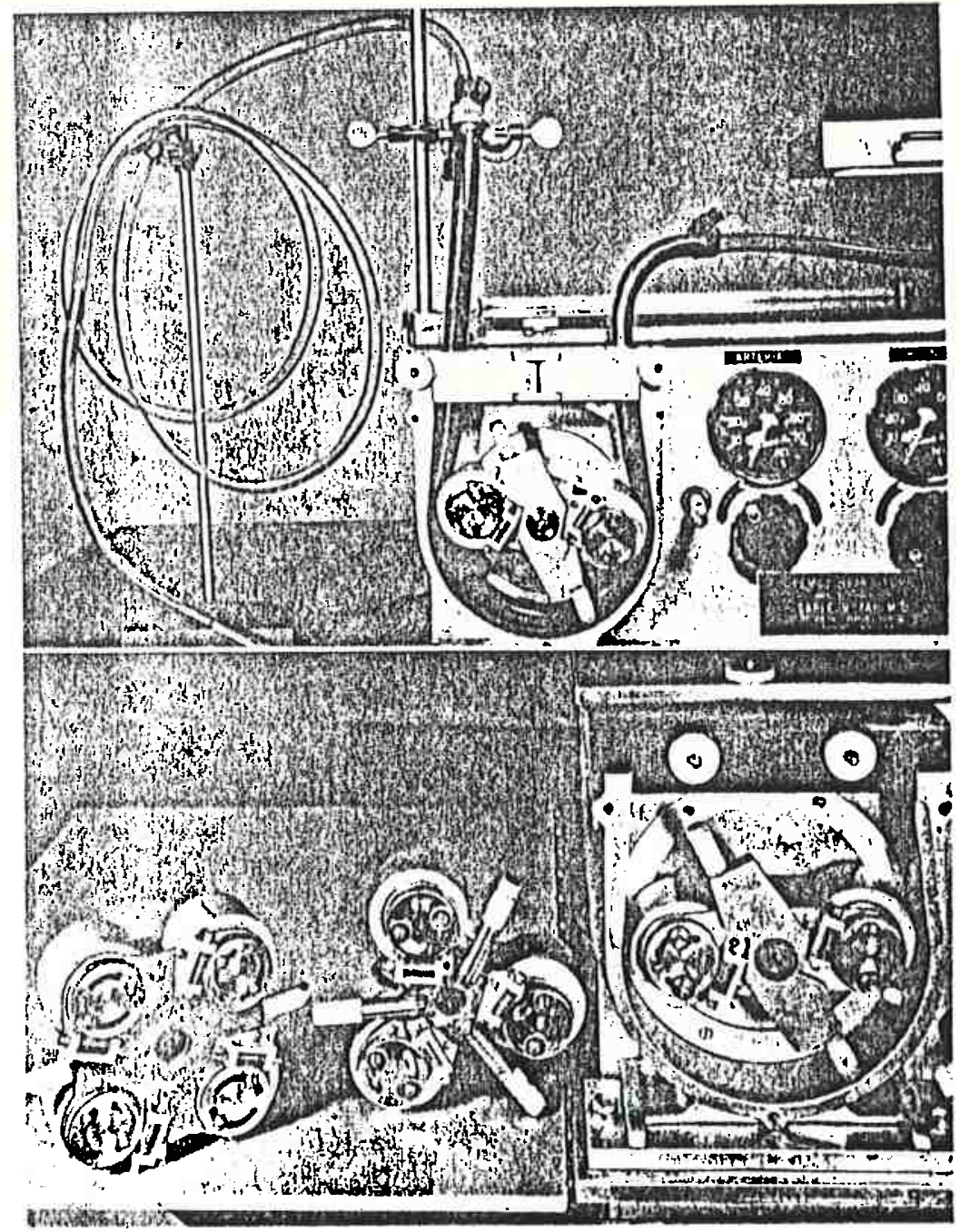

Fig. 2.10. A bomba de roletes usada no experi mento de Head e colaboradores, 1960.

impelido pela bomba, aumentando a pressão na linha arterial.

2) A adição de roletes no sistema de bombeamento aumen ta significativamente a hemōlise, sem aumentar o fluxo na mes ma proporção. 
3) A configuração da curva de pressão do pulso den tro da bomba é influenciada pelo comprimento do seu trato. En compridando-o, a ejeção do volume impelido é prolongada e a pressão e o fluxo mäximos são sustentados durante grande parte do ciclo de bombeamento. Este resultado contrasta com aquele obtido pela ação normal do coração, onde a grande parte do vó lume impelido è ejetado em um dëcimo do ciclo.

4) Diminuindo a dimensão da câmara de bombeamento de cresce o volume impelido mas exige-se um aumento na velocidade da bomba para manter o fluxo. Este resultado limita a faixa de fluxo para ejeção dos menores volumes impelidos. Aumentando a câmara hâ um consequente aumento do fluxo e a hemólise produzi da diminui.

5) Aumentando o diâmetro da cânula arteria1 obtem-se uma pressão na linha arterial significativamente menor, para um dado fluxo. Entretanto, esta diminuição da pressão e, conse quentemente, do gradiente de pressão através da cânulà arterial, não é associada com uma diminuição significativa no nível de hemölise.

6) O fator significativo responsável pela hemölise de vido à bomba é a compressão da sua câmara pelos roletes ocluso res: O volume impelido afeta a hemólise somente por influenciar a velocidade da bomba. O gradiente de pressão através da cânu la arterial acarreta um dano ao sangue, mas quantitativamente sua ação é pequena. O nível absoluto da pressão da linha arté rial não influencia a hemólise.

7) O nível da pressão aórtica durante a perfusão es 
tä relacionado com o fluxo, enquanto a quantidade de sangue no paciente perfundido permanece constante. Entretanto, a relação entre o fluxo e a pressão aórtica não é linear, sendo maiores fluxos associados com um efeito decrescente da pressão sanguí nea. Em individuos normais este è, provavelmente, um resultado dos reflexos moderadores originados nos seios carótidos e ten dendo a manter uma pressão arterial constante sobre uma larga faixa de saídas cardíacas (Levy, 1954). Em situaçōes encontra das em cirurgias com o coração aberto, onde grandes quantida des anormais de sangue retornam às câmaras do coração via si nus coronārios, artérias bronquiais ou vảlvula aórtica incompe tente, esta relação não se mantēm. Nestas circunstâncias o flu xo tem pequeno efeito sobre o nível da pressão aórtica, além de um certo ponto.

8) As pulsaçōes dentro da aorta, quando a perfusão è conduzida pelo próprio coração, são consideravelmente amorteci das se comparadas com aquelas existentes nas linhas da bomba e do circuito extracorpóreo sanguíneo. As flutuações de pressão dentro da tubulação da bomba refletem as diferenças em elastí cidade entre esta e os vasos sanguíneos. Na tubulação, a pres são do pulso aumenta conforme aumenta a pressão da linha arte rial e a tubulação se torna menos elástica. A elasticidade na bomba pode ser aumentada extendendo a câmara de latex de borra cha de 18 para 36 centímetros alẻm do ponto de saída da bomba (Fig. 2.10), resultando em um decrëscimo das pulsações na $1 \underline{i}$ nha pela diminuição da pressão sistólica e aumento da diastóli ca. Não hâ variaçōes no fluxo, pressão média na linha ou hemóli se, resultante deste depulsador. Observe-se ainda que é peque 
na a duração, dentro do ciclo da bomba, quando os roletes não estão funcionando. E neste breve intervalo de tempo que ocorre a flutuaçāo da pressão. A largura do pulso de pressão na aorta tambëm $\vec{e}$ afetada pelo volume impelido e pelo gradiente de pres são atravess da cânula arterial. Um aumento do volume impelido de quatro vezes e meia, acarreta duplicaçāo da pressão do pul so na aorta.

Em 1971, Netter voltava a enfatizar a necessidade de bombas sem vảlvulas para produzirem menos hemólise e trombose, bem como serem mais fáceis de limpar e esterilizar. A bomba sem válvulas descrita era essencialmente a tradicional bomba de roletes.

Em 1973, Conceição e Gomes afirmavam que uma bomba ideal deveria diminuir ao máximo o traumatismo do sangue, con seguir regular o fluxo de acordo com as necessidades do pacien te, permitir que seu volume-minuto pudesse ser medido e impul sionar um volume sanguíneo de 200 a $5.000 \mathrm{ml} / \mathrm{min}$. contra uma pressão de $180 \mathrm{~mm}$ de $\mathrm{Hg}$. Enfatizavam ainda a importância da cor reta regulagem dos roletes, considerando-se como tal a menor oclusão capaz de impedir completamente o refluxo de uma coluna líquida de āgua com um metro de altura.

Em 1977, Jacobson e Webster afirmavam categoricamen te que a bomba de sangue ideal ainda estava por ser projetada. Deveria evitar a hemólise, impelir o sangue à vazão de até 5 $1 / \mathrm{min}$. contra uma pressão de $180 \mathrm{~mm} \mathrm{Hg}$, sendo o fluxo controlá vel e precisamente conhecido, de modo a ser mantido constante. Esta condição era estabelecida como decorrente da manutenção 
do volume sanguíneo na mäquina coração-pulmão artificial em um nível constante, após atingir-se o equilíbrio. o fluxo sanguí neo deveria ser controlado pela monitoração do volume de san gue. A bomba deveria ser fácil de limpar e esterilizar, deven do operar em condições absolutamente estéreis de modo a evitar infecções, e não deveria conter espaços mortos onde o sangue pudesse coagular. Considerando que a anestesia diminui a tempe ratura do paciente, atuando no seu sistema regulador, sugeriase que essa temperatura deveria ser controlada. Por outro lado, estabelecia-se que se a máquina fosse conectada a um paciente e mais tarde desconectada, essa interrupção da circulação deve ria ser mínima. Não deveria também ocorrer flutuação significa tiva no volume sanguíneo circulante e o sangue nos pulmões e no coração do paciente deveria retornar nesse volume sanguíneo circulante. Concluiam afirmando que o princípio pelo qual as bombas sanguíneas operavam ainda era pela compressão peristál tica de tubos plásticos elásticos, usando-se bombas de roletes.

Finalmente, observe-se que a velocidade angular do rotor da bomba sanguínea, pode ser determinada dividindo-se o fluxo necessário teoricamente pelo volume de sangue impelido em cada rotação. Considerando-se o fluxo máximo de $6000 \mathrm{ml} / \mathrm{min}$., e um valor médio de $50 \mathrm{~m} 1$ de sangue impulsionado por rotação, ob tem-se uma velocidade angular máxima de 120 rotações/minuto pá ra aplicações em adultos e 60 rotações/minuto para aplicações pediátricas. Este resultado justifica a existência de reduto res nos motores elétricos, desde os primeiros modelos de bom bas de circulação extracorpórea. 
Outros trabalhos sobre bombas sanguíneas são rela cionados nas Referências Bibliográficas porēm apenas reforçam os resultados anteriormente citados.

\subsection{A Máquina Coração-Pulmão Artificial Ideal}

As características apresentadas na secção anterior, indiscutivelmente sāo necessārias para uma máquina coraçãopulmão artificial idea1. Entretanto, Moraes e Barros Moraes (1979a, 1979b) demonstraram que não são suficientes. Suger $\underline{\mathbf{i}}$ ram algumas inovações a serem incorporadas na māquina ideal, resultando em um Sistema de Circulação Extracorpórea abrangen te. Sua parte motora deveria possibilitar um fluxo de perfu são atē $6000 \mathrm{ml} / \mathrm{min}$, ajustảvel de maneira contínua e 1 inear, com uma calibração e controle precisos para evitar traumatis mo sanguíneo por excesso de compressão e variaçāo do fluxo efetivo, uma vez que este varia, a uma dada velocidade angu lar do rotor, com a maior ou menor compressão exercida pelos roletes. Para aumentar ao máximo possível a segurança, a qua lidade, a funcionalidade e a confiabilidade do equipamento, se riam incorporadas as seguintes inovações ou modificações rela tivas aos modelos existentes na época:

1) Sistema com dispositivos de segurança e proteção contra choques elétricos, compatível com as exigências descri tas em Normas Internacionais e Brasileiras para equipamentos eletro-médicos da categoria CF.

2) Sistema modular, propiciando reposições rāpidas 
dos subsistemas vitais (em segundos) para o caso de eventual falha no funcionamento. Os mödulos venosos, também denominados aspiradores de campo cirūrgico, seriam ainda intercambiāveis e emergencialmente, substituiriam o módulo arterial.

3) Possibilidade de medida e ajuste eletromecãnico el ou eletrônico da compressão dos roletes nos tubos plästicos, acarretando maior precisão tanto no ajuste como na calibração, alëm de maior facilidade e rapidez em uma eventual necessidade de recalibração, minimizando consequentemente a ocorrência de hemólise. Os dois braços dos roletes seriam ajustados conjunta mente, por um mecanismo patenteado pelo autor e colaborador (ver detalhes no Apêndice B).

4) Possibilidade de medidas digitais, e de controles do fluxo sanguíneo e da velocidade angular do rotor de cada bomba sanguínea, disponível em todos os módulos, desde que uma unidade venosa pode ser utilizada inclusive como bomba artifi cial para perfusão em crianças de baixo peso.

5) Incorporação de um sub-sistema de refrigeração au tônomo, através de um módulo de refrigeração especialmente pró jetado e de acordo com a outra patente referida anteriormente e apresentada no Apëndice $C$.

6) Introdução de subsistema termométrico para perma nente e uniforme controle das temperaturas do paciente e dos fluidos circulantes nos reservatörios de água.

7) Introdução de sub-sistema cronométrico para medi da e controle de intervalos de tempo relativos às durações de anōxia (ou de ação da solução cardioplégica, atualmente) e da 
ação do anticoagulante, evitando acidentes devidos a coagula ções dentro das durações estabelecidas ou a uma parada cardía ca anóxica prolongada, falhas estas quase sempre fatais. Com a utilização do módulo proposto eliminar-se-ia as consequências de falhas humanas causadas por esquecimento, distração ou má cronometragem do perfusionista. Alarmes äudio-visuais adicio nais alertariam o operador no instante do término de cada in tervalo de tempo.

8) Incorporação de controle eletrônico de níveis de sangue no oxigenador, através de um dispositivo de alarmes āu dio-visuais quando houver uma diminuição do volume sanguíneo for necido pela bomba arterial, em vinte e cinco por cento. Em um segundo estágio, com nível de quarenta por cento de sangue no oxigenador, parada total da referida bomba, evitando ocorrência de embolia aérea ocasionada pelo bombeamento de ar para o inte rior do sub-sistema arterial. Alarmes āudio-visuais diferentes dos anteriores possibilitariam a sinalização e o alerta neces sārios tambēm neste caso.

9) Incorporação de detetor de bolha na linha arterial, parando incontinente o motor arterial e os motores ve nosos. Alarmes äudio-visuais auxiliares seriam incluídos.

10) Introdução de um sub-sistema de monitoração e ví gilância dos níveis de água quente e fria nos reservatórios cor respondentes, contendo alarmes audio-visuais para sinalização e alerta, bem como inclusão de sinalizaçāo de níveis máximos de água nos tanques, visando evitar transbordamentos.

11) Incorporação de um sub-sistema de energia autôno mo, a ser ativado automaticamente no caso de eventual interrup 
ção no fornecimento normal de energia elêtrica. Seriam incluí das ainda lâmpadas de emergência, vossibilitando a visão dire ta do nível de sangue no oxigenador.

12. Introdução de tampas transparentes protetoras es camoteáveis para os roletes, protegendo tanto o seu perfeito funcionamento como o próprio operador.

o conjunto de especificacões e exigências apresenta do define as características de uma máquina de circulação ex tracorpórea ideal de acordo com as limitações impostas pelo pre sente estado científico-tecnológico. Estas características fo ram consideradas obrigatórias no projeto do Sistema de Circula ção Extracorpörea desenvolvido pelo autor.

Possivelmente o rāpido avanço científico-tecnológico atual permitirā uma mäquina mais aperfeiçoada. Por exemplo, se ria desejável um novo processo de bombeamento que permitisse suprimir o problema da hemōlise, o que dependerá de futuras pes quisas a serem desenvolvidas na área. Além disso, as a iteraçōes superficiais e os desgastes da tubulação pressionada pelos roletes da bomba peristältica são atualmente objeto de vários es tudos (Jackman e col., 1980; Lemiski, 1980; Kurusz e co1.,1980; Leong e col., 1980; Laohapaud e col., 1982; Bommer e col.,1983a e 1983b; Buckley, 1984 e Morley. e col., 1986) questionando-se inclusive a prōpria conveniência da utilização dessas bombas em cirurgias cardíacas com circulação extracorpoórea. 
CAP ITULO I I I

CONCEPÇAOO DO SISTEMA DE CIRCULAÇAO EXTRACORPOREA DE ACORDO COM O CONCEITO INTEGRADO DE SEGURANÇA DE EQUIPAMENTO ELETRO-MEDICO

3.1. Introduçāo

A funcionalidade do Sistema de Circulação Extracorpoo rea proposto foi verificada pelo desempenho apresentado nos pri meiros protótipos construídos, os quais inclusive comprovaram a viabilidade das inovações sugeridas. Entretanto, as vārias tentativas para a determinação de um processo de fabricação ade quado ao equipamento demonstraram a necessidade da utilização de diretrizes e conceitos de segurança em aparelhos eletro-mé dicos. De fato, ao iniciar-se a fase de desenvolvimento das unidades que serviriam de cabeças de série de uma linha de fạ bricação, constatou-se a necessidade de uma criteriosa concep ção do Sistema, considerando as rigorosas características de qualidade, confiabilidade e segurança imposta pela particular ärea de aplicação.

Vărios autores enfatizam a importância de aspectos de segurança em Engenharia Biomëdica (Webster e Cook, 1979; Web ter, 1978; Bahil1, 1981,. Jacobson e Webster, 1977; Traisler, 1981; Dalziel 1972; Cromwel1 e outros, 1980) porém normalmente não consideram o seu conceito integrado. Esta conceituação apli 
cada ao desenvolvimento de equinamento eletro-médico, será apre sentada inicialmente neste capítulo, sendo posteriormente especificadas as características construtivas e de fabricação do Sistema de Circulação Extracorpórea, de acordo com tal filosofia de implementação. Embora a preocu pação principal seja a segurança, também serão consideradas diretrizes referentes à confiabilidade de operação e controle de qualidade.

0 procedimento adotado pretende estabelecer un mode1o de concepção para equipamentos eletro-médicos, servindo para futuras implementações em Instrumentação Biomédica. Entretanto, leituras comblementares são recomendáveis, enfatizando-se, principalmente, as Normas Técnicas listadas na Referência Bibliogräfica, McPhum, 1981, Scott e Paasche,1966, Lunt, 1983, Physiological Measurement. Topic Group,1983, Sti1lman,1983, Roberts, 1982 e Stoner e col.,1982. Especial atenção deve ser dada à Norma Brasileira NBR 9153 da ABNT e à Publicação 601-1 da IEC.

3.2. O Conceito Integrado de Segurança de Equipamentos Eletromédiccs Um equipamento eletro-médico utilizado na prática médica pode expor, intencionalmente ou não, tanto o paciente e o seu meio ambiente, co mo o operador e o nrónrio equipamento ou a instalação, a uma série de ris cos. Consequentemente, necessita-se estabelecer um níve1 de segurança ade quado através de medidas apropriadas para proteger, em primeiro lugar, o paciente e o operador e, secundariamente, os outros alvos sobre os quais podem recair esses perigos.

Alguns aspectos específicos da utilização de equipamento elétrico na prática médica, implicam na imp̣ortância das precauçōes de seguran ça. Os mais significativos referem-se à limitada capacidade do ser humano absorver as diferentes formas de energia, à vulnerabilidade do paciente e, muitas vezes, à possibilidade de sua prọpria vida ficar na dependência do 
funcionamento do equipamento. Neste ültimo caso, até a confia bilidade do instrumento e da instalação se tornam fatores de se gurança .

Por outro 1ado, o próprio equipamento impõe exigên cias sobre sua estabilidade técnica. Inicialmente, ressalte-se que a sua vida útil e determinada pela qualidade inicial, pelo efeito das condições ambientais, pela frequência de utilização e pela supervisão durante essa utilização, bem como pela sua manutenção. Deve-se salientar ainda que, apesar da probabilida de de ocorrerem várias falhas não ser nula, algumas das quais podem ser prevenidas por inspeção e manutenção periódicas, os seus efeitos podem ser minimizados atravës de uma adequada con cepção tẻcnica considerando o método de produção empregado e comportando coeficiente de segurança suficientemente elevado, redundâncias è dispositivos de proteção. Estes dévem conside rar a robustez elétrica e mecânica inicial, as consequências da utilização e do desgaste, o domínio dos métodos de fabrica ção e as condições de transporte e de armazenamento.

Normalmente os danos causados são devidos aos proble mas acarretados em operação normal ou na condição de primeira Falha, e à falta ou interrupção de funcionamento do equipamen to. Deve-se considerar ainda o erro humano possível durante a operação do aparelho (International Electrotechnical Comission, Publicação 513,1976$)$. Observe-se que é sempre considerado o conceito da condição de primeira falha, que estabelece a possi bilidade de implementação de um sistema de proteção com o qual qualquer primeira falha pode ser detetada antes de ocorrer uma segunda. Esta condição deve ser indicada ao operador quer por 
um sinal inconfundivel e facilmente reconhecível, quer por ins peção periơdica.

Os fatores anteriormente descritos e um estudo cuida doso de normas e da literatura científica atuais, levam à defi nição do Conceito Integrado de Segurança: A segurança de um equipamento eletro-mëdico não pode serr, em geral, conseguida apenas por incorporações realizadas no equipamento, mas por uma combinação de medidas abrangendo este $\vec{u} 1$ timo, a instalação elētrica do edifício, a manutenção e a sua aplicação.

Deve-se ressaltar que a segurança serā sempre um con ceito relativo, exigindo medidas que propiciem uma proteção ade quada sem restringir a função normal do equipamento. As normas técnicas distinguem três categorias de segurança básicas, a sa ber:

a) segurança incondicional: equipamento $\overrightarrow{\mathrm{e}}$ projetado de modo a serem incorporados todos os meios apropriados para excluir risco.

b) segurança condicional: se a segurança incondicio nal não for realizável, são aplicados meios de proteção extẹ nos especiais.

c) segurança descritiva: se a segurança condicional nāo atingir os resultados pretendidos, são definidas condiçōes sob as quais è possivel a operação segura.

Presume-se, de um modo geral, que o equipamento ele tro-médico é operado sob a responsabilidade de pessoas qualifi cadas, de acordo com as instruções para utilização e com a hạ bilidade exigida para a aplicação médica específica. A aplica 
Ção de energia no paciente, durante o diagnóstico ou tratamen to, realizada como função intencionalmente requerida do equipa mento, faz parte da responsabilidade do médico. Todavia, a afe rição e/ou indicação exata da quantidade de energia deve ser as segurada pelo equipamento: Deve-se exigir do médico e do pes soal que trabalha sob sua responsabilidade, capacitação sufí ciente para operar o equipamento e conhecimento dos possíveis riscos decorrentes. Em casos mais graves, os avisos de precau ção devem ser afixados no equipamento, ou transcritos nas ins truções para utilização. Enganos inconscientes e típicos pode rão ser evitados por meio da disposição adequada dos comandos e das conexões, ou por meio de bloqueios.

A utilização segura de um equipamento eletro-médico está, a princípio, sob a responsabilidade de seu operador. Em seu auxílio deve-se incorporar ao aparelho um manual contendo - Cōdigo de Aplicação, que deverá dar informaçōes precisas sọ bre o seu emprego seguro e confiável bem como informar às auto ridades responsäveis sobre medidas de organização e de inspe ção, bem como programas de treinamento e instrução.

3.3. Agentes de Riscos Associados à Utilização de Equipamentos Eletro-Médicos.

A aplicação do conceito integrado de segurança de equipamento eletro-médico exige anālises específicas dos vārios agentes de riscos associados à sua utilização, sendo normalmen te considerados os seguintes: 
- Energia elétrica

- Forças mecānicas

- Perturbações râdio-elétricas

- Temperaturas excessivas

- Fógo

- Agentes químicos

- Erro humano

- Falha de componente

- Interrupção no fornecimento de energia

- Anormalidades ambientais

Como decorrência, estabelecem-se as seguintes catego rias de prescrições de segurança:

- Segurança contra risco elétrico

- Segurança contra risco mecânico

- Segurança contra risco de explosão

- Segurança contra risco de inceendio

- Segurança contra risco de radiações

- Segurança contra risco de ruído

- Segurança contra risco de temperaturas excessivas e fogo

- Segurança contra riscos ambientais

- Segurança da instalação

Todas essas categorias serão consideradas na concep ção do Sistema de Circulação Extracorpoórea. 
3.4. O Sistema de Circulação Extracorpórea

O Sistema de Circulação Extracorporea (S.C.E.) pro posto visa atender as exigências da máquina coração-p̧ulmão ar tificial ideal, sendo concebido conforme o conceito integrado de segurança para equipamento eletro-médico. Um diagrama esque mático do S.C.E. é apresentado na Fig. 3.1, onde são indicados os vārios sub-sistemas existentes. Os vārios setores existentes no painel do equipamento implementado, conforme apresentado no Capítulo IV, são mostrados na fotografia correspondente à Fig. 3.2 .

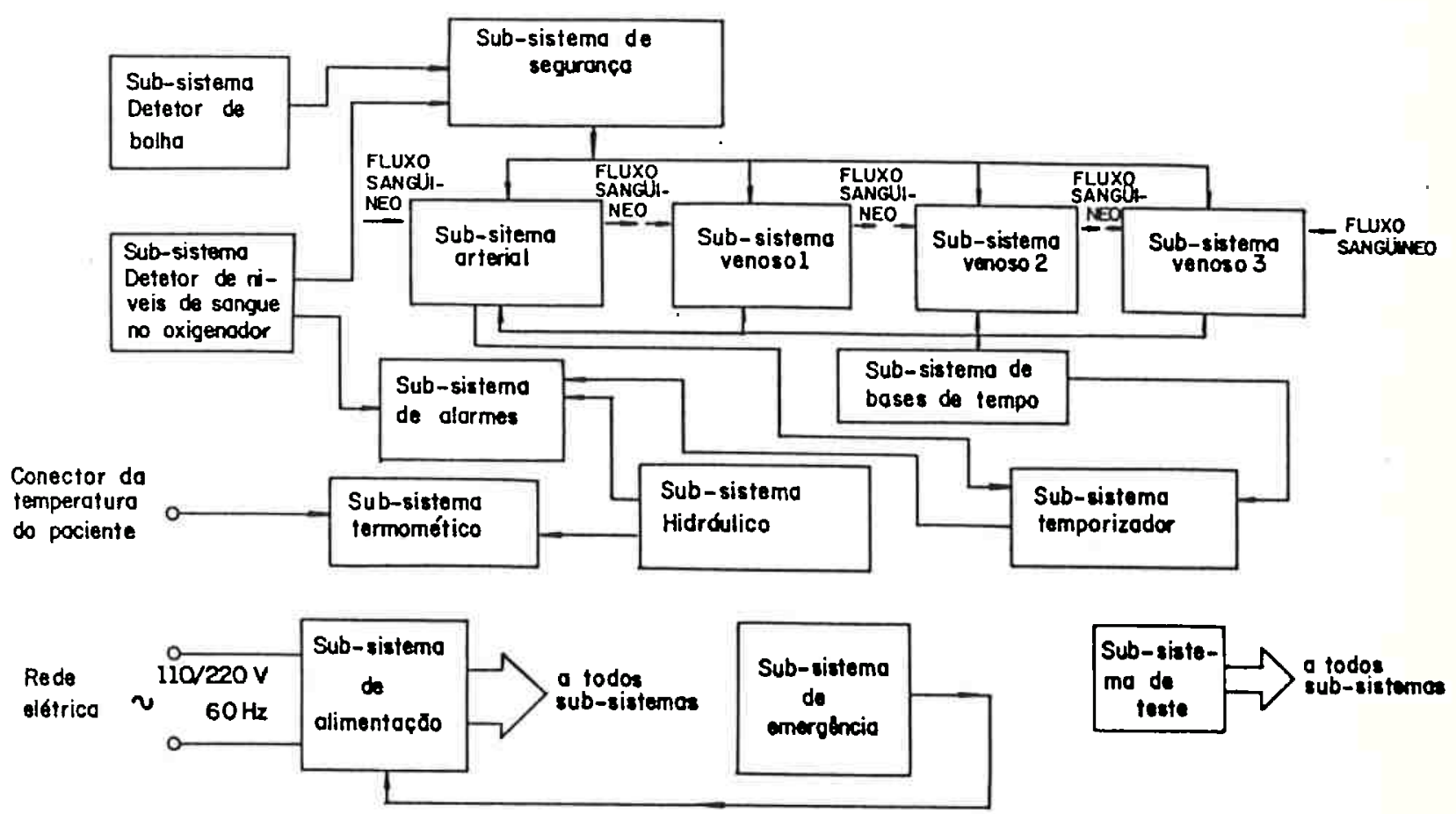

Fig. 3.1. Diagrama Esquemático do Sistema de Circulação Extracorpórea. 


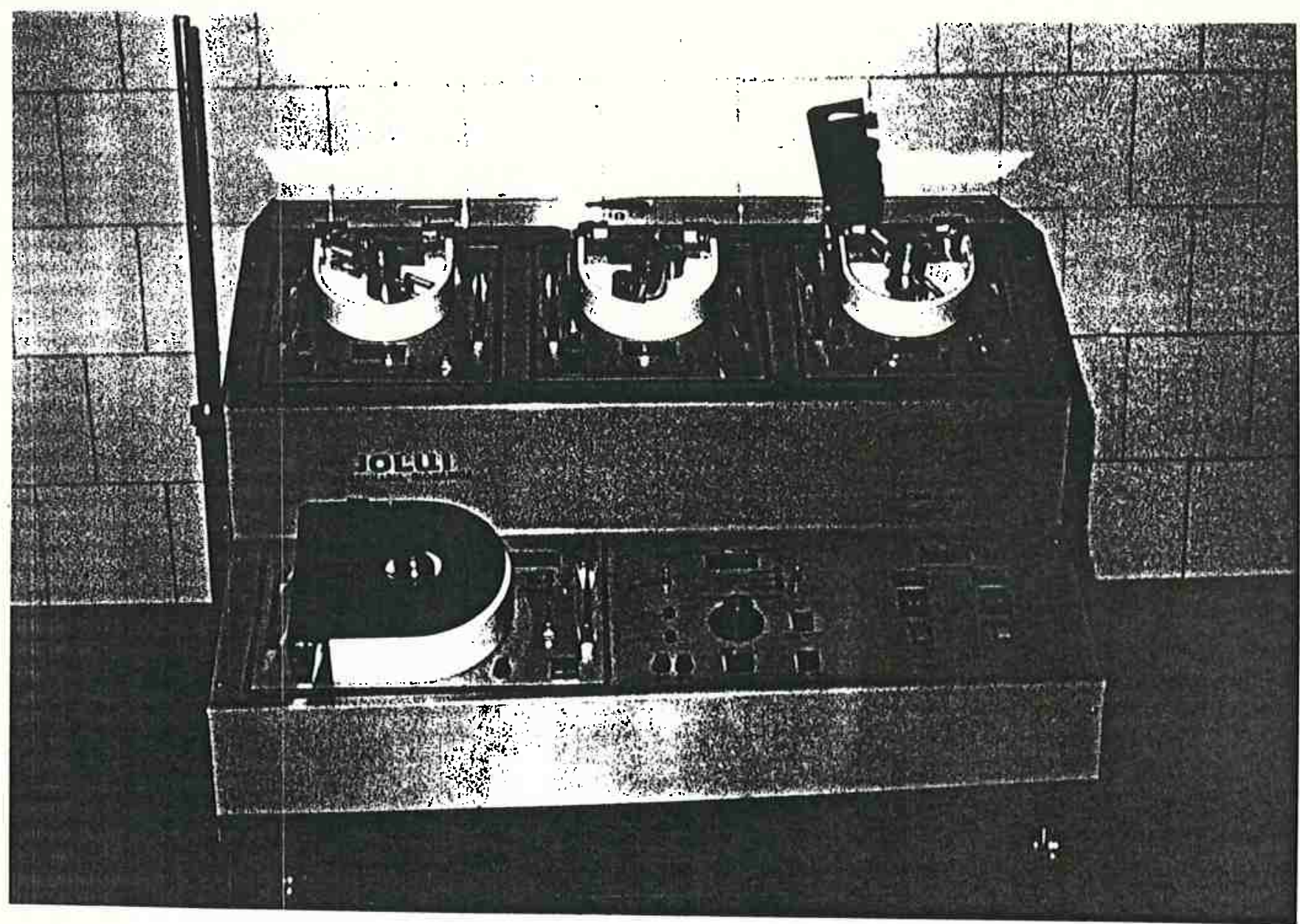

Fig. 3.2. Vista frontal do Sistema de Circula ção Extracorpórea.

A seguir serão apresentados sucintamente os vários sub-sistemas constituintes do S.C.E. com seus controles e sele tores de painel.

3.4.1. Sub-Sistemas Motores

O sub-sistema mais importante do conjunto é o módulo arterial que recebe o sangue proveniente do oxigenador e o en via ao paciente, sob alta pressão. Os três mōdulos venosos são 
responsáveis pela aspiração do sangue extravazado no campo c $\underline{i}$ rürgico, bombeando-o para o oxígenador onde se mistura com a porção sanguínea escoada gravitacionalmente das veias cavas. En tretanto, em situações emergenciaìs uma ou mais partes venosas poderão substituir a arterial, razão pela qual suas concepções devem seguir os mesmos critérios desta ültima. Estes quatro mó dulos constituem a parte motora do S.C.E. As bombas sanguíneas arterial e venosas, totalmente independentes entre si, são acio nadas por motores elétricos que possuem circuitos de controle, medição e sinalização das velocidades angulares dos eixos dos rotores e dos fluxos sanguíneos correspondentes. Acoplado ao eixo do motor elétrico, cada bomba possue o seu próprio eixo com uma porção terminal-frontal denteada (pinhão) onde são aco plados perpendicularmente dois braços denteados (cremalheiras) possuindo roletes livres em seus extremos, os quais comprimem a tubulação por onde flue o sangue (Fig. 3.3.). Uma das origi nais contribuições deste trabalho corresponde ao mecanismo que possibilita o ajuste simultâneo da pressão dos dois roletes através da movimentação longitudinal dos braços, controlando a distância entre a parede externa do rolete e a parede interna da caçapa suporte da tubulação e, consequentemente, do lúmen do tubo por onde escoa o fluído sanguíneo. Cada módulo possue con trole, medição e sinalização da abertura desse lựmen.

Conforme pode ser verificado na Fig. 3.3., o paine1 de cada módulo motor contém uma bomba sanguínea. Um controle deslizante linear possibilita a seleção da desejada velocidade angular do rotor e, consequentemente, do fluxo de sangue. Uma chave seletora de três posições permite a seleção da medida da 


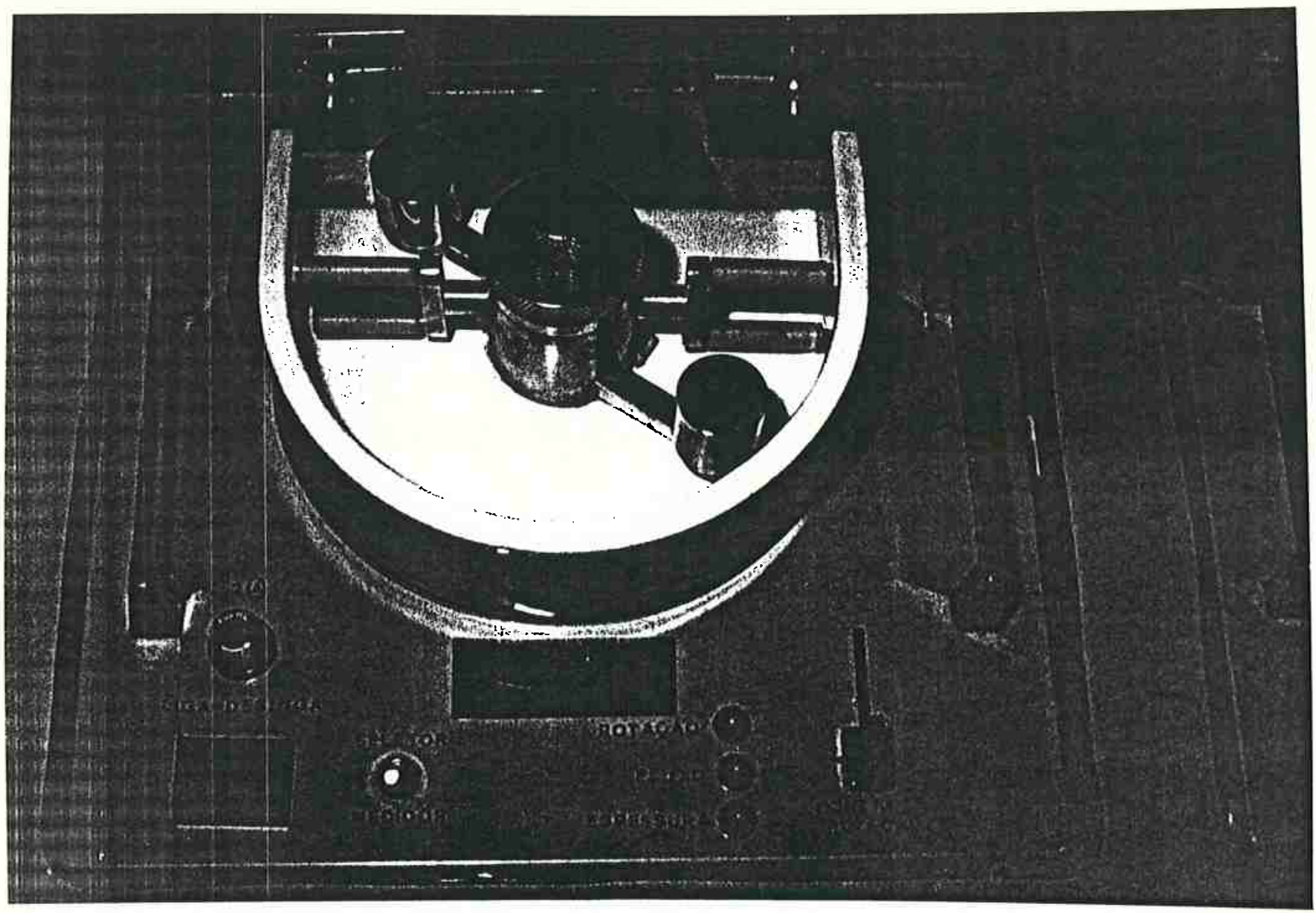

Fig. 3.3. Paine1 dos môdulos motores.

vèlocidade angular do rotor, do fluxo sanguíneo ou do lúmen ajustado no tubo plästico, cuja leitura pode ser efetuada atra vés de um mostrador decimal de 3 dígitos disposto logo acima da chave. Três diodos emissores de luz vermelha indicam a gran deza selecionada. Um porta-fusível e um interruptor acionador do mōdulo, contendo uma lâmpada incorporada que acende quando este é ativado, completam o painel. 
3.4.2. Sub-Sistema Detetor de Bolha.

O sub-sistema detetor de bolha contém um sensor pos $\underline{i}$ cionado imediatamente após a saída da bomba sanguínea arterial. Ao ser detetada uma bolha é enviado um sinal elétrico ao subsistema de segurança que interrompe instantaneamente a circula ção extracorpórea e aciona um alarme sonoro e outro visual.

\subsubsection{Sub-Sistema Detetor de Níveis de Sangue no Oxigenador}

O sub-sistema detetor de níveis de sangue no oxigena dor, é constituído por dois sensores dispostos sobre o elemen to de oxigenação. Um desses sensores está posicionado a um ní vel correspondente a vinte e cinco por cento abaixo do nível normal de sangue e, quando acionado acende um diodo emissor de luz vermelha e um alarme contínuo. O outro sensor está locali zado em uma altura correspondente a quarenta por cento abaixo da normal e envia um sinal elétrico ao sub-sistema de seguran ça quando a quantidade de sangue no oxigenador não atingir es te nível. Tambẻm neste caso, hä interrupção instantânea da cir culação extracorpörea e o acionamento de alarmes sonoro e v $\underline{i}$ sua I.

3.4.4. Sub-Sistema de Segurança

O sub-sistema de segurança ao receber os sinais elé tricos enviados pelos detetores de bolha e/ou de níveis de san 
gue no oxigenador paralisa de imediato a circulação extracorpó rea, interrompendo a energização dos circuitos motores dos sub -sistemas venosos e arterial. Também desenergiza a alimentação do motor de qualquer um dos módulos, no caso de carga excess $\underline{i}$ va no respectivo motor.

\subsubsection{Sub-Sistema Hidräulico}

O uso da técnica de hipotermia exige a circulação de água fria ou quente no permutador térmico existente no oxigena dor. Para atender a essa necessidade, o sub-sistema hidräulico contēm um circuito de refrigeração e outro de aquecimento. 0 primeiro é constituído por um reservatório de āgua (tanque de água fria) incorporado com um minirefrigerador, e o segundo com pōe-se de outro reservatōrio de água (tanque de ảgua quente) contendo uma resistência aquecedora e um termostato. A resis tência de aquecimento é acionada pelo painel, ao passo que a temperatura da ägua quente é ajustada pelo seletor do termosta to (Fig. 3.4.).

o fluxo de ägua quente ou fria é selecionado por dois botões mutuamente exclusivos, que ativam dois pares alternati vos de vālvulas solenoides hidrāulicas.

O sub-sistema hidrāulico contém circuitos de deteção, sinalização e alarmes dos níveis de āgua nos dois reservatórios. Dois conjuntos de sensores resistivos correspondentes aos ní veis mínimo, normal e mäximo são incorp̣orados e acionam diodos bicolores emissores de luz que emitem luz verde com níveis 


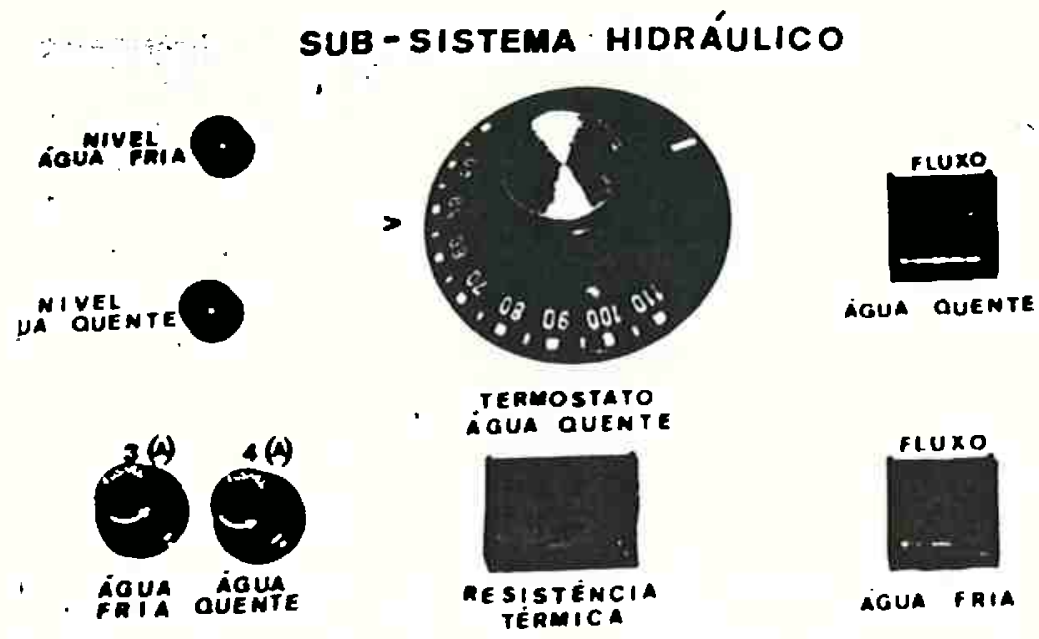

Fig. 3.4. Painel do sub-sistema hidrāulico

de água entre o normal e o máximo, e luz vermellha em caso con trário. A sinalização visual do nível máximo está localizada superiormente e ao lado do orifício pelo qual se coloca água no respectivo tanque. As sinalizações dos níveis mínimo e. nor mal estão localizadas no painel frontal (Fig. 3.4.). Alëm do alarme visual descrito, quando o nível de água cai abaixo do mínimo é acionado um alarme sonoro com um tom contínuo e di ferente para cada reservatório.

o circuito de deteçāo de nível normal em cada tanque também aciona circuitos de controle e segurança de vazão das ảguas quente e fria, permitindo ou não a energização do minire 
frigerador e da resistência de aquecimento. Por outro lado, a bomba hidräulica somente pode ser ativada se o nível de água em cada reservatório estiver acima de um mínimo. Um ladrão pa ra escoamento de ägua em excesso de qualquer tanque protege o interior do equipamento de qualquer risco de alagamento.

3.4.6. Sub-Sistema Termomëtrico

O sub-sistema termomëtrico mede e indica através de mostradores de visualização decimais, existentes no painel ací ma do setor hidráulico, uma dentre as temperaturas das äguas existentes nos reservatōrios ou a prōpria temperatura do paci ente, obtida por um cabo acessório que se liga a um conector existente na lateral esquerda do equipamento. Uma chave seleto ra próxima aos mostradores permite a seleção do sinal térmico a ser medido e trés diodos emissores de luz vermelha indicam a fonte térmica selecionada para a medição (Fig. 3.5.).

Uma chave de alavanca monoestável colocada abaixo da chave seletora anteriormente mencionada, possibilita uma fácil verificação da calibração do circuito. Quando acionada, o mos trador deve indicar $36.2{ }^{\circ} \mathrm{C}$. 


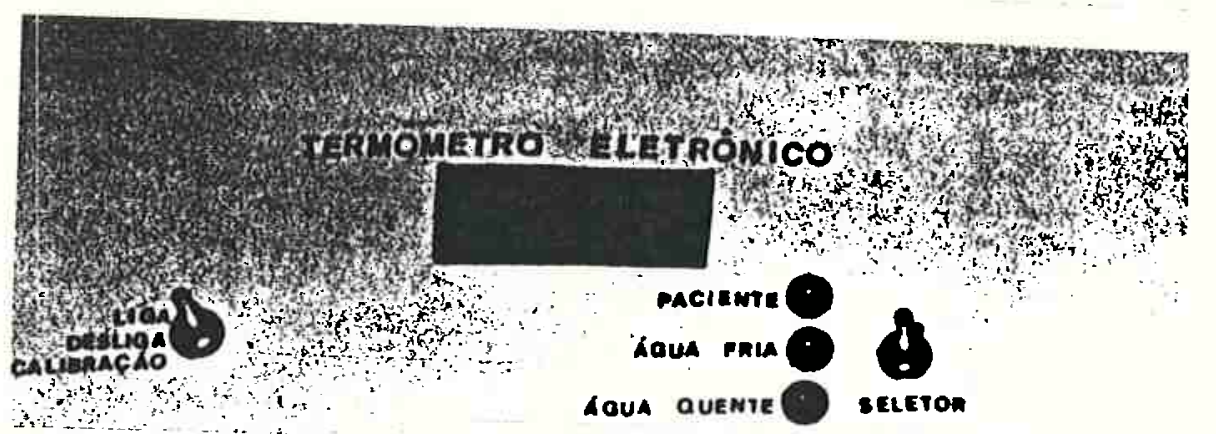

Fig. 3.5. Painel do sub-sistema termometrico

3.4.7. Sub-Sistema Temporizador

Para auxiliar a equipe cirúrgica no pinçamento

da aorta, usado até o início desta década, incorporou-se ao siste ma de Circulação Extracorpórea um temporizador programāvel com intervalo de tempo selecionāvel por comutadores digitais que aciona um alarme áudio-visual no instante do término do inter valo selecionado. Neste instante, a lâmpada existente na pró pria chave de acionamento do circuito, que normalmente está ạ̣agada quando não acionado o módulo e estâ continuamente ace 
sa durante a contagem, passa a piscar na frequência de $1 \mathrm{~Hz}$ e um tom intermitente soa em um alto-falante. O contador cessa a contagem e somente com dois toques sucessivos de botão de acio namento do circuito há possibilidade de reinício da operação. Poder-se-ia usar o módulo tanto para o intervalo de tempo de anóxia ( $\cong 20$ minutos) como para a perfusão coronariana ( $\cong 4-5$ minutos). Atualmente, com a utilização sistemática de soluções cardioplégicas, a técnica de pinçamento da aorta está em desuso. Entretanto, devido a razões históricas este circuito continui rā a ser chamado temporizador de anöxia, apresentando ainda uma função importante desde que a mencionada solução protege o mio cárdio somente por aproximadamente vinte minutos. Ultrapassado esse tempo, necessita-se reinjetar nova dose diretamente na ar téria coronária ou na raiz da aorta, dependendo da técnica cí rúrgica adotada. Este intervalo de tempo poderā ser monitorado pelo Sistema de Circulação Ex́tracorpoórea.

Por outro 1ado, o procedimento cirúrgico exige a apli cação periódica de heparina diretamente no sangue existente no oxigenador, a cada vinte e cinco minutos, aproximadamente. Des sa forma não há coagulação. Para auxiliar na administração do anticoagulante incorporou-se ao S.C.E. um circuito monitor de dosagem de heparina, tambêm constituído por um temporizador pro gramável análogo ao de anóxia, porẻm com a diferença de não ser bloqueado ao final da contagem mas reiniciar automaticamen te nova contagem. Ao tērmino de cada contagem aciona alarmes áu dio-visual similares ao outro temporizador, mas emitindo um tom intermitente em outra frequência. Possue tambēm um botão monoestável ao lado da chave de acionanento do circuito no pa $\underline{i}$ 
nel frontal, o qual inibe este alarme sonoro (Fig. 3.6.)

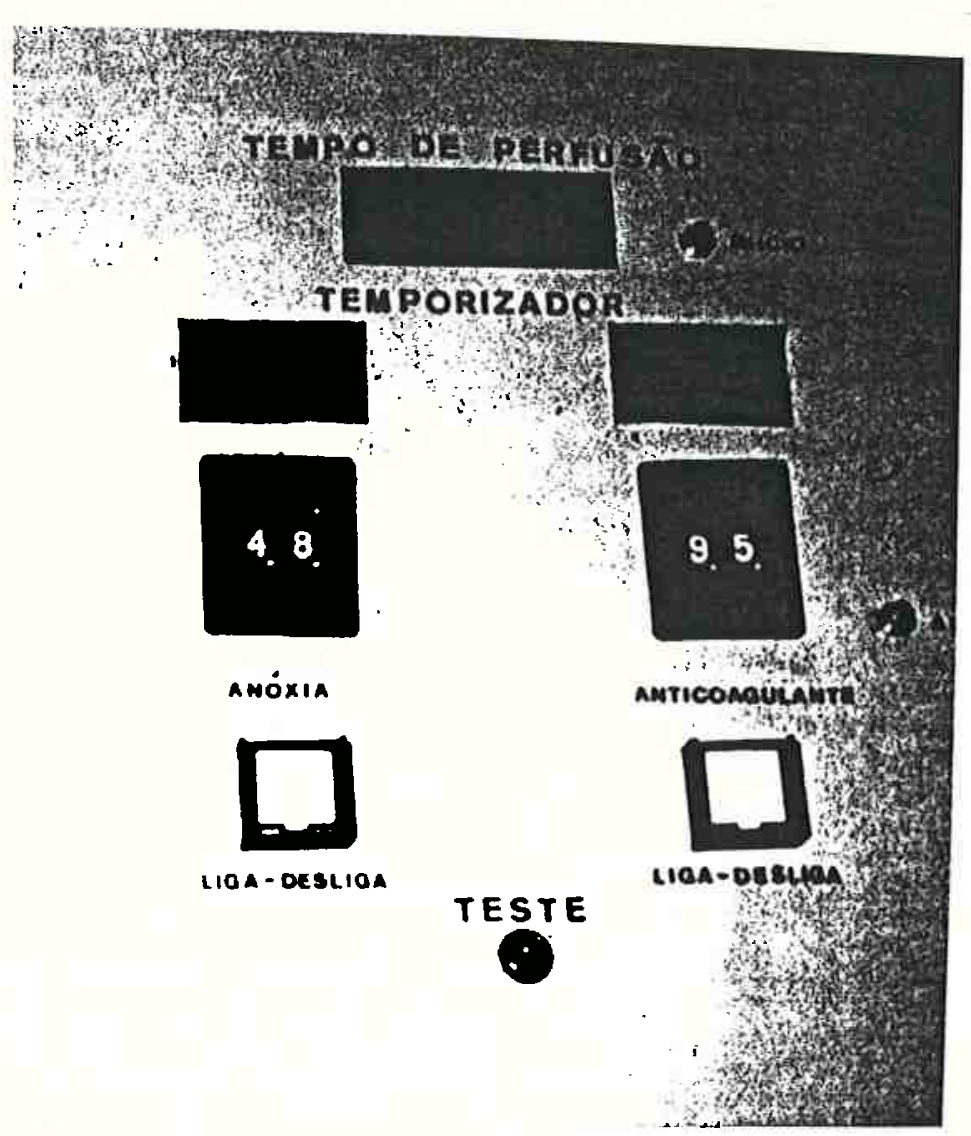

Fig. 3.6. Painel do sub-sistema temporizador.

Tanto o temporizador de anóxia como o de heparina pos suem mostradores de visualização decimais que indicam a conta gem em cada instante. Ao término da contagem o ponto decimal de cada um passa a piscar intermitentemente; no circuito de anóxia - visor mantém a leitura fixa até novo acionamento da chave. Na parte de heparina hä um reinício automätico.

o tempo de perfusão é medido e indicado em mostradores de visualização decimais existentes no painel frontal logo aci ma dos temporizadores de anōxia e heparina (Fig. 3.6.). o cir cuito é acionado conjuntamente com o motor arterial, indicando 
o tempo transcorrido desde o início efetivo da perfusão. Ao final da cirurgia fornece a sua duração total. Um botão monoes tável existente ao lado do visor possibilita o reinício da con tagem em qualquer instante e o ponto decimal correspondente ao dígito de horas pisca a cada segundo, indicando a operação efe tiva do mödulo arterial.

3.4.8. Sub-Sistema de Alarmes

O sub-sistema de alarmes sonoros é constituído por seis secções acionadas pelos dois sensores de níveis normais dos reservatórios de āguas quente e fria, pelos circuitos tem porizadores de anóxia e heparina e pelos sensores dos detetores de bolha e de nível mínimo de sangue no oxigenador. Os alarmes destes detetores e dos sensores dos níveis de ägua emitem sons continuos, diferentemente dos tons intermitentes emitidos pelo acionamento dos temporizadores. Dessa forma, as sensações sono ras em cada caso são significativamente diferentes, impossibi litando interpretações errōneas.

3.4.9. Sub-Sistemas de Bases de Tempo

O sub-sistema de bases de tempo (relógios) fornece sinais pulsados nas diferentes frequências necessārias ao fun cionamento dos värios sub-sistemas. Estes sinais correspondem a tensōes com formas de onda retangulares nas frequências de 
$100 \mathrm{kHz}, 10 \mathrm{~Hz}, 1 \mathrm{~Hz}, 0.5 \mathrm{~Hz}, 0.25 \mathrm{~Hz}$ e $0.1 \mathrm{~Hz}$.

\subsubsection{Sub-Sistema de Teste}

O sub-sistema de teste é constituído por um botão mo noestável existente no painel frontal (Fig.3.2). Quando acio nado, acende todos os diodos emissores de 1 uz, e todas as 1 âm padas existentes na mäquina, bem como ativa os alarmes incorpo rados, que emitem os respectivos tons, contínua ou intermitente mente.

3.4.11. Sub-Sistema de Alimentação

O sub-sistema de alimentação possibilita a energiza ção de todo o sistema atravēs de tensão monofāsica alternada se noidal de $110 \mathrm{~V}$ ou $220 \mathrm{~V}, 60 \mathrm{~Hz}$. Possue transformadores com isolação conveniente, um deles alimentando os circuitos de al ta tensão de aquecimento e refrigeração, e o outro 1igado às värias fontes de tensão contínua necessárias ao equipamento.

3.4.12. Sub-Sistema de Emergência

O sub-sistema de emergência é constituído por uma uni dade geradora de energia elétrica autônoma possibilitando su prir as necessidades bāsicas do S.C.E. no caso de interrupção 
do fornecimento pela concessionäria local. Possue ainda um jo go de lâmpadas de emergência, posicionado ao lado da haste su porte do oxigenador, para iluminá-1o nesta condição emergen cial.

3.5. Especificações Particulares das Partes Essenciais do S.C.E.

As partes essenciais do Sistema de Circulaçāo Extra corpórea são constituídas pelos módulos motores, sub-sistema hi dráulico, sub-sistema temporizador, sub-sistema termométrico e sub-sistemas de alimentação e de emergência. Nesta secção se rão apresentadas as especificações particulares dessas partes.

\subsubsection{Sub-Sistemas Motores}

O elemento princìnal de cada sub-sistema motor $\overrightarrow{\mathrm{e}}$ a bomba sanguínea. Conforme estabelecido anteriormente, deverá possibilitar um fluxo sanguíneo até $61 / \mathrm{min}$, selecionado 1 i nearmente, contra uma pressão de carga de $180 \mathrm{~mm} \mathrm{Hg}$. A veloci dade angular do rotor deverá atingir $120 \mathrm{rpm}$ correspondendo a $50 \mathrm{ml}$ de sangue impulsionados por ciclo. As dimensões da bomba deverão ser compatíveis com as tubulaçōes usadas atualmente nos procedimentos cirúrgicos. Os módulos motores deverão ser super visionados pelo sub-sistema de segurança e conter "circuitos de controle, medição e sinalização do fluxo sanguíneo, da velocí dade de rotação do rotor e do lúmen pré-ajustado no tubo plás 
tico por onde flue o sangue.

A parte mecânica da bomba sanguínea é constituída pe la carcaça ou caçapa e pelo rotor (Fig. 3.7.).

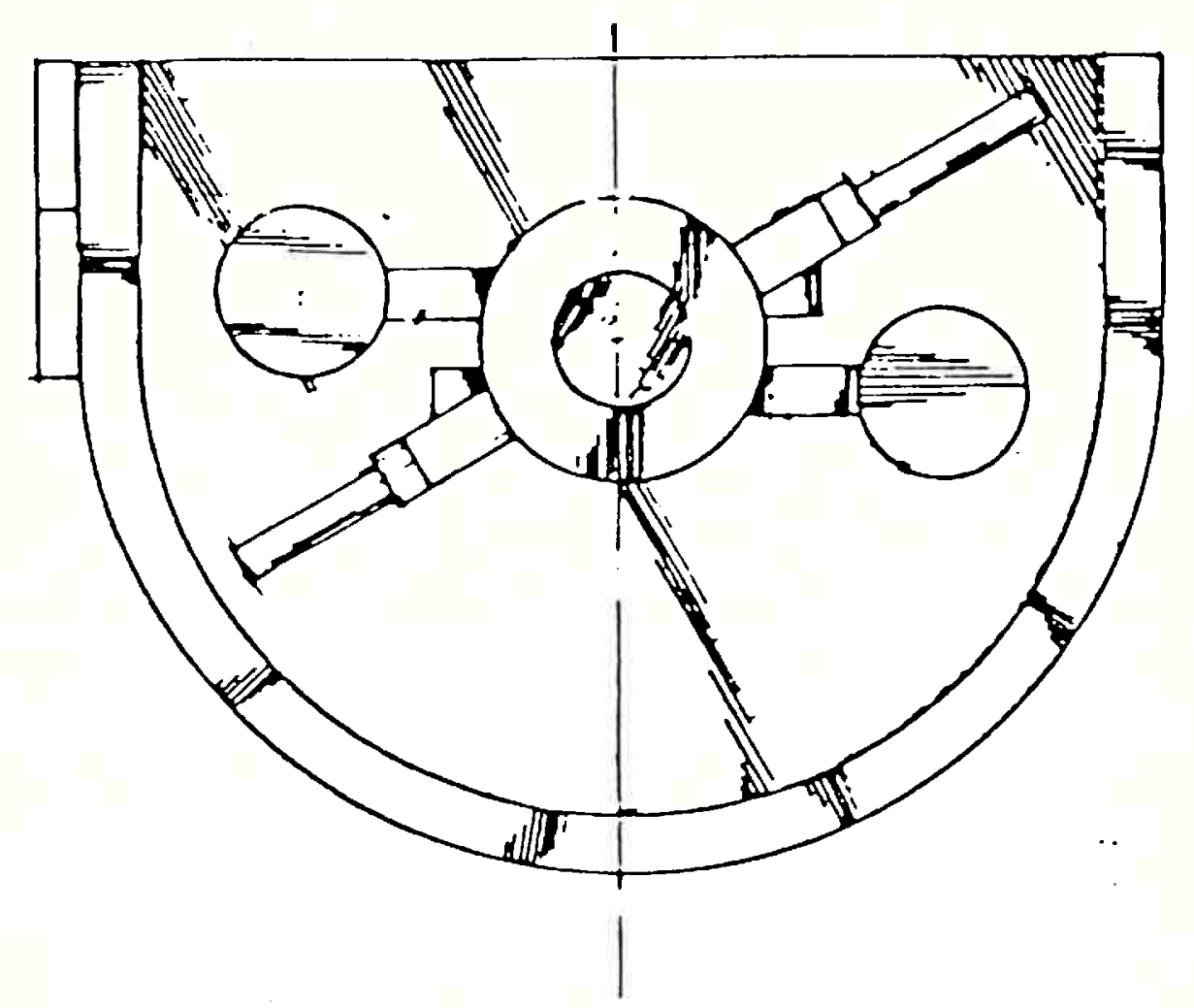

Fig. 3.7. Bomba Sanguínea

Devido às bitolas dos tubos utilizados nas linhas ve nosas e arterial, as dimensões das carcaças dos módulos veno sos deverão ser diferentes daquelas apresentadas no arterial. As Figs. 3.8 e 3.9 . apresentam as dimensões exigidas para as respectivas caçapas. O material constituinte é alumínio fundi do especial, recoberto com nylon de cor branca. 


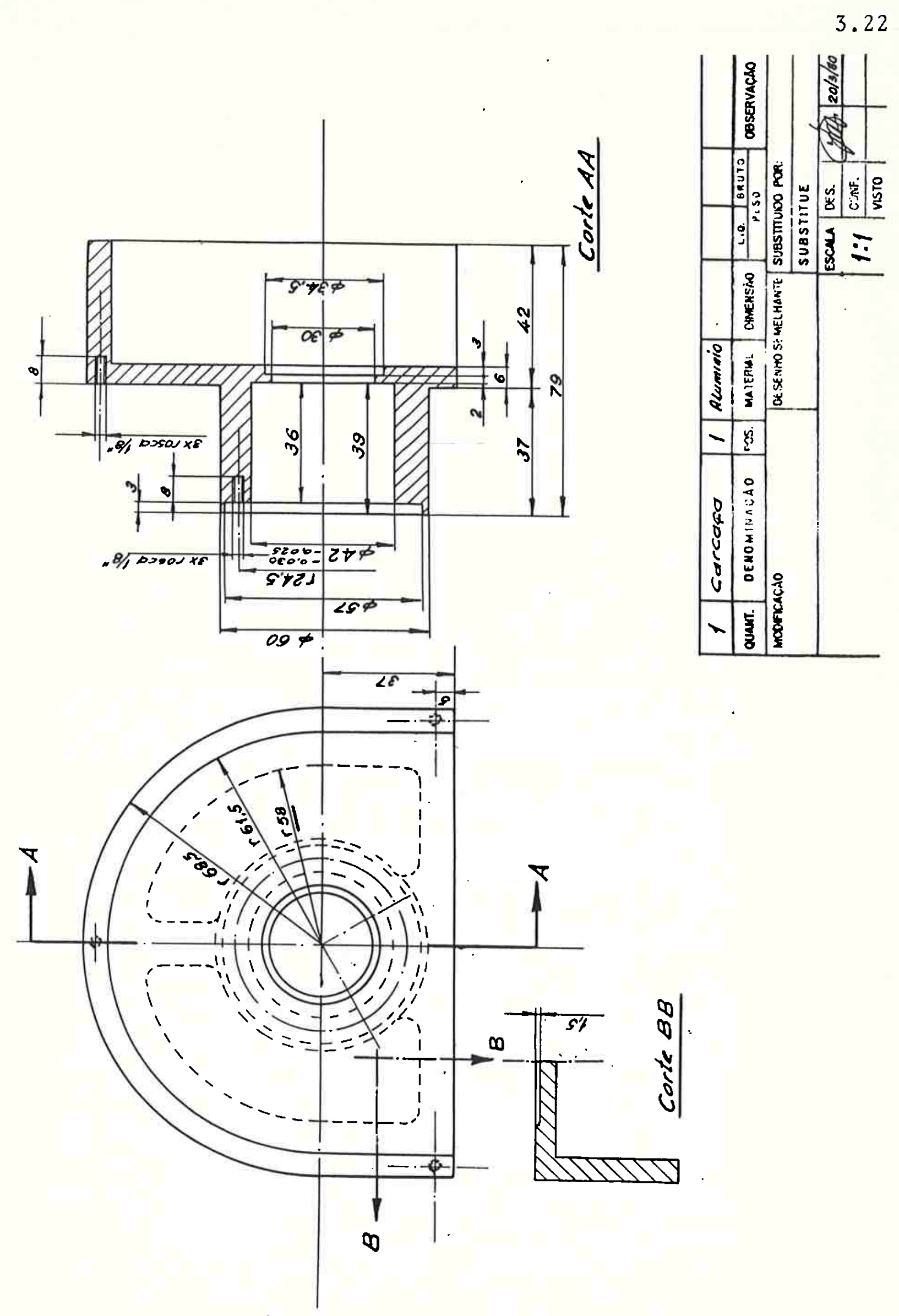

Fig. 3.8. Carcaça de um mōdulo venoso 

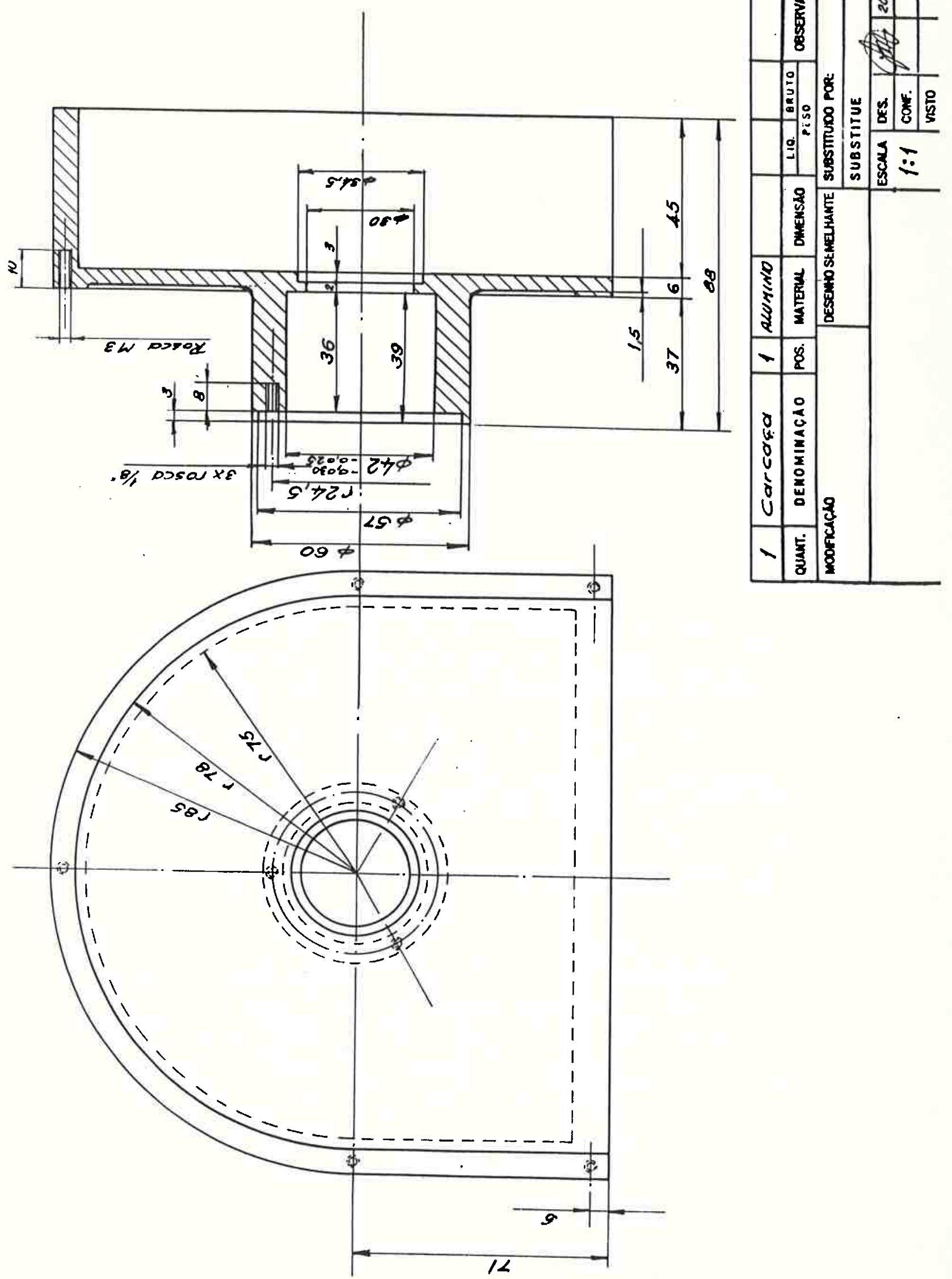

Fig. 3.9. Carcaça do módulo arterial 
O rotor incorpora a inovação descrita como aperfe $\underline{i}$ çoamento em bombas no Apêndice B, permitindo um fäcil ajuste dos roletes em função da espessura efetiva do tubo de borracha usado na circulação sanguínea. Este ajuste deve atuar nos dois roletes de uma só vez e não deve necessitar de ferramenta. A vista de corte apresentada na Fig. 3.10 apresenta seus itens constituintes. Um aspecto construtivo fundamental a ser res saltado è a exigência do rolamento auto-blocante incorporado ao rotor, impossibilitando rotação no sentido contrário ao espec $\underline{i}$ ficado. Observe-se tambêm a inclusão do disco perfurado, prin cipal componente do transdutor para medição da velocidade de rotação do rotor e do fluxo sanguíneo.

O motor elëtrico, incorporado com redutor mecânico, que acionará a rotor deve possuir especificaçōes compatíveis com as exigências anteriormente estabelecidas para a bomba sanguínea. Os motores deverão ser de corrente contínua de imã permanente e com tensão declarada de alimentação igual a 24 Volts, satisfazendo as prescrições de segurança contra choque elétrico. A potência a ser cedida pelo rotor ao sangue e o tor que correspondente podem ser determinados através das seguin tes equações (Shames, 1962; Vieira, 1971; Macintyre, 1980):

$$
h_{e}+\frac{P}{\gamma}+\alpha_{e} \frac{v_{e}^{2}}{2 g}+H_{B_{u}}=h_{s}+\frac{P_{s}}{\gamma}+\alpha_{s} \frac{v_{s}^{2}}{2 g}
$$

onde: he $\equiv$ cota do centro de gravidade do elemento de entrada, em relação a um plano de referência.

$\mathrm{h}_{\mathrm{S}} \equiv$ cota do centro de gravidade do elemento de saída, em relação, a um plano de referência. 


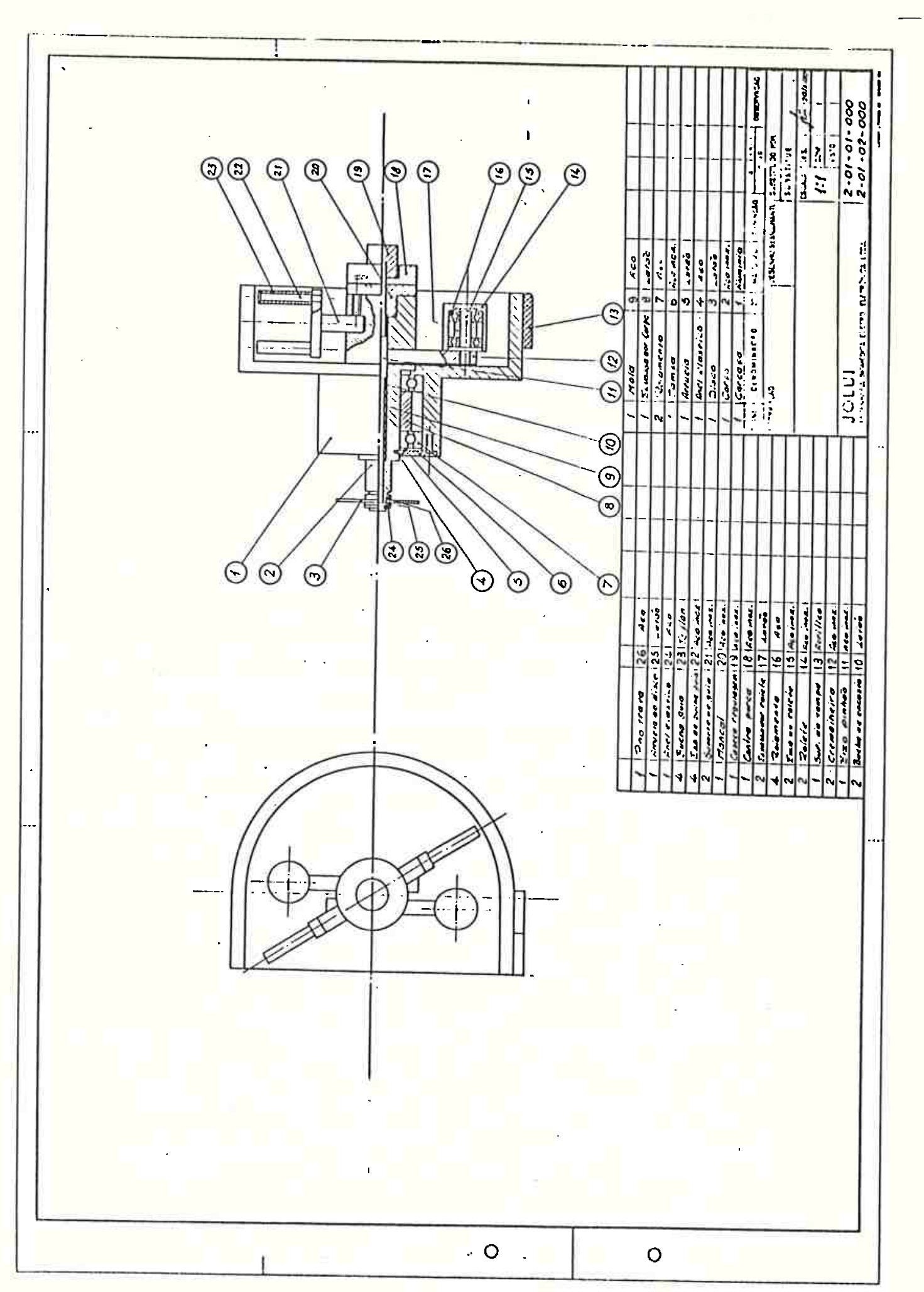

Fig. 3.10. Rotor da bomba sanguínea. 


$$
\begin{aligned}
& \mathrm{p}_{\mathrm{e}} \equiv \text { pressão no elemento de entrada } \\
& \mathrm{p}_{\mathrm{s}} \equiv \text { pressão no elemento de saĩda } \\
& \gamma \equiv \text { peso específico do sangue } \\
& v_{\mathrm{e}} \equiv \text { velocidade média na secção do elemento de entrada } \\
& v_{\mathrm{s}} \equiv \text { velocidade mëdia na secção do elemento de saída } \\
& \mathrm{g} \equiv \text { aceleração gravitacional local } \\
& \alpha_{\mathrm{e}} \equiv \text { fator de correção de Coriollis no elemento de entrada } \\
& \alpha_{\mathrm{s}} \equiv \text { fator de correção de Coriollis no elemento de saída } \\
& \mathrm{H}_{\mathrm{B}} \equiv \text { altura ütil da bomba }
\end{aligned}
$$

$$
\mathrm{P}_{\mathrm{B}}=\gamma \cdot \phi \cdot \mathrm{H}_{\mathrm{B}}
$$

onde: $\mathrm{P}_{\mathrm{B}_{\mathrm{u}}} \equiv$ potência ütil da bomba

$$
\phi \quad \equiv \text { fluxo sanguíneo }
$$

Das curvas de potência $x$ rotação angular da bomba, ob tém-se o torque necessārio. Em particular, a potência mecânica relaciona-se com o torque do rotor pela seguinte expressão:

$$
P_{B}=T \cdot \omega
$$

onde: $\mathrm{P}_{\mathrm{B}} \equiv$ potência mecânica da bomba

$$
\begin{aligned}
& \mathrm{T} \equiv \text { torque do rotor } \\
& \omega \equiv \text { velocidade angular do rotor }
\end{aligned}
$$

Considerando-se a equação de continuidade de mecānica dos fluídos e a ärea da secção transversal de tubulação da bom ba praticamente constante, conclui-se que: 


$$
\alpha_{e} \frac{v_{e}^{2}}{2 g}=\alpha_{s} \frac{v_{s}^{2}}{2 g}
$$

Por outro lado, os elementos de entrada e de saída das bombas sanguíneas possuem a mesma cota relativamente a um plano horizontal de referência, decorrendo que

$$
h_{e}=h_{s}
$$

Estes ültimos resultados aplicados às Eqs. 3.1 e 3.2 levam à seguinte espressão:

$$
\mathrm{P}_{\mathrm{B}}=\gamma \cdot \phi \cdot \frac{\mathrm{p}_{\mathrm{s}}-\mathrm{p}_{\mathrm{e}}}{\gamma}=\phi \cdot\left(\underline{p}_{\mathrm{s}}-\mathrm{p}_{\mathrm{e}}\right)
$$

Como o fluxo sanguíneo máximo è de 6 l/min. e a difẹ rença de pressão a ser estabelecida entre os elementos de saída e de entrada da bomba é de $180 \mathrm{~mm} \mathrm{Hg}$, resulta uma potência ütil de aproximadamente $2,45 \mathrm{Kgfm} / \mathrm{s}$. Considerando as vārias perdas da bomba, o rendimento do motor elétrico e um fator de seguran ça necessärio, será exigido um motor elétrico de $9,5 \mathrm{Kgfm} / \mathrm{s}$ (ou $1 / 8 \mathrm{HP}$ ) para o módulo arterial e $5,1 \mathrm{Kgfm} / \mathrm{s}$ (ou $1 / 15 \mathrm{HP}$ ) para os módulos venosos.

O torque máximo necessário em cada caso pode ser est $\underline{i}$ mado pela equação 3.3 ou por curvas formadas pelo fabricante.No primeiro caso resulta aproximadamente $0,8 \mathrm{~N} . \mathrm{m}$ para o módulo ar terial.

Ressalte-se, finalmente, que a tubulação plástica a ser fornecida pelos fabricantes deverá suportar os esforços in ternos devidos ao fluxo sanguíneo e os esforços externos devi 
dos à ação dos roletes.

Os mödulos motores deverão conter circuitos eletroeletrônicos que possibilitem o controle, a medição e a sinali zação do fluxo sanguíneo e da velocidade de rotação do rotor. bem como a medição e a sinalização do lúmen ajustado na tubula ção. As medidas deverão apresentar indicaçāo digital.

Os módulos deverão ser do tipo encaixável e deslizan te em bastidores, permitindo rāpida reposição (em menos de 20 segundos). O módulo arterial deverā ter uma unidade de reserva. Uma manivela deverá ser incorporada ao Sistema, possibilitando - acionamento manual da bomba sanguínea do módulo arterial na condição de falta de energia elétrica da rede local e de falha no sub-sistema de emergência do S.C.E.

3.5.2. Sub-Sistema Hidrāulico

Os elementos essenciais do sub-sistema hidräulico são a bomba hidráulica, as vālvulas solenoides, o mini-refrigerador, a resistência de aquecimento e o correspondente termostato. As características dos permutadores térmicos existentes nos oxige nadores comerciais disponiveis determinam as necessidades des ses itens.

3.5.2.1. Bomba Hidräulica

A bomba hidráulica deve manter a circulação de ãgua 
no oxigenador de modo a permitir cirurgias em condiçōes hipo térmicas. Entretanto, três premissas bāsicas devem ser conside radas:

a) Nas perfusões em hipotermia, a diferença de tempe ratura entre o fluído do permutador térmico e o sangue do re torno venoso não deve exceder $10^{\circ} \mathrm{C}$.

b) A temperatura da āgua na entrada do permutador não deve ultrapassar $42{ }^{\circ} \mathrm{C}$.

c) A temperatura mínima compatível com a vida humana é de $23{ }^{\circ} \mathrm{C}$.

Um fluxo hidräulico máximo de $101 /$ min é normalmente exigido pelos oxigenadores comerciais, sendo a pressão limita da a $500 \mathrm{~mm} \mathrm{Hg}$. A bomba hidräulica deverä manter este fluxo, sendo alimentada no māximo $\operatorname{com} 24 \mathrm{~V}_{\mathrm{ca}}$ ou $50 \mathrm{~V}_{\mathrm{cc}}$. Não necessí ta redutores, possibilitando rotações da ordem de milhares de rpm e a potência do motor deve ser de 1/10 HP. A entrada de água deverá ser de $1 / 2$ polegada e a saída em $3 / 8$ de polegada para compa tibilizar com o restante do sub-sistema. Deverá suportar inde finidamente bloqueio na saída.

3.5.2.2. Vảlvulas Solenoides

As válvulas solenoides deverão permitir a seleção do fluxo de ảgua quente ou fria no oxigenador, sendo construídas em bronze fundido e com entrada em $3 / 4$ de polegada e saída em $1 / 2$ polegada. Deverão ser projetadas especialmente nara uso 
com ảgua, alimentação de $24 \mathrm{~V}_{c c}$ e potência máxima de $10(w)$.

3.5.2.3. Mini-refrigerador

As condiçōes exigidas pelos permutadores térmicos são similares às existentes em bebedouros comerciais. Para diminuir o custo do equipamento, deve-se utilizar uma unidade de refri geração comercial correspondente a um conjunto hermético 1/6 $1 / 5 \mathrm{HP}$ - 110 ou $220 \mathrm{~V}$, desde que satisfaça as condições de se gurança, qualidade e confiabilidade compatíveis com as prescri çōes gerais,conforme a secção seguinte. Deve conter um compres sor, uma base condensadora, trilho, ventilador e utilizar freon -12 , excluindo-se as válvulas de serviço. o evaporador deverá ser de cobre com dimensões compatíveis com o tanque, porém ob jetivando a mais eficiente permuta térmica possível. O termos tato deverá possibilitar temperaturas tão baixas quanto $4{ }^{\circ} \mathrm{C}$.

3.5.2.4. Resistência de Aquecimento

A resistência de aquecimento deverá possibilitar um aumento máximo de $50{ }^{\circ} \mathrm{C}$ em. 5 litros de āgua, capacidade do re servatörio correspondente, em 40 minutos. A energia térmica envolvida no processo pode ser calculada pela seguinte expres são:

$$
Q=m \cdot c \cdot \Delta T
$$


onde: $\mathrm{Q} \equiv$ Quantidade de calor, em calorias

$\mathrm{m} \equiv$ massa da āgua, em gramas

$\mathrm{c} \equiv$ calor específico da água $\left(1 \mathrm{cal} / \mathrm{g}{ }^{\circ} \mathrm{C}\right.$ a $\left.15{ }^{\circ} \mathrm{C}\right)$

$\Delta \mathrm{T} \equiv$ diferença de temperatura, em graus Celsius

Os valores numéricos anteriormente estabelecidos in dicam a necessidade de $250.000 \mathrm{cal}$ ou aproximadamente $1,05 \times 10^{6} \mathrm{~J}$, correspondente a uma potência de $435 \mathrm{w}$. A tensão de alimentação deverá ser de $110 \mathrm{~V}$ ca. , $60 \mathrm{~Hz}$ e as características de isolação, entre o tubo de aço inoxidāvel, ou latão niquelado ou vidro e o elemento resistivo, deverão satisfazer as exigências determi nadas na secção seguinte. O dispositivo deverà obrigatoriamen te conter um terminal para aterramento da superfície condutora externa, sendo tubular com fixação circular atravēs de duas bụ chas e rosca de $1 / 4$ de polegada BSP. Deverá ser concebido para operar imerso em água, devendo-se eventualmente usar um par de resistências.

3.5.2.5. Termostato de Aquecimento

O termostato a ser usado na parte de controle da tem peratura da água quente deverā ser ajustável, com uma faixa de atuação de $30-110{ }^{\circ} \mathrm{C}$, tipo nolo simples, com histerese de $4{ }^{\circ} \mathrm{C}$. Deverá apresentar características de chaveamento corresponden tes a $15 \mathrm{~A} / 380 \mathrm{~V}$. 
3.5.2.6. Considerações Adicionais

O sub-sistema hidräulico deverä possuir circuitos de controle e de segurança dos fluxos de àgua quente.ou fria, bem como impossibilitar o acionamento da bomba se não houver a quan tidade mínima exigível de āgua em cada reservatōrio. Circuitos de deteção, sinalização e alarmes deverão ser incorporados de modo a monitorar os níveis mínimo, normal e mäximo em cada tan que. O mini-refrigerador e a resistência aquecedora deverão ser acionados apenas se houver pelo menos o nível normal de água nos reservatórios. Deverá possuir ainda proteção contra exces so de água nos reservatórios, prevenindo transbordamentos.

3.5.3. Sub-Sistema Temporizador

o sub-sistema temporizador deverá permitir a monito ração e a medição dos tempos de perfusão, de anóxia e de dosa gem da heparina. o tempo māximo mensurāvel de perfusão deve ser de 9 horas e. 59 minutos e os intervalos de tempo máximos con trolados e medidos, correspondentes aos temporizadores de ant coagulante e anóxia, de 99 minutos. Alarmes äudio-visuais de verão ser incorporados e a parte de heparina possuir reinício automático de contagem.

3.5.4. Sub-Sistema Termomētrico

o sub-sistema termomêtrico deverā permitir a medida 
da temperatura da água quente ou fria circulante no sistema hi dráulico. Também a temperatura do paciente deverá ser passível de medida, com o painel indicando a fonte térmica selecionada. 0 fundo de escala deve ser de $99.9{ }^{\circ} \mathrm{C}$. Uma chave de painel de verá acionar um circuito de verificaçāo de calibração, indican do no visor decimal a leitura de $36.2{ }^{\circ} \mathrm{C}$.

3.5.5. Sub-Sistema de Alimentação

O sub-sistema de alimentação deverá ser projetado con siderando que o equipamento pertence à classe I, tipo CF.

Deverā possuir dois transformadores, um para alimen tação dos circuitos de alta tensão do mini-refrigerador e da resistência de aquecimento, e outro para alimentação dos cir cuitos de baixa tensão do restante do S.C.E.

Tambēm deverá considerar o acionamento automätico de uma unidade autônoma geradora de energia no caso de queda na tensão da rede elëtrica local.

As seguintes prescriçōes devem ser consideradas para os dois transformadores:

a) Transformador monofásico, tipo seco, aberto ou ven tilado, à prova de curto circuito não inerentemente, dotado de prensa-cabos nas entradas e nas saídas, com amortecimento de picos transientes superpostos à tensão da rede e com proteção contra descargas capacitivas (International Electrotechnical Co mission, IEC, Publicações 127 e 241). 


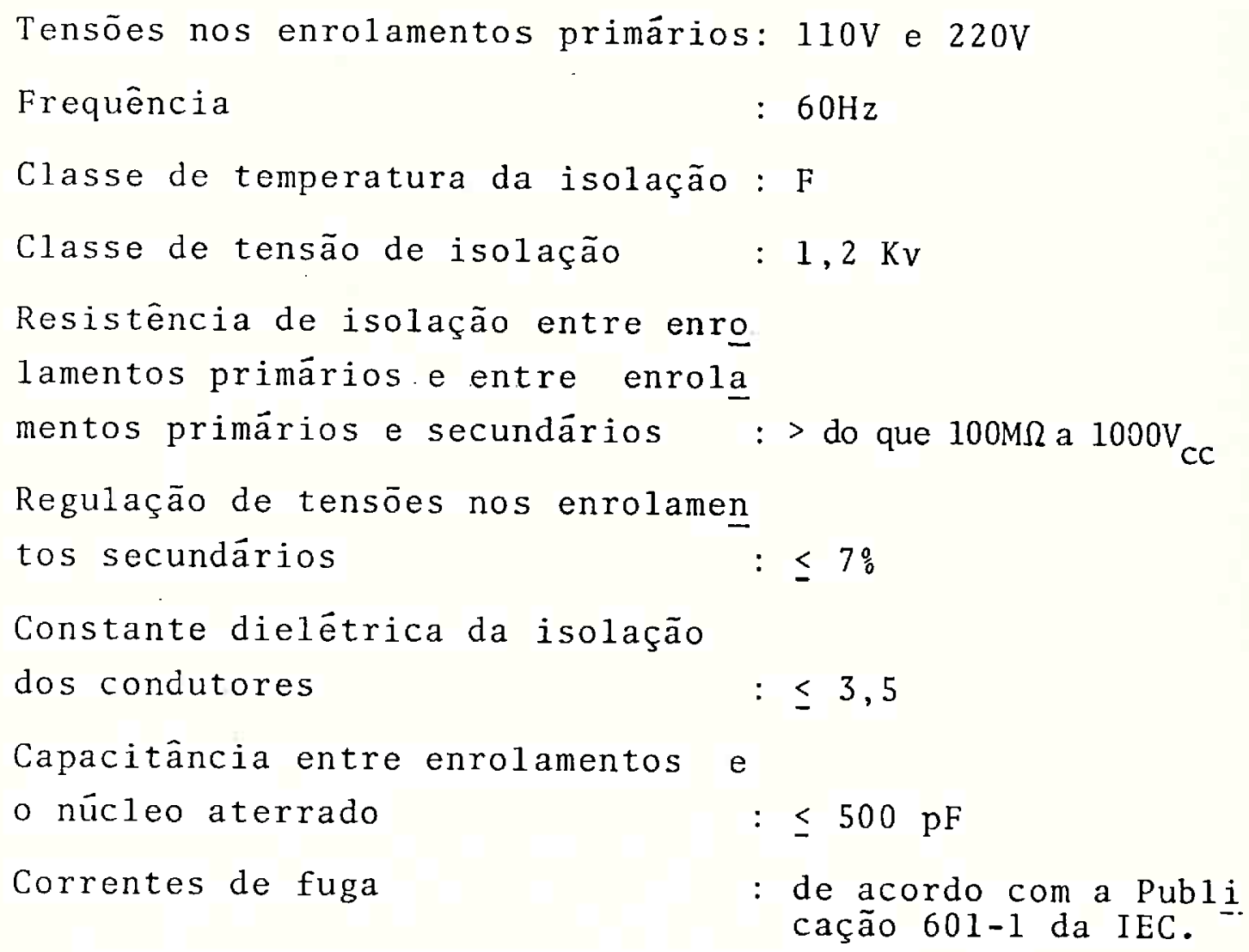

b) O transformador de rede deve ser acondicionado dentro do envólucro do equipamento ou possuir uma cobertura protetora inacessivel. A conformidade deve ser verificada por inspeção.

c) A separação dos enrolamentos primários e secundạ rios deve ser estabelecida por um dentre os seguintes modos:

$c_{1}$ ) enrolando em bobinas separadas.

$c_{2}$ ) enrolando sobre uma bobina com uma parte iso lante separando os enrolamentos.

$c_{3}$ ) enrolando sobre uma bobina, com enrolamentos concéntricos e possuindo uma blindagem de co bre protetora, com uma espessura total não inferior a $0,13 \mathrm{~mm}$. A isolação entre os enro 
lamentos e a blindagem aterrada pode consis tir de mais de uma camada.

$c_{4}$ ) enrolando concentricamente sobre uma bobina, com os enrolamentos separados por uma isola ção elétrica capaz de suportar a temperatura limite estabelecida pela Publicação 601-1 da IEC. O ensaio da camada de isolaçāo deve ser - especificado para isolação reforçada. A con formidade deve ser verificada por inspeção.

d) Os terminais não devem ser localizados na cobertú ra externa dos enrolamentos. Todas as conecções internas das bobinas devem ser adequadamente isoladas e os materiais isolan tes devem ser suficientemente fixados.

e) O material isolante e qualquer impregnação deve ser compatível com o material isolante do fio.

A isolação entre camadas deve ser ao longo de to do o enrolamento. Algum meio mecânico deve ser disponível para prevenir deslocamento das extremidades sob a isolação entre-ca madas. A conformidade deve ser verificada por inspeção.

f) Se uma blindagem aterrada para proteção possuir apenas uma camada, deve possuir uma dobra em sobreposição de pelo menos $3 \mathrm{~mm}$. A extensão da blindagem deve ser pelo menos igual ao comprimento do enrolamento primário. A blindagem ater rada deve possuir um contorno bem acabado.

g) Os enrolamentos de alta tensão devem ser simétrí cos em relação ao núcleo aterrado.

h) Os enrolamentos devem ser separados por b1indagens 
com terminais acessiveis para aterramento. As blindagens ater radas para proteção contra correntes induzidas magnética e ele trostaticamente, entre primário e secundärio, devem ser cons $\underline{i}$ deradas resistiva e capacitivamente.

i) Os enrolamentos primários devem ser totalmente blindados com resistência elêtrica suficientemente pequena.

os enrolamentos secundários devem ser divididos à metade, com as duas metades idênticas enroladas sobre o núcleo sendo balanceadas eletrostaticamente e impregnadas (deslocar os enrolamentos secundärios pelo nūcleo até obtèr uma tensão en tre $S_{1}$ e o nūcleo igual à tensão entre $S_{2}$ e o núcleo, conforme Fig. 3.11).

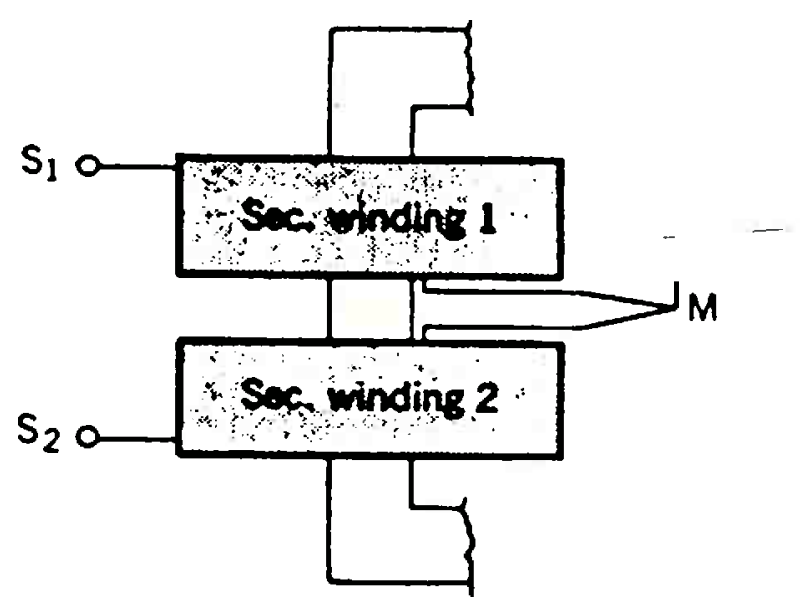

Fig. 3.11. Esquema do enrolamento secundārio do transformador de rede indicando os terminais $S_{1}$ e $S_{2}$. Reproduzido de Dalziel (1972). 
j) Se possivel os enrolamentos devem possuir dupla iso lação.

\begin{abstract}
1) A blindagem eletrostática entre os enrolamentos primário e secundārio deve ser aterrada visando minimizar a capacitância entre esses enrolamentos.
\end{abstract}

m) Os enrolamentos contíguos podem ser:

i) enrolados em bobinas separadas.

ii) enrolados em uma bobina com isolante forte en tre eles.

iii) enrolados em uma bobina com os enrolamentos se sobrepondo e tendo uma blindagem de cobre com pelo menos $0.1 \mathrm{~mm}$ de espessura entre eles, com a blindagem tendo uma conexão de terra de pelo menos $16 / 0.20 \mathrm{~mm}$. A isolação entre os enrolamentos e a blindagem aterrada deve pos suir pelo menos $0,3 \mathrm{~mm}$ de espessura.

n) A isolação entre enrolamentos e entre os enrola mentos e o nücleo ou a blindagem aterrada deve suportar o en saio de intensidade de rigidez dielëtrica, sujeitando-se a $1500 \mathrm{~V}$ sem ruptura.

o) Os transformadores devem ser protegidos no lado primärio com fusíveis de valor declarado igual ao dobro da cor rente declarada do transformador. 0 lado secundärio deve ser pro tegido com um disjuntor termo-magnëtico miniatura.

p) A instalação deve possuir transformador de isola çào para uso médico.

As especificações particulares para os dois transfor 
madores a serem usados no Sistema de Circulação Extracorpórea são as seguintes:

- Transformador para alimentação dos circuitos de alta tensão do minirefrigerador e da resisténcia de aquecimento: tensões/correntes declaradas nos enrolamentos secundários : $110 \mathrm{~V} / 10 \mathrm{~A}, 110 \mathrm{~V} / 3 \mathrm{~A}$ potência aparente declarada : 1,430VA

- Transformador para alimentação dos circuitos de baixa tensão do S.C.E.:

tensōes/correntes declaradas nos enrolamentos secundários : $12 \mathrm{~V} / 4 \mathrm{~A} ; 12 \mathrm{~V}+12 \mathrm{~V} / 4 \mathrm{~A}$; $24 \mathrm{~V} / 9 \mathrm{~A} ; 24 \mathrm{~V} / 4 \mathrm{~A}$.

potência aparente declarada : 460VA

3.5.6. Sub-Sistema de Emergência

O sub-sistema de emergência constitue uma unidade ge radora de energia autônoma possibilitando um regime de traba lho contínuo ao Sistema de Circulação Extracorpōrea mesmo em condição de queda da rede elétrica local. Apenas as seções de refrigeração e aquecimento não devem ser acionadas nessa condi ção emergencial, acarretando o funcionamento do equipamento por aproximadamente 5 horas.

A unidade deverá fornecer uma tensão contínua de $24 \mathrm{~V}$, sob corrente de até $20 \mathrm{~A}$, a qual será automaticamente aplicada aos circuitos de baixa tensão do S.C.E. no instante em que a tensão da rede cair abaixo de 80 volts durante 10 segundos. 0 
subsistema devera incorporar circuito de carga de baterias e medidores de tensão de saída e corrente de carga. o painel de verá possuir a sinalização conveniente para fácil interpreta ção do funcionamento deste acessório do S.C.E.

\subsection{Prescrições Gerais e Ensaios do Sistema de Circulação Ex- tracorpórea.}

O Sistema de Circulação Extracorpörea deve ser clas sificatlo como pertencente à Classe I de equipamentos eletromé dicos, do tipo CF, à prova de anestésicos e de pingos, e para serviço contínuo. Deve satisfazer tanto às prescrições de Nor mas Gerais de aparelhos elétricos para fins médicos, como à Normas Particulares aplicäveis à sua categoria (IEC, Publica ção 601-1; IEC, Publicação 513; NFPA, Publicação N:70; Depart ment of Health and Social Security, Hospital Technical Memoran dum $\mathrm{n}: 8$; IEC, Documentos 62A (Central office) 24-I through X; Canadian Standards Association, CSA C22.2 N¹25; AAMI,

ANS I SCL 12/78; IEC, Documento 62A (Secretariat) 52; IEC, Documento 3C (Central Office) 94; ABNT, Projeto de Norma 3:06.3.2-011). Outras publicaçōes relacionadas nas Referências Bibliogräficas examinam vārias diretrizes estabelecidas nesses textos, bem co mo sugerem modificações ou adendos (Will e Dolan, 1976; Web $\underline{s}$ ter, 1978; Da1zie1, 1972; Roth e col.,1975; Kreste1, 1973; Kanter, 1974; Hewlett Packard, 1971; Siemens, 1973; Gonser e Kraft, 1976), podendo, eventualmente, apresentar novas prescrições utilizäveis. 
Os ensaios do SCE a serem desenvolvidos para verif $\underline{\mathbf{i}}$ cação da conformidade com as prescrições particulares e gerais devem possuir confiabilidade metrológica (Waeny, 1980 e Waeny, 1982). As condiçōes de ensaio e os resultados apresentados pe lo Sistema de Circulação Extracorpórea serão apresentados no Capítulo IV, conjuntamente com as informaçōes referentes à sua implemen taçāo.

3.7. Documentação e Código de Aplicação

O Sistema de Circulação Extracorpórea deve possuir uma documentação contendo, ao menos, as instruções para utili zaçào, uma descrição técnica e uma referência de endereçamento do fabricante. Esses documentos acompanhantes devem ser consi derados como uma parte integrante do equipamento (IEC, Publica çào $601-1)$.

A documentação deve conter um cōdigo de aplicação pa ra auxiliar o operador no emprego seguro e confiāvel do equipa mento (ABNT, NBR 9153). Esta aplicação segura requer inclusive boa organização, conhecimento e responsabilidade na utilização do aparelho e uma certa disciplina quanto à inspeção regular e manutenção. Nessas condiçōes, deve-se informar ainda sobre pro gramas de Organização e Métodos (Andersan, 1980) e programas de treinamento e instrução, inspeção e manutenção (Webster e Cook, 1979). Conjuntamente crmo Código de Aplicação deve-se anexar Publicações nacionais e/ou internacionais para instruir o pessoal administrativo, médico e de enfermagem relativamente 
ao uso seguro de equipamentos eletro-médicos (IEC, Documento 62A (Secretariat) 64; IEC, Documento 62A (Central Office) 22).

3.8. Condições Ambientais, Instalação e Manutenção

O Sistema de Circulaçāo Extracorpōrea deve suportar as seguintes condições ambientais:

a) Operação em uso norma1

- temperatura ambiente entre $+10^{\circ} \mathrm{C}$ e $+40^{\circ} \mathrm{C}$.

- umidade relativa entre $30 \%$ e $75 \%$.

- pressão atmosférica entre $70 \mathrm{KPa}$ e $106 \mathrm{KPa}$.

b) Transporte e armazenamento

O equipamento embalado para transporte e armazena mento deve permitir exposição até 15 semanas nas seguintes con diçōes ambientais:

- temperatura ambiente entre $-40^{\circ} \mathrm{C}$ e $+70^{\circ} \mathrm{C}$.

- umidade relativa entre $10 \%$ e $100 \%$

- pressão atmosférica entre $50 \mathrm{KPa}$ e $106 \mathrm{KPa}$.

Se a duração do transporte e armazenamento exce der 15 semanas, o aparelho deve suportar as condições ambien tais equivalentes à operação em uso normal.

Por outro lado, a instalação deve ser especificamen te projetada para equipamento de classe I, monofásica com ten sões aproximadamente senoidais de $110 \mathrm{~V}$ ou $220 \mathrm{~V} / 60 \mathrm{~Hz}$, para equi pamentos com potência aparente total declarada de entrada supe 
rior a 4KVA e com flutuações de tensão não excedendo $-10 \%$ e $+10 \%$ da tensão nominal, excluídas as flutuações de curta dura ção (com duração inferior a ls) em intervalos irregulares. 0 desvio da frequência não deve exceder $1 \mathrm{~Hz}$. Deve conter ainda um sistema de aterramento e barramento de equalização de poten cial, constituindo um barramento equipotencial central, (IEC, Publicaçāo 513). A sala de cirurgia deverá ser alimentada por meio de transformador de isolação (ou de separação) incorporan do ainda disjuntores de correntes de fuga e monitores de pri meira falha da isolação para a terra. Deverä incorporar ainda supressores de interferência eletromagnética e possuir preven çōes contra explosão e incêndio e precauçōes anti-estāticas. Eventualmente, poderá contar com gerador próprio para alimenta ção especial de emergência, em intervalo de tempo muito curto ou, se for possivel, sem interrupção.

As prescrições para a instalação devem estar confor me as publicações normativas pertinentes (ABNT, Norma NBR 5410; IEC, Documento $62 \Lambda$ (Secretariat) 55), considerando-se também sugestões de vários autores conforme a Referência Bibliogräfica (Dalzie1, 1972, Webster, 1978, Dubovy, 1978, Bahil1, 1981; De Marre e Michae1, 1983).

3.9. Controle de Qualidade e Confiabilidade

O controle de qualidade do Sistema de Circulação Ex tracorpórea deverá considerar tanto o controle de qualidade de fabricação (controle do processo) quanto a inspeção de qualida 
de (Juran e colaboradores, 1979; Lourenço Filho, 1984; Grant, $1952 ;$ Grant, 1985).

o controle de fabricação executado durante o proces so produtivo para manter a qualidade do futuro produto dentro dos limites de uniformidade indicados na especificação de fa bricação, pode usar indiferentemente o controle estatístico de qualidade de fabricação conforme o sistema norte-americano ou inglês.

A inspeção de qualidade efetuada com o produto já existente e objetivando verificar se atende as especificações de aceitação, proporcionando adequada confiança de que determi nados itens e serviços atendem a prescrições contratuais, deve aplicar programas da qualidade e planos de amostragem conven $\underline{i}$ entes. De acordo com a Norma Brasileira NBR-8597/1984 a sele çào do programa mais adequado deve ser conforme a Norma NBR 8593 - Preparação de Programas de Qualidade - Classe 1 (Garan tia) - Procedimento, existente na Coletânea de Normas da ABNT sobre Programas de Qualidade. Os diversos planos de amostragem aplicáveis constam na Coletânea de Normas da ABNT sobre Planos de Amostragem.

Para assegurar completamente a qualidade e a confia bilidade (ABNT, NBR 5462), deve-se aplicar o conceito de con trole total de qualidade (Palmer, 1974) através de técnicas de garantia da qualidade (Calegare, 1985).

O controle total da qualidade é "um sistema para in tegrar esforços de desenvolvimento, manutenção e melhoria da qualidade de värios grupos na organização, resultando em produ 
ção e serviços mais econômicos possíveis e proporcionando a competente satisfação dos consumidores". Esquematicamente, o sistema de controle total de qualidade pode ser representado conforme a Fig. 3.12, sendo principalmente aplicado em quatro äreas funcionais: controle dos novos projetos, controle do ma terial recebido, controle do produto e estudo de processos es peciais.

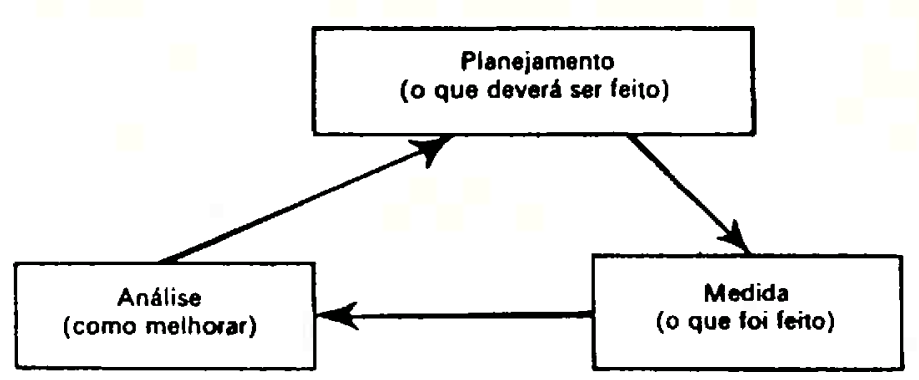

Fig. 3.12. Sistema de Controle Total de Qua1 idade. Reproduzido de Palmer, 1974.

Eventualmente, o controle de qualidade pode ser esta belecido usando a conceituação do Círculo de Controle de Quali dade (Amsden e Amsden, 1976).

Por mais eficiente que seja o Controle de Qualidade, normalmente não propicia garantias cabais definitivas de que o produto ou serviço terá os resultados planejados durante seu 
uso efetivo. Outras ações complementares podem tornar-se im prescindíveis ou convenientes, inclusive para garantir a pró pria confiabilidade. (Smith, 1976; Kapur e Lamberson, 1977; K $\underline{\text { i }}$ venson, 1971). Necessita-se então aplicar o conceito de Garan tia da Qualidade, ou seja, "um conjunto de medidas planejadas e sistemáticas, necessârìas para assegurar que o produto ou ser viço tenha desempenho satisfatōrio quando em consumo ou utili zação". Normalmente considera as características de qualidade conforme os seguintes parâmetros:

- qualidade de projeto

- qualidade de conformação

- continuidade ao longo do tempo (confiabilidade, dis ponibilidade e manutibilidade)

- assistência têcnica 


\section{CAPITULO IV}

IMPLEMENTAÇÃO E ENSAIOS DO SISTEMA DE CIRCULAÇÃO EXTRACORPÓREA

\subsection{Introdução}

o Sistema de Circulação Extracorpórea foi desenvolvi do conforme a concepção estabelecida no capítulo anterior, vi sando atender as especificações exigidas para a máquina cora ção-pulmão artificial ideal. Apesar das necessidades básicas de funcionalidade e qualidade ìmpostas pela própria concepçāo de equipamentos eletro-médicos usando o conceito integrado de se gurança, tambëm foram considerados fatores de simplicidade,cus to e disponibilidade de componentes no mercado nacional. Neste capítulo são apresentados os principais aspectos de implementa ção, bem como os ensaios realizados no equipamento, indicandose neste ültimo caso tanto a metodologia como os resultados ex perimentais obtidos.

4.2. Implementação do Sistema de Circulação Extracorpörea

O diagrama esquemätico do Sistema de Circulação Exx tracorpórea é apresentarlo na Fig. 4.1 , sendo indicados os vārios 
sub-sistemas existentes e os sinais correspondentes.

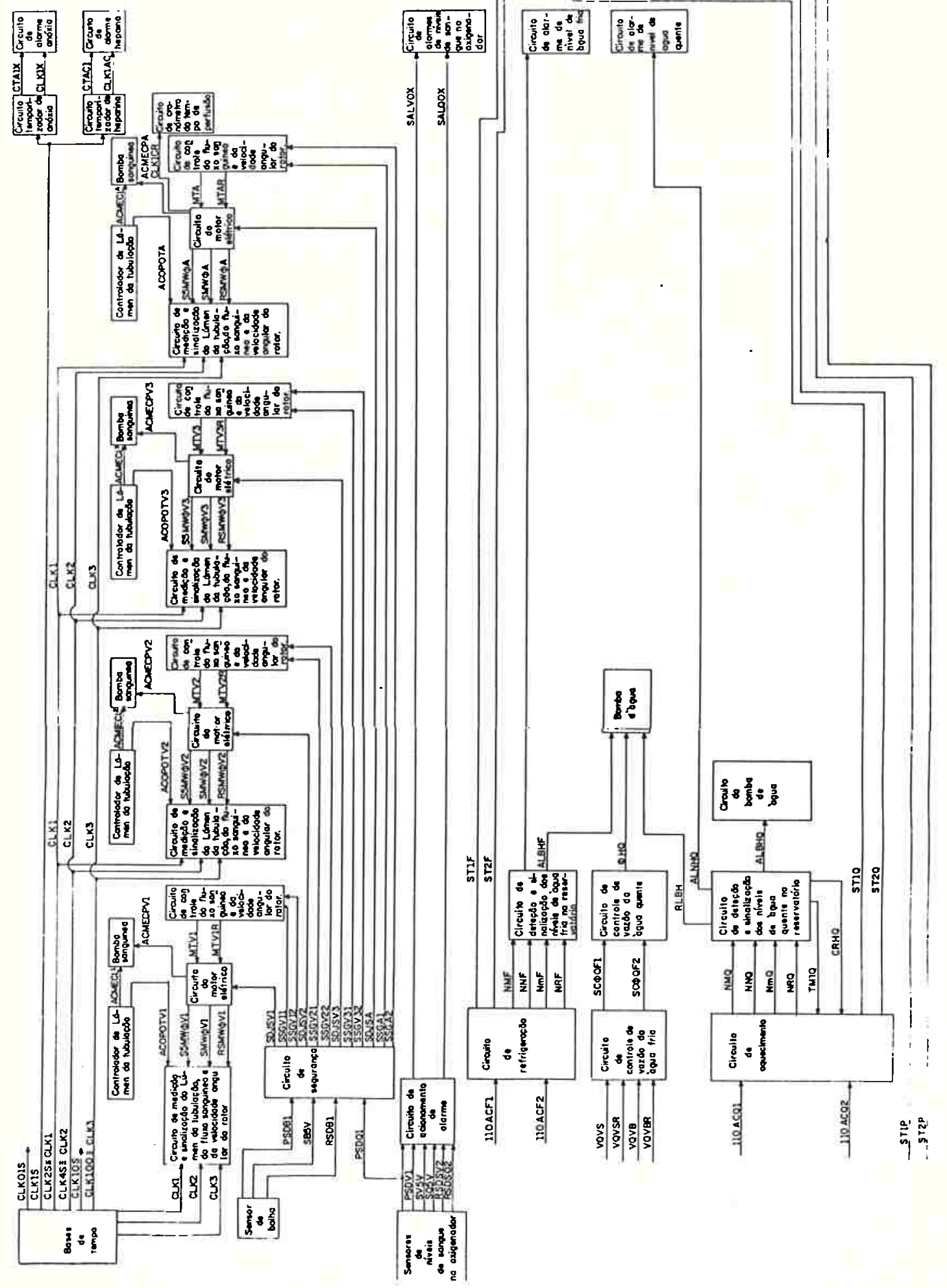

Fig. 4.1.a. Diagrama esquemático de partes do Sistema de Circulação Extracoroórea. 
$4.2 . \mathrm{b}$
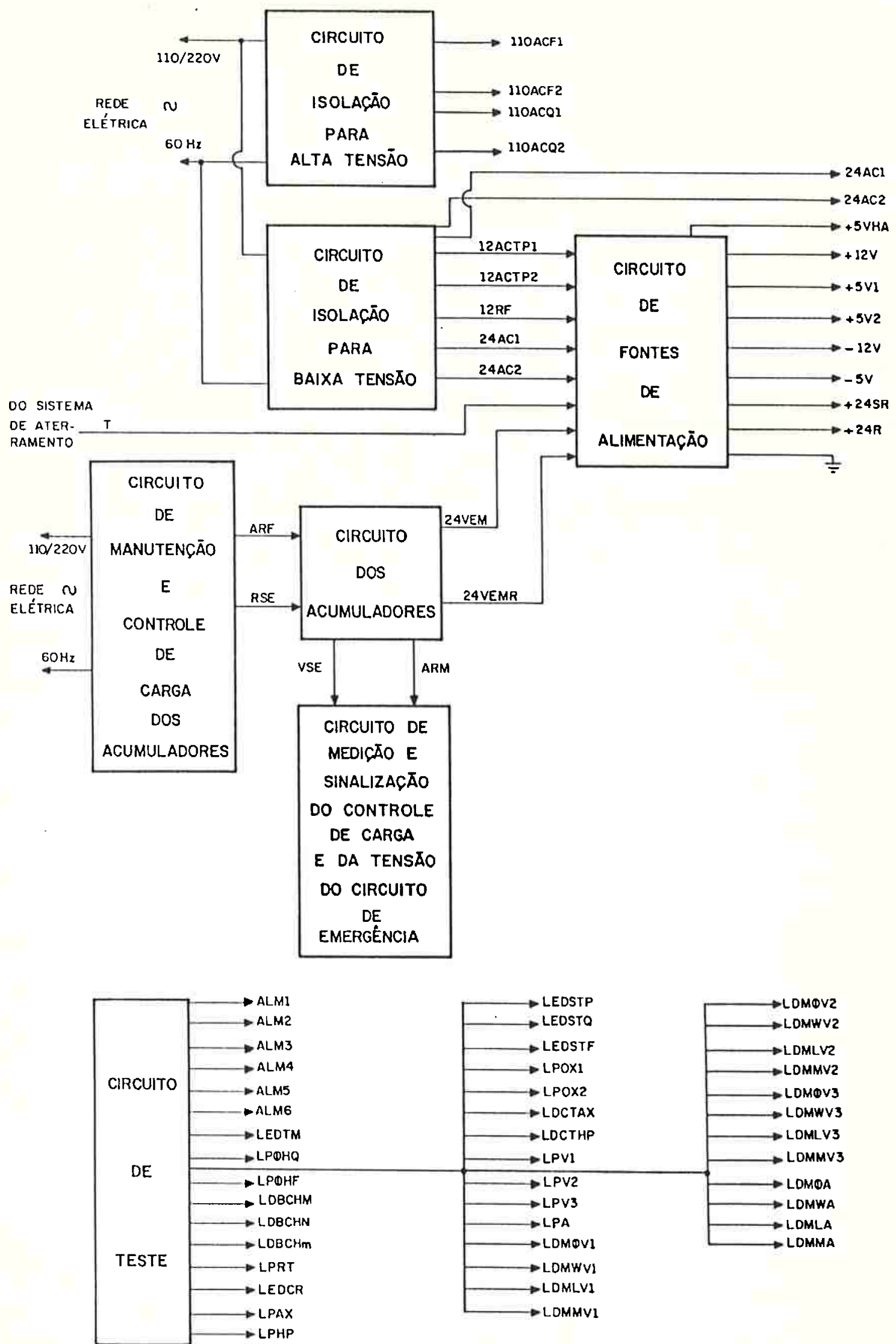

Fig. 4.1.b. Diagrama esquemático dos sub-sistemas de alimentação, de emergência e de teste. 
As informações relativas à implementação do S.C.E. rẹ ferentes às partes eletro-eletrônicas, mecânicas e aspectos de ventilação e de revestimento são apresentadas nesta secção. De vido à grande quantidade de particularidades e detalhes constru tivos do equipamento, apenas os dados essenciais são fornecidos.

\subsubsection{Partes Eletro-Eletrônicas}

A principal parte eletro-eletrônica do Sistema è o circuito acionador de cada uma das bombas sanguíneas, em espe cial, a bomba arterial. Este circuito é basicamente constituído por um motor elétrico incorporado com redutor mecânico e dispo sitivos de controle e medição da velocidade angular de seu eixo, acarretando o correspondente controle e medição do fluxo sanguí neo.

Inicialmente considerou-se a possibilidade de aplica Ção da filosofia empregada em controladores automáticos indus triais para controle da vazāo em uma linha fluídica. Entretanto, os materiais utilizados, bem como as dimensões e as faixas de especificaçōes pertinentes aos dispositivos existentes, aliados a não disponibilidade de itens concebidos para aplicaçōes médi cas e aspectos de custo, inviabilizaram a proposta.

Posteriormente, dois outros sistemas de controle da velocidade angular do rotor foram considerados: o primeiro usou malha de sincronismo de fase, e o segundo consistiu em uma fonte de tensão contínua regulada, ajustável e estabilizada. Os vários ensaios realizados nas duas configurações, considerando a precí 
são necessäria e as faixas de fluxo e de pressão de carga exí gidas, demonstraram a possibilidade de uso da fonte regulada, com. vantagens óbvias relativas à simplicidade, custo e dispon $\underline{i}$ bilidade de itens no mercado nacional.

A seguir serão apresentados os diagramas de circuitos e de tempo, quando cabíveis, alēm da descrição funcional das vārias partes eletro-eletrônicas do Sistema de Circulação Ex tracorpórea.

4.2.1.1. Sub-sistemas motores

A parte eletro-eletrônica constituinte de cada subsistema motor, ou seja, os três módulos venosos e o módulo arte rial, contém o pröprio motor elétrico e um circuito de controle do fluxo sanguíneo pela velocidade angular do rotor da bomba sanguínea, alëm do circuito de medição des sas grandezas e da abertura do lúmen do tubo plástico condutor do sangue.

o motor elétrico é acoplado a um redutor para redu zir a rotação e aumentar o torque disponivel ao rotor, conten do ainda um disjuntor auto-incorporado que desliga automatica mente a alimentação do motor no caso de cargas e/ou temperatú ras excessivas.

0 circuito de controle do fluxo sanguíneo è forneci do na Fig. 4.2, indicando-se tambëm o motor elētrico. Uma ten são alternada senoidal de $24 \mathrm{~V}$ proveniente de um dos transforma dores de rede é aplicada a uma nonte retificadora, com diodos 
semicondutores D1 a D4 de média corrente, e a um capacitor de filtragem $\mathrm{Cl}$ que fornecem a tensão retificada e filtrada ao circuito regulador. Os principais elementos deste último cir cuito são os transistores Qla e Qlb que constituem o regulador série, sendo ligados em paralelo e com dissipadores apropriados devido à corrente solicitada pelo motor elétrico M. O transis tor Q2 completa o regulador na montagem Darlington convencional. Os transistores Q3 e Q4 conjuntamente com os resistores R2, R3 e R4, o potenciometro Pl e o capacitor C2 constituem o detetor amplificador de êrro e o elemento de referência de tensão do circuito. O potenciômetro Pl possibilita ainda a seleção da tensão regulada que alimenta a armadura do motor. O transistor Q5 e os resistores R5, R6 e R7 formam o circuito de proteção contra curto-circuito de saida. A chave $\mathrm{CH}$ e e interruptor principal do circuito. O diodo Zener DZ1 e o resistor $\mathrm{Rl}$ acen dem a lâmpada L1, incorporada ao próprio interruptor, quando es te é acionado. O circuito de alimentação do motor também pode ser interrompido pelo contacto do relé de segurança entre os pontos SSGXX1 e SSGXX2 se houver uma bolha de ar na linha arte rial ou o nível de sangue no oxigenador estiver abaixo de $40 \%$ do nivel normal.

o circuito de medição do fluxo sanguíneo, da velocí dade angular do rotor ou da abertura do lúmen da tubulação con dutora do sangue $\vec{e}$ apresentado na Fig. 4.3.

Em cada bomba sanguínea do S.C.E., existe na extremi. dade posterior do eixo do rotor um disco perfurado mecanicamen te acoplado e solidärio com o rotor. Este disco se movimenta entre o transmissor e o receptor de um interruptor com acopla 


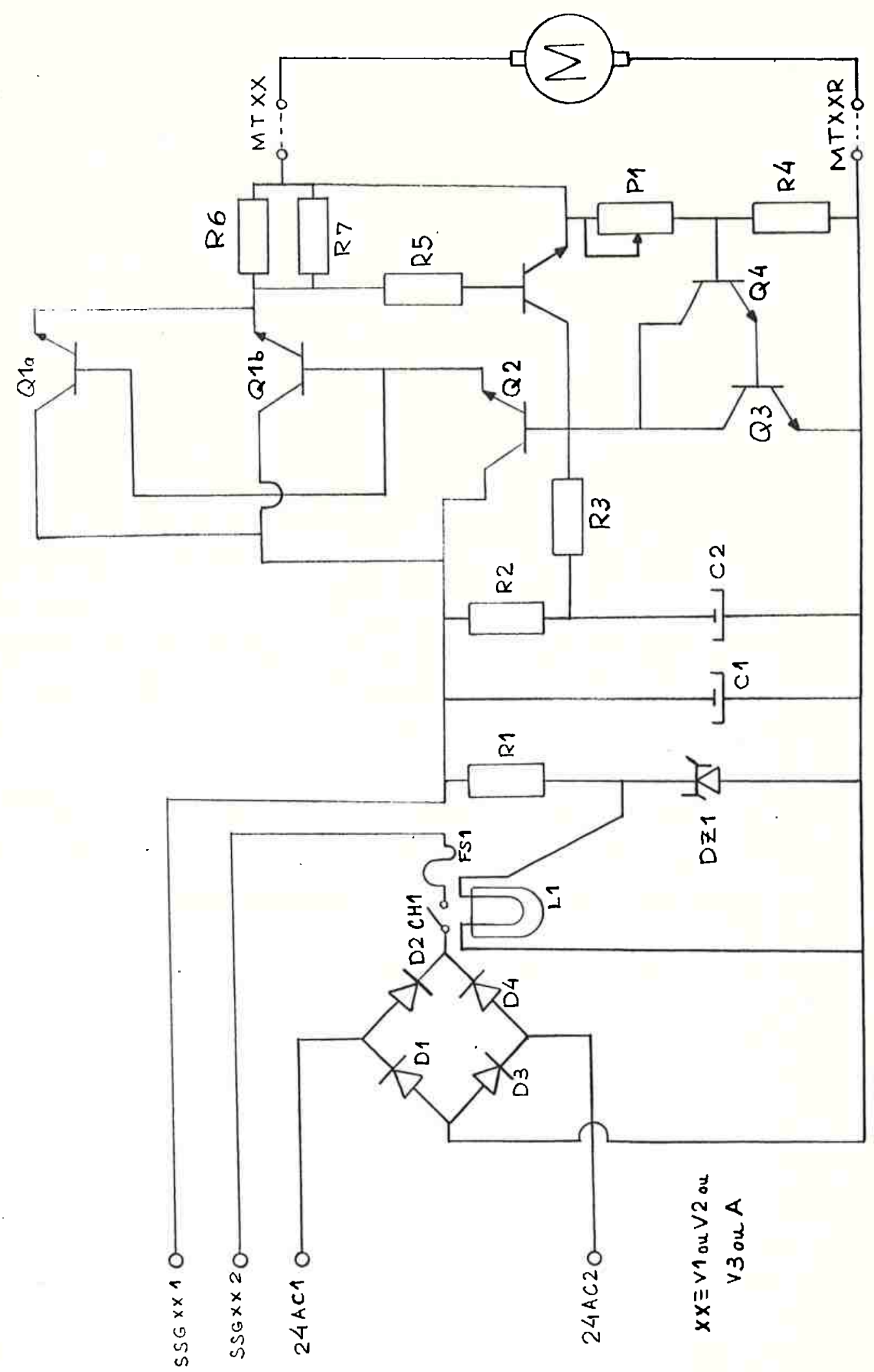

Fig. 4.2. Circuito de controle da velocidade an gular de rotação do eixo do motor elé trico de cada bomba sanguínea, indican do-se o próprio motor. 


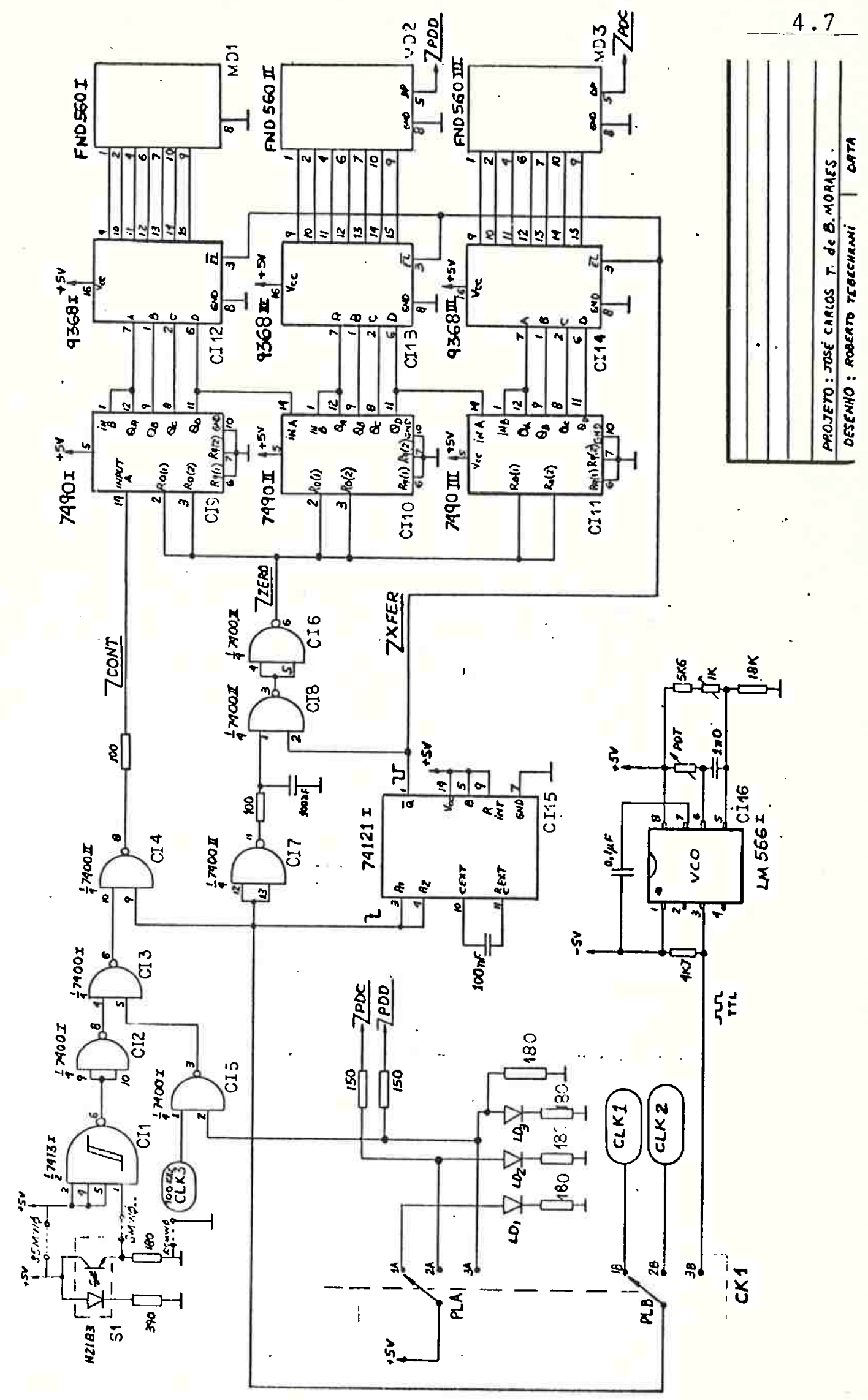

Fig. 4.3. Circuito de medição do fluxo sanguí neo, da velocidade angular do rotor e da abertura do lúmen. 
mento ótico,constituído por um diodo de arseniato de gâlio emis sor de luz infravermelha acoplado a um foto-transistor de silí cio. O sinal proveniente deste transdutor é uma tensão elétri ca quase-retangular com frequência igual a $1 / 60$ da frequência do rotor. Os formatadores de onda CIl e CI 2 ao receberem este sinal, fornecem uma tensão na mesma frequência e com níveis com pativeis com a família TTL.

Por outro lado, o transdutor que possibilita a medi ção do lúmen no tubo plástico é o potenciômetro POT que é aco plado ao eixo pinhão do rotor da correspondente bomba durante o ajuste do lümen. Durante este ajuste, o eixo do rotor deve ser comprimido contra o painel da bomba pela cabeça de regula gem e acoplado ao potenciômetro de dez voltas, que apresentará entre o cursor e uma de suas extremidades uma resistência elé trica proporcional à abertura do lümen. Nessas condições, o oscilador controlado por tensão VCO fornece em sua saída uma tensão elétrica retangular com período proporcional à resistên cia do transdutor resistivo, a qual é ligada ao ponto $3 \mathrm{~B}$ da chave CKl.

A chave CK1 seleciona a grandeza a ser medida de tal forma que nas posições 1,2 e 3 possibilita as leituras do flu xo sanguíneo, da velocidade angular do rotor e da abertura do lümen, respectivamente. Os diodos emissores de luz vermelha LD1, LD2 e LD3 indicam a grandeza selecionada.

Os circuitos medidores do fluxo de sangue e da rota ção do rotor utilizam as configurações tradicionais de contado res usados para determinação da frequência, enquanto o circuito 
de medida do lúmen usa a configuração clássica de um medidor de período. No primeiro caso, o sinal proveniente do acoplador ót co, convenientemente formatado, vai ser contado em uma janela determinada pela tensão retangular CLK1 ou CLK2 proveniente do sub-sistema de base de tempo. No último caso, é a tensão com $100 \mathrm{KHz}$ correspondente à CLK3 deste sub-sistema, que serā con tada durante um intervado de tempo (janela) determinado pelo período da tensão de saída do VCO. Os sinais de contagem, zera gem e transferència, internos ao circuito da Fig. 4.3, indicam as portas lógicas e o multivibrador monoestảvel associados. 0 estágio contador propriamente dito é constituído pelos circui tos integrados CI9 a CIll indicando-se as leituras no sistema de numeração decimal pelos mostradores MD1, MD2 e MD3. Os cir cuitos integrados $\mathrm{C} 12$ a C14 propiciam a conversão-decodificação necessária, bem como fornecem os niveis de corrente compativeis aos mostradores.

As Figs. 4.4 e 4.5 apresentam os diagramas de circui to e de tempo nas vārias posiçōes da chave CK1.

4.2.1.2. Sub-sistemas detetores de bolha e de níveis de sangue no oxigenador

o circuito do detetor de bolha é constituído por um acoplador ótico-eletrônico, posicionado imediatamente após a saida da bomba arterial, e pelos resistores R1 e R2 (Fig. 4.6). o circuito é alimentado pela fonte de tensão contínua de $5 \mathrm{~V}$. Uma bolha atravessando entre o emissor e o detetor do sensor 


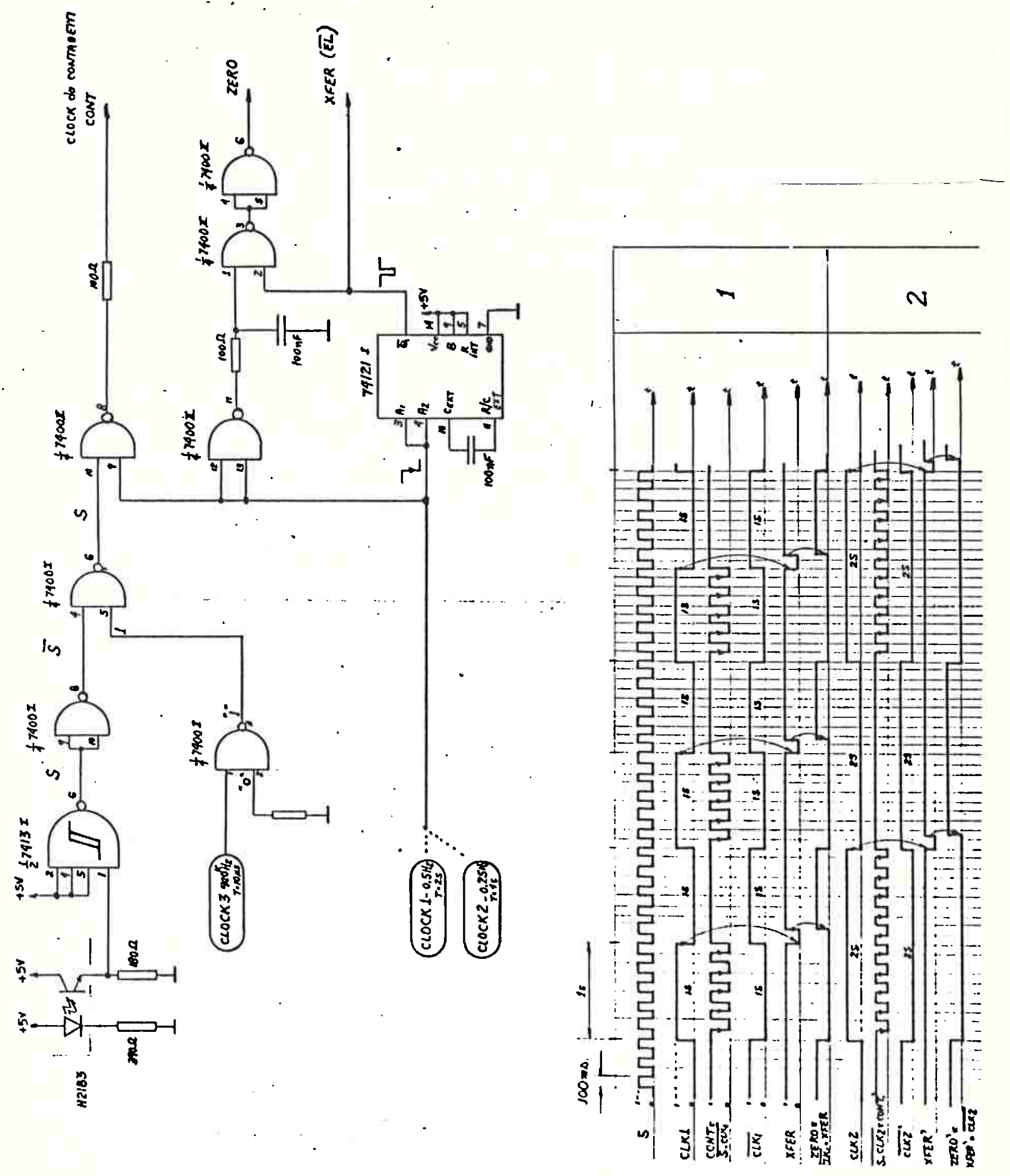

Fig. 4.4. Diagramas de circuito e de tempo do medidor de fluxo sanguíneo e de ve locidade angular do rotor. 


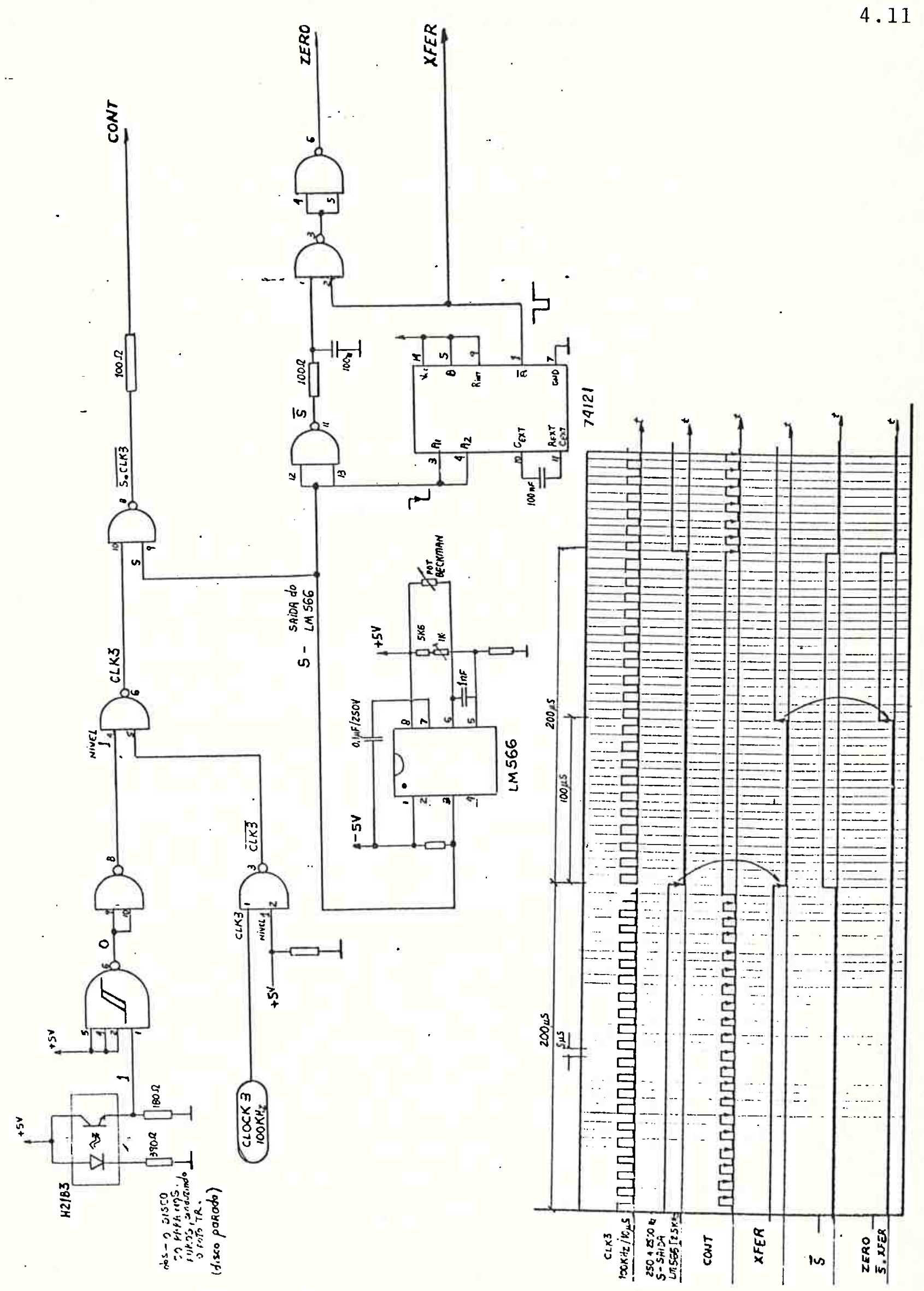

Fig. 4.5. Diagramas de circuito e de tempo do medidor de lúmen. 
acarreta um sinal PSDB1 que è enviado ao circuito de segurança para imediata desativação dos sub-sistemas motores.

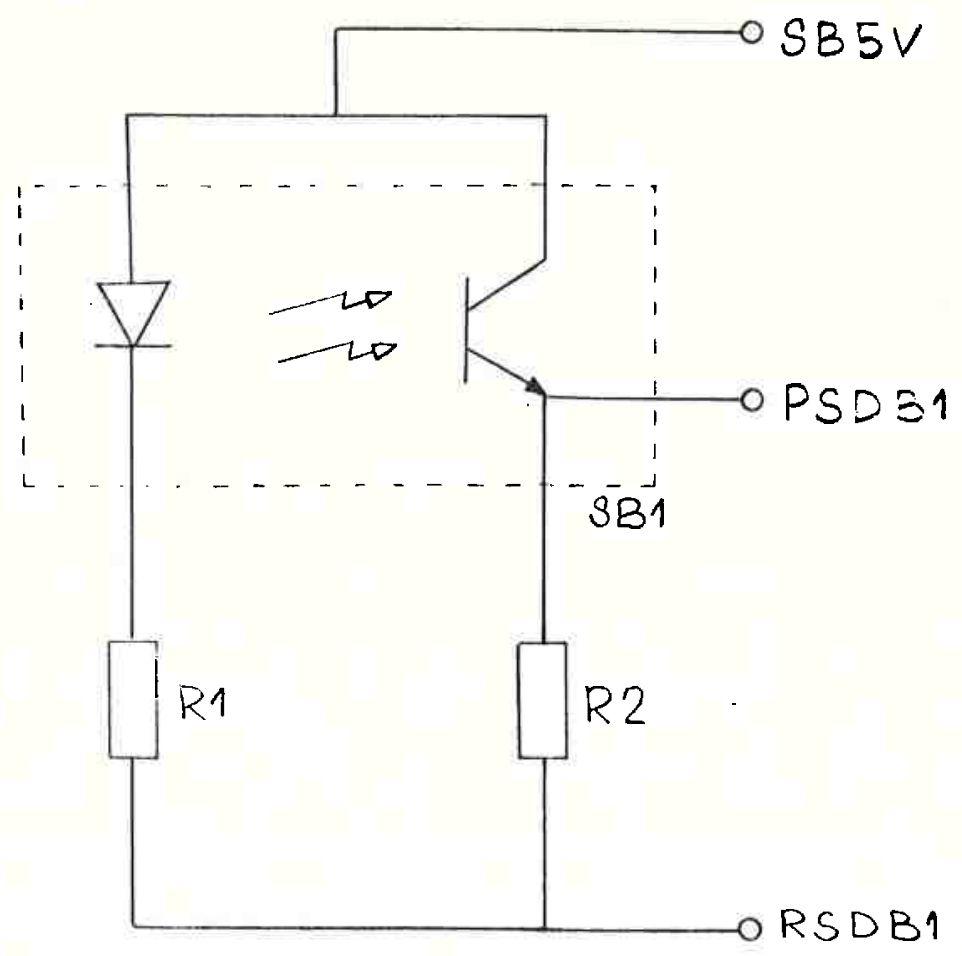

Fig. 4.6. Circuito detetor de bolha

O sub-sistema detetor de níveis de sangue no oxigena dor é constituído por dois interruptores ótico-eletrónicos po sicionados sobre o oxigenador em níveis correspondentes a $25 \%$ e 40\% abaixo do seu nível normal de sangue (Fig. 4.7). Na au séncia de sangue entre o emissor e o detetor do dispositivo cor respondente ao nível de $25 \%$, um sinal elétrico PSDV1 è enviado ao formatador de onda CI1, o qual aciona um relé RLl através de um circuito inversor transistorizado constituido pelos tran sistores Q1 e Q2, conjuntamente com os diodos D1, D2, D3 e os 
resistores R3, R4, R5. O diodo D4 protege a bobina do relé con tra os transitórios decorrentes dos chaveamentos dos transisto res. Ao ser acionado o relē, seus contactos alimentam o diodo emissor de luz vermelha DLl bem como enviam um sinal SALVOX ao sub-sistema de alarmes para ativar o alarme sonoro corresponden te. 0 circuito correspondente ao nivel de $40 \%$ do oxigenador é idêntico ao de $25 \%$ apenas com a propriedade de enviar o sinal PSDQ1 tambēm ao circuito de segurança para desativar os moto res do Sistema no caso de nível de sangue no oxigenador abaixo do mínimo prē-estabelecido.

4.2.1.3. Sub-sistema de segurança

O sub-sistema de segurança habilita ou inibe os moto res dos módulos venosos e arterial. O circuito eletrônico cor respondente é indicado na Fig. 4.8 .

Os sinais PSDB1 e PSDQ1 provenientes dos sensores per tencentes aos circuitos detetores de bolha e de nível mínimo de sangue no oxigenador $(40 \%)$ são formatados pelo disparador de Schmitt CI1. Os sinais aplicados à porta de seleção CI2 ativam o circuito inversor transistorizado, que aciona o relé de segu rança RL cujos contatos habilitam ou inibem a alimentação dos quatro motores existentes no Sistema. A inibição ocorre se pe lo menos um sinal ativo for recebido dos sensores. Os disjunto res auto-incorporados em cada motor são considerados pertencen tes ao sub-sistema de segurança. 

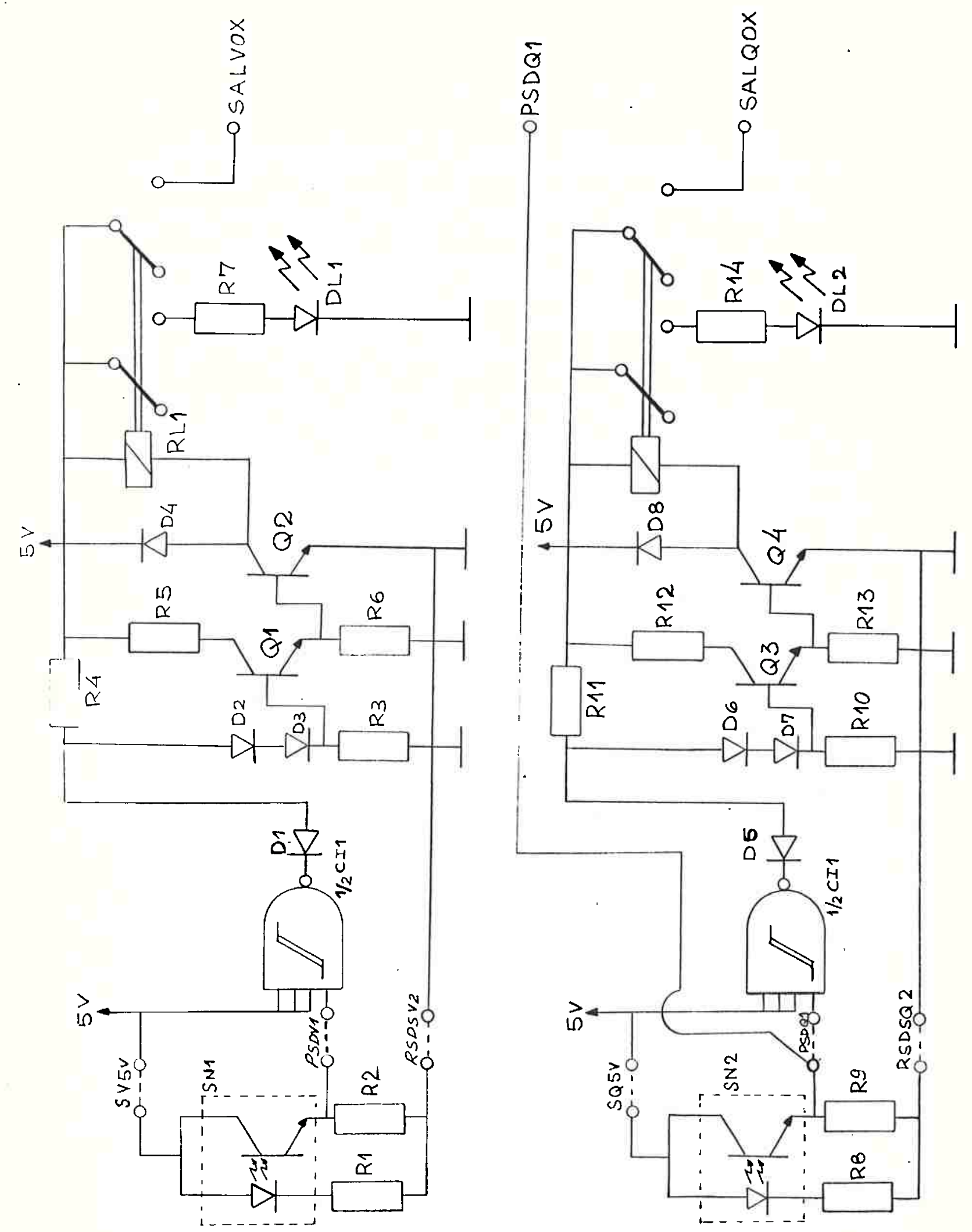

Fig. 4.7. Circuito detetor de níveis de sangue no oxigenador. 


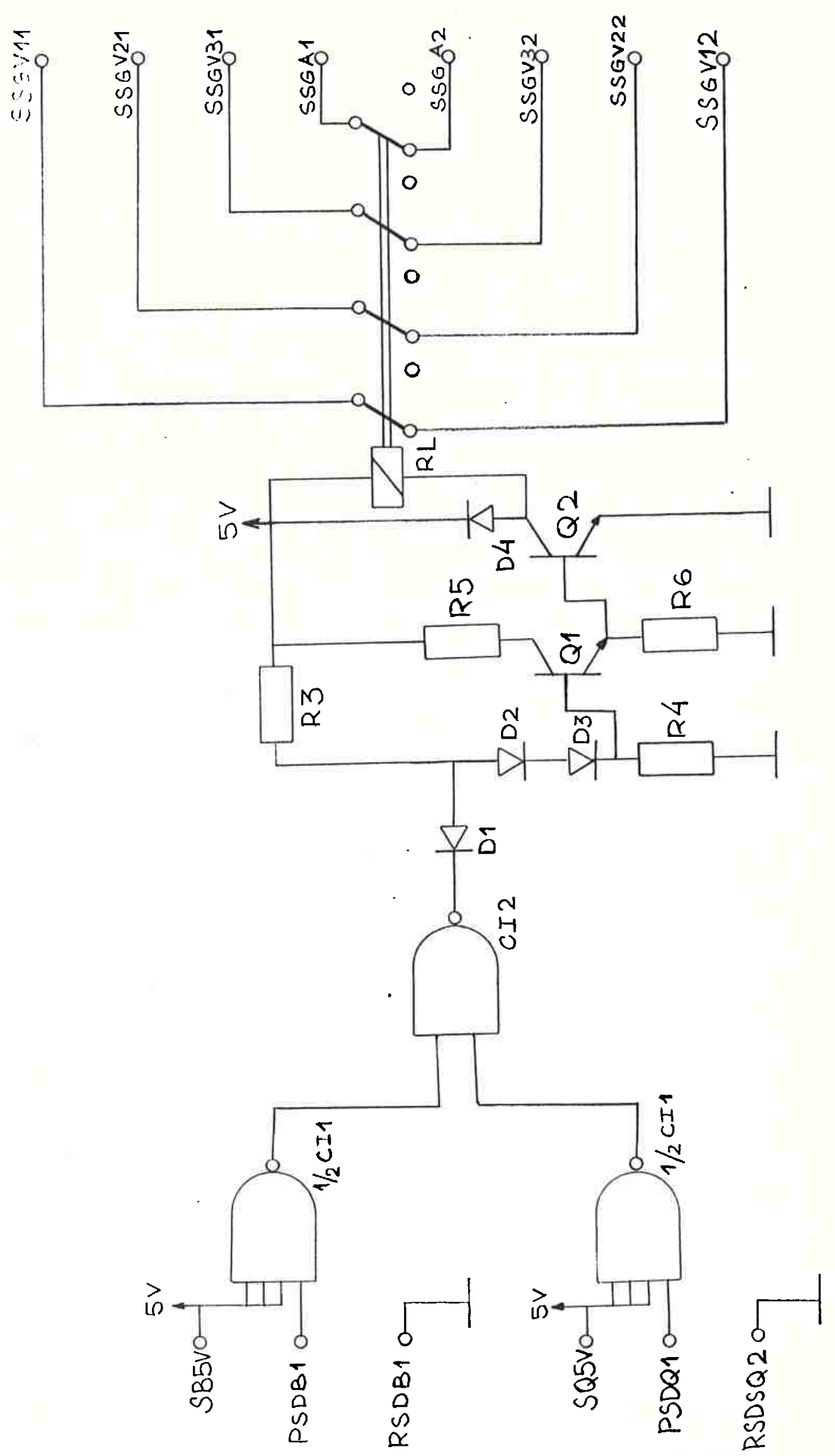

Fig. 4.8. Circuito do sub-sistema de segurança. 


\subsubsection{Sub-sistema hidräulico}

A Fig. 4.9 apresenta um esquema geral indicando as principais partes elétricas e hidräulicas dos circuitos de con trole para aquecimento, refrigeração e fluxos das äguas quente e fria do sub-sistema hidráulico.

Conforme pode-se observar na Fig. 4.9, alëm das prin cipais unidades deste sub-sistema que são os próprios elemen tos de refrigeração e aquecimento, nos reservatórios de ảgua existentes estão instalados tambëm os sensores térmicos e de níveis de líquido, que enviam os sinais de controle e medição para outras partes do Sistema. Também são indicadas a bomba d' ägua e os dois pares de válvulas solenoides responsāveis pelo correto fluxo hidräulico no equipamento.

Os elementos bäsicos de comando dos fluxos de ägua são apresentados na Fig. 4.10, onde são indicados os dois bo tões de seleção desse fluxo, com as lâmpadas auto-incorporadas, o fusível para a bomba d'água e as vālvulas solenoides.

Os circuitos de alimentação do mini-refrigerador e da resistência de aquecimento são apresentados na Fig. 4.11, in dicando-se o botão de acionamento dessa resistência e o circui to de alimentação da sua lâmpada, bem como o termostato sele tor da temperatura regulada e os contactos do relè de nível nor mal do tanque de àgua quente.

A Fig. 4.12 apresenta o circuito de comando, sinali zação e alarmes, acionado pelos sensores de níveis de ägua nos reservatórios de água quente e ägua fria. Estes sensores atuam 


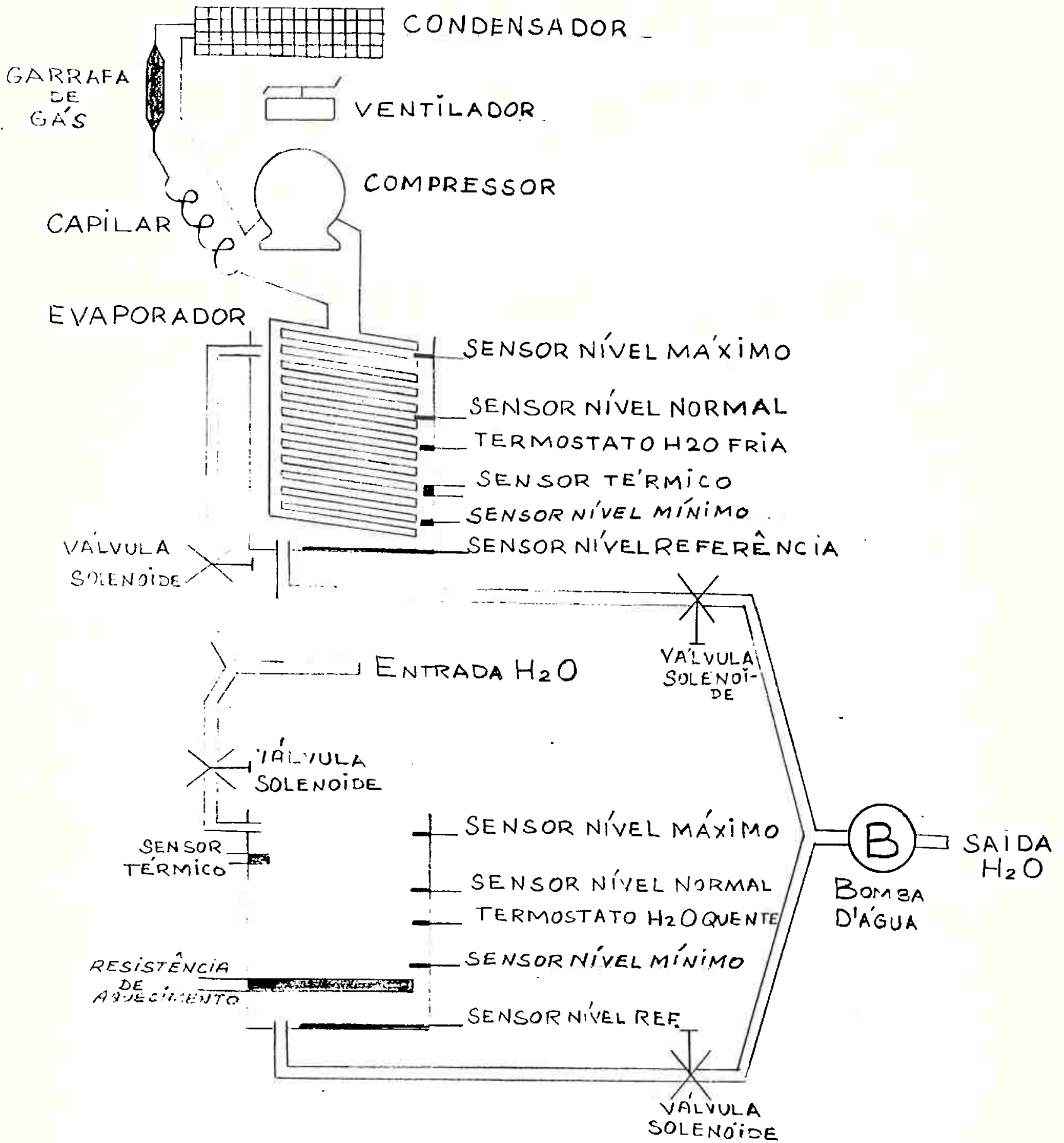

Fig. 4.9. Elementos principais dos circuitos de aquecimento, refrigeração e flu xos de água quente e água fria do sub-sistema hidräulico. 


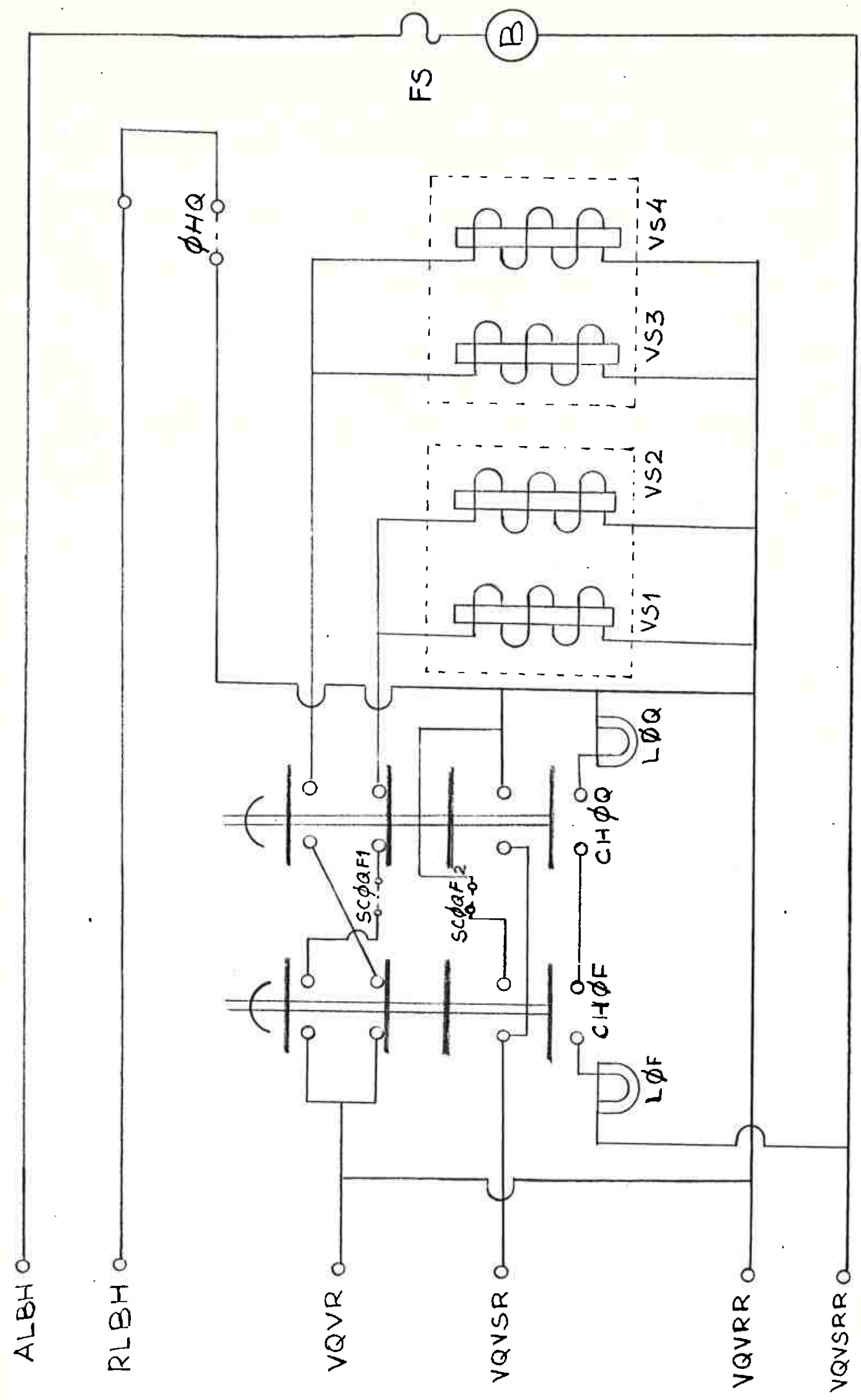

Fig. 4.10. Circuito de comando dos fluxos das äguas quente e fria. 


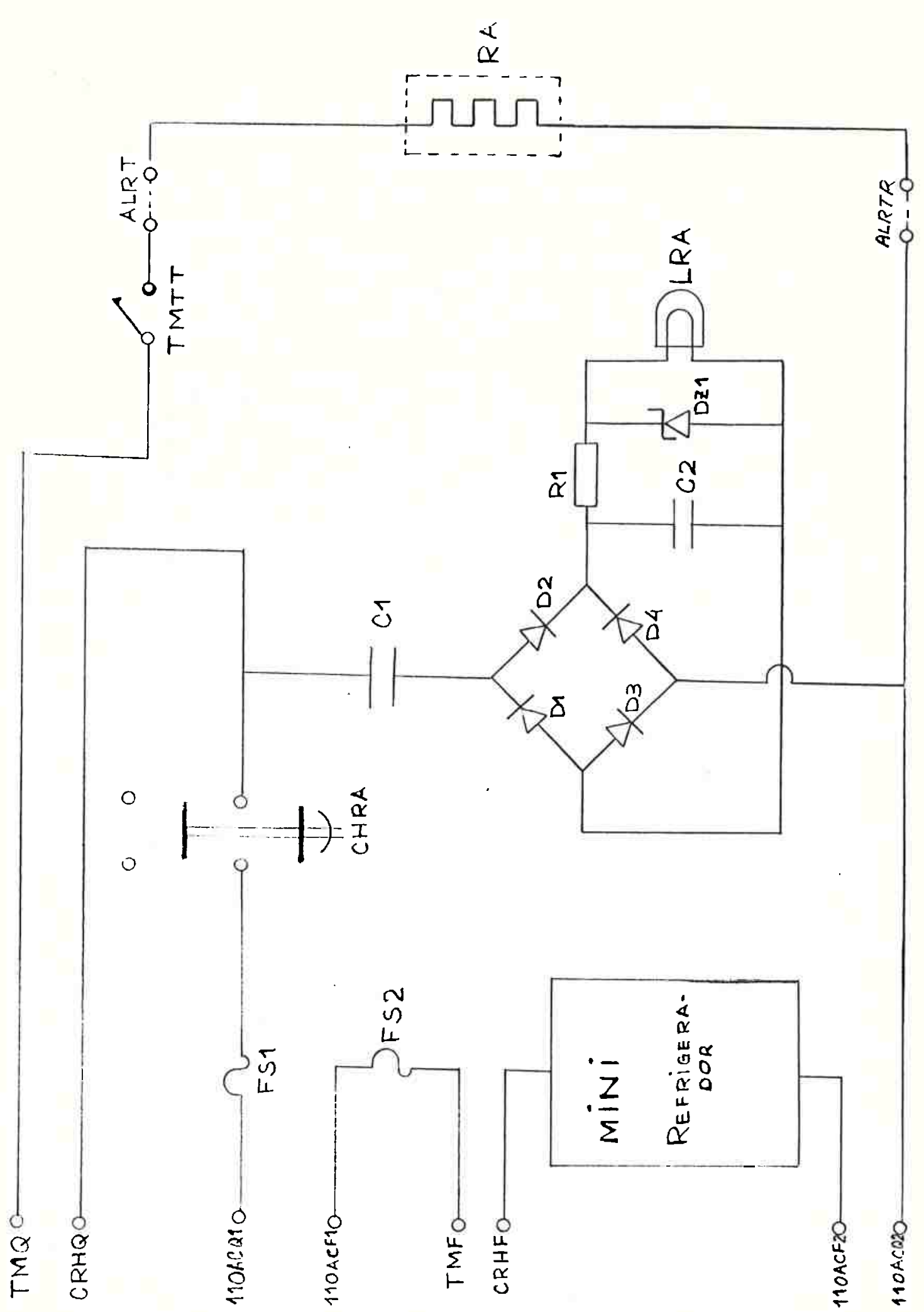

Fig. 4.11. Circuitos de alimentação do minirefrigerador e da resistência de aquecimento. 
por ação resistiva e enviam sinais aos circuitos detetores de níveis constituídos, por exemplo pelos transistores Q1 e Q2 e resistores R1 e R2 para o detetor de nível máximo no reservató rio de água quente. Cada circuito detetor de níveis mäximo e normal aciona o correspondente relé, contendo um diodo prote tor de transitórios, cujos contactos acionam diodos bicolores emissores de luz verde e vermelha e enviam sinais ao sub-siste ma de alarmes. Por outro lado, os circuitos detetores de nível mínimo de àgua em cada tanque acionam dois relés com contactos em série que ṕossibilitam ou não a alimentação da bomba hidrāu 1 ica.

A Fig. 4.13 fornece uma visão de conjunto do sub-sis tema hidráulico, com alguns elementos do sub-sistema de ala $\underline{r}$ mes.

4.2.1.5. Sub-sistema termomëtrico

O sub-sistema termometrico indica a temperatura do paciente ou a temperatura da āgua existente em cada um dos re servatórios do sub-sistema hidräulico. São usados três senso res idênticos ST1, ST2 e ST3 constituídos por um transdutor AD590 (Analog Devices, 1978) que fornecem uma corrente elétri ca linearmente proporcional à temperatura, em graus Kelvin, de cada uma das fontes térmicas (Fig. 4.14).

A chave seletora CK1 permite a seleção da fonte tēr mica e o regulador de corrente constituido pelo transistor de efeito de campo $\mathrm{Q} 1$, o potenciómetro $\mathrm{P} 1$ e o resistor $R 2$ conver 

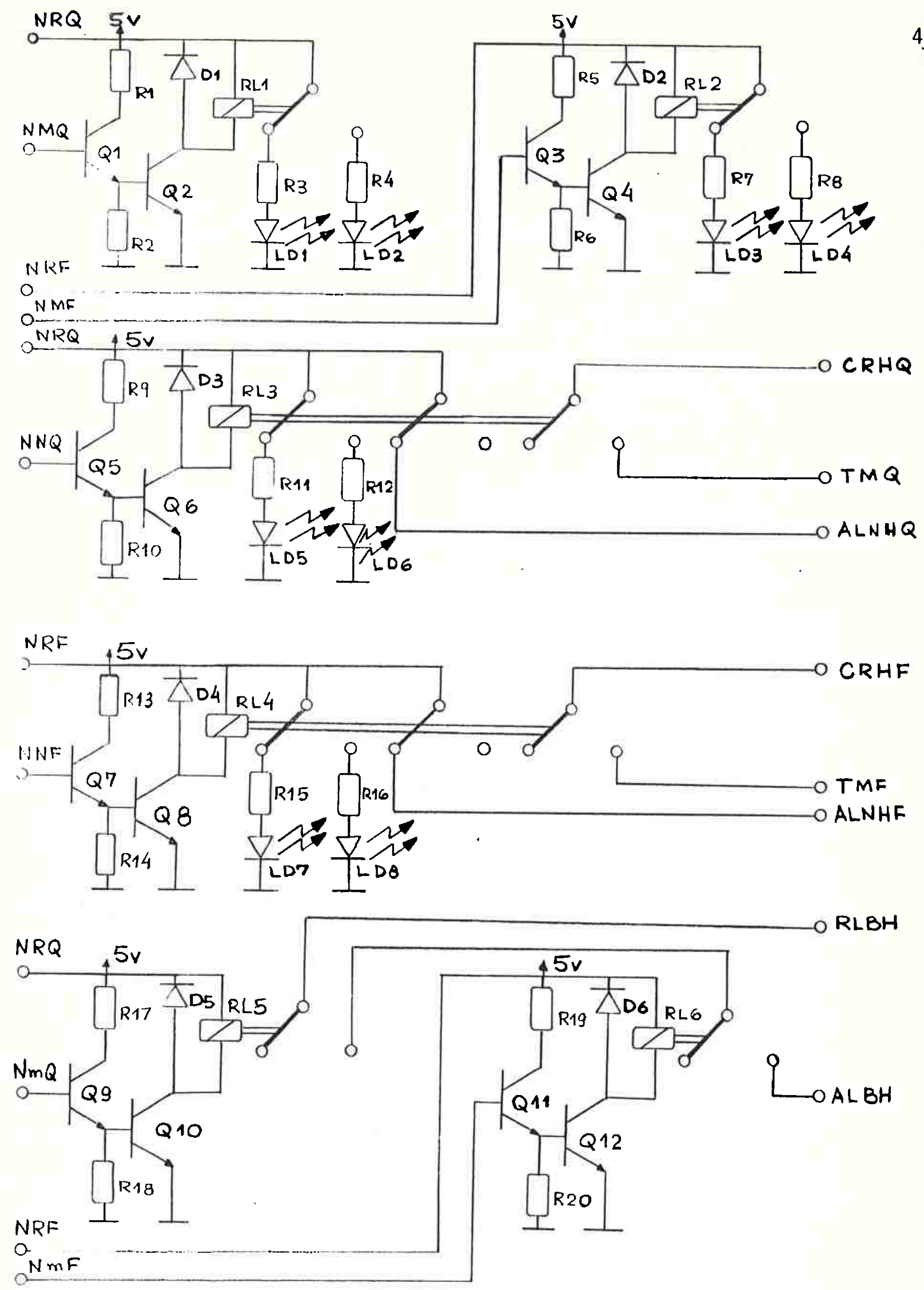

Fig. 4.12. Circuito dos detetores de niveis nos reservatórios de àguas quen te e fria. 


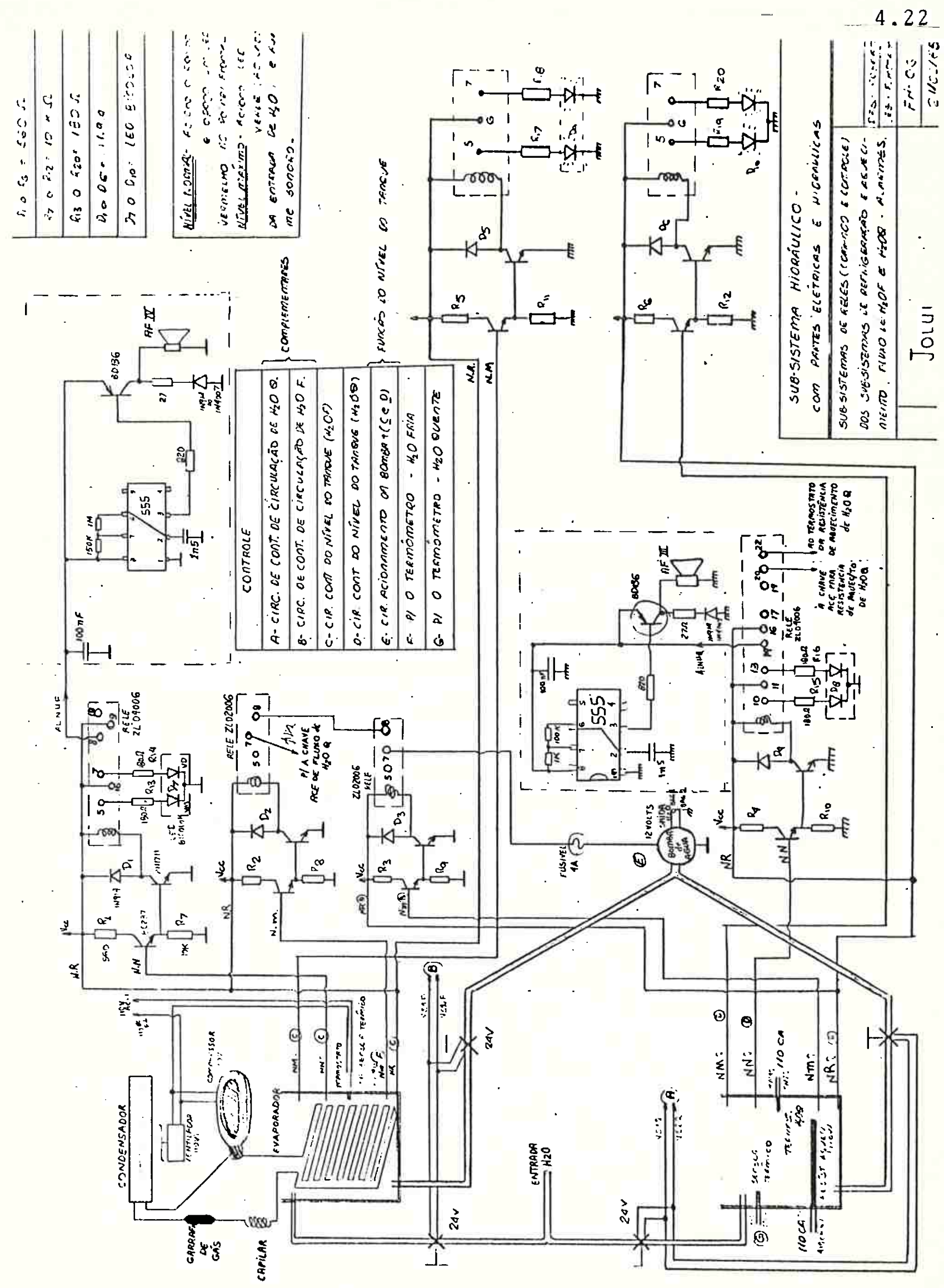

Fig. 4.13. Visão de conjunto do sub-sistema hidräulico. 


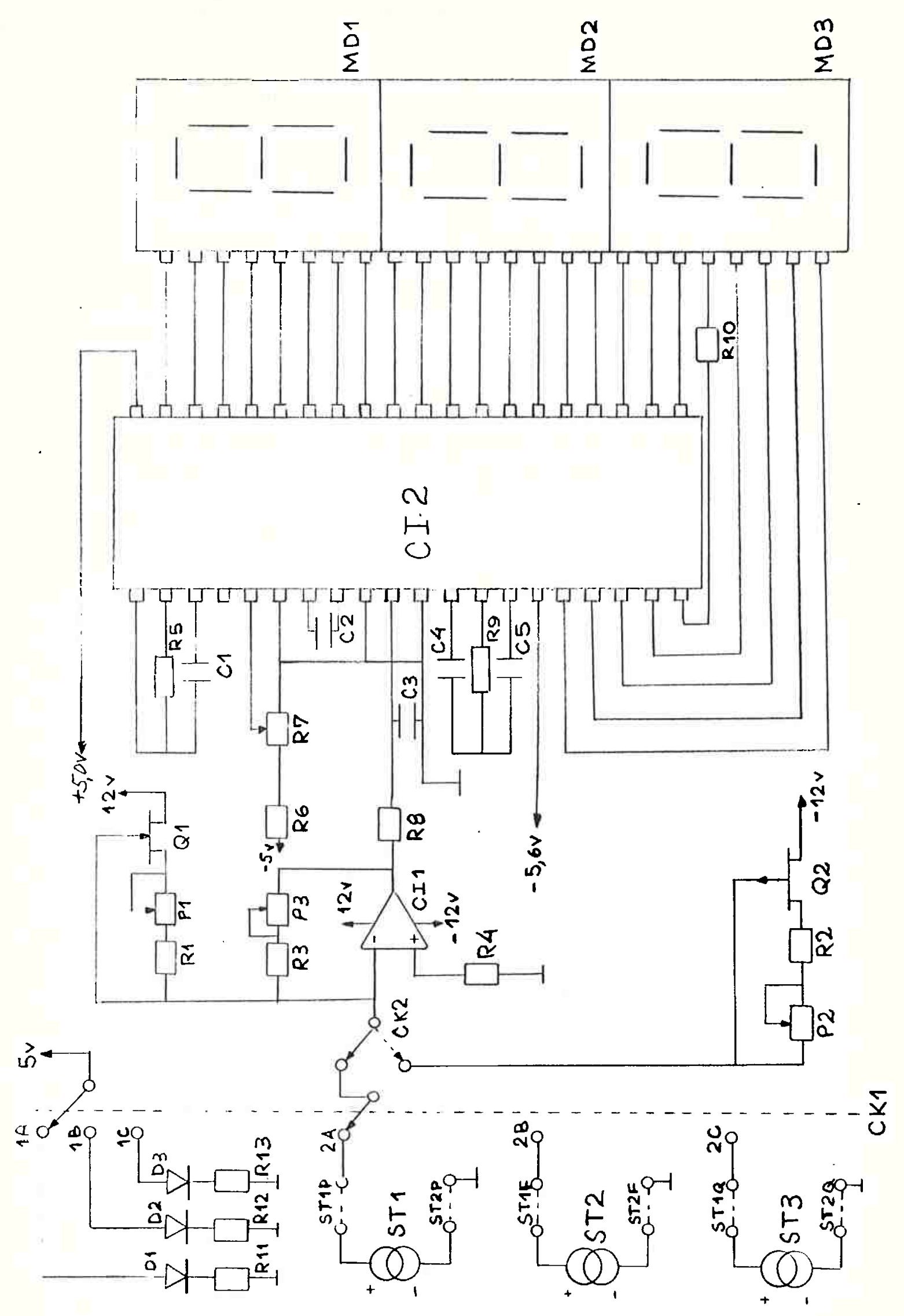

Fig. 4.14. Circuito eletrônico do sub-sistema termométrico. 
te a medida em graus Celsius. 0 amplificador operacional CI1, o resistor R3 e o potenciometro P3 constituem um conversor cor rente-tensão linear, cuja saída corresponde a uma tensão elé trica linearmente proporcional à temperatura em graus Celsius. Esta tensão é medida por um voltímetro composto nelo circuito integrado CI2 associado aos resistores R5 a $R 9$ e dos capacito res C1 e C5. A saída do voltímetro è aplicada diretamente a um indicador decimal de 3 dígitos.

o sub-sistema termométrico incorpora um circuito pa ra fācil e rápida verificação da calibração do medidór, atra vês da chave CK2, do transistor de efeito de campo Q2 do resis tor R2 e do potenciómetro P2. Este conjunto fornece uma corren te constante que ao ser injetada no conversor corrente-tensão, resulta numa leitura de $36.2^{\circ} \mathrm{C}$ no mostrador decimal.

\subsubsection{Sub-sistema temporizador}

O circuito temporizador de anóxia, cujo diagrama é indicado na Fig. 4.15, é constituído basicamente pelos diviso res de frequência CI1 a CI4 e comutadores digitais $\mathrm{CH} 2$ e $\mathrm{CH} 3$ na configuração convencional de um temporizador programável. Re cebe o sinal de $1 \mathrm{~Hz}$ do sub-sistema de base de tempo e após as divisões necessārias o resultado é aplicado aos circuitos inte grados CI9 e CI10 para efetuar a decodificação binäria-decimal e fornecer os niveis de corrente necessärios aos mostradores de cimais MD1 e MD2, os quais indicam a contagem em minutos. As portas lögicas CI5 e CI8 conjuntamente com os transistores Q1 
e Q2, os resistores R1 a R8 e os diodos D1 a D4 possibilitam a realimentação necessária para que o contador interrompa a con tagem no instante em que atinge o valor selecionado pelos comu tadores digitais, enviando ainda um sinal CTAlX para o sub-sis tema de alarmes sonoros. Neste instante, o circuito composto pe lo transistor Q3, os resistores R9 e R10 e os diodos D5 e D6 acio nam intermitantemente a lâmpada incorporada à chave CHl que passa a piscar na frequência de $1 \mathrm{~Hz}$, o mesmo acontecendo com o ponto decima1 do mostrador decimal correspondente à unidade.

O temporizador do anticoagulante è praticamente aná logo ao de anóxia, apenas com a modificação de que a realimen tação incorporada ao circuito reinicia a contagem no instante em que o temporizador atinge o valor selecionado pelos comuta dores digitais (Fig. 4.16). Incluiu-se também um botão CzRAC de zeragem assíncrona e prioritäria no contador, acionado pelo. painel.

As Figs. 4.17 e 4.18 apresentam os diagramas de tem po dos dois temporizadores descritos.

o cronômetro do tempo de perfusão é constituído por um conjunto de divisores de frequência em circuitos integrados e decodificadores-acionadores de três mostradores decimais. A chave que aciona o cronômetro é a mesma que ativa o módulo a terial, razão pela qual o tempo medido corresponde efetivamen te ao tempo de perfusão. o botão CRZCR possibilita a zeragem assíncrona e prioritāria do cronômetro e o ponto decimal do mostrador da unidade pisca em uma frequência de $1 \mathrm{~Hz}$. Os diagra mas de circuitr e de tempo do cronômetro de perfusão estão in dicados nas Figs. 4.19 e 4.20 . 
岁

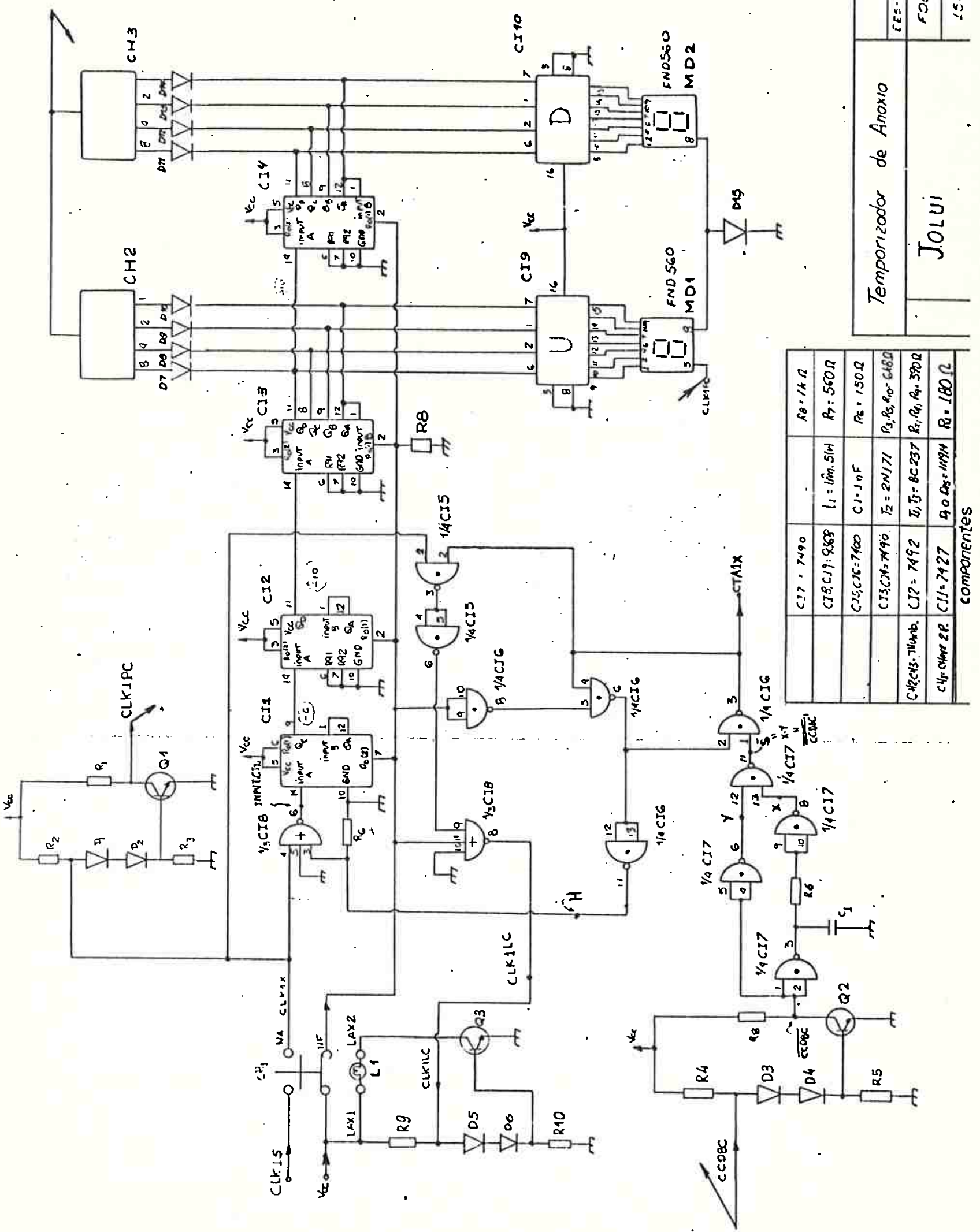

Fig. 4.1b. Circuito do temporizador de anóxia. 


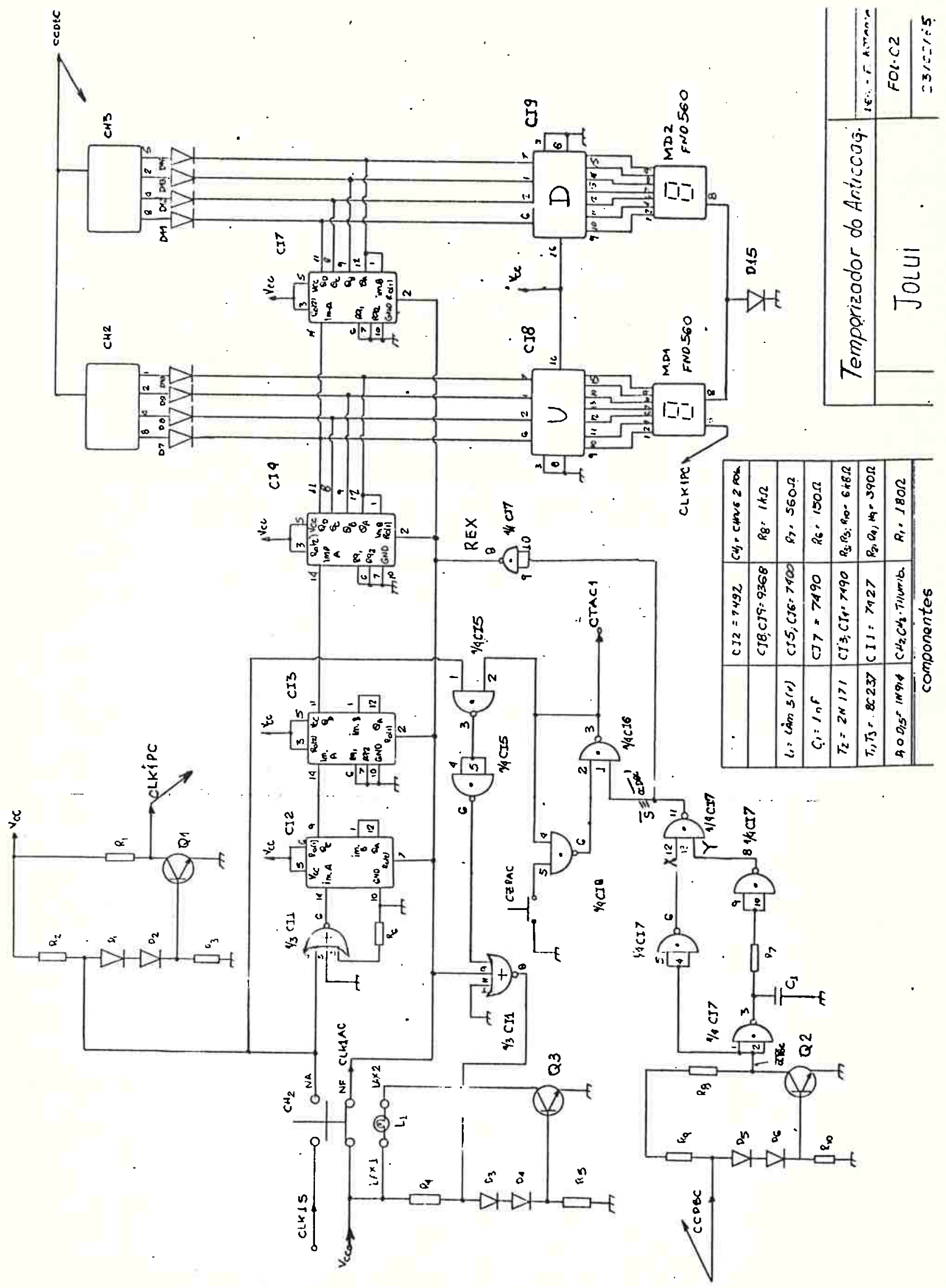

Fig. 4.16. Circuito do temporizador de heparina. 


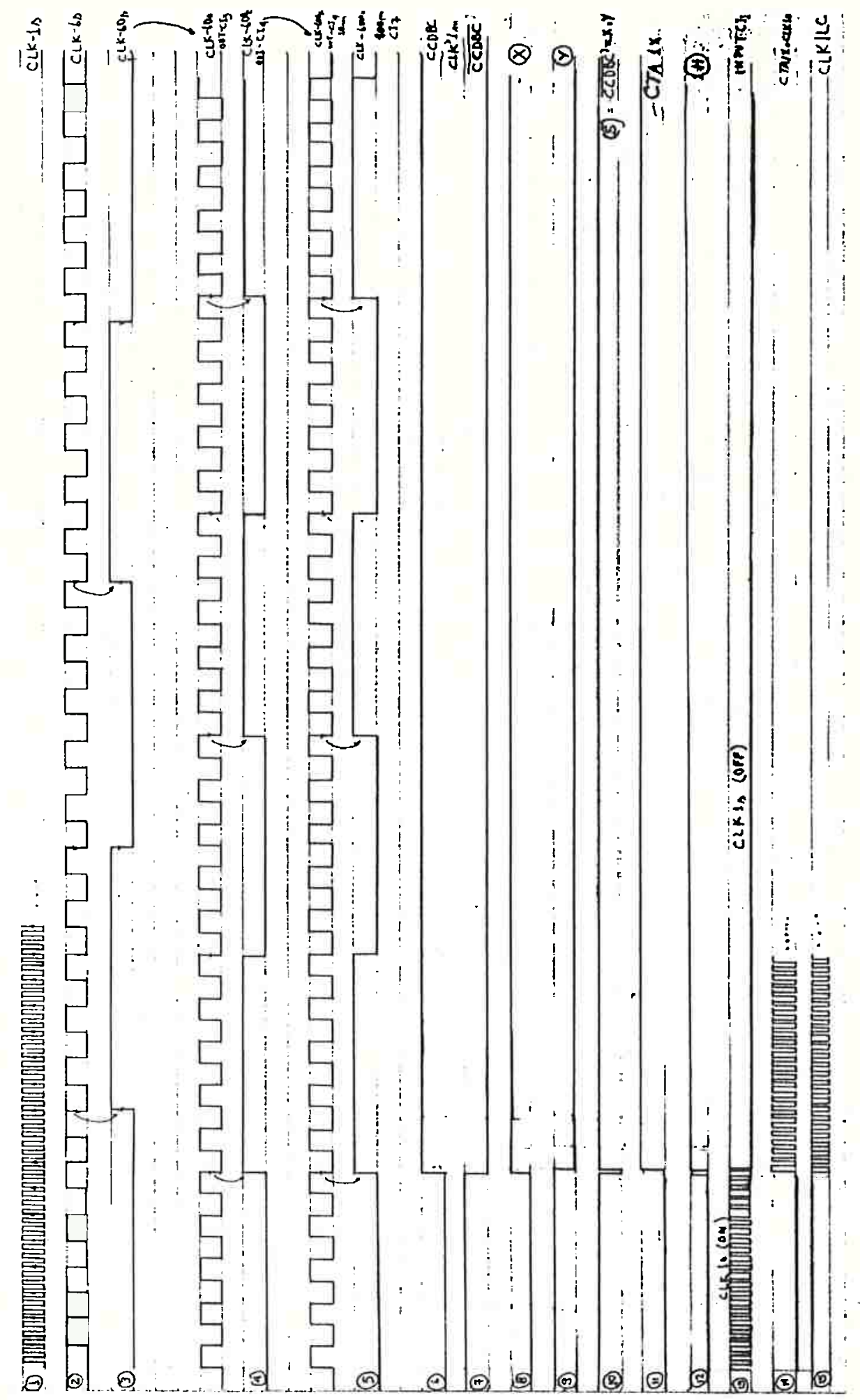

Fig. 4.17. Diagrama de tempo do temporizador de anoxia. 


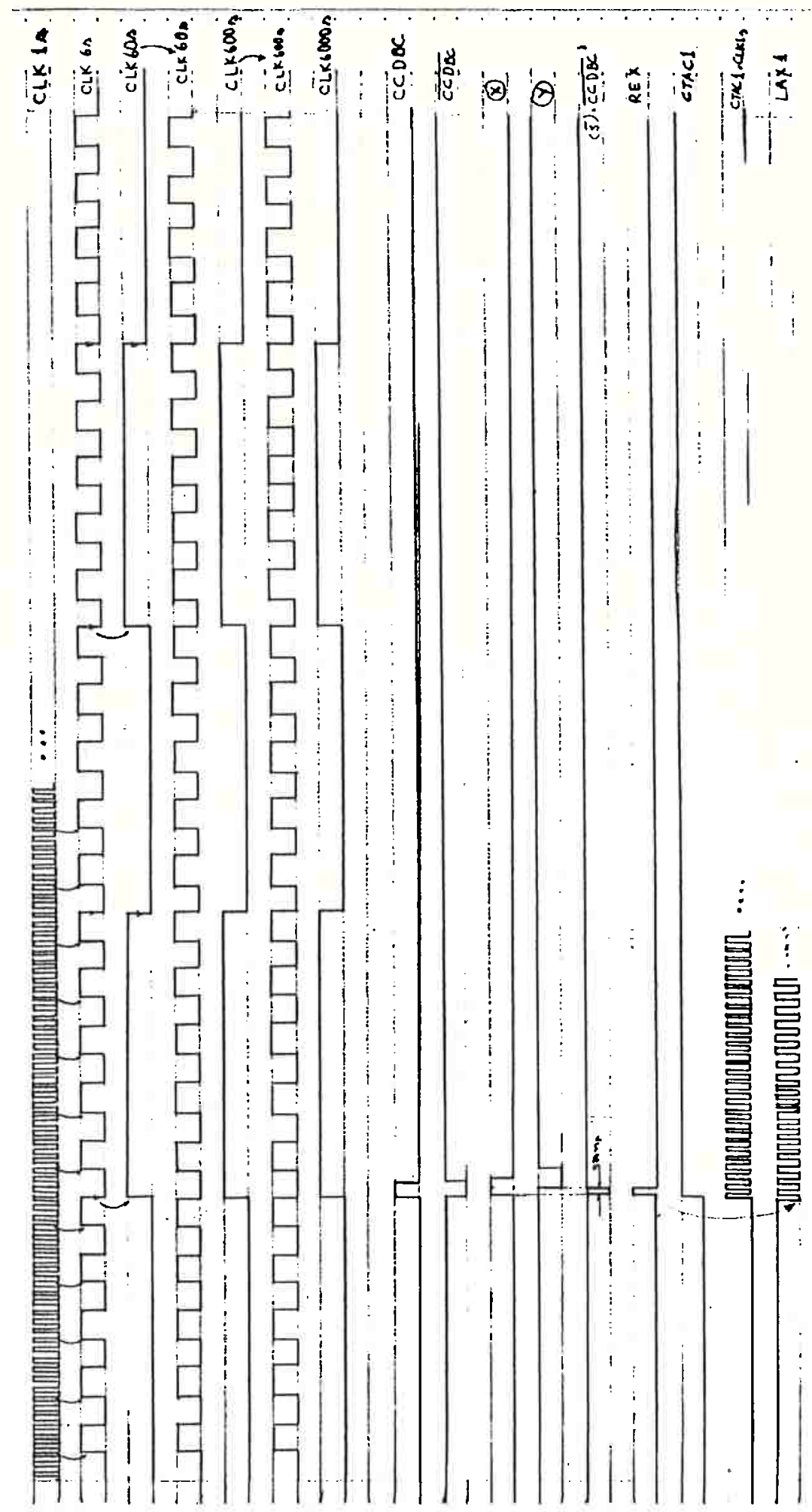

Fig. 4.18. Diagrama de tempo do temporizador de heparina. 

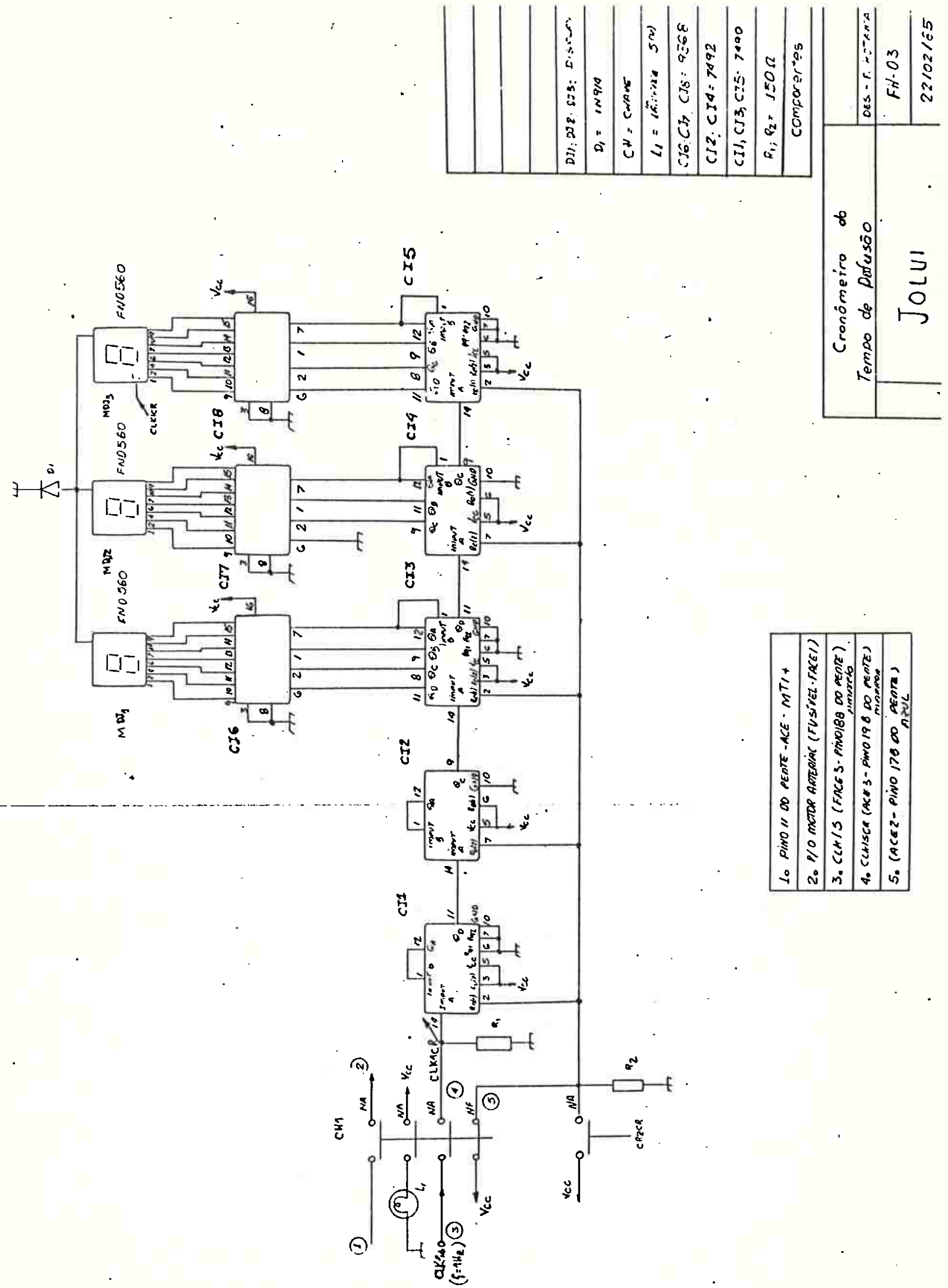

Fig. 4.19. Circuito do cronômetro de perfusão. 

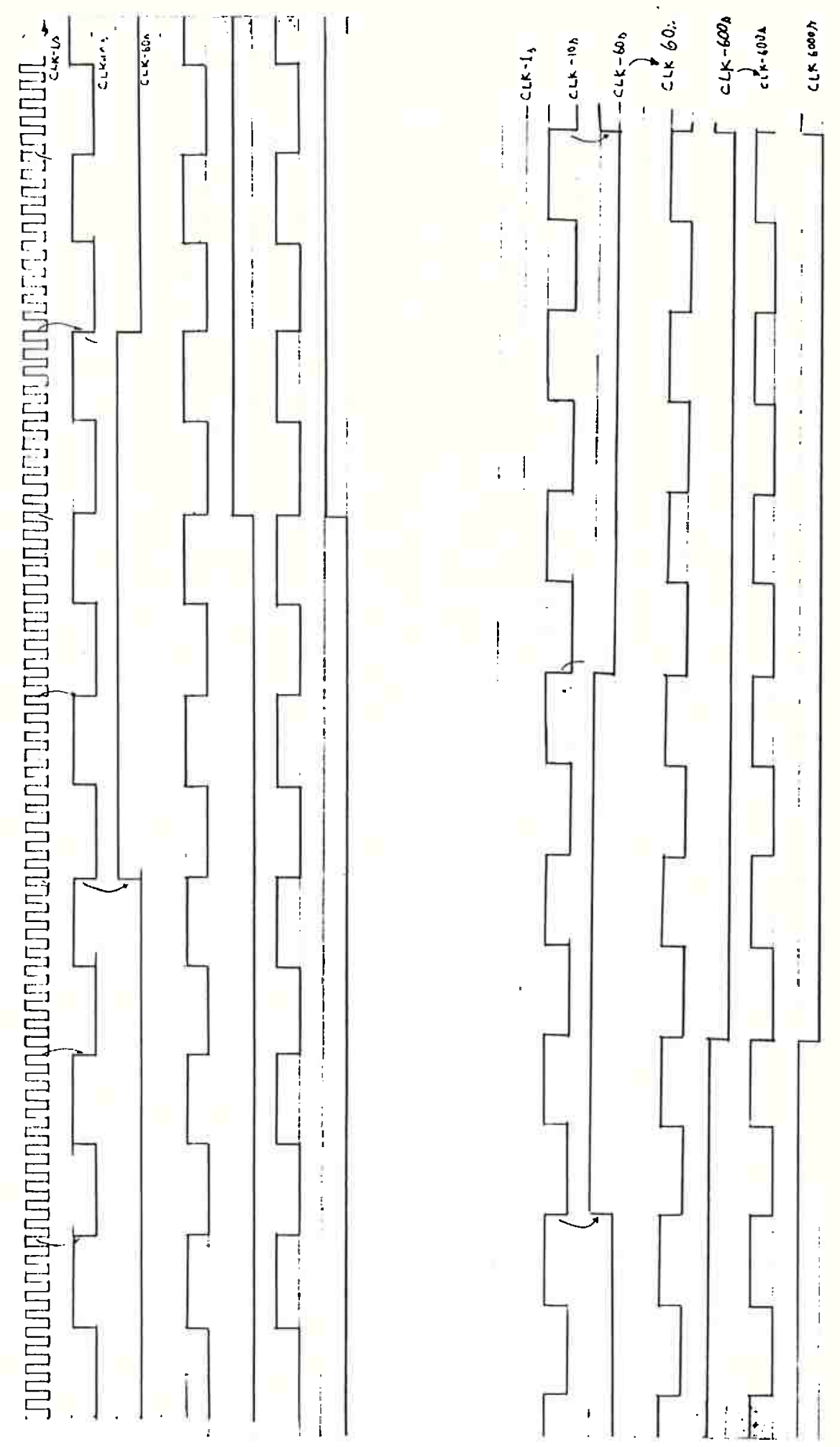

Fig. 4.20. Diagrama de tempo do cronômetro de perfusão. 
4.2.1.7. Sub-sistema de alarmes sonoros.

O sub-sistema de alarmes representado na Fig. 4.21 recebe os sinais CLK1X, CTA1X, CLK1AC e CTAC1 dos temporiza dores de anöxia e heparina, assim como os sinais ALNHQ e ALNHF dos circuitos detetores de nível normal de água nos reservató rios do sub-sistema hidráulico e os sinais SALVOX e SALQOX do detetor de níveis de sangue no oxigenador. Esses sinais atuam sobre multivibradores astáveis em circuitos integrados os quais acionam alto-falantes que emitem tons indicativos dos vários alarmes sonoros necessärios: Os tons são diferentes em cada sec ção e as portas 10 gicas do circuito integrado CI1 inibem ou ha bilitam os astáveis correspondentes aos alarmes dos temporiza dores resultando em tons intermitentes.

4.2.1.8. Sub-sistema de bases de tempo.

O sub-sistema de bases de tempo contém dois gerado res de ondas retangulares controlados a quartio, bem como cir cuitos integrados divisores de frequência de maneira a forne cer todos os sinais de relógios necessários ao equipamento, con forme a Fig. 4.22. A Fig. 4.23 apresenta o correspondente dia grama de tempo.

4.2.1.9. Sub-sistema de Teste

o sub-sistema de teste è constituído por um conjunto 


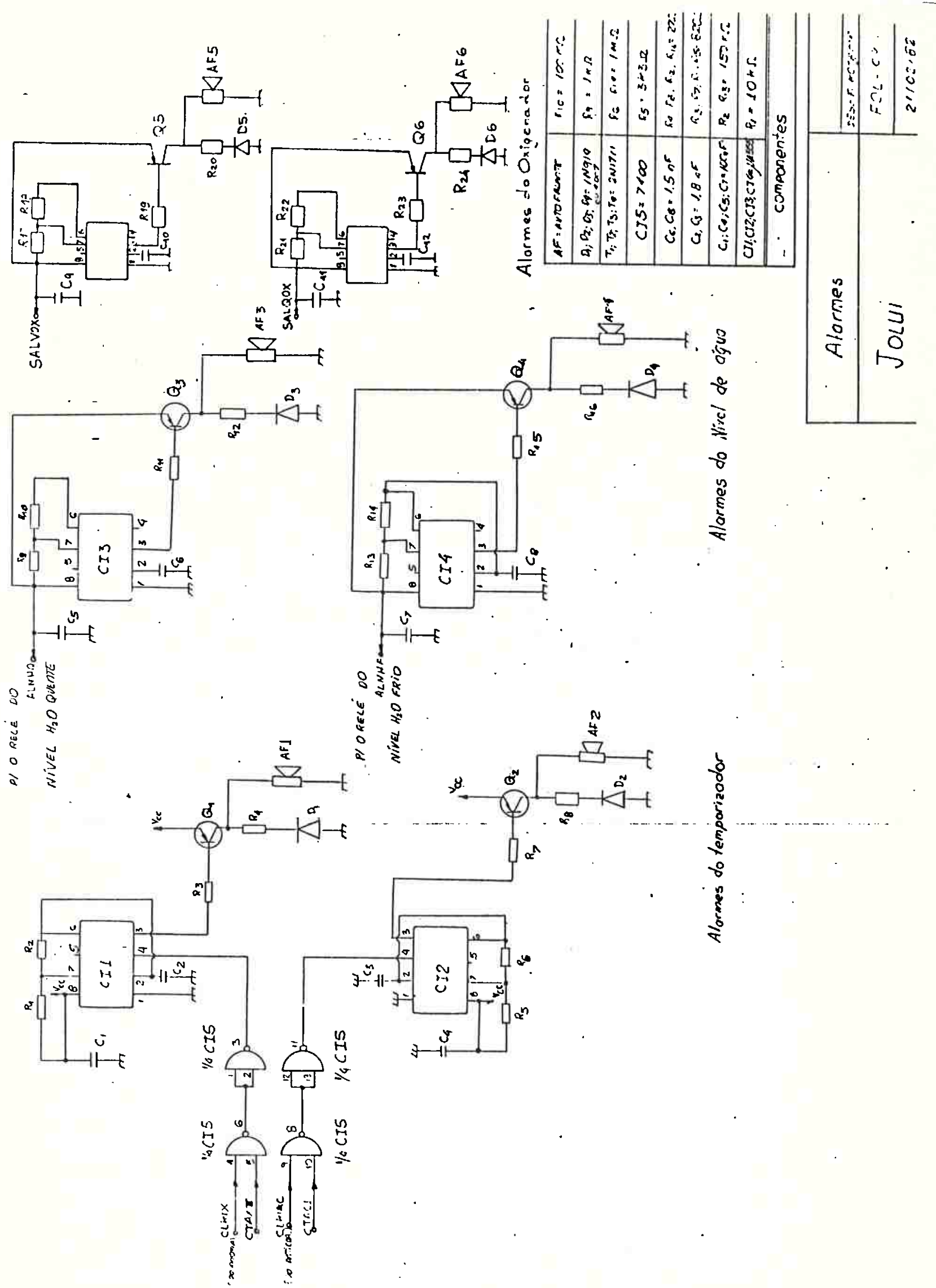

Fig. 4.21. Circuito do sub-sistema de alar mes sonoros. 


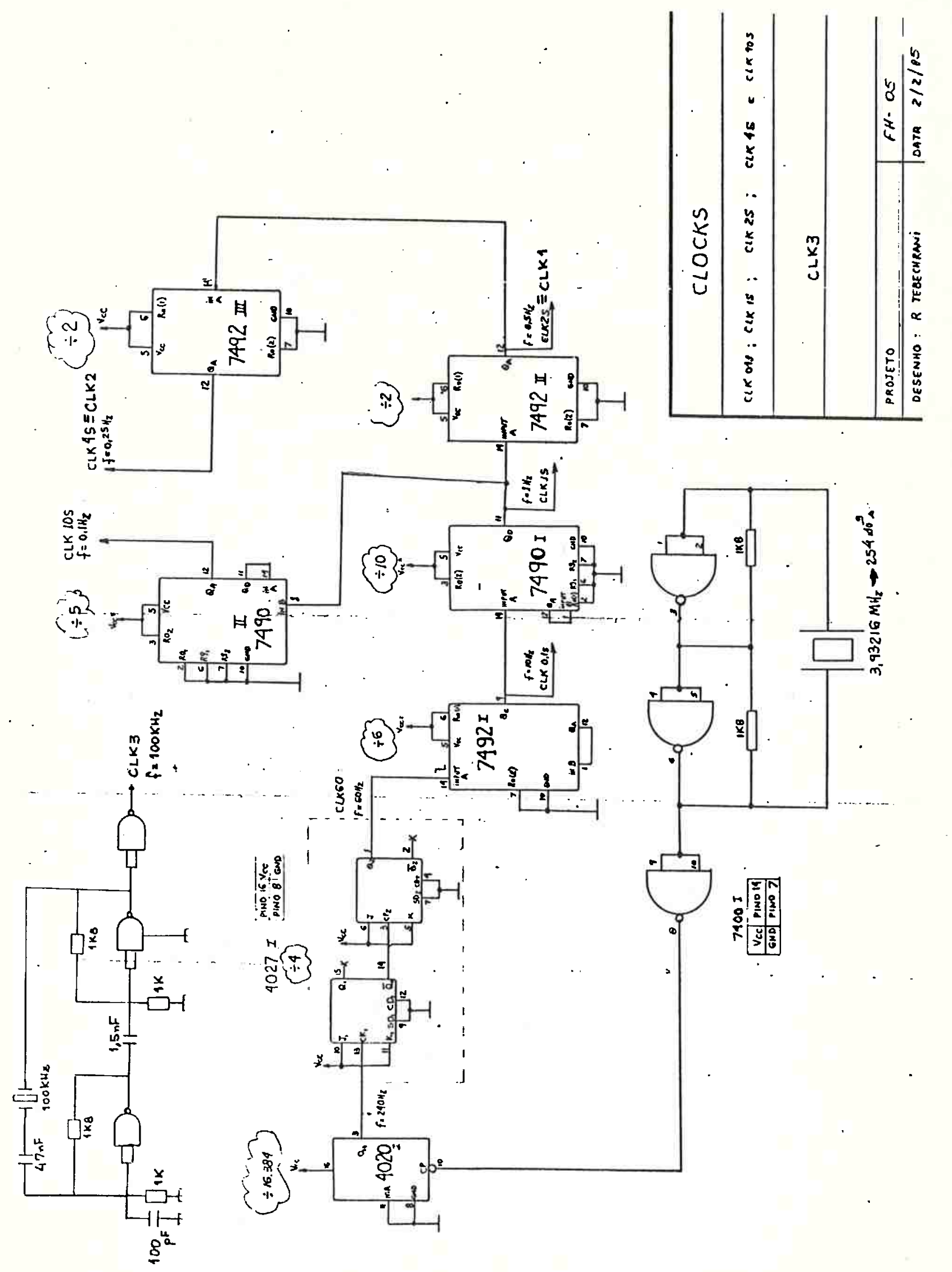

Fig. 4.22. Circuito do sub-sistema de bases de tempo. 


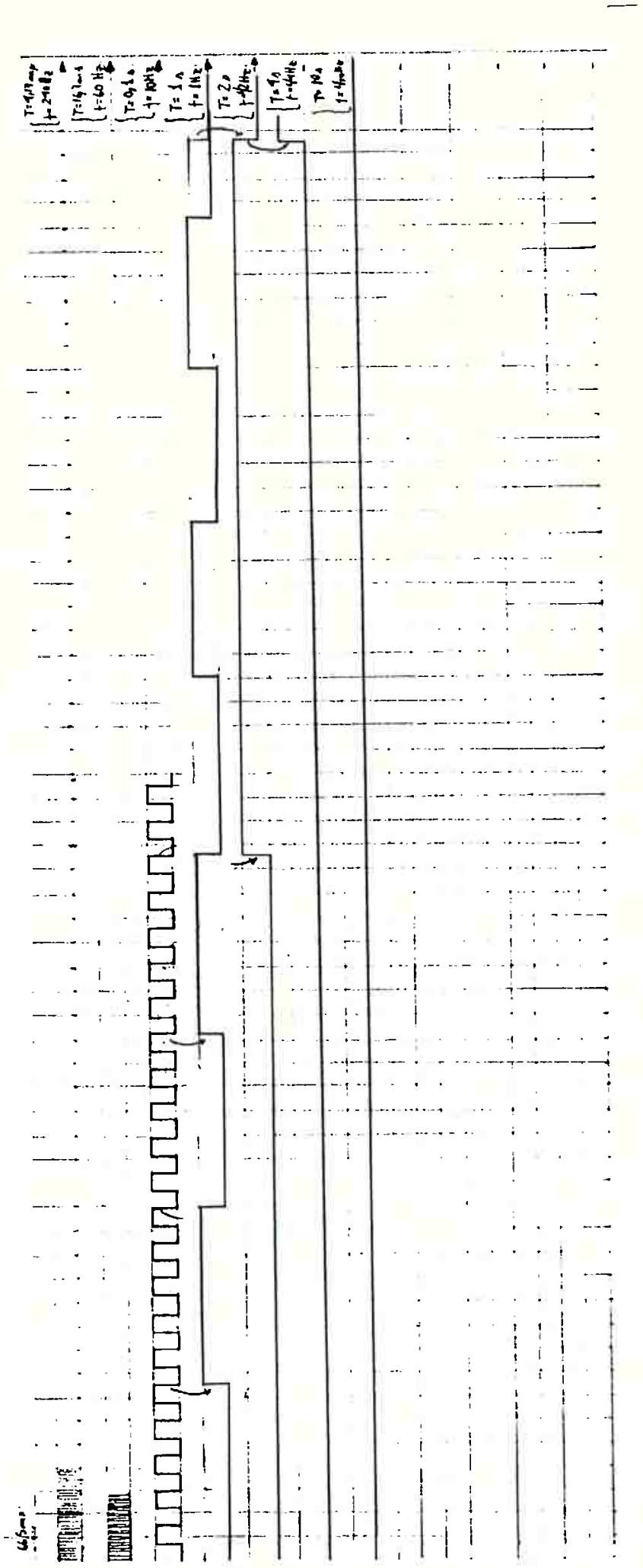

Fig. 4.23. Diagrama de tempo do sub-sistema de base de tempo. 
de relés energizāveis por um botão monoestāvel de teste BTl exis tente no painel (Fig. 4.24). Os vários contactos dos relés, quan do acionados, ativam os diodos emissores de luz, os mostradores decimais e as lâmpadas do painel. Tambêm alimentam as duas lâm padas para iluminação do oxigenador e acionam os alarmes do Sistema.

4.2.1.10. Sub-sistema de àimentação

O sub-sistema de alimentação é constituído pelos dois transformadores de rede, disjuntores, interruptores, proteto res de sobre-tensão e sobre-corrente, circuitos retificadores, filtros e reguladores que fornecem as tensões alternadas e con tínuas necessārias às vārias partes do equipamento. A Fig.4.25 apresenta o circuito correspondente.

4.2.1.11. Sub-sistema de emergência

O sub-sistema de emergência indicado na Fig. $4.26 \bar{e}$ constituído por um circuito convencional carregador de bateria com instrumentos de medição indicativos da tensão terminal da fonte e da corrente de carga. O sensor de linha, com acionamen to automātico do relé, permite a comutação da energização do Sistema de Circulação Extracorpörea da rede elétrica para este gerador emergencial. Duas lâmpadas para iluminação do oxigena dor são incorporadas para uso nesta condição. 


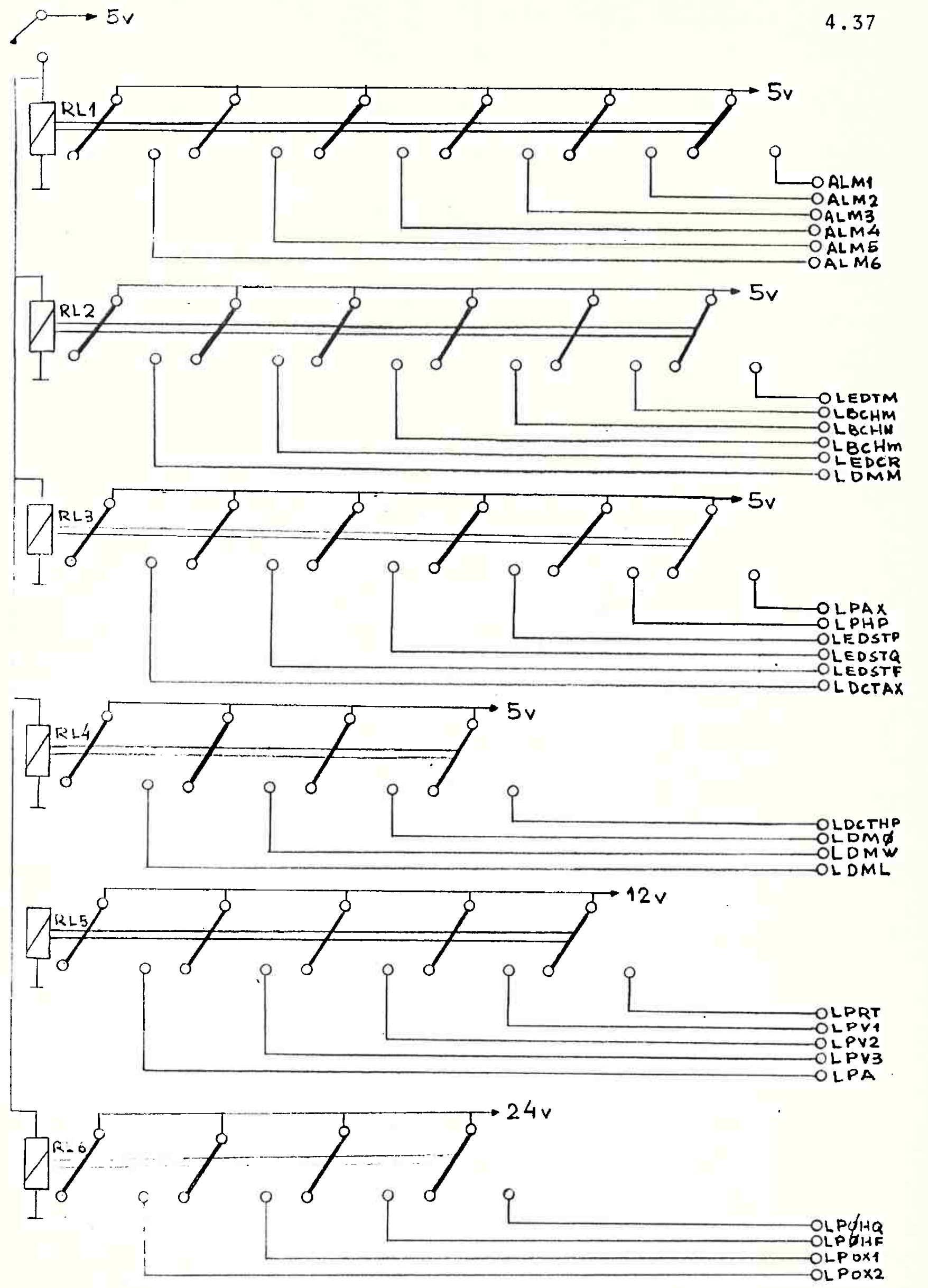

Fig. 4.24. Circuito do sub-sistema de teste. 


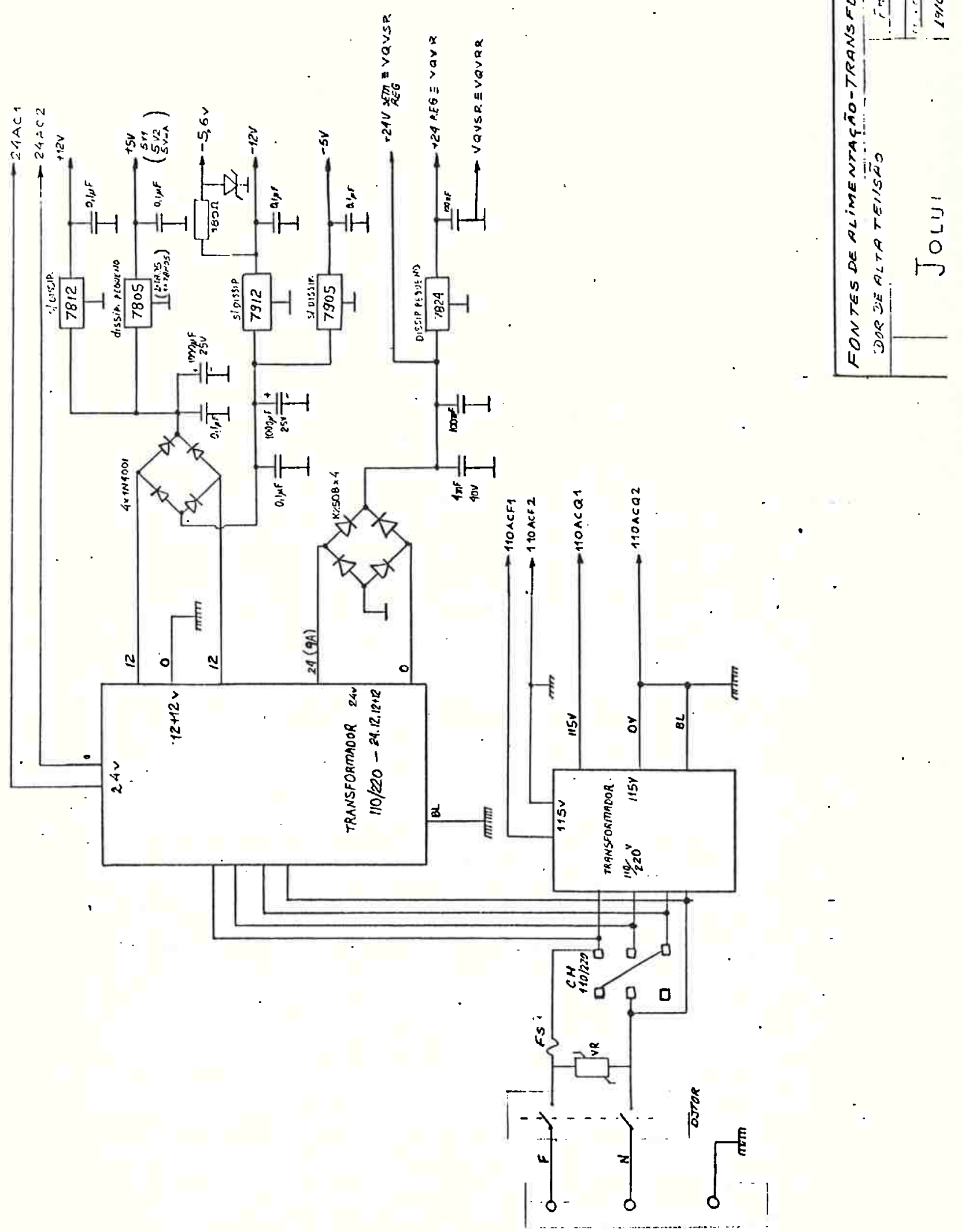

Fig. 4.25. Circuito do sub-sistema de alimentação. 


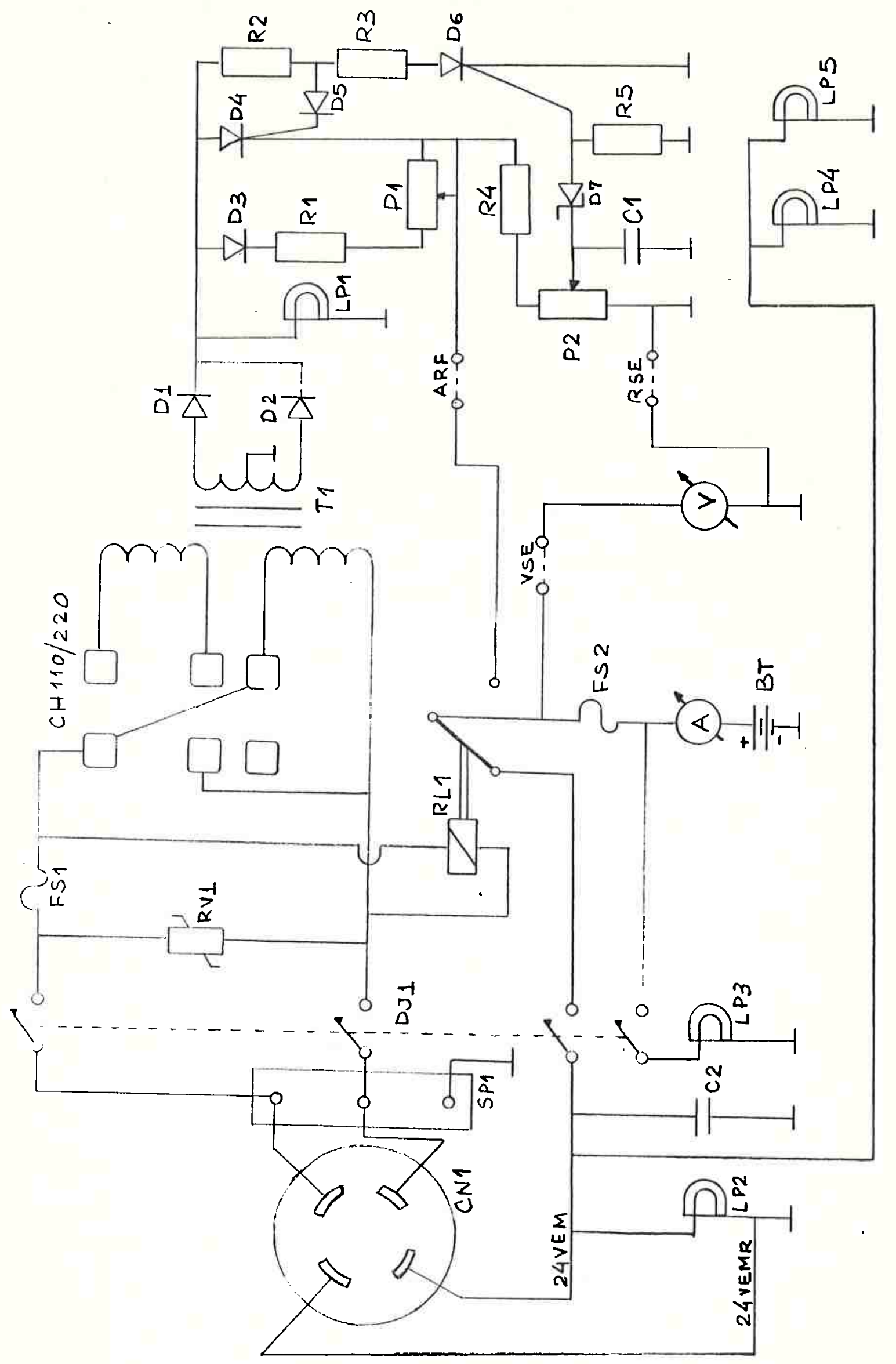

Fig. 4.26. Circuito do sub-sistema de emergência . 
+.2.2. Partes Mecânicas

As principais partes mecânicas do Sistema de Circula çāo Extracorpórea correspondem às bombas sanguíneas, constituí das por uma carcaça de aluminio em forma de $U$ onde se apoia a tubulação plästica. Um orifício circular em sua porção central possibilita o acoplamento do rotor da bomba com o eixo do redu tor incorporado ao motor elétrico que o aciona. A tubulação é confiormada por guias e suportes apropriados. Detalhes referen tes à bomba sanguínea foram fornecidos no Capitulo III, comple mentados com o Apêndice B. Tanto os módulos venosos como o a $\underline{r}$ terial sāo encaixāveis para rạpida rep̣osição, se necessārio.

Na Fig. $4.27 \overrightarrow{\mathrm{e}}$ apresentado o painel fronta1. Para simplicidade de manutenção este painel bascula por dobradiça co locada em sua parte inferior.

4.2.3. Refrigeração

O Sistema de Circulação Extracorpórea é resfriado por ventilação forçada, seguindo a filosofia de projeto de res friamento de equipamentos eletrônicos por mapeamento (Zuanel1a e Perez, 1986).

4.2.4. Revestimento

o revestimento da caixa do Sistema de Circulação Ex 


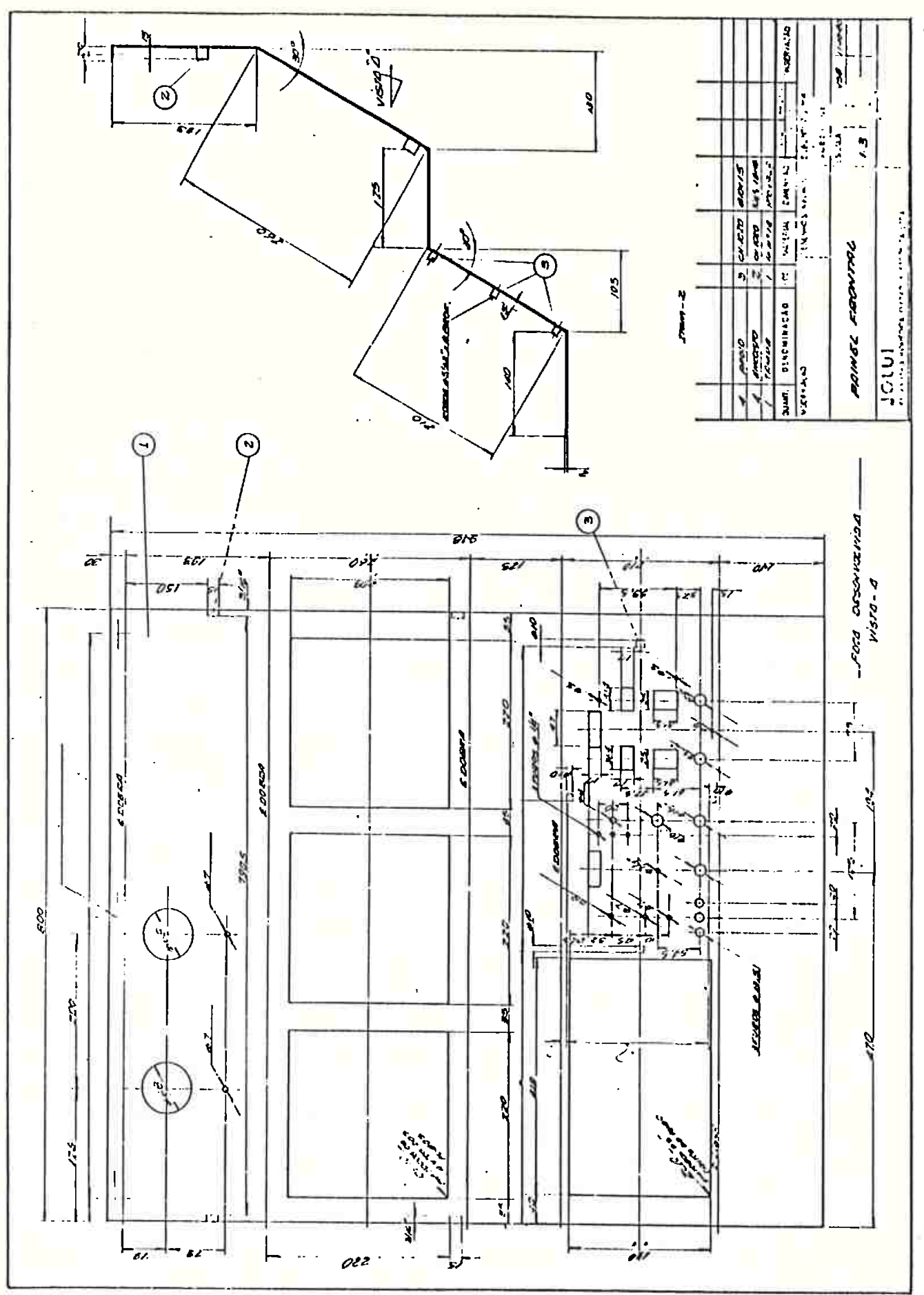

Fig. 4.27. Painel frontal do Sistema de Circulação Extracorpórea. 
tracorpoorea foi feito pela tẻcnica de projeção eletrostätica de pigmentos. Esta técnica oferece uma solução eficiente para problemas devidos à corrosão química e atmosférića, possibil tando ainda proteçāo a abrasão e impacto, isolação elétrica conveniente e acabamento perfeito. As propriedades físicas e químicas do material de revestimento foram criteriosamente ana lisadas em relação aos aspectos decorrentes da particular apli cação do Sistema.

Devido à sua característica móvel, o equipamento foi protegido contra impactos, atravës de um friso auto-adesivo contendo uma guarnição de plástico e borracha esponja.

4.3. Ensaios Realizados no Sistema de Circulação Extracorpórea

Os ensaios realizados foram de tipo, ou seja, ef tuados sobre o equipamento pronto. Salvo menção em conträrio, foram realizados uma unica vez em um exemplar representativo.Ape nas os principais ensaios são relatados e se basearam nas pres crições estabelecidas a seguir. Inicialmente são apresentados os ensaios para fins de segurança e posteriormente os ensaios funcionais.

4.3.1. Condições Ambientais dos Ensaios

Para ensaios correspondentes ao uso normal, as con dições ambientais simularam as condiçōes normais de utiliza 
ção, ou seja,

- temperatura ambiente entre $15^{\circ} \mathrm{C}$ e $35^{\circ} \mathrm{C}$.

- umidade relativa entre $45 \%$ e $75 \%$

- pressão atmosférica entre $85 \mathrm{KPa}$ e $106 \mathrm{KPa}$.

Preferencialmente, procurou-se realizar as medições

nas condições atmosfëricas especificadas como tipo C (IEC, P $\underline{u}$ b1 icação 601-1), ou seja,

Temperatura $\left({ }^{\circ} \mathrm{C}\right): 27 \pm 2{ }^{\circ} \mathrm{C}$

Umidade relativa: $65 \pm 5 \%$

O equipamento foi protegido contra correntes de ar ou outras condições que pudessem afetar a validade do prōprio ensaio.

Para os ensaios correspondentes a tratamento de pre condicionamento à umidade, em estado estacionärio, foram esta belecidas as seguintes condições:

a) O equipamento e partes do equipamento foram ins talados sem as coberturas utilizadas durante o transporte ou armazenamento e as partes que podem ser removidas sem o uso de ferramenta foram retiradas e submetidas a tratamento simul tâneo com a parte principal. Tampas de acesso que podem ser abertas ou removidas sem uso de ferramenta foram abertas ou retiradas, correspondentemente.

b) O tratamento foi realizado em câmara ümida con tendo ar com umidade relativa de $93 \pm 2 \%$. A temperatura do ar na câmara em todos os locais onde o equipamento pudesse ser posicionado foi mantida dentro de $1^{\circ} \mathrm{C}$ de qualquer valor conve 
niente $\mathrm{T}$ na faixa de $+20^{\circ} \mathrm{C}$ a $+30^{\circ} \mathrm{C}$. Antes de ser colocado na câmara ümida, o equipamento foi aquecido a uma temperatura en tre $\mathrm{T}$ e $\mathrm{T}+4^{\circ} \mathrm{C}$ e mantido nessa temperatura no mínimo por 4 ho ras, antes do tratamento à umidade. o equipamento foi então mantido na câmara durante 168 horas ininterruptas, sendo poste riormente secado durante 12 horas à temperatura de $30 \pm 2^{\circ} \mathrm{C}$. No vamente foi montado e sujeito aos ensaios necessários.

4.3.2. Condições de Alimentação E1étrica

Os circuitos de alimentação utilizados nas médições elëtricas foram os indicados nas Figs. $4.28,4.29$ e 4.30 .

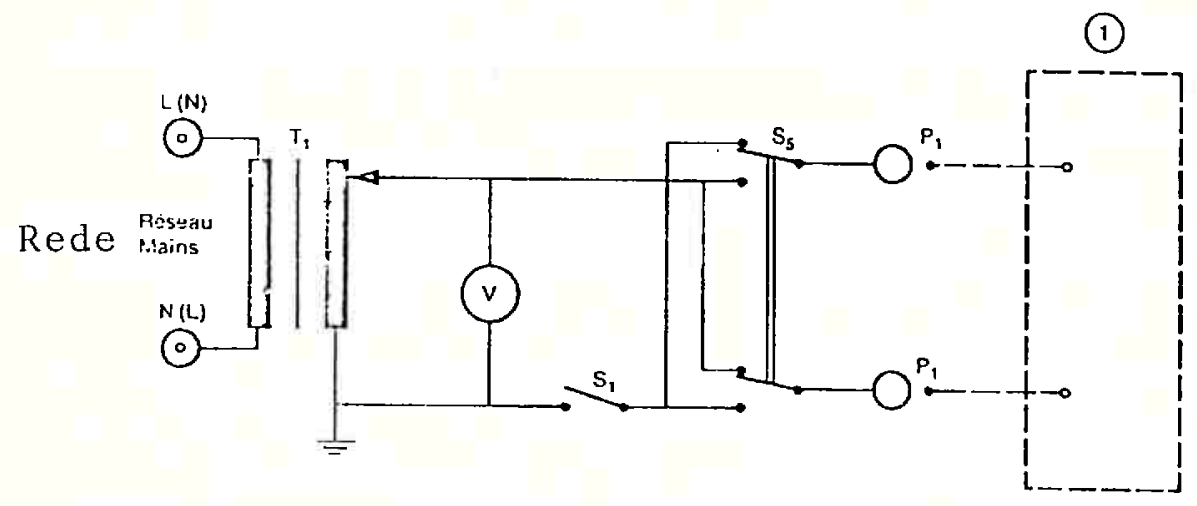

1- Equipamento

Fig. 4.28. Circuito de alimentação para medição, com um lado da rede de alimentação aproximadamente ao potencial de terra. Reproduzido da Publicação IEC-601-1. 
(1)

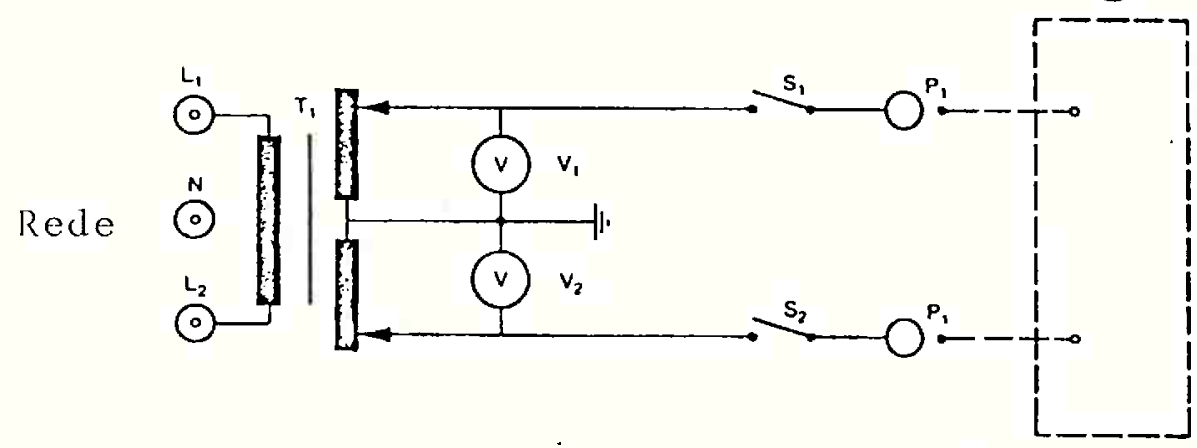

1 - Equipamento

Fig. 4.29. Circuito de alimentação para medição, com uma rede de alimentação aproximadamente simétrica em relação à terra. Reproduzido da Publicação IEC.601-1.

(2)

(1)

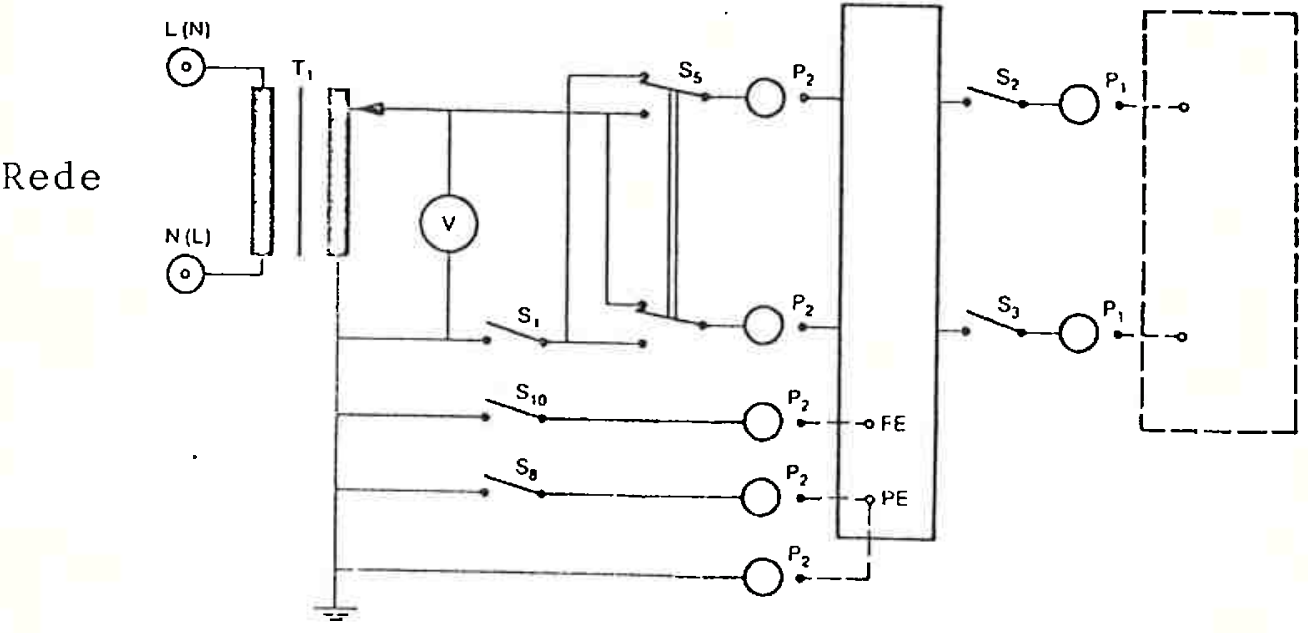

1 - Equipamento

2 - Fonte de Alimentação Específica

FE - Terminal de Aterramento Funcional

PE - Terminal de Aterramento para Proteção

Fig. 4.30. Circuito de alimentação para medição, com uma fonte de alimentação monofásica especificada para equipamento de Classe I. Reproduzido da Publicação IEC . 601-1. 
As tensões de alimentação corresponderam a $110 \%$ do valor declarado das possíveis tensões de alimentação (110V e $220 \mathrm{~V})$ com flutuações inferiores a $2 \%$ e com frequência entre 59 e $61 \mathrm{~Hz}$.

0 equipamento foi conectado ao circuito de alimenta ção atravês de um cabo do mesmo tipo normalmente usado e com $3 m$ de comprimento, sendo posicionado tão longe quanto possível de fios de alimentação não blindados. o cabo do paciente, para medida de sua temperatura, foi colocado sobre uma superfície isolante com constante dielëtrica praticamente unitäria e 200 cm acima de uma superfície condutiva aterrada.

\subsubsection{Ensaios de Correntes de Fuga.}

O dispositivo usado na medição das correntes de fuga é apresentado na Fig. 4.31. Em alguns ensaios usou-se um osci loscópio para verificação da forma de onda e da frequência das värias correntes medidas. A precisão do instrumento de medição foi sempre melhor do que 5\%.

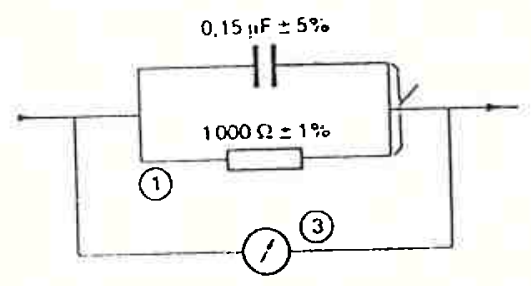

(2)

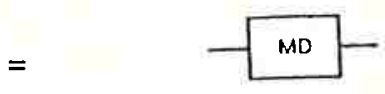

1 - Resistência de Medição

2 - Impedância de Medição

3 - Osciloscópio ou Milivoltímetro de Valor Eficaz Verdadeiro

MD - Dispositivo de Medição

Fig. 4.3I. Dispositivo de medição. Reproduzido da Publicação IEC.601-1. 
Os circuitos de medição das vãrias correntes de fuga são indicados nas Figs. 4.32, 4.33,4.34,4.35,4.36,4.37 e 4.38 .

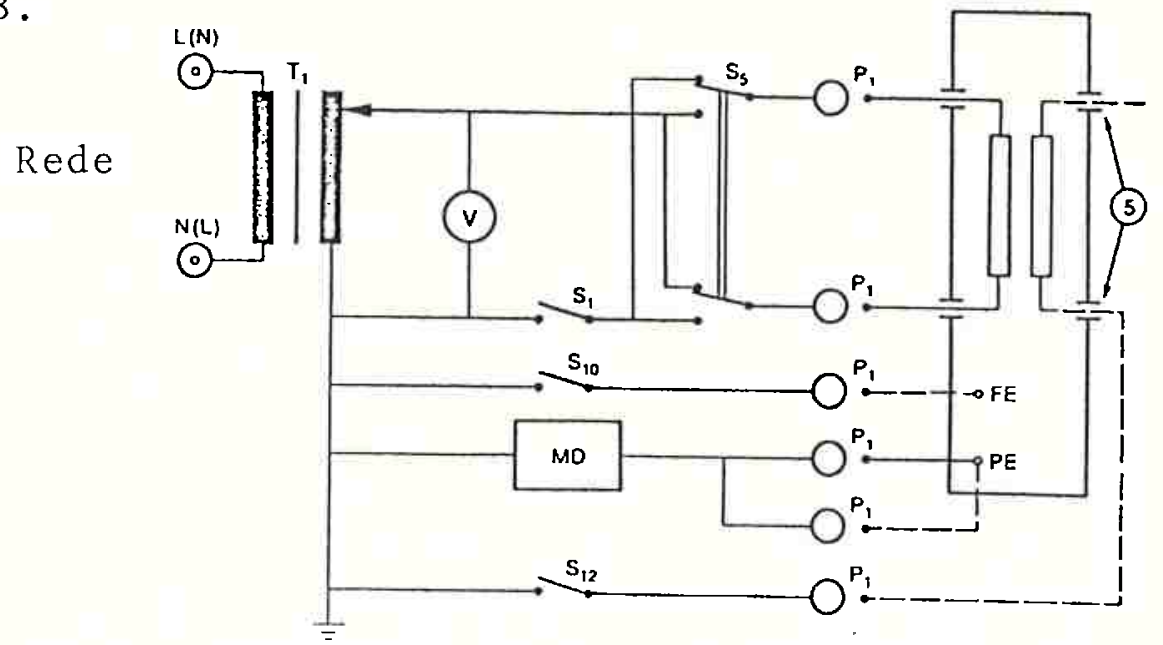

5 - Parte Aplicada

FE - Terminal de Aterramento Funcional

PE - Terminal de Aterramento para Proteção

Fig. 4.32. Circuito de medição para a corrente de fuga para terra de um equipamento de Classe I com ou sem parte aplicada. Reproduzido da Publicaşão IEC.601-1.

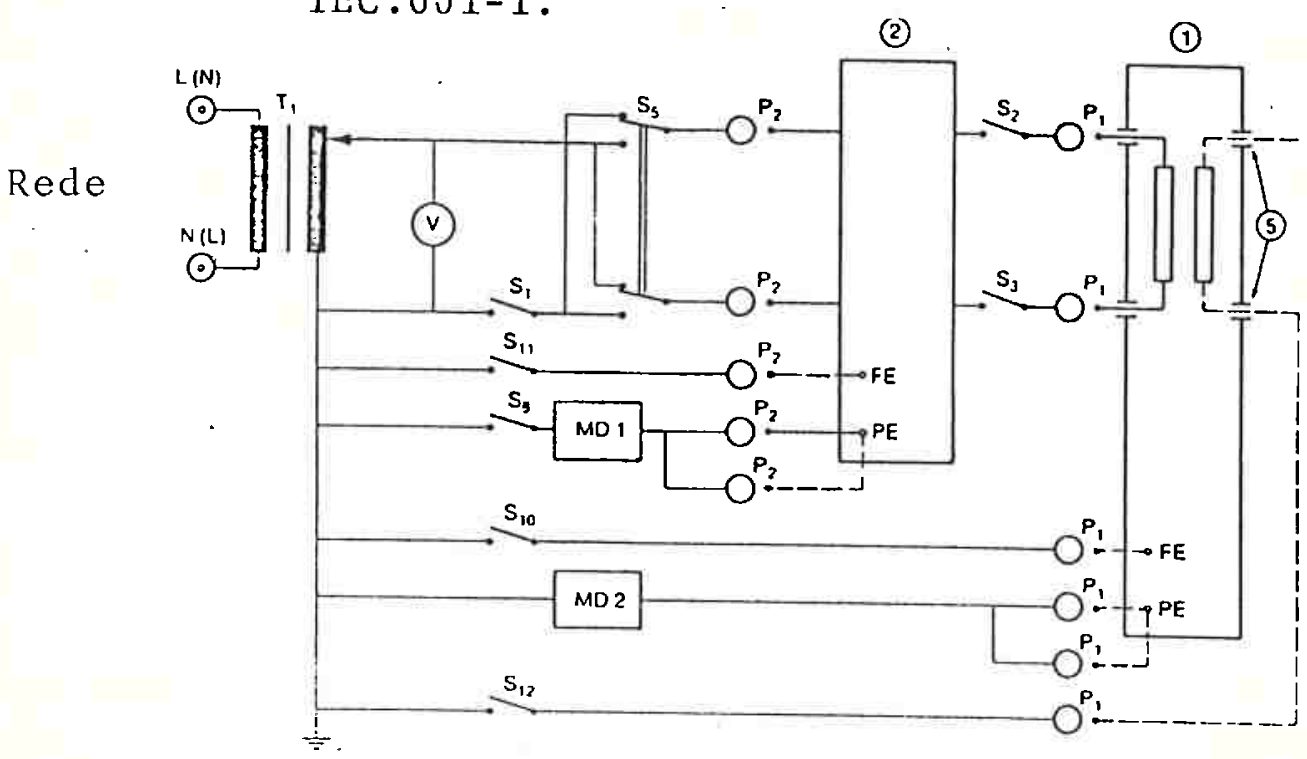

Fig. 4.33. Circuito de medição para a corrente de fuga para terra de um equipamento de Classe I com ou sem parte aplicada, especificado para uso em uma rede conforme a Fig. 4.30. Reproduzi do da Publicação IEC.601-1. 


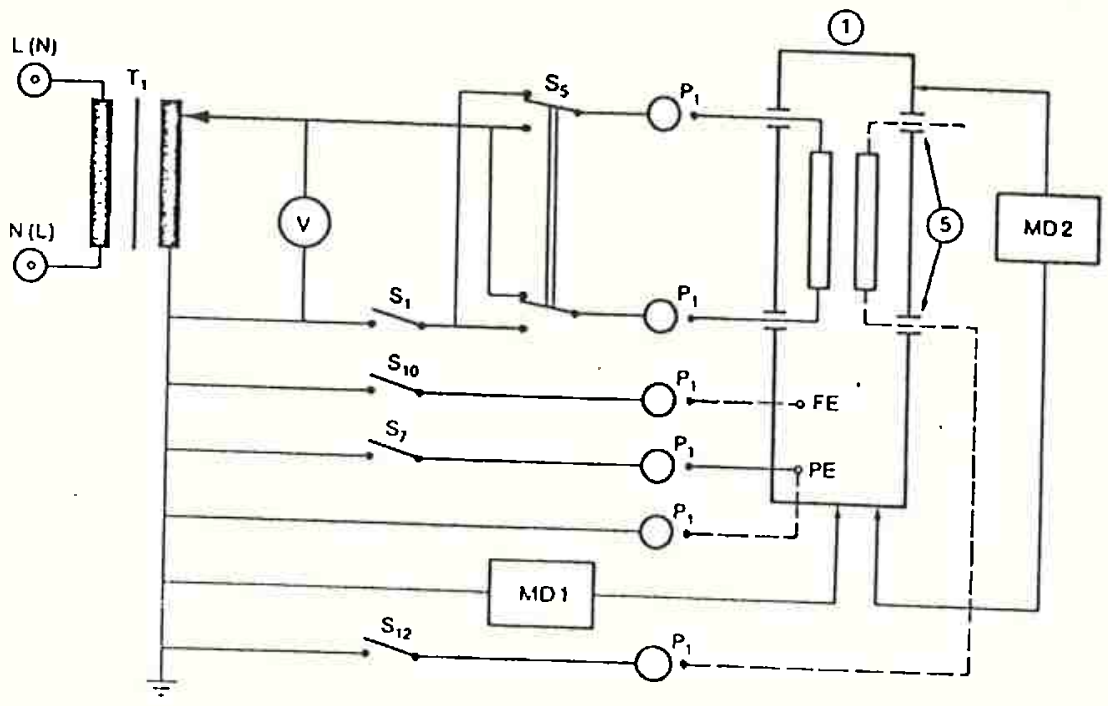

Fig. 4.34. Circuito de medição para a corrente de fú ga através do invölucro de um equipamento de Classe I. Reproduzido da Publicação IEC.601-1.

(2)

(1)

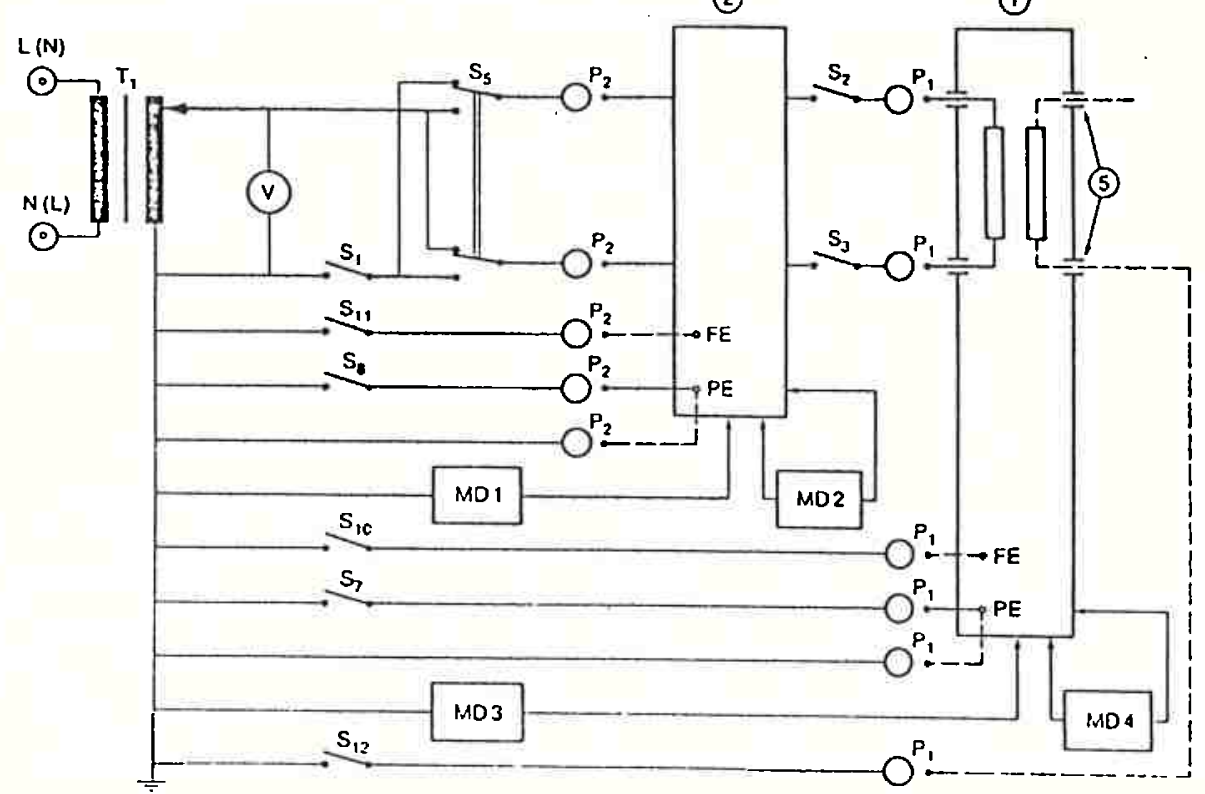

Fig. 4.35. Circuito de medição para a corrente de fu ga através do invólucro de um equipamento de Classe I com ou sem parte aplicada, es Fig. 4.30. Reproduzido da Publicação IEC. $601-1$. 
(1)

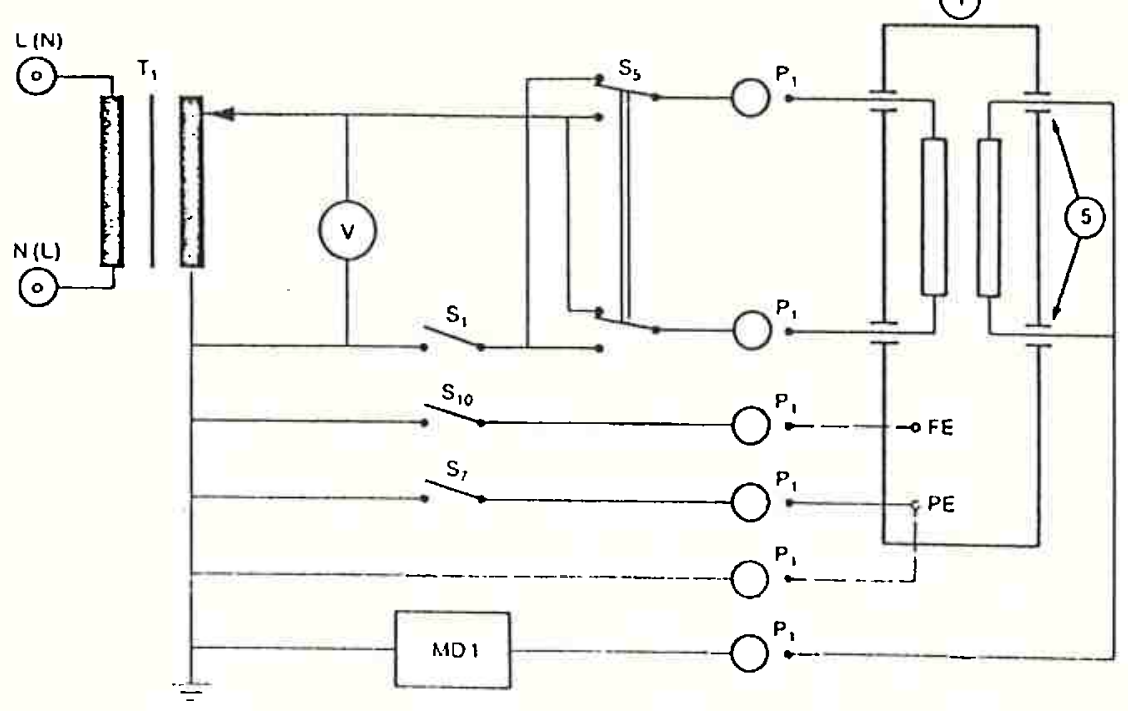

Fig. 4.36. Circuito de medição para a corrente de fu ga através do paciente, da parte aplicada para terra, de equipamento de Classe I. Keproduzido da Publicação IEC.601-1.

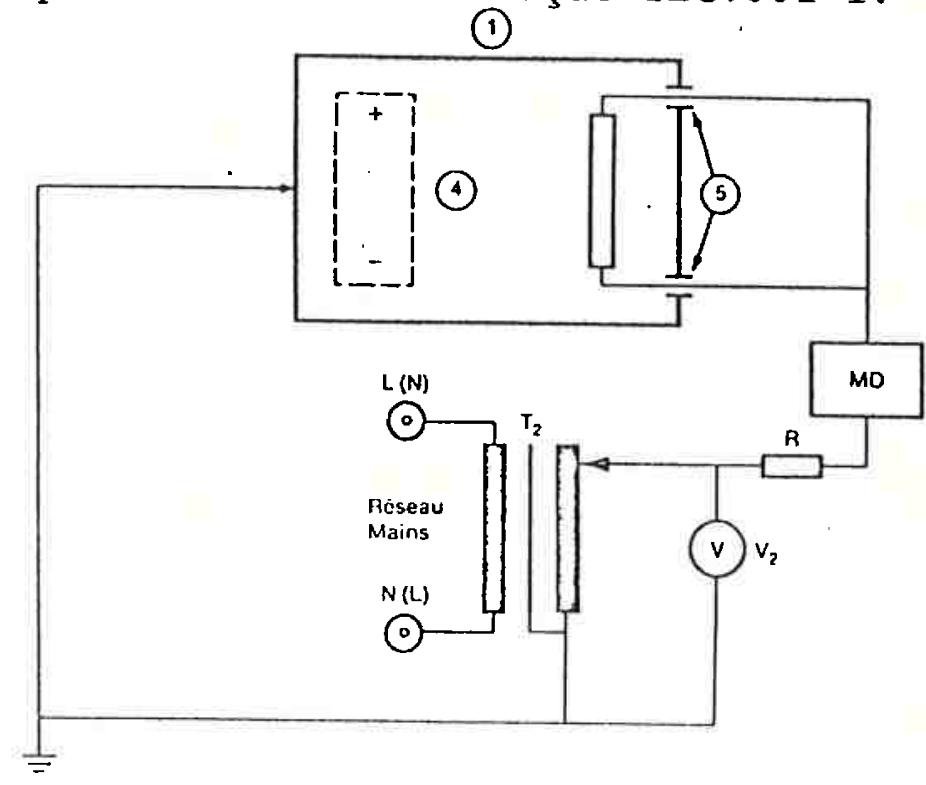

4 - Fonte de Alimentação Elêtrica Interna

Fig. 4.37. Circuito de medição para a corrente de fuga através do paciente, via uma parte aplicada isolada tipo $F$ (flutuante) para o corpo do equipamento possuidor de fonte de alimentação elétrica interna. Reproduzido da Publicação IEC.601-1. 
(1)

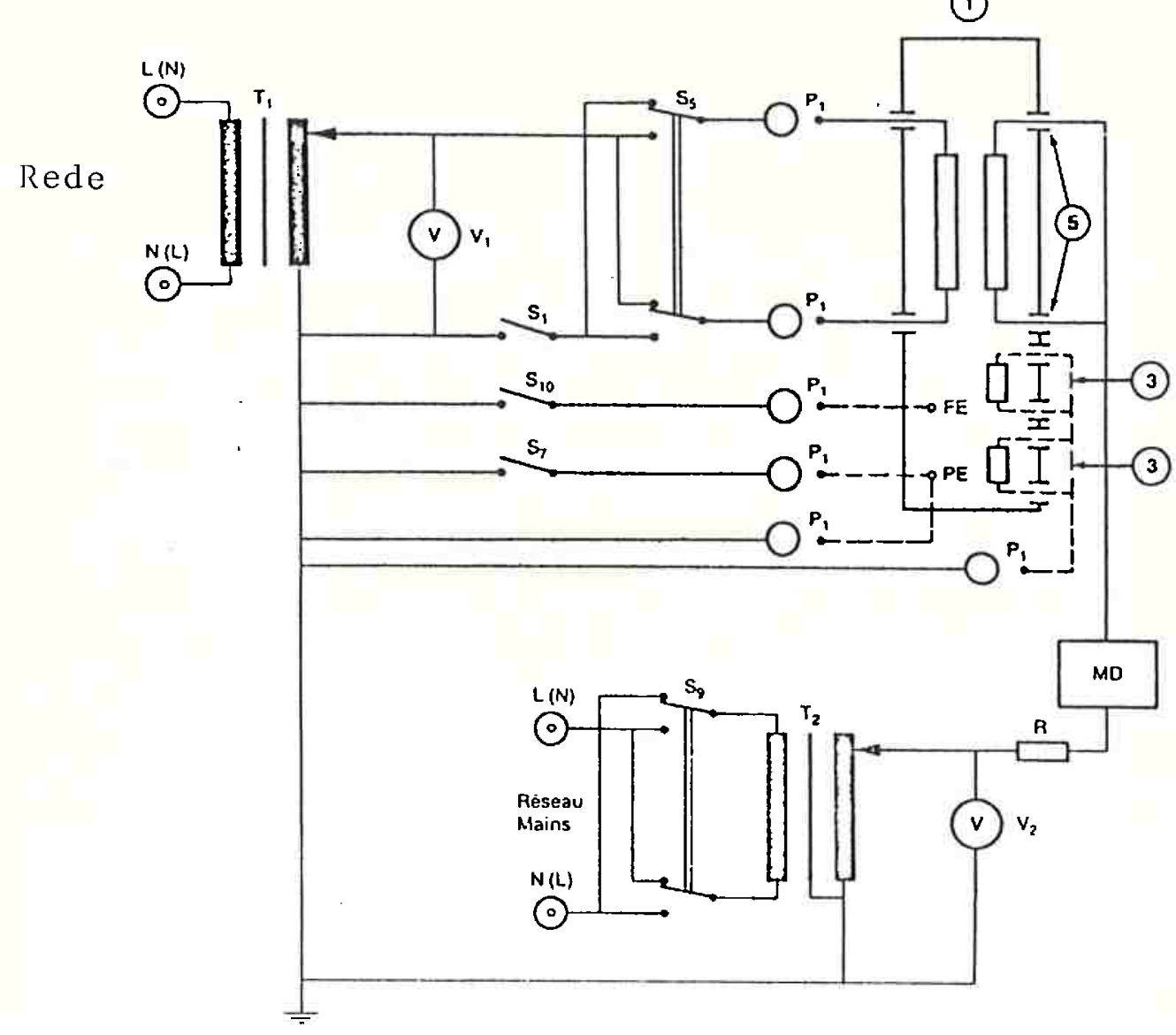

3 - Parte de Entrada ou de Saída de Sinal

Fig. 4.38. Circuito de medição para a corrente de fuga através do paciente via uma parte aplicada isolada tipo $F$ (flutuante) de equipamento Classe I, para a terra, causada por uma ten são externa na parte aplicada. Reproduzido da Publicação IEC.601-1.

Os valores permanentes dessas correntes foram inves tigados nas possíveis combinações das seguintes condições:

a) Sob temperatura de operação normal após tratamen to de precondicionamento à umidade.

b) Sob condições normal e nas seguintes condições de primeira falha: 
$\mathrm{b}_{1}$ ) interrupção de qualquer um dos condutores de alimentação.

$\mathrm{b}_{2}$ ) interrupção do condutor de aterramento para proteção.

$b_{3}$ ) curto circuito em cada uma das partes const $\underline{i}$ tuintes de uma isolação dupla.

$\mathrm{b}_{4}$ ) curto circuito da isolação entre a parte apli cada e partes vivas do circuito secundário.

$b_{5}$ ) com uma tensão de $110 \%$ da maior tensão decla rada de alimentação entre a parte aplicada is lada e terra (apenas para corrente de fuga pa ra o paciente).

c) Com o equipamento energizado nas condições de pron tidão e completamente operante.

d) Com os supressores de interferência de altas fre quências conectados.

e) Com conexões normal e invertida da rede de alimen tação.

f) Com o terminal de aterramento funcional conectado e não conectado.

g) Com a parte aplicada conectada e não conectada ao lado aterrado do circuito de alimentação para medição (apenas para correntes de fuga para a terra e através do invólucro).

O ensaio das correntes de fuga realizado no Sistema de Circulação Extracorpórea considerou as possiveis combina ções dessas condições, que foram estabelecidas pelos interrup tores existentes nos circuitos de medição. Devido à grande quan 
tidade de resultados experimentais decorrentes, apenas una amos tra representativa e conclusiva ê apresentada nas Tabelas 4.1, 4.2 e 4.3.

3.3.4. Ensaio de Rigidez Dielētrica

A rigidez dielétrica foi investigada entre as seguin tes partes do equipamento (referir-se à Fig. 4.39):

- entre a parte a ser ligada à rede e o corpo do equi pamento $(A-a)$

- entre as partes de polaridade oposta da parte a ser ligada à rede (A-f)

- entre a carcaça e tampas condutivas revestidas ou impregnadas com material isolante e uma folha de metal, aplicada apenas para fins de ensaio, em con tacto com a superfície do revestimento, se a dis tância medida através do revestimento, entre pon tos da parte a ser ligada à rede e esta carcaça ou tampas for menor do que o menor caminho através do ar exigido $(\mathrm{A}-\mathrm{g})$.

- entre uma folha de metal não maior do que $20 \mathrm{~cm} \times 10 \mathrm{~cm}$, aplicada em contacto com botões, chaves, puxado res, eixos, suportes, etc., que possam tornar-se sob tensão em condição de primeira falha $(A-h)$.

- entre o corpo do equipamento e uma folha metálica envolvendo um cabo de alimentação flexível (A-j).

- entre a parte a ser ligada à rede e a parte aplica 


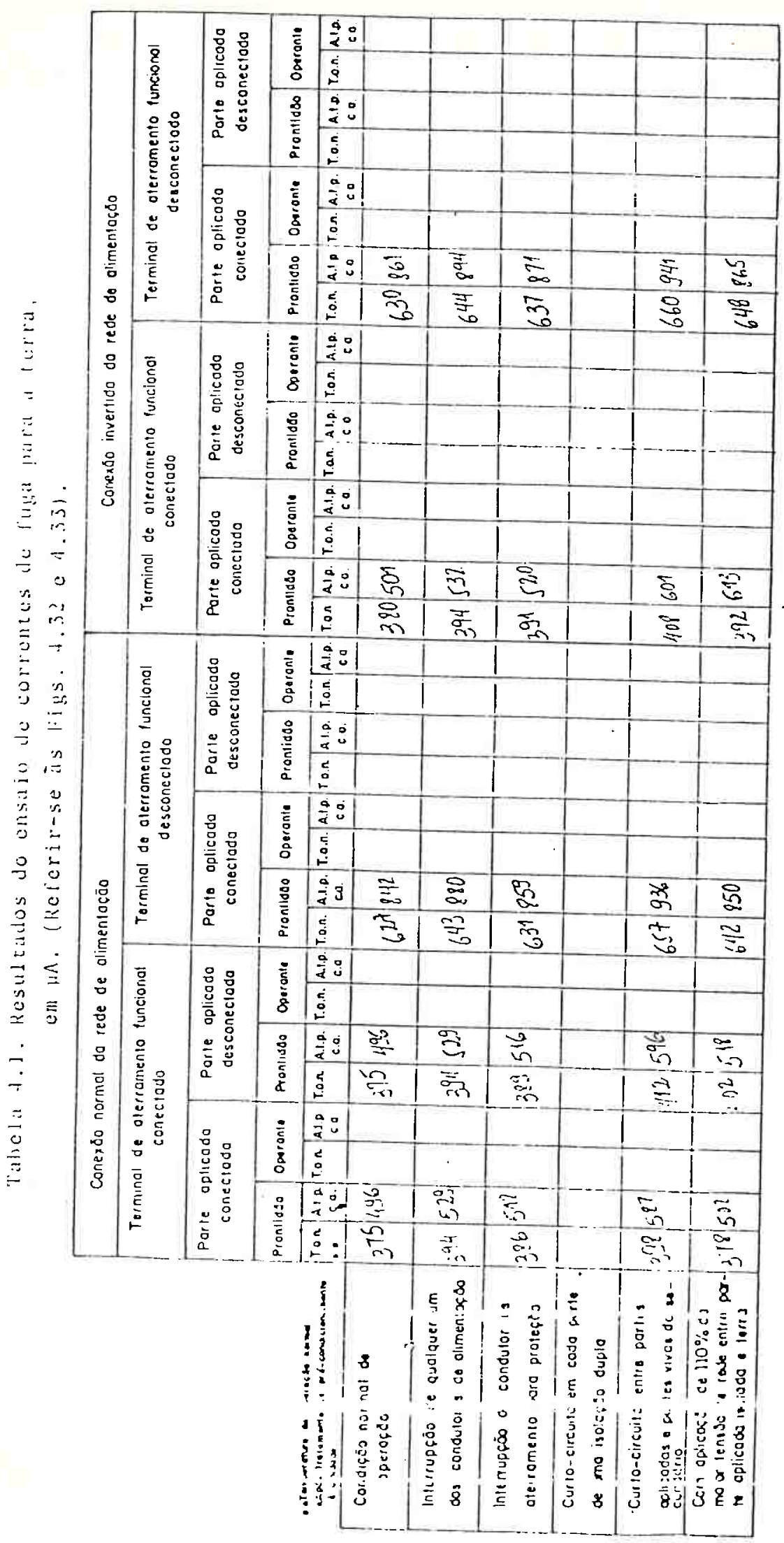




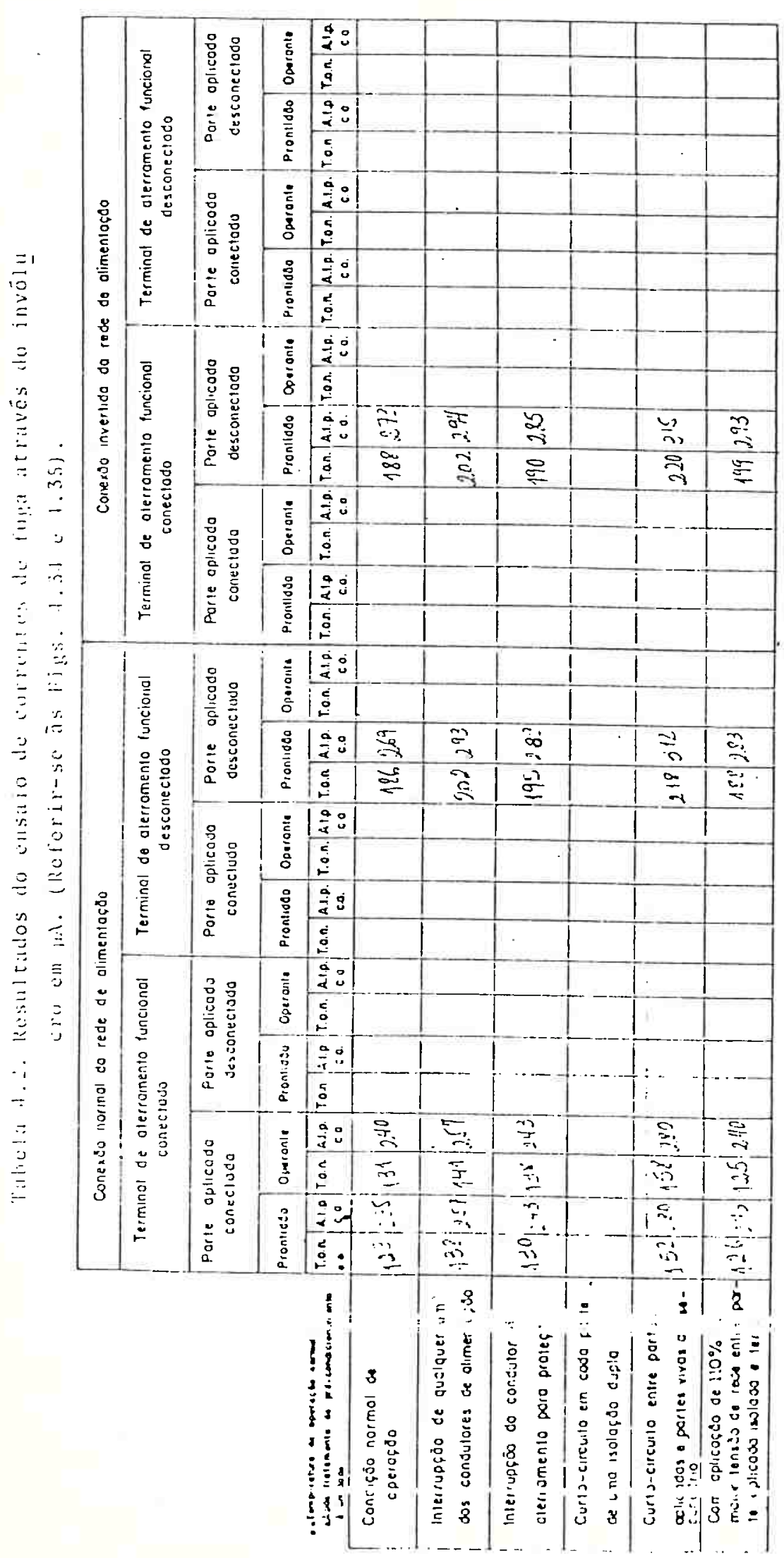




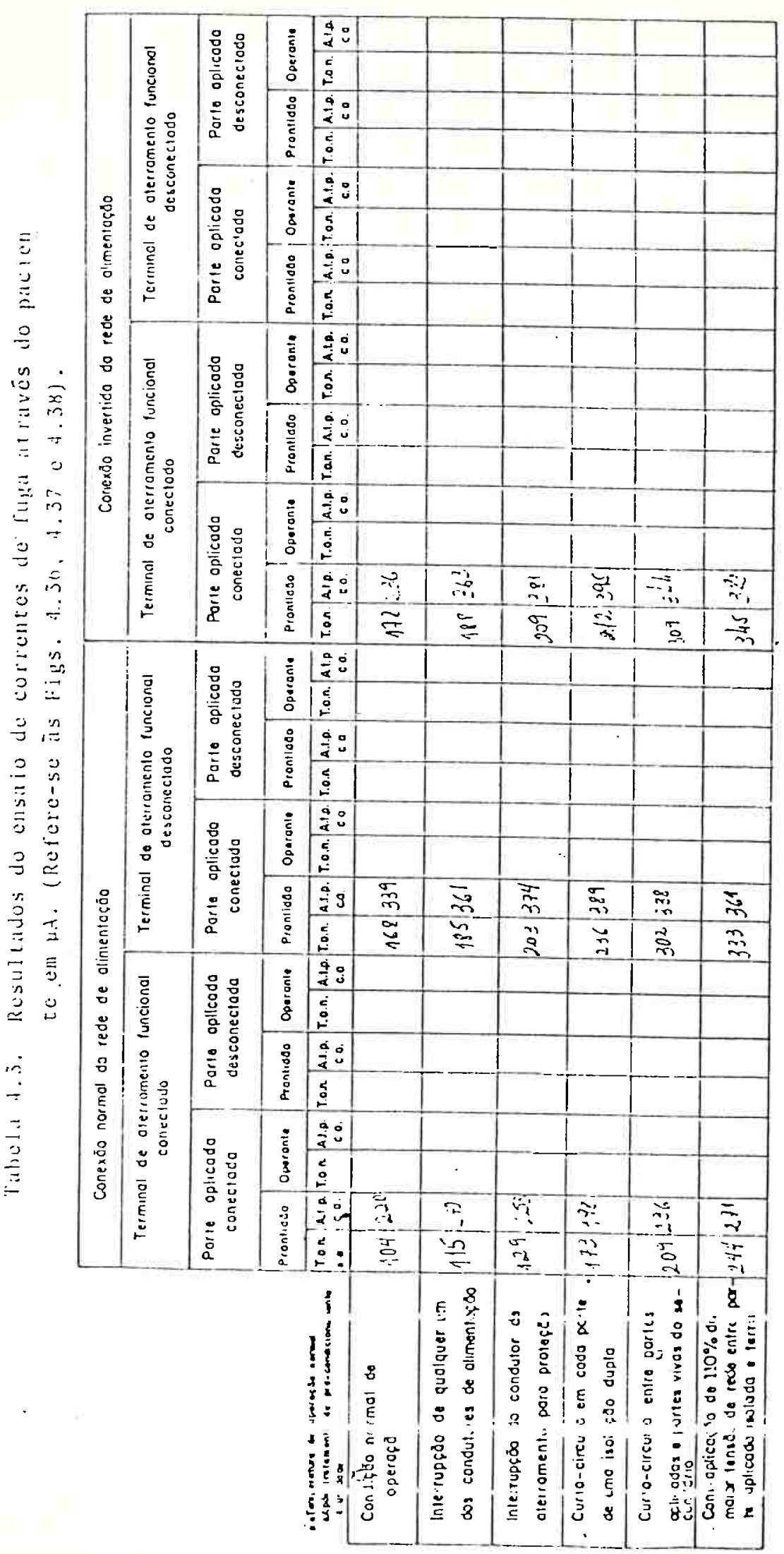



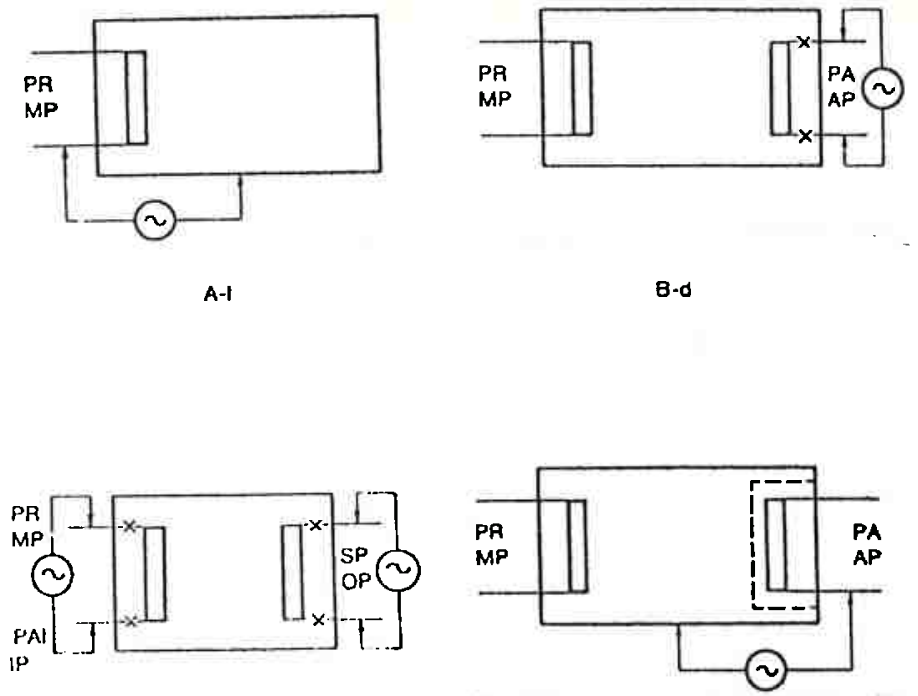

B-a

B-1
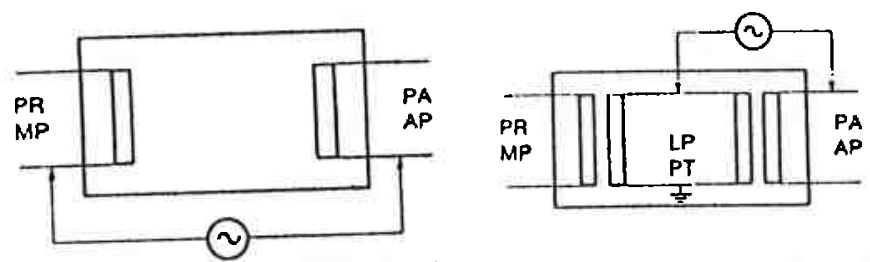

MP - Parte da Rede

IP - Parte de Entrada

OP - Parte de Saída

AP - Parte Aplicada

LP - Parte Viva

Fig. 4.39. Caminhos de isolação e circuitos para ensaio da rigidez dielétrica. Reproduzido da Publicação IEC.601-1. 
da $(B-a)$.

- entre partes da parte aplicada (B-b).

- entre o corpo do equipamento e a parte aplicada iso lada. Neste caso a tensão de ensaio é de $500 \mathrm{~V}$ e im pedâncias de proteção que poderiam ser destruídas durante o ensaio devem ser removidas $(B-d)$.

- entre a parte aplicada e qualquer parte sob tensão, excetuando-se a parte a ser ligada à rede ou uma parte da parte aplicada (B-f).

A tensão de ensaio foi escolhida conforme a Tabela 4.4 e aplicada durante 1 minuto, nas frequências nulas e de $60 \mathrm{~Hz}$

Tabe1a 4.4 Tensões para ensaio de rigidez dielëtrica, em Volts.

$\begin{array}{ccc}\text { Isolação a ser ensaiada } & \mathrm{U}=110 \mathrm{~V} & \mathrm{U}=220 \mathrm{~V} \\ \mathrm{~A}-\mathrm{a} & 1000 & 1500 \\ \mathrm{~A}-\mathrm{f} & 1000 & 1500 \\ \mathrm{~A}-\mathrm{g} & 1000 & 1500 \\ \text { A-h } & 1000 & 1500 \\ \text { A-j } & 1000 & 1500 \\ \text { B-a } & 3000 & 4000 \\ \text { B-b } & 1000 & 1500 \\ \text { B-d } & 1000 & 1500 \\ \text { B-f } & 3000 & 4000\end{array}$

Nota: U - tensão declarada da rede de alimentação.

O ensaio de rigidez dielétrica no Sistema de Circula ção Extracorpórea foi aplicado considerando as seguintes par 
tes do equipamento: transformadores de rede, motores elétricos dos módulos venosos e arterial, bombas sanguíneas, elementos do mini-refrigerador, bomba hỉdráulica, vâlvulas solenoides, resis tência de aquecimento, cabo de medição de temperatura do paci ente, ponta de prova térmica, invölucro do equipamento e ele mentos de seu painel, cabo de alimentação. Em todos os casos, os materiais isolantes constituintes das värias partes e seus revestimentos suportaram normalmente as tensões aplicadas.

4.3.5. Ensaios nos Transformadores de Alimentação

Os ensaios nos transformadores de alimentação foram realizados com os mesmos circuitos e condições de alimentação apresentados no item anterior. Os transformadores estavam em suas posições normais de uso e com os dispositivos de proteção em operação normal.

As seguintes condições foram satisfeitas durante o ensaio:

a) Ensaio rea1izado apoós o equipamento atingir condi çoes de equilíbrio térmico.

b) Ensaio realizado em um enrolamento de cada vez, sendo os outros enrolamentos ou secções carregados conforme o uso normal do equipamento.

c) O transformador deve suportar por 30 minutos uma carga tal que a corrente de ensaio nos circuitos com fusiveis seja $110 \%$ acima da sua corrente declarada, sendo os fusiveis substituídos por elos de impedância desprezível. 
d) As temperaturas dos enrolamentos do transformador são determinadas colocando-se o equipamento em um canto de en saio, constituído por duas paredes perpendiculares, um piso e um teto (se necessário), todos em madeira compensada com $20 \mathrm{~mm}$ de espessura e pintados de preto. As dimensões das paredes, p $\underline{i}$ so e teto devem ser pelo menos $115 \%$ das dimensões do equipamen to, o qual deve ser colocado o mais próximo possível do canto. o ensaio deve ser realizado à temperatura ambiente, cujas va riações devem ser anotadas, o ensaio deve ser efetuado após o equipamento atingir o equilíbrio térmico, durante cinco horas e trinta minutos. A medição da temperatura é efetuada pelo mé todo da variação da resistência do enrolamento de cobre, segun do a equação:

$$
\Delta \mathrm{T}=\frac{\mathrm{R}_{2}-\mathrm{R}_{1}}{\mathrm{R}_{1}}\left(234,5+\mathrm{T}_{1}\right)-\left(\mathrm{T}_{2}-\mathrm{T}_{1}\right)
$$

onde: $\Delta \mathrm{T} \equiv$ aumento da temperatura, em ${ }^{\circ} \mathrm{C}$.

$R_{1} \equiv$ resistência do enrolamento no início do ensaio, em ohms .

$\mathrm{R}_{2} \equiv$ resistência do enrolamento no final do ensaio, em ohms

$\mathrm{T}_{1}=$ temperatura da sala no início do ensaio, em ${ }^{\circ} \mathrm{C}$.

$\mathrm{T}_{2}=$ temperatura da sala no final do ensaio, em ${ }^{\circ} \mathrm{C}$.

e) O transformador deve ser ensaiado relativamente a correntes de fuga e rigidez dielétrica da isolação entre espí ras e camadas dos enrolamentos primários e secundários confor me a secção anterior, apenas que a tensão neste último ensaio 
deve ser correspondente a 5 vezes o limite superior da faixa de tensão declarada.

f) Tambëm a rigidez dielétrica entre o núcleo e a blindagem entre enrolamentos primário e secundärio deve ser ensaiada e se o enrolamento primärio possuir um ponto de cone xão identificado para o neutro da rede, ta1 ponto deve ser conec tado ao núcleo e à blindagem. Se não existir esta identificação, cada extremidade do enrolamento primārio deve ser ligada suces sivamente, ao núcleo e à blindagem.

g) Durante o ensaio de rigidez dielétrica todos os enrolamentos não destinados a serem ligados a rede devem ser deixados abertos. Enrolamentos destinados a serem aterrados em um ponto ou a serem operados em um potencial muito próximo da terra, devem ser ligados ao núcleo.

O ensaio nos transformadores de rede do Sistema de Circulação Extracorpoorea forneceu os seguintes resultados:

a) Ensaio sob condição normal de operação:

$a_{1}$ ) ensaio de rigidez dielétrica: resultado normal (bom)

$a_{2}$ ) ensaio de temperatura dos enrolamentos: $96^{\circ} \mathrm{C}$

$a_{3}$ ) ensaio de sobrecorrente: resultado normal(bom)

$a_{4}$ ) ensaio de correntes de fuga: relatado em item anterior.

b) Ensaio após tratamento de pré-condicionamento à umidade:

$\mathrm{b}_{1}$ ) ensaio de rigidez dielétrica: resultado satis fatörio 
$\mathrm{b}_{2}$ ) ensaio de temperatura dos enrolamentos: $168^{\circ} \mathrm{C}$

$b_{3}$ ) ensaio de sobrecorrente: resultado satisfató rio.

$b_{4}$ ) ensaio de correntes de fuga: relatado em item anterior.

\subsubsection{Ensaio da Potência Aparente Absorvida na Entrada}

o ensaio da potêncìa aparente absorvida na entrada foi realizado com o equipamento nas condições normais de utili zação, tanto com a1imentação de $110 \mathrm{~V}$ como com $220 \mathrm{~V}$. A medição foi efetuada através da tensão e da corrente de entrada, em re gime estacionärio. Os instrumentos de medição indicavam o va lor eficaz verdadeiro e a potência foi calculada pelo produto da corrente pela tensão de alimentação.

O ensaio de potência aparente absorvida na entrada forneceu uma corrente em regime estacionário de 11,6 (A) para a limentação declarada de 110 (V) e 5,9 (A) para alimentação de $220(\mathrm{~V})$, resultando nos dois casos uma potência aparente de aproximadamente 1300 (VA).

3.4.7. Ensaio para Verificação de Partes Sob Tensão

0 equipamento destinado a ser ligado à rede por meio de um plugue deve ser projetado de modo que um segundo após desconectar do plugue, a tensão entre os pinos do plugue ou 
entre qualquer pino do plugue e o corpo do equipamento não de ve exceder $50 \mathrm{~V}$. Este requisito tambëm se aplica se o equipa mento for desligado por meio de uma chave antes da desconexão do plugue.

A conformidade deve ser verificada pelo seguinte en saio:

- O equipamento é operado na tensão de alimentação de clarada ou no limite superior da faixa de tensões declaradas.

- O equipamento não $\overrightarrow{\mathrm{e}}$ desligado pela chave lịga-des liga mas desconectado da rede pelo plugue.

- A tensão entre os pinos do plugue e entre os pinos e o corpo do equipamento é medida um segundo após a desconexão, com um voltímetro que não apresente efeito de carga. A medida não deve exceder $50 \mathrm{~V}$ e o'ensaio deve ser realizado dez vezes.

- Este ensaio não precisa ser desempenhado se forem usados capacitores supressores de interferência com uma capaci tância, entre cada linha e o terra de proteção, de pelo menos 3000 pF para tensões declaradas até $250 \mathrm{~V} / 50 \mathrm{~Hz}$ ou $5000 \mathrm{pF}$ até $125 \mathrm{~V} / 60 \mathrm{~Hz}$.

- Capacitores ou partes de circuitos ligados a eles, que se tornam acessiveis após o equipamento ser desligado e a tampa de acesso ser removida imediatamente, não devem ter uma tensão residual de $50 \mathrm{~V}$, ou se este valor for excedido, não de ve ter uma energia excedente de $2 \mathrm{~mJ}$.

A descarga dos capacitores pode ser efetuada por um arranjo de circuitos ou por um dispositivo de descarga que é ativado pela remoção da tampa. Se não for possível, a tampa de 
acesso deve ser removida apenas com uma ferramenta incluida ms acessórios e que permita a descarga manual se aceitäve1. Tanto o(s) capacitor(es) e/ou os circuitos conectados devem ser ind cados com marcaçōes.

A eficiência do dispositivo de descarga automätica de ve ser determinada pelo seguinte ensaio: o equipamento é opera do na tensão declarada e então desenergizado e qualquer tampa de acesso é removida. Imediatamente deve-se medir a tensão re sidual de qualquer capacitor ou partes de circuitos acessíveis e suas energias retidas devem ser calculadas. Se for especifí cado um dispositivo de descarga não automática pelo fabricante, sua inclusão e marcação devem ser asseguradas por inspeção.

Por outro lado, o equipamento deve ser construído e montado de modo que haja uma proteção adequada contra um con tacto acidental com partes vivas. Esta exigência se aplica pa ra todas as posições do equipamento com operação em uso normal, mesmo apōs a abertura de janelas e a remoção de partes destacá veis sem o uso de ferramentas. Durante a inserçāo ou remoção de lâmpadas deve ser assegurada proteção contra contato acidental com partes vivas, se a substituição da lâmpada for possível sem ferramenta. A conformidade pode ser verificada por inspeção ou por inserção de dedo de prova (Fig. 4.40) normalizado, aplica do com força não inferior a $30 \mathrm{~N}$.

Partes removíveis devem ter a fixação mecanicamente verificada por um ensaio com uma força não inferior a $20 \mathrm{~N}$ du rante $10 \mathrm{~s}$. 


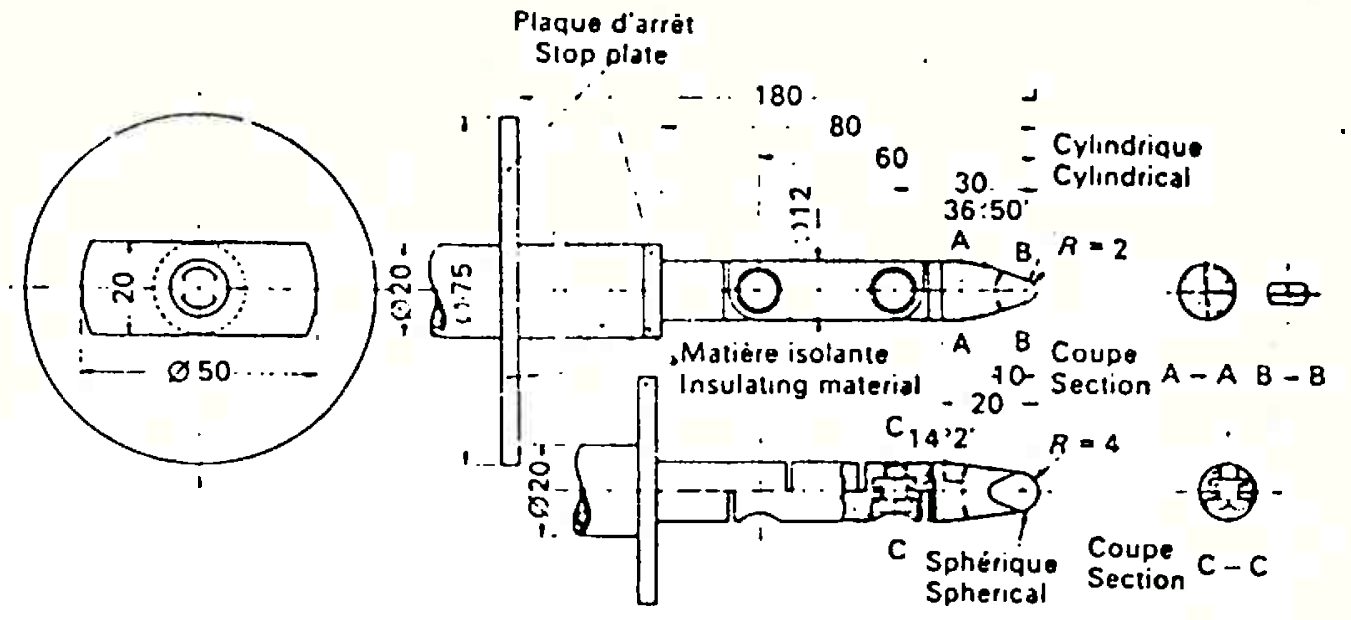

Dimensions en millimètres

Tolerances:

sur les angles $\pm 5^{\circ}$

sur les dimensions:

inférieures ì $25 \mathrm{~mm}: \stackrel{+0}{+0.05}$

supéneures à $25 \mathrm{~mm}: \pm 0,2$

\section{Dimensions in millimetres}

Tolerances:

on angles $\pm 5^{\circ}$

on line ar dimensions:

less than 25 inin: $\quad+0$

over 25 inm: $\quad \pm 0.2$

Fig. 4.40. Dedo de prova normalizado. Reorodu zido da Publicação IEC.601-1.

Finalmente, qualquer abertura na tampa do equipamen to deve ser posicionada e dimensionada de modo que seja preve nido o acesso a partes vivas. O ensaio deve utilizar um disco de $4 \mathrm{~mm}$ de diâmetro e suspenso verticalmente com um fio condu tor de $100 \mathrm{~mm}$ de comprimento que não deve tornar-se sob tensão ao penetrar na mäquina. São permitidas aletas (vene zianas) para ventilação, porém convenientemente posicionadas.

Todos os ensaios descritos foram realizados no Siste ma de Circulação Extracorpórea fornecendo resultados dentro dos intervalos aceitāveis estabelecidos na Publicação IEC.601-1.

4.3.8. Ensaio da Resistência Elëtrica de Condutores de Prote ção

Para equipamento com um cabo de alimentação destacạa 
vel, a resistência entre o contacto de proteção no condutor (de entrada) de alimentação do equipamento e qualquer outra parte que $\vec{e}$ a êle conectada para fins de proteção,não deve exceder $0,1 \Omega$.

A resistência do condutor de aterramento para prote ção não deve exceder $0,1 \Omega$, mesmo que para atingir essa condi ção deva-se usar um condutor combitola maior do que a necessá ria para satisfazer a corrente declarada. A conformidade é veri ficada passando uma corrente entre $10 \mathrm{~A}$ e $25 \mathrm{~A}$. A corrente é cir culada durante pelo menos $5 \mathrm{~s}$ entre o pino de aterramento para proteção no plugue da rede ou o terminal de aterramento para proteção ou o contacto de aterramento para proteção no conector (de entrada) de alimentação do equipamento e cada uma das par tes condutivas acessiveis que podem tornar-se sob-tensão em con dição de primeira falha. Mede-se a tensão entre os dois pontos e calcula-se a resistência pela lei de Ohm.

O ensaio realizado no Sistema de Circulação l:Extracor pórea utilizou corrente de $20 \mathrm{~A}$, resultando uma resistência no condutor de aterramento para proteção de $0,06 \Omega$.

4.3.9. Ensaios de Impacto

O eletrodo para medição da temperatura do paciente não pode apresentar risco de segurança como resultado de uma que da. O ensaio de conformidade exige que a amostra caia livremen te a partir de três posições iniciais diferentes, da altura de um metro sobre uma superfície de madeira dura, com densidade su 
perior a $700 \mathrm{Kg} / \mathrm{m}^{3}$ e com espessura de $50 \mathrm{~mm}$, apoiada sobre um bloco de concreto plano. Após o ensaio não devem resultar fis suras visiveis a olho nu bem como lascas superficiais. Nenhuma parte sob tensão deve ficar exposta e o eletrodo deve satisfa zer as exigências do ensaio de rigidez dielētrica.

Por outro lado o equipamento deverá resistir à mani pulação mais violenta, sendo ensaiado deixando-o cair de uma a 1 tura de 2 cm sobre uma prancha de madeira dura com $50 \mathrm{~mm}$ de es pessura e com dimensões no mínimo 1,5 vezes maiores do que as da base do aparelho. A prancha deve estar assentada em uma ba se de concreto e deve-se realizar a queda por três vezes, a partir da posição apresentada em uso normal. Apös o ensaio ne nhuma parte sob tensão deverá ficar exposta. o ensaio foi rea lizado no Sistema de Circulação Extracorpóres obtendo-se resul tados dentro dos limites tolerados pela Publicação IEC.601-1.

\subsubsection{Ensaio de Estabilidade Posicional}

o equipamento deve apresentar estabilidade posicional em um plano inclinado com inclinação superior a $10^{\circ}$ em relação à horizontal. No caso específico do Sistema de Circulação Ex tracorpórea, a incorporação de rodízios com freios possibilitou atender a esta prescrição.

\subsubsection{Ensaios Contra Riscos por Temperatura Excessiva}

A superfície lateral externa do equipamento não pode 
exceder $40^{\circ} \mathrm{C}$. O ensaio deve ser realizado na condição de uso normal medindo-se os pontos significativos externos da carcaça do equipamento com medidores de temperatura com precisão me lhor do que $5 \%$. Ao ser aplicado no Sistema de Circulação Extra corpórea, o ensaio indicou temperaturas inferiores a $38^{\circ} \mathrm{C}$ em todos os pontos medidos do invólucro.

\subsubsection{Ensaio Contra Transbordamento}

o equipamento deve ser inclinado de $15^{\circ}$ em relação à horizontal e os reservatórios de ägua não deverāo apresentar transbordamento. O ensaio deve ser realizado com uma quantida de suplementar de 1 íquido correspondente a $15 \%$ da capacidade regular, durante 1 minuto. O ensaio foi efetuado no Sistema de Circulação Extracorpórea com resultado normal.

\subsubsection{Ensaio para Prova de Pingos}

o equipamento deve ser colocado em posição de uso normal e submetido durante 5 minutos a uma chuva artificial de $3 \mathrm{~mm}$ por minuto, caindo verticalmente de uma altura de 2 metros acima da parte superior do aparelho (Fig. 4.41). Terminada a asperção, o equipamento deve ser secado conforme o item 4.3.1.

Tanto durante o ensaio quanto após a secagem, o apa relho deve apresentar condições normais de funcionamento. Esta exigência foi satisfeita no ensaio realizado com o Sistema de 
Circulaçāo Extracorpórea.
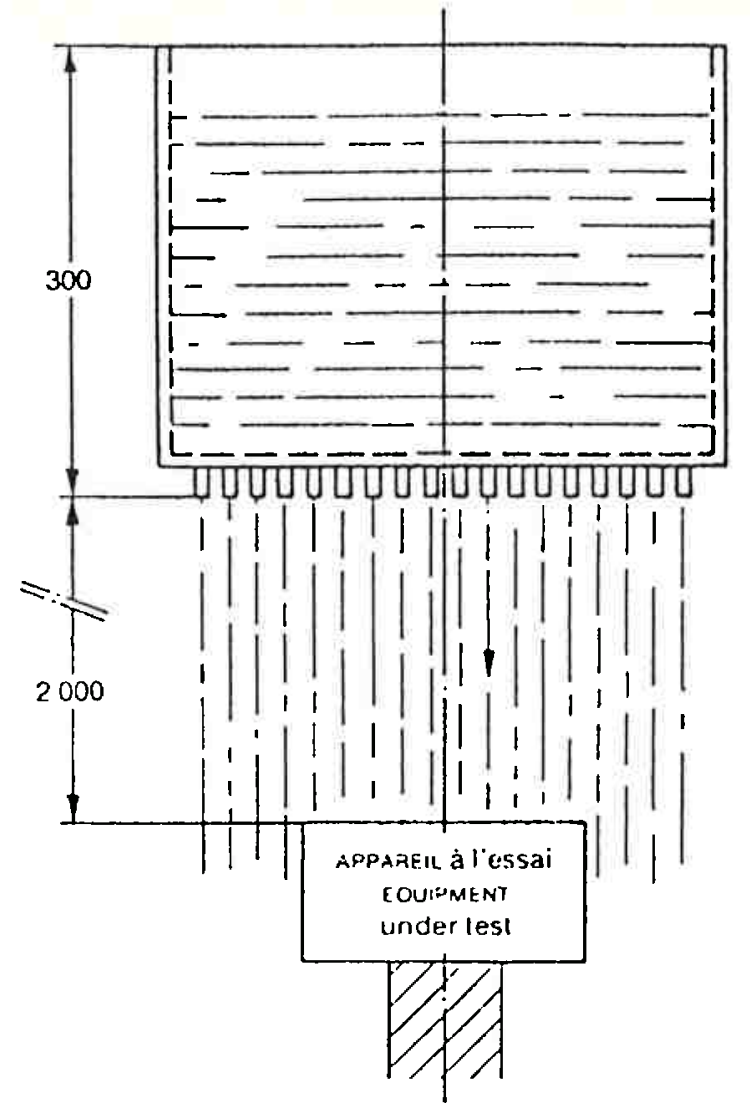

NOTA: o suporte deve ser menor que o equipamento sob ensaio

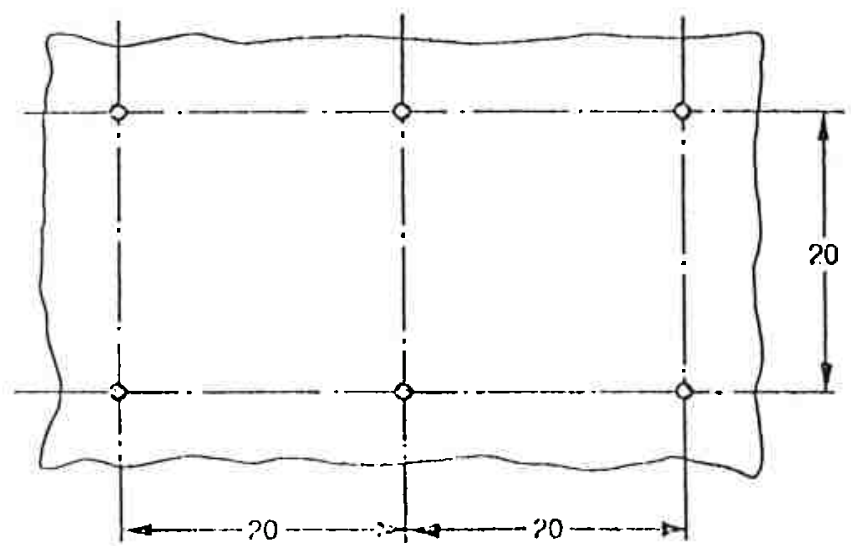

Fig. 4.41. Aparelho para ensaio de um Equipamento à prova de projeção de líquidos. Repro duzido da Publicação 601-1, IEC. 


\subsubsection{Ensaio Funcional}

0 ensaio funcional do Sistema de Circulação Extracor pórea verificou inicialmente o desempenho das bombas sanguíneas. o ajuste dos roletes foi efetuado de modo que não houvesse rẹ fluxo de água, usada como fluído circulante no ensaio, com a bomba sustentando uma coluna hidrāulica de Im de altura. Foi estabelecida uma pressão de $180 \mathrm{~mm} H \mathrm{Hg}$ na saída da bomba e mediu -se o fluxo resultante. Constatou-se a possibilidade de varia ções de fluxo desde $0,151 / \mathrm{min}$ até $6,81 / \mathrm{min}$. Posteriormente ve rificou-se o efeito da variação da pressão de carga, na saída da bomba, sobre o fluxo, concluindo-se pela existência de uma regulação melhor do que $4 \%$. Os medidores de fluxo, velocidade angular do rotor e abertura do lúmen na tubulação foram aferi dos e ensaiados com instrumentos possuidores de precisão me 1hor do que $2 \%$.

A segunda fase do ensaio funcional verificou as ca racterísticas de desempenho das partes hidráulicas do equipa mento, constantando-se inicialmente que os 4 litros de água existentes em cada um dos reservatórios foram aquecidos e res friados, com variações térmicas de $50^{\circ}$ e $25^{\circ} \mathrm{C}$, respectivamente, em menos de 30 minutos. Com a ägua quente ou fria circulando pe lo oxigenador, os dois termostatos mantiveram a temperatura em uma faixa de $\pm 2^{\circ} \mathrm{C}$. A vazão de ägua foi mantida no oxigenador in corporado ao Sistema em aproximadamente $6,51 / \mathrm{min}$. Os alarmes e sinalizações áudio-visuais foram ensaiados com resultado per feito.

Os sub-sistemas termomëtrico e temporizador foram en 
saiados utilizando instrumentos de referência com precisões me 1hores do que $2 \%$ e forneceram resultados de acordo com as espe cificações pré-estabelecidas.

0 sub-sistema de emergência foi acionado com a tensão de alimentação nominal sendo aplicada na máquina principal e posteriormente diminuída para $80 \mathrm{~V}$. 0 módulo de emergência en trou em ação 11 segundos após o instante de aplicação desta úl tima tensão de alimentação. Nesse ensaio as partes de aquecí mento e refrigeração do S.C.E. foram previamente desativadas. o Sistema de Circulação Extracorpórea alimentado pelo módulo de emergência operou normalmente.

A inspeção para verificação do funcionamento do subsistema de teste e de outras prescrições estabelecidas pelos textos normativos demonstrou a existência de conformidade.

4.4. Análise dos Resultados Obtidos nos Ensaios do Sistema de Circulação Extracorpórea.

Os resultados obtidos nos ensaios de correntes de fü ga e temperatura dos enrolamentos dos transformadores de rede não satisfazem as exigências prescritas para equipamentos ele tro-médicos. Ensaios desenvolvidos individualmente, tanto nos transformadores de rede como no compressor do mini-refrigerador, na bomba d'ägua, na resistência de aquecimento e nos motores elētricos existentes no Sistema de Circulação Extracorpörea, de monstraram que apesar das solicitações aos fornecedores de dis positivos com características particulares de acordo coma apli 
cação mêdica, esta exigência não foi satisfeita, o que justifi ca os maus resultados apresentados.

Os outros ensaios de segurança, bem como o ensaio fun cional do Sistema, forneceram resultados compatíveis com as prescrições estabelecidas. 
CAPITULO $\mathrm{V}$

CONCLUSÃO

A implementação de um abrangente Sistema de Circula ção Extracorpōrea, desenvolvido utilizando a filosofia de con cepção de equipamentos eletro-médicos considerando o conceito integrado de segurança, consistiu na principal contribuição des ta pesquisa à ärea de Instrumentação Biomédica. A escolha des te Sistema, que substitui a máquina coração-pulmão artificial tradicional, exigiu a determinação das especificações de uma máquina coração-pulmão hipotética ideal e permitiu a definição de um modelo de concepção aplicado a um dos equipamentos médi cos mais críticos, sob o ponto de vista de riscos contra cho que eletrico. Os resultados obtidos demonstraram a real e con veniente utilização desse modelo, bem como a sua própria viabi lidade.

Värias consequências práticas vantajosas decorreram deste trabalho. Os primeiros resultados positivos ocorreram 1 o go no início da presente década quando as inovações e modifica ções propostas no novo Sistema de Perfusão acarretaram uma sig nificativa mudança na atuação dos fabricantes desse tino de equipamento. Uma anảlise, mesmo superficial, realizada nas bom bas coração-pulmão artificiais existentes na eppoca do início 
desta pesquisa, demonstra que não havia qualquer preocupação en tre os produtores dessas māquinas relativamente a aspectos de segurança. A quase totalidade dos aparelhos nacionais usava um auto-transformador ligado diretamente à rede de energia elëtri ca para alimentar os motores dos módulos venosos e arterial. Simples retificadores e filtros completavam os circuitos de alimentação desses motores, responsáveis pela circulação san guínea no paciente durante cirurgias cardíacas. Ainda hoje,blo cos de gelo são usados nas partes de refrigeração das bombas de perfusão comerciais, acarretando muitas vezes adiamentos in convenientes de cirurgìa, devido a falta desse elemento refr $\underline{\mathbf{i}}$ gerante pelas mais variadas causas. Com a apresentação da pró posta do Sistema de Circulação Extracorpórea em Congressos Cí entíficos, a totalidade dos fabricantes se conscientizou da ne cessidade de segurança em seus produtos.

Por outro lado, o Sìstema de Circulação Extracorpōrea apresentado não possue sofistìcaçāo desnecessāria, como ' pode ria aparentar à primeira vista, mas funcionalidade e qualidade compatíveis com as exigências de sua particular aplicação. Es ta constatação tambëm foi verificada junto a cirurgiōes cardía cos e técnicos de perfusão. Entretanto, no final da dëcada pas sada a funcionalidade das bombas de perfusão disponíveis era a mínima necessāria, consistindo apenas em movimentar, refrige rar (comblocos de gelo) e aquecer o sangue perfundido, com a eventual inclusão de medição de temperaturas através de um ins trumento analógico. Com a divulgação do S.C.E. possibilitou-se que algumas de suas inovaçōes e modificaçōes fossem incorpora das em vārios modelos existentes no mercado. Pode-se afirmar 
que os aparelhos destinados a auxiliar as cirurgias cardíacas na atualidade, apesar de não possuirem a funcionalidade e a se gurança equivalentes à proposta neste trabalio, possuem as con diçōes mínimas para atuar nessa aplicaçāo.

Outra consequência vantajosa deste trabalho refere-se à manutenção, sem dúvida a maìor preocupação dos responsāveis por divisões médico-hospitalares contendo instrumental bio-mé dico. De acordo com a concepção estabelecida, o problema da ma nutenção de equipamentos eletro-médicos é automaticamente mini mizado, se não sanado.

Um sub-produto deste projeto, que procurou sanar uma lacuna que inviabilizava a própria Instrumentação Biomédica, foi a elaboração de projetos de Normas Técnicas, praticamente inexistentes em âmbito nacional. Esforços foram desenvolvidos neste sentido e hoje pode-se afirmar que värios textos normati vos estão na iminência de tornarem-se püblicos e utilizâveis pelas comunidades científica e empresarial. Mais do que os pró prios documentos normativos, é significativa a existência de uma mentalidade, ainda embrionäria mas perceptível, voltada à normalização e qualificação, tanto nos usuärios como nos fabri cantes. Vảrias atividades desempenhadas nesses ūltimos anos atra vés de Congressos, Simpósios, Cursos de Atualização e Especia lização, alêm daquelas realizadas em Orgãos Normativos, contrí buiram para este novo estado de aceitação das necessidades prio ritārias de qualificação e normalização. Características de confiabilidade e funcionalidade começam inclusive a ser exigi das pelos usuários e oferecidas por alguns fabricantes. A pro posta deste trabalho poderā contribuir para a determinação de 
uma diretriz para concepções de futuros equipamentos, incenti vando ainda outros trabalhos nesse setor. Observe-se, entretan to, que novos conhecimentos e a própria dinâmica da tecnologia deverão determinar propostas de concepção de equipamentos biomédicos no futuro, podendo-se inclusive atingir o estágio da viabilidade e conveniência de padronização.

Duas questōes devem ser levantadas na conclusāo des te trabalho: a precisão usada na comprovação da proposta e a própria possibilidade de comercialização do produto. A causa para a não conformidade de algumas especificações de segurança com as prescrições exigidas e a eventual impossibilidade de co mercialização do produto $\vec{e}$ a mesma: a inexistência de implemen tos disponiveis em linhas normais de fabricação destinados à particular aplicação na ärea bio-mēdica. Nessas condições, tais itens são considerados fora de sêrie e consequentemente oneram o produto final a ponto de tornā-1o não comercializável ou não competitivo. Entretanto, se a indústria médico-hospitalar ini. ciar a produçāo de equipamentos com itens fabricados conforme as exigências de segurança, essa demanda aumentará com a conse quente redução de custo. E, se o próprio parque industrial ele tro-mēdico crescer, a redução serā ainda maior. Conclui-se fá cilmente pela necessidade de incentivo tanto à requisição de implementos com características compatíveis com as prescrições de segurança quanto à própria expansão e consolidação da indús tria nacional no setor de dispositivos e equipamentos para a Saūde. Em relação ao Sistema de Circulação Extracorpōrea imple mentado, não foi possível, por fatores econômicos ou de dispo nibilidade no mercado, utilizar todos os itens com as especifi 
cações desejadas, resultado compatível com o objetivo do traba lho que determinou a elaboração de um modelo para concepção e não para implementação.

Ao longo do desenvolvimento desta pesquisa pretendeu - se atender a grande maioria das solicitações estabelecidas nos Documentos e Relatórios correspondentes às aspiraçōes tanto das comunidades científica e empresarial como de Órgãos do Governo. Em particular, no atendimento à solicitação de "transferência de tecnologia desenvolvida nos centros de pesquisa para o sé tor produtivo, com qualidade compatível com as exigencias da específica aplicação, elaborando ainda normas de segurança e qualidade que possam ser aplicadas na homologação de produtos nacionais, incentivando a aquisição pelos mercados interno e externo e evitando a importação".

O desempenho verificado nos últimos anos indica cla ramente que a Engenharia Biomédica contribuirā significativa mente para a melhoria da Saúde no Brasil e para a consolidação da indústria nacional nesse setor. Entretanto, a responsabili dade pelo necessärio desenvolvimento deve ser compartilhada tan to pelas equipes de Engenharia Biomédica existentes, como pe los dirigentes empresariais do setor médico-odontológico-hospi talar, alêm das agências de fomento e Orgãos de Governo. Dessa forma poderemos atingir o estágio de país avançado, caracter $\underline{i}$ zado pelo maciço investimento tanto em pesquisa como em desen volvimento, e pela rảpida utilização dos resultados da pesqui sa em aplicaçōes präticas. 


\title{
APENDICE A
}

\section{FUNDAMENTOS DO SISTEMA VASCULAR SANGUINEO. BASES ANATÔMICAS E FISIOLOGICAS.}

\begin{abstract}
O sistema vascular compreende um örgão central, o co ração, uma rede de vasos nos quais circulam o sangue e a linfa, bem como órgāos e tecidos hematopoéticos responsāveis pela for mação de elementos morfológicos do sangue (Erhart, 1969). 0 sistema vascular sanguíneo é um circuito fechado de vasos pe los quais circula o sangue (Figs. A1 e A2), tendo o coração co mo órgão muscular oco, conträtil e expelindo em fluxo rítmico o sangue pelas artérias (vias centrífugas) e o recebendo de volta pelas veias (vias centrípetas).
\end{abstract}

Partindo do coraçāo, as artērias ramificam-se redu zindo gradativamente de calibre (artērias de grande, médio e pequeno calibres) finalmente constituindo as arteríolas, às quais se seguem vasos pré-capilares, precedendo os verdadeiros capilares e penetrando nos örgãos onde, a nível de vasos capí lares, se processam as trocas de substāncias nutritivas do san gue pelas substāncias residuais dos tecidos. Os vasos capila res venosos constituem-se na continuação dos vasos capilares ar teriais e, por confluências sucessivas, diminuem em nümero e. aú mentam progressivamente de calibre, acabando por constituirem as veias que: desembocam no coração. o sistema vascu 


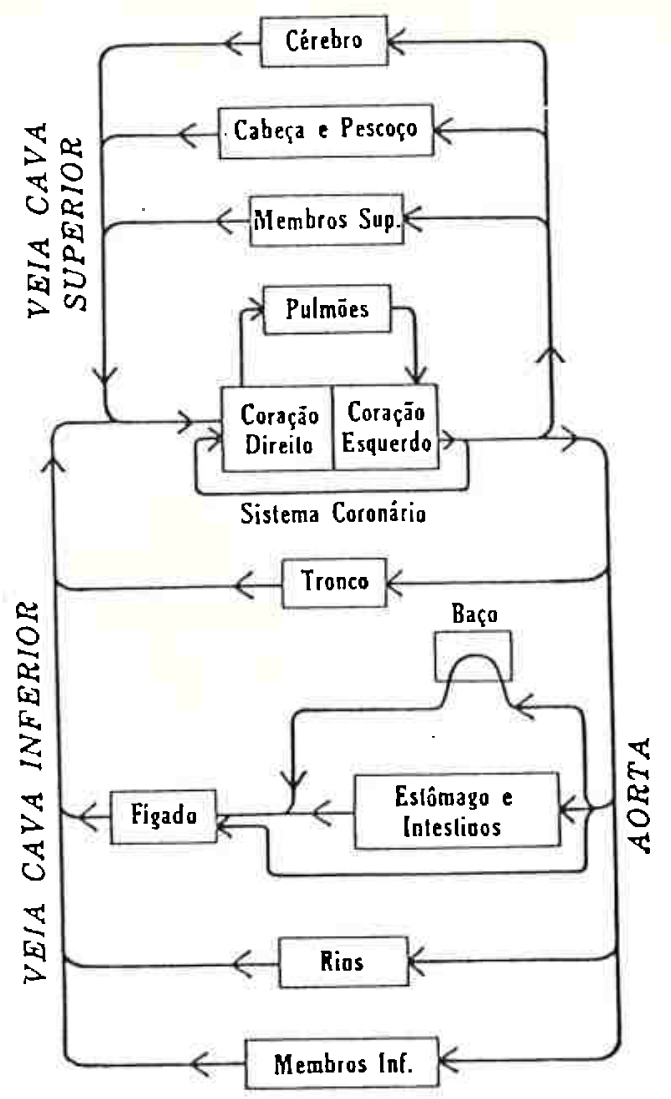

Fig. A1. Esquema da Circulação Humana. Reproduzido de Winton e Bay1 iss, 1970 .

lar sanguíneo é constituído pelo subsistema correspondente à circulação grande ou geral e por outro subsistema, denominado circulação pequena ou pulmonar, interconectados pelas cavida des do coração. A grande circulação distribui o sangue, rico em oxigênio e elementos nutritivos, a todo o organismo e o traz de volta ao coração carregado de gás carbônico e elemen tos residuais, de onde a circulação pulmonar o leva aos pul. mões para que retorne oxigenado pela hematose. A circulação pulmonar é essencialmente funcional desde que a circulação nu 


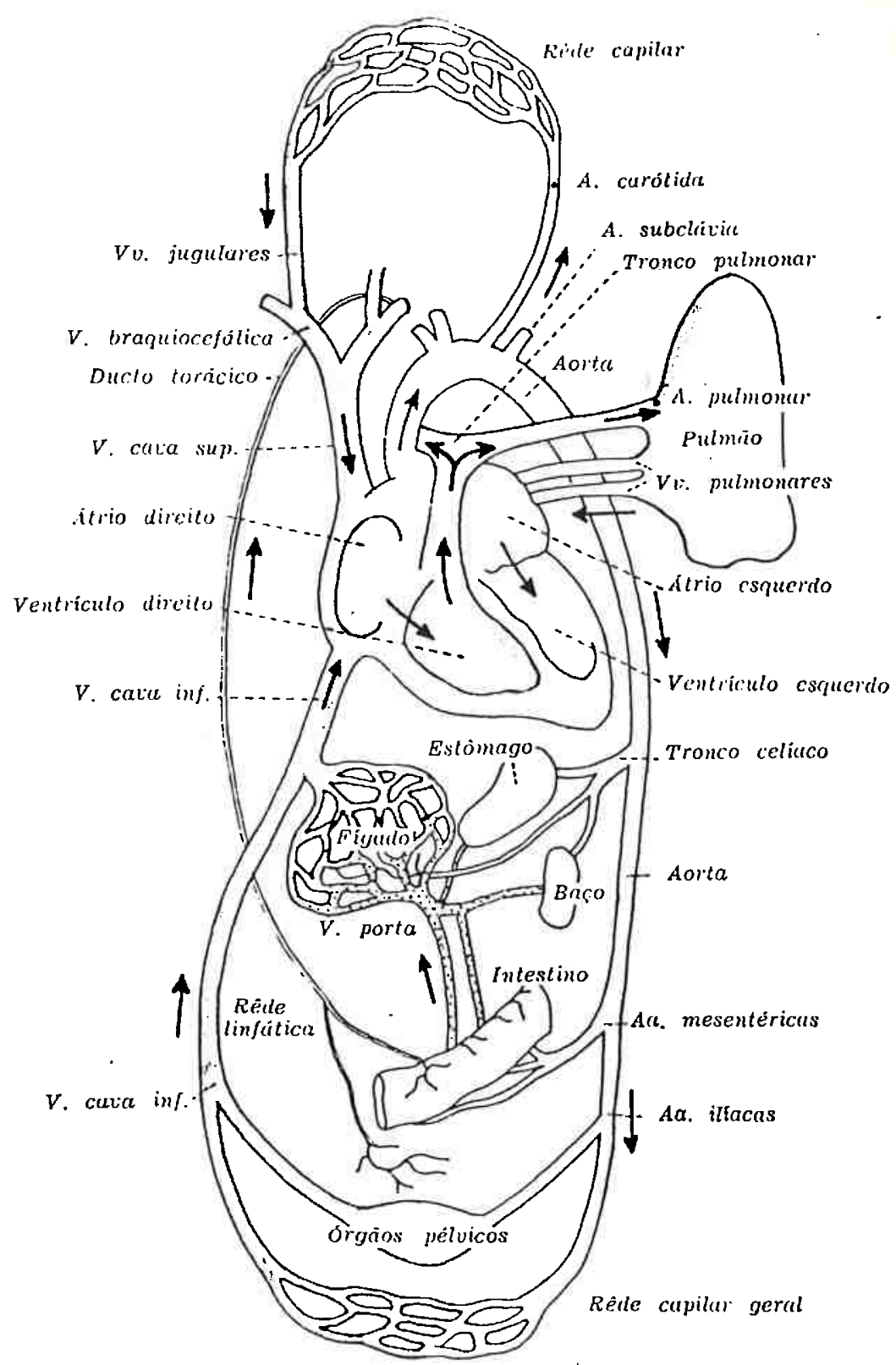

Fig. A2. Esquema Geral do Sistema Vascular. Reproduzido de Erhart, 1969.

tritiva dos pulmões é realizada pela grande circulação através dos vasos bronquiais (Rushmer, 1976 e Winton e Bayliss, 1970).

o coraçāo é um órgão cavitārio e contrātil, const i 
tuído essencialmente por tecido muscular e apresentando quatro cavidades: os átrios direito e esquerdo e os ventrículos dire to e esquerdo (Figs. A3, A4 e A5). Cada átrio comunica-se com o ventrículo homônimo através do óstio átrio-ventricular, um orifício provido de valva. Separando as cavidades direita e es querda do coração hã um septo músculo-membranáceo, o septo car díaco, apresentando uma pequena área fibrosa, denominada por ção membranácea, na região de transição da porção inter-atrial à inter-ventricular.

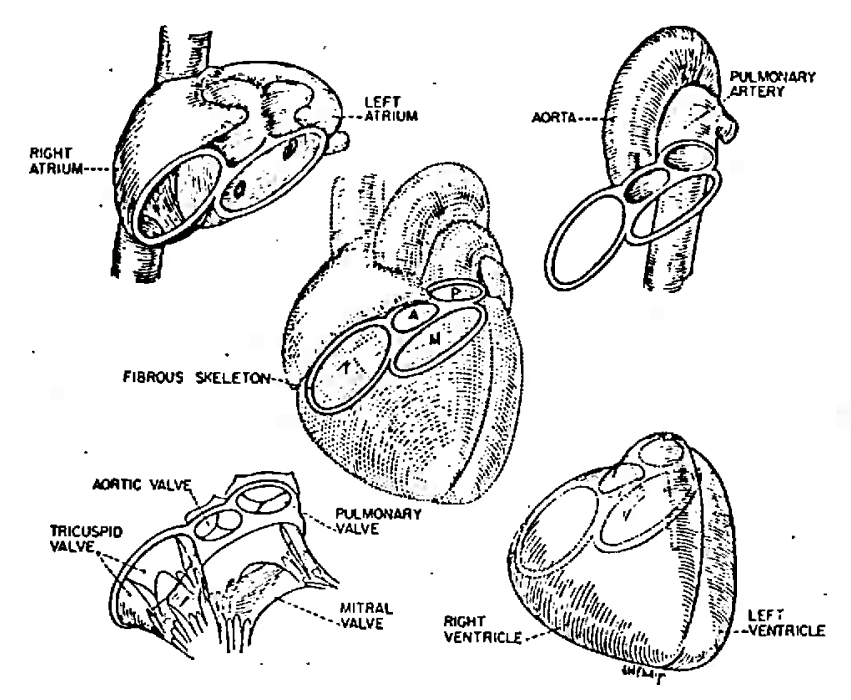

Fig. A3. Componentes Anatômicos do Coração. Reproduzido de Rushmer, 1976. 

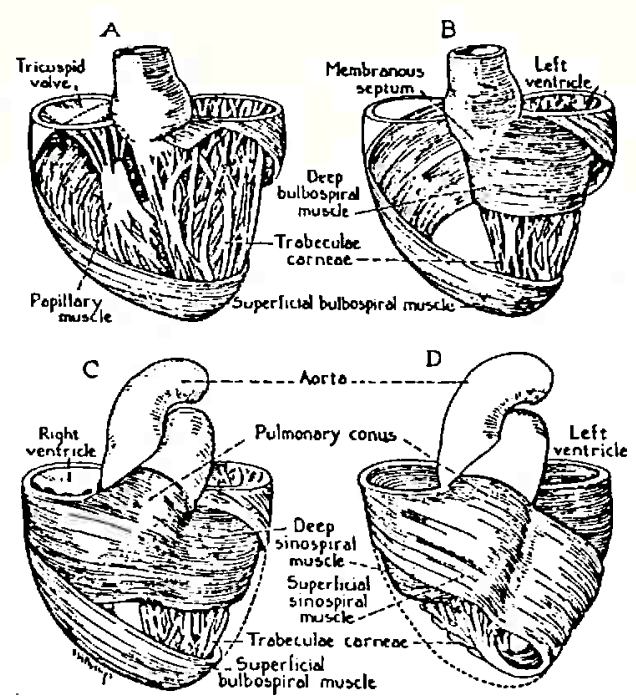

Fig. A4. Anatomia das Paredes Ventriculares. Reproduzido de Rushmer, 1976.

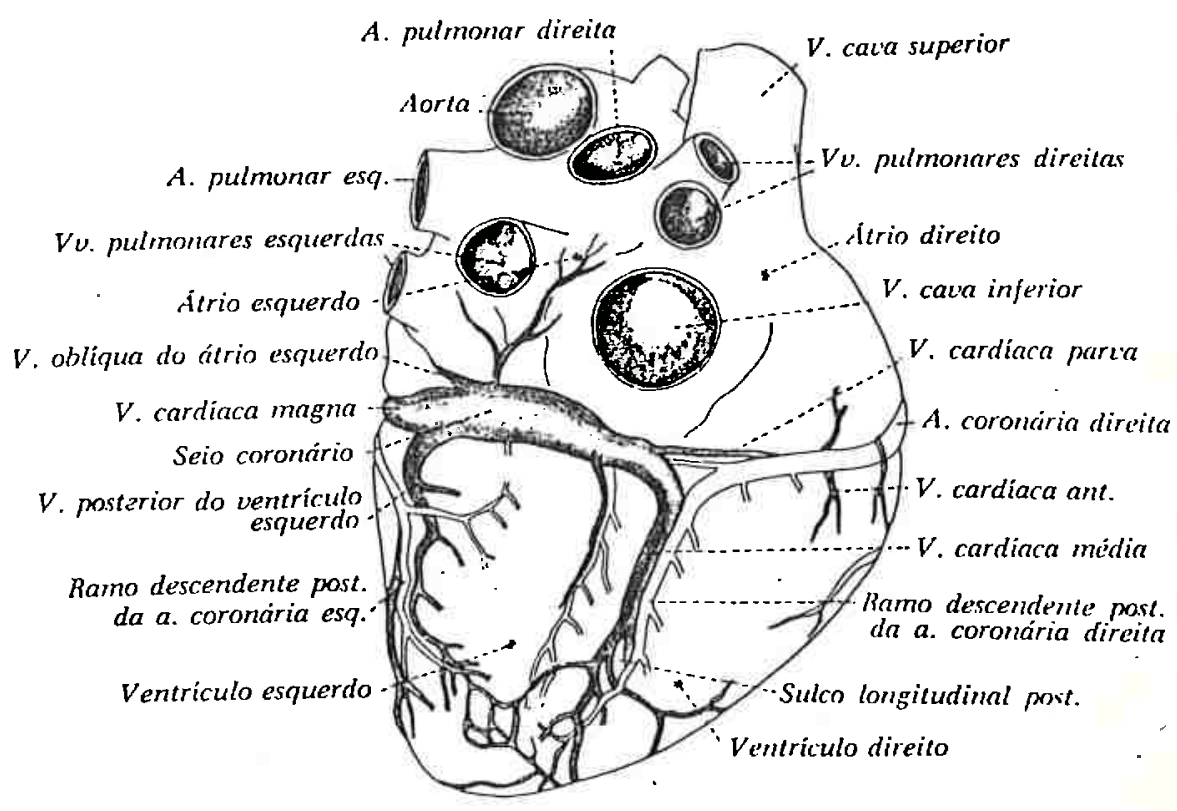

Fig. A5. Coração, Artērias Coronárias e Veias Cardíacas. Vista Inferior. Reproduzido de Erhart, 1969. 


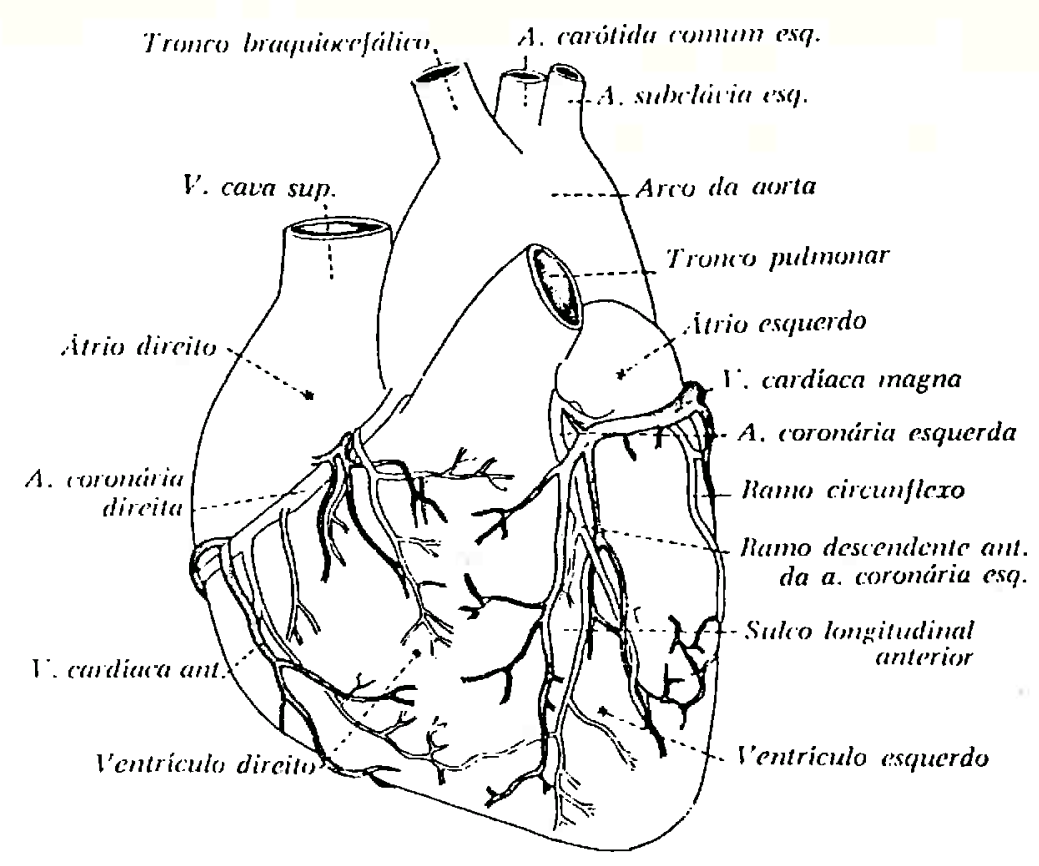

Fig. A5. Coração, Artërias Coronärias e Veias Cardíacas: Vista ventrocra nial. Reproduzido de Erhart,1969.

o ätrio direito recebe sangue venoso das veias cavas inferior e superior, bem como do seio coronário, vaso venoso do próprio coração, proveniente da circulação geral, e o envia ao ventrículo homolateral que por sua vez o impulsiona aos pul mões. o átrio esquerdo recebe sangue arterializado proveniénte das quatro veias pulmonares da pequena circulação, envia-o ao ventrículo esquerdo que, por contrações rítmicas o impulsiona à grande circulação atravês da aorta, completando o circuito (Fig. A6). Pode-se considerar o hemisfërio direito do coração como sendo venoso e o hemi-coração esquerdo, arterial. 


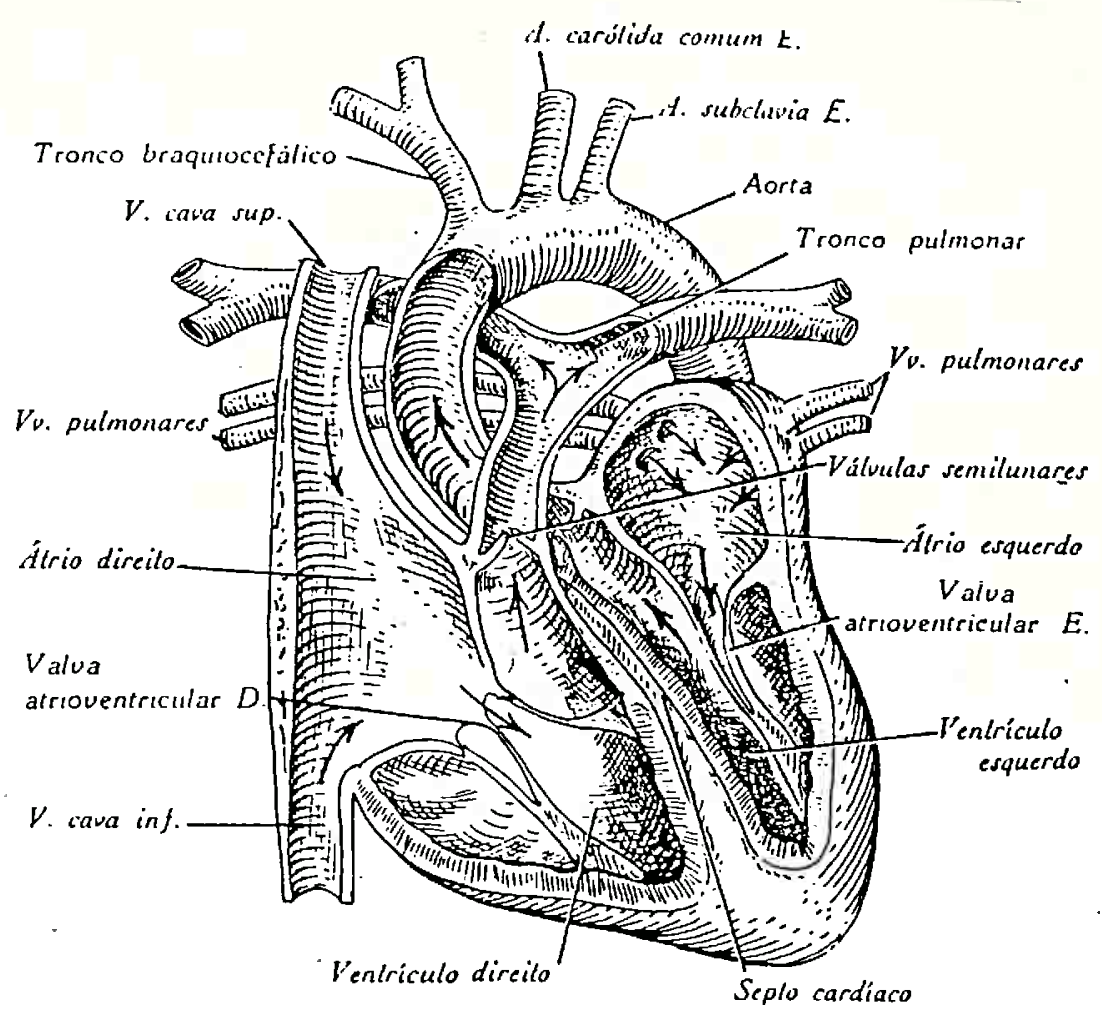

Fig. A6. Esquema das Cavidades Cardíacas In dicando o Sentido da Circulação. Reproduzido de Erhart, 1969.

o fluxo unidirecional é imposto pela ação das valvas do coraçāo (Fig. A7) pois as veias cavas e o seio coronário são providos desses dispositivos, reduzidos nos adultos; o ätrio direito comunica-se com o ventrículo direito pelo óstio átrioventricular, provido da valva tricúspide; o ventrículo direito comunica-se com o tronco pulmonar pelo óstio do mesmo nome, on de hä a valva do tronco pulmonar. O ätrio e o ventrículo es querdos comunicam-se por um östio contendo a valva mitral. Fí nalmente, no óstio da aorta existe a valva da aorta. o funcio namento das valvas processa-se de modo alternado pois quando 
as välvulas semilunares das valvas do tronco pulmonar e da aor ta se abrem, franqueando a passagem do sangue impulsionado pe los correspondentes ventrículos para a aorta e o tronco pulmo nar, fecham-se as valvas àtrio-ventriculares a fim de evitar o refluxo de sangue para os átrios. Quando as valvas átrio-ven triculares se abrem e o sangue passa dos ātrios para os ventrí culos correspondentes, as vālvulas semilunares mantém-se fechạ das evitando o refluxo.

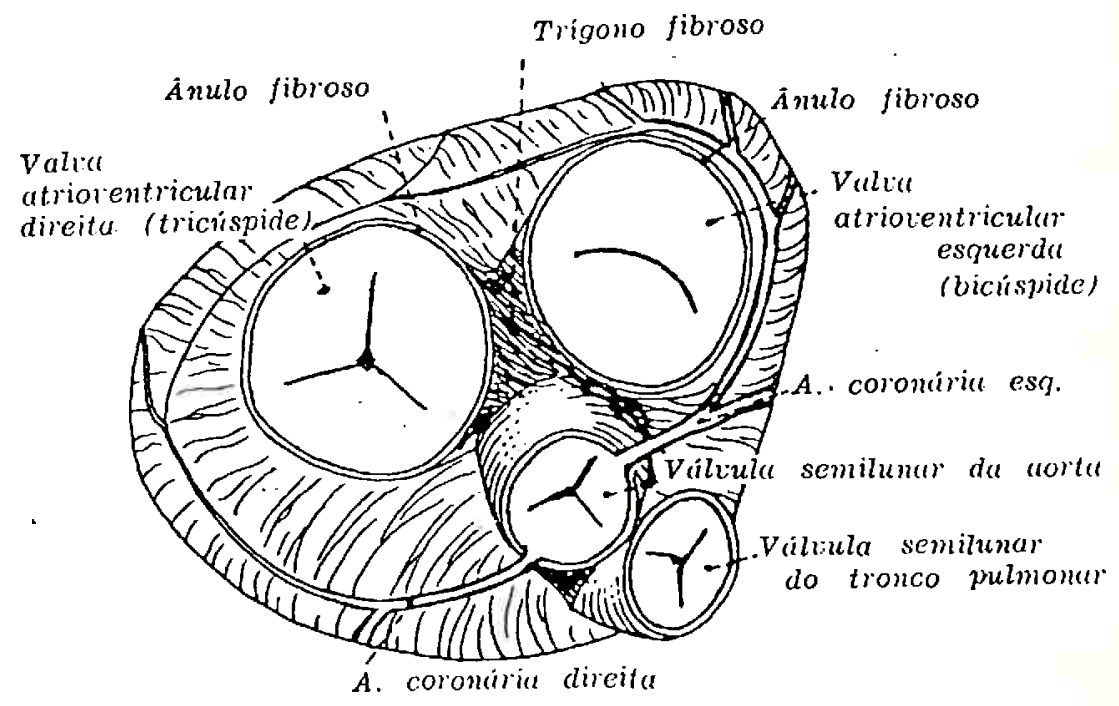

Fig. A7. Representação Esquemätica do Esqueleto fibroso do coração e dos óstios: ātrio ventriculares direito e esquerdo, do tronco da pulmonar e da aorta. Vista superior. Reproduzido de Erhart, 1969.

O sistema condutor do coração é um aparelho próprio excito condutor (Fig. A8) responsāvel pela propagação das con 
traçōes rítmicas sucessivas dos átrios e dos ventrículos, com preendendo: 1) nodo sino-atrial, localizado no ätrio direito e abraçando ventralmente a desembocadura da veia cava superior, e enviando finas ramificaçōes aos ātrios direito e esquerdo ; 2) nodo ātrio-ventricular, situado na espessura da porção mem branācea do septo cardíacio, imediatamente acima da inserção da cúspide septal da valva átrioventricular direita (tricüspide); de sua extremidade (polo) posterior partem prolongamentos para o àtrio direito e pela extremidade oposta tem como continuação o fascículo ätrioventricular; 3) fascículo ' ätrio-ventricular (feixe de His), continuação do nodo ātrio-ventricular, ocupa na sua porção inicial (tronco do fascículo) o septo àtrio ven tricular junto à borda superior da porção muscular do septo in traventricular. A seguir, divide-se em dois ramos, direito e esquerdo, um para cada ventrículo; estes ramos percorrem as correspondentes faces do septo interventricular e assim permi tem a propagação das contraçōes dos ātrios para os ventrículos. Em corações de mamíferos o nodo sinu-atrial está localizado na junção da veia cava superior com o ätrio direito. o nodo ätrio ventricular AV está situado na parte posterior direita do sep to inter-atrial. Os dois nodos não são ligados por tecido espe cífico do sistema de condução. As fibras miocárdicas atriais, porém, convergem e misturam-se com as do nodo AV. Este nodo con tinua com o feixe de His, que se divide na parte superior do septo inter-ventricular, em ramos direitos e esquerdos. Estes ramos descem no sub-endocárdio, em cada lado do septo, e aca bam no sistema de Purkinje, cujas fibras se distribuem para to das as partes do miocárdio ventricular. 


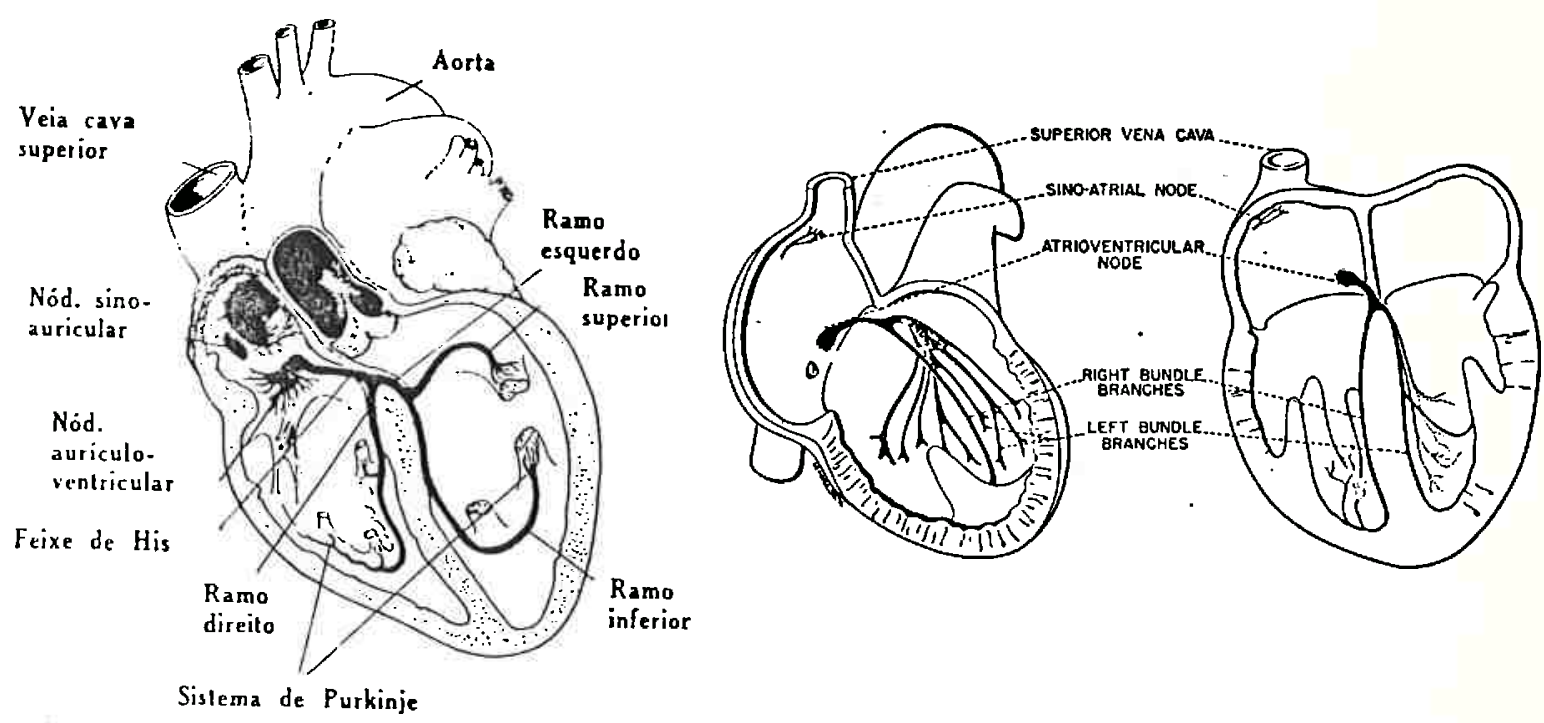

Fig. A8. Sistema de condução do coração. Reprodụ zido com permissão de Goldman: Principles of Clinical Electrocardiography, 6 th ed. Lange, 1967). Reproduzido de Gan non, 1972 e Rushmer, 1976.

As värias partes do coração trabalham normalmente nu ma certa sequência (Gannong, 1972): a contração atrial (sísto le atrial) é seguida da contração ventricular (sístole ventri cular) e, durante a diástole hā relaxamento das quatro cavida des (Fig. A9). O nodo sinu-atrial (nodo SA), o nodo aurícu lo-ventricular (nodo AV), o feixe de His com seus ramos di reito e esquerdo, e o sistema de Purkinge são estruturas es pecíficas que formam as partes de condução do miocárdio e apre sentam maior frequência cardíaca que o miocárdio (Figs. Alo e A11). O nodo AS despolariza-se, em condições normais, mais ra 
nidamente e o estimulo é conduzido para as outras regiões an tes de ocorrer sua despolarização espontânea. Por isso, o nodo sino-atrial é "o marca-passo" normal do coração. A sua despola rização rítmica determina a frequência cardíaca. Os impulsos gerados no nodo SA passam pelo miocárdio atrial até o nodo $\mathrm{AV}$, deste para o feixe de His e seus ramos, para chegar finalmente ate o miocárdio ventricular através do sistema de Purkinge.

A despolarização que nasce no nodo SA atravessa ra dialmente o miocárdio atrial, convergindo para o nodo AV. A despolarização atrial é completada em aproximadamente 0,1 segun do. Sendo lenta a velocidade de condução no nodo AV, hã um re tardo de aproximadamente 0,1 segundo, denominado retardo do no do AV, da condução da excitação para os ventrículos. Este re tardo é diminuído pela estimulação dos nervos simpáticos do co ração e aumentado pela estimulação dos nervos vagos. A partir da parte superior do septo, a onda de despolarização passa em 0,08-0,1 (s) atravēs das fibras de Purkinje, de condução rāpi da, para todas as partes dos ventrículos. Nos seres humanos, a despolarização do miocárdio ventricular inicia-se no lado es querdo do septo intraventricular e desloca-se inicialmente pa ra a direita, atravessando a parte média do septo, e posterior mente a onda de despolarização desce pelo septo até a ponta do coração. Em seguida a onda sobe às paredes ventriculares atē o sulco horizontal, passando simultaneamente do endocärdio em direção à superfície do epicárdio. As ủltimas partes do cora ção a se desnolarizaren são a região basal posterior do ventrícu 10 esquerdo, o cone pulmonar e a região mais alta do septo. 


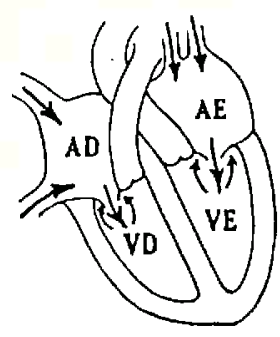

Fim de diástole

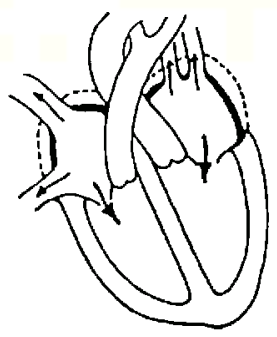

Sístole

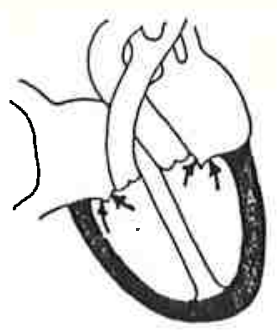

Conlraçāo

isométrica do ventriculo

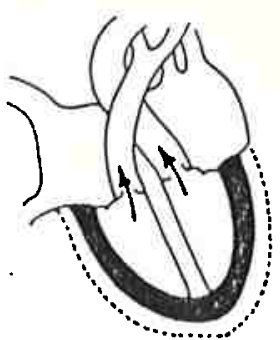

Expulsio ventricular

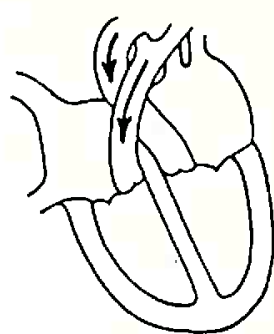

Relexamento isométrico do ventrículo

Fig. A9. O fluxo sanguíneo no coração e nos vasos grandes du rante o ciclo cardíaco. As regiōes que se contraen em cada fase, são indicadas em prêto. $A D$ e $A E$, átrio di reito e esquerdo; $V D$ e VE, ventrículo direito e es querdo. Reproduzido de Gannong, 1972.
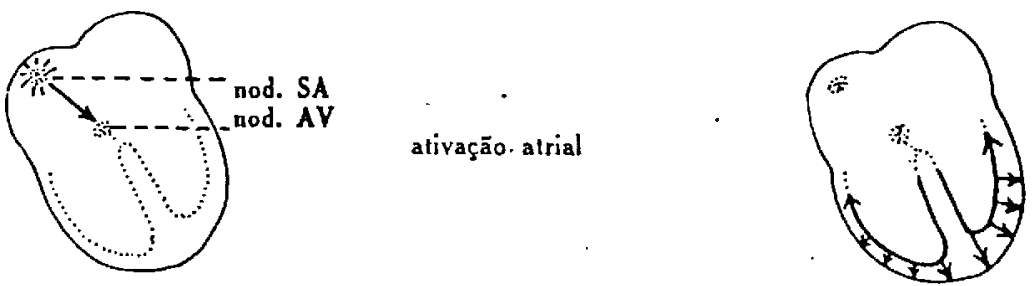

alivação da parte maior do ativaçäo. atrial miocárdio ventricular, partin-
do da superficie endocardial
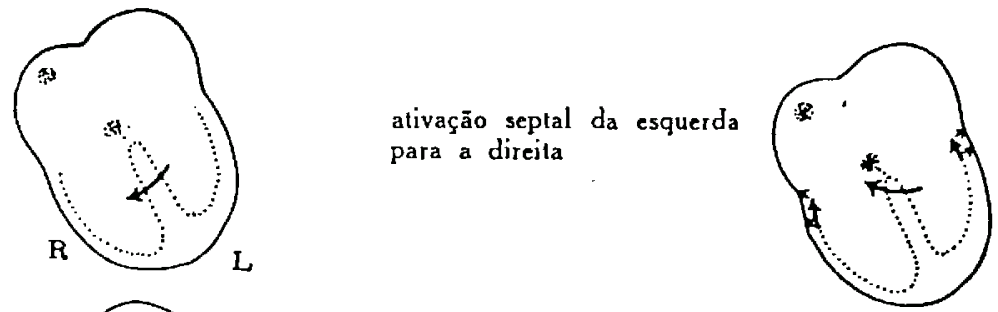

alivação alrasada da regiāo ativação septal da esquerda para a direita

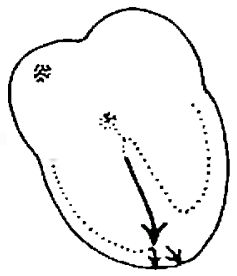

ativação da região antero-septal do miocárdio ventricular esterior do ventrículo esquerdo e do cone pulmonar

Fig. A10. Condução normal da atividade elétrica no coração. (Reproduzida com a permissão de Goldman: Principles of Clinical Electrocardiography, 6th ed. Lange, 1967) Reproduzido de Gannong, 1972. 


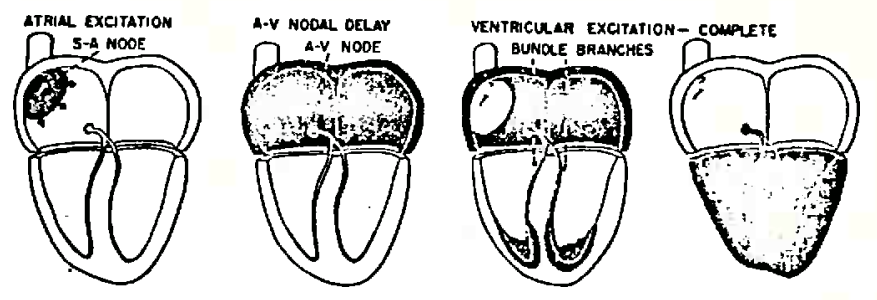

Fig. All. Sequência da Excitação Cardíaca. Reproduzido de Rushmer, 1976.

Este processo de despolarização normal provoca uma onda de contração que se propaga sobre o miocárdio. Nas fibras musculares a contração inicia-se logo após a despolarização e continua ainda por aproximadamente $50 \mathrm{milisegundos}$ depois da repolarização completa. O sangue aflui ao coração durante a diástole, enchendo tanto os àtrios como os ventrículos. 0 aflu xo diminui à medida em que os ventrîculos se distendem e, espe cialmente em frequência baixa, as válvulas AV se colocam em po sição de fechamento. A pressão nos ventrículos continua baixa e no final do diāstole as valvas mitral e tricúspide, situadas entre os átrios e os ventrículos, estão abertas e as valvas aórticas e pulmonares estão fechadas.

A contração atrial (sîstole atrial) faz entrar certa quantidade adicional de sangue nos ventrículos. Entretanto, dois terços do enchimento ventricular entram passivamente du rante a diástole. A contração do miocárdio atrial, que envolve os orifícios das veias cavas e pulmonares, diminue o diâmetro 
da entrada destas veias e a inercia do sangue que entra no co ração tende a manter o sangue dentro dele, embora haja um cer to regurgitamento do sangue para as veias durante a sistole atrial. A fase inicial da sístole ventricular, denominada fase isométrica ou isovolumétrica, perdura até que se abrem as vâl vulas aórticas e pulmonares. As valvas AV fecham-se no início da contração isométrica dos ventrículos, que exercem pressão sobre o sangue existente em suas cavidades. O encurtamento mus cular é muito pequeno mas a pressão intraventricular aumenta rapidamente. A duração desta fase è de aproximadamente 0,05(s). Durante a contração isomëtrica as valvas mitral e triscuppede abaulam-se para dentro dos átrios provocando um curto mas agudo aumento da pressão intra-atrial. No instante em que a pressão do ventrículo esquerdo ultrapassa a pressão diastólica na aor ta de aproximadamente $80 \mathrm{~mm}$ de $\mathrm{Hg}$, e no ventriculo direito,igual à pressão diastólica da artéria pulmonar de $10 \mathrm{~mm}$ de $\mathrm{Hg}$, abremse as valvas aórticas e pulmonares e tem início a fase de ex pulsão ventricular.

A expulsão è inicialmente rảpida mas diminui no de correr da sistole. A pressão intraventricular eleva-se ao seu máximo para depois diminuir um pouco até o final da sístole ven tricular. A pressão mäxima corresponde a $\pm 125 \mathrm{~mm} \mathrm{Hg}$ no ventrí culo esquerdo, sendo inferior a $25 \mathrm{~mm} \mathrm{Hg}$ no ventrículo direito (Fig. Al2). Bem no fim da sístole a pressão aórtica tórna-se naior do que, a intraventricular, mas durante um intervalo de tempo muito curto, o que faz com que o sangue continue no seu movimento em direção à periferia devidoa sua inërcia, ou momen tum. As valvas AV são puxadas para baixo pela contração do mio 
cárdio ventricular, causando diminuição da pressão intra-atrial. A quantidade de sangue expulsada de cada ventrículo durante a contração é de 70 a $90 \mathrm{ml}$ durante o repouso. No fim da sístole cada ventrículo contëm ainda $50 \mathrm{ml}$ de sangue, aproximadamente, constituindo o volume sistólico final.

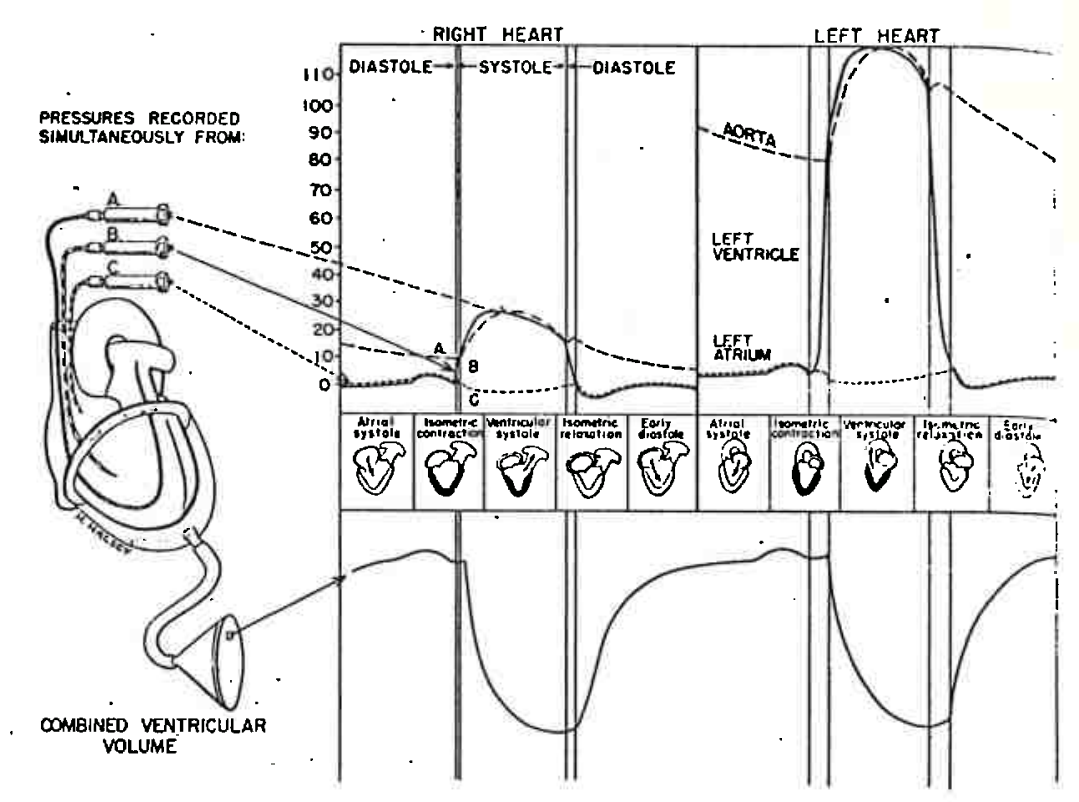

Fig. Al2. Efeitos mecânicos de contração cardíaca. Reproduzido de Rushmer, 1976.

o início da diástole ocorre quando o miocárdio ven tricular acha-se completamente contraído e a pressão intraven tricular, que jà se encontrava em declínio, diminui mais rapi damente. Esta fase denomina-se protodiảstole, com duração de aproximadamente 0,04 (s), finalizando-se quando é vencido o momentum da massa sanguínea expulsa. Neste instante, as va 1 vas aórticas e pulmonares se fecham provocando vibrações no san 
gue e nas paredes dos vasos. Depois do fechamento das valvas, a pressão intraventricular continua a cair rapidamente durante a fase do relaxamento isométrico dos ventrículos. Esta fase ter mina quando a pressão intraventricular torna-se menor do que a pressão intra-arterial, abrindo-se neste instante as valvas AV, o que permite a entrada do sangue nos ventrículos. No início, o enchimento é rápido, diminuindo à medida em que se processa a diāstole. A pressão intra-atrial aumenta depois da sístole ventricular até que as valvas AV se abrem. Neste instante a pressão intra-atrial cai para logo depois se elevar lentamente, atê a sistole atrial seguinte. 


\begin{abstract}
APENDICE B
RELATORIO DESCRITIVO, REIVINDICAÇOES E RESUMO DA PATENTE DE INVENÇÃO "APARFEIÇOAMENTOS EM BOMBAS".
\end{abstract}

A presente, patente refere-se a aperfeiçoamentos em máquinas denominadas de "circulação extracorpórea", "coração ar tificial", "māquiina coração-pulmão" ou similares, usadas nor malmente em cirurgias cardíacas, renais, ou outras, com bombas para infusão de substāncias quaisquer.

Conforme $\vec{e}$ do conhecimento geral, as operações do co ração ou outras têm a finalidade de liberar o ōrgão para que a operação possa ser processada sem qualquer perigo para o pa ciente, exigindo uma circulação extracorpörea para manter a pressão, o oxigênio e a temperatura normais.

Tais aparelhos recebem, por exemplo, o sangue prove niente das veias cavas do paciente e ainda o sangue extravaza do do paciente durante a operação. Para que o sangue possa cir cular normalmente no organismo do paciente são previstas bom bas acionadas por motores, constituídas por um eixo giratório acoplado ao motor no qual são fixados dois braços radiais dia metralmente opostos, possuindo roletes em seus extremos, livres, que comprimem intermitentemente a tubulação que contém o san gue proveniente do paciente e enviado ao oxigenador. 
As bombas necessitam de hastes radiais reguläveis a fim de possibilitar uma maior ou menor compressão no tubo por onde flui o sangue e, até o momento, esta regulagem è realizada manualmente, separadamente em cada uma das hastés, através de parafusos, de modo que as hastes são encompridadas ou encolh $\underline{i}$ das e por fim fixadas no comprimento desejado, uma de cada vez, resultando uma regulagem imprecisa e realmente dificil.

A presente patente soluciona o problema apresentado, possibilitando uma regulagem automática para as duas hastes conjuntamente, afastando ou comprimindo os roletes contra os tubos por onde flui o sangue, tornando a regulagem mais fácil e precisa. Além disso, o dispositivo de regulagem aciona um po tenciómetro, ou componente similar, resultando em uma medida da espessura entre o rolete e a parede curva da caçapa da tubu laçāo. A medida é indicada digitalmente no painel onde uma chạ ve seletora possibilita ainda medidas de fluxo sanguíneo e ve locidade angular do eixo do motor, o que foi possível pela in corporação de circuitos eletrônicos no sistema.

Os desenhos indicados nas Figs. B1 e B2 ilustram a presente patente.

Segundo a invenção, os aperfeiçoamentos em bombas, ob jeto da presente patente, se referem ao ajuste simultāneo das hastes do rolete e de medidas de espessura do tubo, fluxo de sangue e velocidade angular do motor; as mäquinas similares normalmente conhecidas, possuem quatro bombas que recebem o sangue proveniente do paciente e o enviam de volta para o cor po. As quatro, ou mais bombas podem ser ou não iguais e para 
B. 3

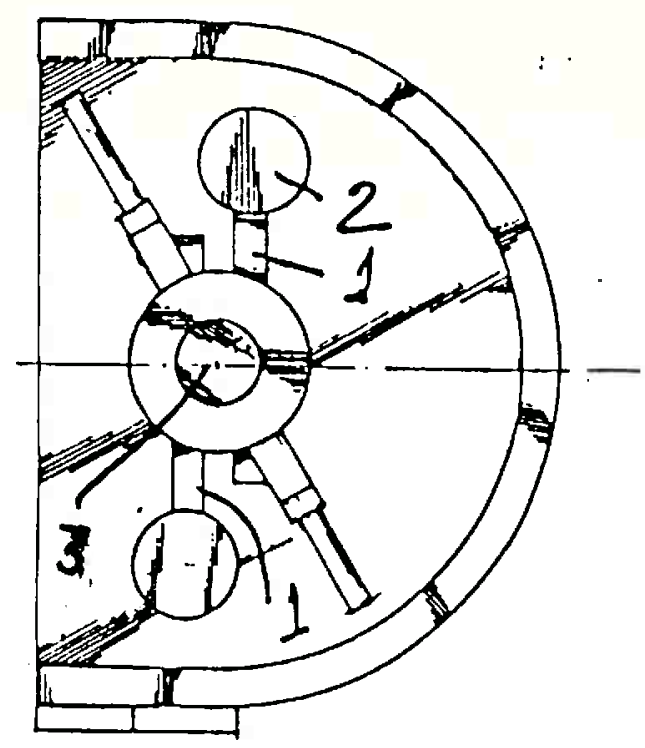

Fig. B1. Vista frontal da bomba sanguínea.

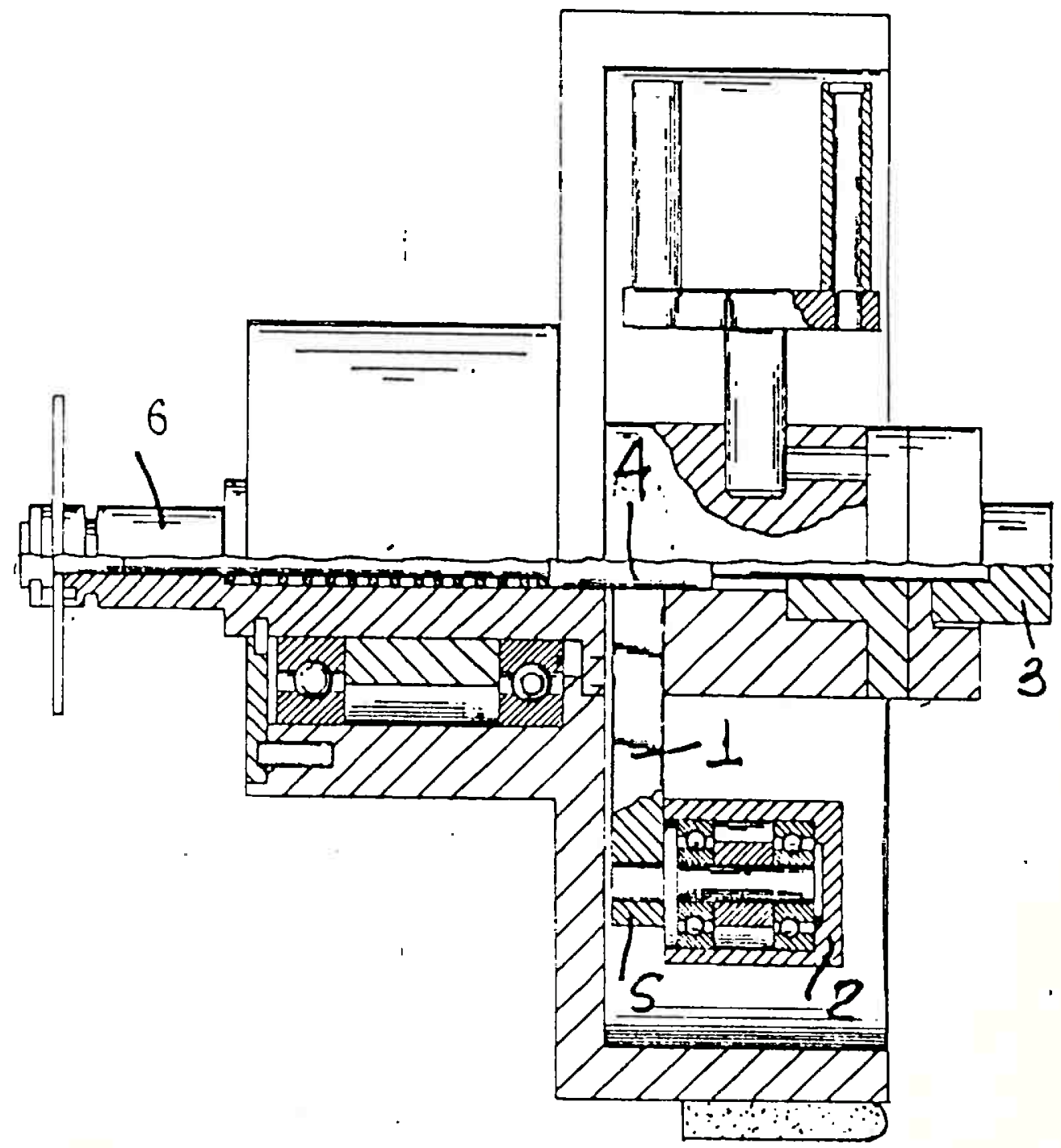

Fig. B2. Vista em corte'transversal da bomba sanguínea. 
as mesmas finalidades.

Assim a regulagem do curso axial das hastes (1) dos roletes (2) è feita simultaneamente atravēs de botão, parafuso ou similar (3) acoplado a um pino (4), o qual apresenta inter namente ao corpo (6) do dispositivo um longo trecho denteado(4), onde se acoplam cremalheiras (5) previstas nas extremidades in ternas das referidas hastes (1). Alternativamente, a regulagem automática das hastes poderia ser feita através de um minimotor acoplado ao eixo, o qual poderia ser acionado simplesmente por chave existente no painel.

O mesmo pino que afasta ou comprime os roletes, con forme mencionado anteriormente, tem movimento longitudinal a fim de se acoplar a um dispositivo qualquer, por exemplo, um potenciômetro que aciona um medidor digital, o qual indicará a distância do afastamento dos roletes em relação à parede da car caça diretora da tubulação. Acoplamentos do eixo do motor a dis positivos convenientes possibilitam medidas alternativas e adi cionais do fluxo sanguíneo e da velocidade angular dos roletes. As inovações a serem patenteadas garantem condiçōes de operações mais perfeitas, precisas e controladas, resultan do em maior segurança para o paciente.

RE IVINDICAÇÕES

1. "APERFEIÇOAMENTOS EM BOMBAS", caracterizados pe 
1o fato de a regulagem do curso axial das hastes 1 , em cujos extremos são previstos roletes, poder ser feita simultaneamen te atravês de botão, parafusio, ou similar 3 acoplado a um pino 4 o qual apresenta, internamente ao corpo 6 do dispositivo, um longo trecho denteado 4 , onde se acoplam cremalheiras 5 previs tas nas extremidades internas das referidas hastes 1; alterna tivamente, a regulagem automática das hastes poderia ser feita através de um mini-motor acoplado ao eixo, o qual poderia ser acionado simplesmente por uma chave existente no paine1.

2. "APERFEIÇOAMENTO EM BOMBAS", como reivindicado em 1, caracterizado pelo fato de, o mesmo pino que afasta ou compri me os roletes acima mencionados ter movimento longitudinal a fim de se acoplar a um dispositivo qualquer, por exemplo, um potenciómetro que aciona um medidor digital, o qual indicarà a distância do afastamento dos roletes em relação à parede da carcaça diretora da tubulação; acoplamentos do eixo do motor a dispositivos convenientes possibilitam medidas alternativas e adicionais do fluxo sanguíneo e da velocidade angular dos ro letes.

RESUMO

Patente de Invenção "APERFEIÇOAMENTOS EM BOMBAS", com preendendo regulagem do curso axial das hastes em cujos extre mos são previstos roletes ser feita simultaneamente através de botão, parafuso, ou similar acoplado a um pino o qual apresen 
ta, internamente ao corpo do dispositivo, um longo trecho den teado, onde se acoplam cremalheiras previstas nas extremida des internas das referidas hastes; alternativamente, a regula gem automätica das hastes poderia ser feita através de um mi ni-motor acoplado ao eixo, o qual poderia ser acionado sim plesmente por uma chave existente no painel. 


\section{APENDICE C}

RELATORIO DESCRITIVO, REIVINDICAÇOES E RESUMO DA PATENTE DE INVENÇÃO "REFRIGERADOR".

A presente patente refere-se a aperfeiçoamento em processo para circulação extracorpórea ou coração artificial, máquina coração-pulmão ou similares, usadas normalmente em cí rurgias cardiacas, renais, ou outras, com bombas para infusão de substâncias quaisquer.

Conforme é do conhecimento geral, as operações do co ração, ou outras, têm a finalidade de liberar o órgão para que a operação possa ser processada sem qualquer perigo para o pa ciente, exigindo uma circulação extracorpoórea para manter a pressão, o oxigênio e a temperatura normais.

Tais processos se referem, por exemplo, ao fato de receberem o sangue proveniente das veias cavas do paciente e ainda o sangue extravasado do paciente durante a operação. Pa ra que o sangue possa circular normalmente no organismo do pa ciente, são previstas bombas acionadas por motores, e para res friar o sangue usualmente se utiliza gêlo colocado manualmente, o que não oferece grande segurança pois, além de nunca se sa ber a quantidade realmente exigida de gêlo, podem ocorrer ac $\underline{i}$ dentes de esquecimento, falta de gêlo e outros. 
o processo em questão, soluciona os problemas ocasio nados, através de um minirefrigerador para resfriar o sangue que vai para o oxigenador, refrigerador este equipado com vâa rios acessórios e particularidades relatadas a seguir, garan tindo melhores condiçōes de funcionamento e maior confiabilida de ao conjunto, uma vez que o resfriamento do sangue è automá tico.

o processo, objeto da presente patente, o "REFRIGERA DOR" é uma denominação para uma inovação inédita e peculiar a ser incorporada às máquinas usualmente denominadas "coração a $\underline{r}$ tificial" ou "máquina coração-pulmão" ou ainda "máquina de cir culação extracorpórea" constituído por um sub-sistema refrige rador completo equipado com indicadores de painel, circuitos de controle e para medição da temperatura do paciente, ou do sangue do paciente ou ainda de substâncias existentes em recí pientes incorporados ao sistema. Inclui, ainda, um sub-sistema elétrico com lâmpadas de iluminação de emergência do oxigena dor. O sistema prevê a inclusão de circuitos de controle para acionamento de vários dispositivos existentes, em função dos níveis dos líquidos existentes em tanques, podendo inclusive im pedir o acionamento de bomba(s) e resistência(s) elétrica (s) para aquecimento. A fim de se possibilitar controle, indicação no painel e medição parcial e/ou total dos tempos de perfusão, de anticoagulação e de anóxia são incorporados ao sistema cro nômetros e circuitos temporizadores eventualmente acionando alarmes sonoros e visuais. Na eventualidade de falta de ener gia elétrica fornecida pela concessionāria local, o sistema opera com uma unidade geradora de energia elétrica de emergên 
cia, a qual contêm proteção para diversos dispositivos incluin do as bombas e os roletes. Botões de testes existentes no pai nel possibilitam a verificaçäo räpida e eficaz do funcionamen to dos indicadores e alarmes sonoros e luminosos do sistema.

O minirefrigerador $\overrightarrow{\mathrm{e}}$ acoplado a um evaporador coloca do em um dos recipientes de líquido, possibilitando resfriamen to automático deste líquido ao se ligar o sistema. 0 fluxo des te líquido é selecionado entre este recipiente eoutro conten do resistência(s) elétrica(s) para aquecimento, sendo a bomba responsāvel pela ciṛculação do líquido controlada pelos níveis existentes nos dois recipientes. Na realidade, hä.sensores de níveis máximo, normal e mínimo para os dois recipientes. Ou tros sensores existentes nos dois recipientes, bem como um sen sor externo colocado no paciente, possibilitam controle e acio namento de dispositivos do sistema, bem como medidas das tempe raturas correspondentes com indicaçōes no painel e alarmes so noros e visuais.

Um sub-sistema incorporado ao sistema possibilita tem porização e medidas de tempo a fim de possibilitar controle,me didas e indicação no painel de tempos totais e parciais de per fusão, anticoagulação e anóxia, possuindo ainda alarmes de vā rios tipos.

Geração de energia elétrica de emergência é possível atravès de uma unidade autônoma que è acionada automaticamente quando da falta de energia elétrica fornecida pela concessioná ria local, contendo ainda lâmpadas para iluminação do oxigena dor coutros focos de luz. 
Indubitavelmente o conjunto de itens incorporados constitui algo novo e funcional, possibilitando uma maior ver satilidade e utilidade das māquinas desta categoria.

REIVINDICAÇOES

1. "REFRIGERADOR", mäquinas usualmente denominadas "coração artificial" ou "mäquina coração-pulmão" ou ainda "mā quina de circulaçāo extracorpórea", caracterizado pelo fato de o sangue passar por um sub-sistema refrigerador completo equi pado com indicadores de painel, circuitos de controle e. para medição da temperatura do paciente, ou do sangue do paciente ou ainda de substâncias existentes em recipientes incorporados ao sistema; inclui, ainda, um sub-sistema elëtrico com lâmpa das de iluminação de emergência do oxigenador; o sistema prevê a inclusão de circuitos de controle para acionamento de vários dispositivos existentes, em função dos níveis dos líquidos exis tentes em tanques, podendo inclusive impedir o acionamento de bomba(s) e resistência(s) elëtrica(s) para aquecimento.

2. "REFRIGERADOR", como reivindicado em 1, caracter $\underline{i}$ zado pelo fato de; a fim de possibilitar controle, indicação no painel e medição parcial e/ou total dos tempos de perfusão, de anticoagulação e de anóxia, serem incorporados ao sistema cro nômetros e circuitos temporizadores eventualmente acionando alarmes sonoros e visuais; na eventualidade de falta de ener gia eletrica fornecida pela concessionāria local, o sistema 
opera com uma unidade geradora de energia elëtrica de emergên cia, a qual contém proteção para diversos dispositivos incluin do as bombas e os roletes. Botões de testes existentes no pa nel possibilitam a verificação rāpida e eficaz do funcionamen to dos indicadores e alarmes sonoros e luminosos do sistema.

3. "REFRIGERADOR", como reivindicado at $\overrightarrow{\mathrm{e}} 2$, caracte rizado pelo fato de o liquido ser resfriado automaticamente ao ser ligado o sistema, e o fluxo deste líquido é selecionado en tre este recipiente e outro contendo resistência(s) elétrica(s) para aquecimento, sendo a bomba responsāvel pela circulação do líquido, controlada pelos níveis existentes nos dois recipien tes; Controle e acionamento de dispositivos do sistema, bem co mo medidas das temperaturas correspondentes com indicações no painel e alarmes sonoros e visuais.

4. "REFRIGERADOR", como reivindicado até 3 , caracte rizado pelo fato de as medidas de tempo serem temporizadas, a fim de possibilitar contrôle, medidas e indicação no painel de tempos totais e parciais de perfusão, anticoagulação e anöxia, possuindo ainda alarmes de vārios tipos.

RESUMO

Patente de Invenção "REFRIGERADOR", em que o sangue passa por um sub-sistema refrigerador completo equipado com in dicadores de painel, circuitos de controle e para medição da temperatura do paciente, ou do sangue do paciente ou ainda de 
substâncias existentes em recipientes incorporados ao sistema; inclui, ainda, um sub-sistema elétrico com lâmpadas de ilumina ção de emergência do oxigenador; o sistema prevê a inclusão de circuitos de controle para acionamento de vários dispositivos existentes, em função dos níveis dos líquidos existentes em tanques, podendo inclusive impedir o acionamento de bomba(s) e resistência(s) elétrica(s) para aquecimento; a fim de possibi litar controle, indicação no painel e medição parcial e/ou to tal dos tempos de perfusão, de anticoagulação e de anóxia, são incorporados ao sistema cronómetros e circuitos temporizadores eventualmente acionando alarmes sonoros e visuais. 


\author{
APENDICE D \\ DOCUMENTOS ACOMPANHANTES. CÓDIGO DE APLICAÇAOO
}

o equipamento médico deve ser concebido, produzido e utilizado de acordo com um conjunto de prescrições apropriadas para proteger tanto o paciente e o operador quanto o ambiente, os equipamentos $e$ as instalações contra os riscos inerentes a sua particular aplicação. Para atender a essa exigência, todo equipamento destinado a algum uso na prätica mēdica deve con ter documentos acompanhantes contendo ao menos as instruções para utilização, uma descrição técnica e a referência de ende reço do fabricante que permita ao usuärio reportar-se para even tual contacto. Um código de aplicação auxilia o usuário a em pregar o equipamento de maneira segura e confiävel, devendo ser anexado à documentação (ABNT, NB961; IEC, Publicação 601-1). Cumpre ressaltar que a utilização segura de qualquer equipamen to médico está primariamente sob a responsabilidade do opera dor, que deve observar escrupulosamente as instruções forneci. das pelo fabricante. A documentação anexada ao equipamento de ve ser considerada corro uma de suas partes integrantes.

O objetivo deste Apêndice é estabelecer, resumidamen te, um conjunto de prescrições bāsicas sobre a conceituação e as diretrizes de segurança relativas aos documentos acompanhan tes. Seu conteúdo aplica-se não somente ao Sistema de Circula 
ção Extracorpórea desenvolvido neste trabalho mas a todo equi pamento destinado a ser utilizado na prática médica. Apesar do autor possuir a documentação do Sistema de Circulação Extracor pórea, não a incluirâ neste texto devido a sua extensão.

As instruçōes para utilização devem conter toda a in formação necessária para operar o equipamento de acordo com as suas especificações e sem exceder os limites de segurança. Dé verả incluir, ao menos, uma explanação sobre:

- descrição geral e especificações do equipamento;in formações gerais de operação.

- a atuação dos comandos; características de paine1.

- a visibilização de valores dos sinais de entrada, de saída e de controle.

- a sequência de operações.

- as partes de entrada e de saída de sinal que se des tinam a conexões com outros equipamentos especificados ou com o próprio paciente. Neste último caso, devem ser fornecidos os mëtodos de limpeza, de de sinfecção e/ou de esterilização a serem empregados nas partes em contacto com o paciente durante a utilização normal. Quando necessário, deve-se in dicar os agentes de esterilização apropriados e de clarar os limites de temperatura, pressão, umidade 
e tempo de aplicação que aquelas partes podem tó lerar.

- as partes extraíveis e/ou intercambiāveis e os aces sórios, indicando o modo de efetuar as conexōes e desconexōes necessārias dessas partes e acessórios.

- a reposição de material que é consumido durante a operação do equipamento.

- advertência referindo-se à necessidade da verifica ção periódica ou da substituição da fonte de alimentação adicional em equipamento operado sob a tensão da rede e dotado de tal fonte adicional. Se o equipamento for de classe I para operar sob ten são da rede com utilização alternativa de uma fon te de alimentação elétrica interna, deve-se incluir uma declaração estabelecendo que o equipamento de ve ser operado com a fonte de alimentação elétrica interna sempre que houver dưvida sobre a integrida de da instalação do condutor de aterramento para proteção.

- diretrizes para assegurar o emprego sem risco e a manutenção adequada de equipamento dotado de bate rias recarregáveis. Se o equipamento possibilitar o uso com fonte(s) de alimentação(ões) especificada(s) e/ou carregador de bateria deve(m) ser identificada(s) essa(s) fonte(s) ou carregador de bate ria.

- advertência, ou símbolo correspondente a um aviso 
desse tipo, referindo-se a existência de partes sob tensão destinadas a serem conectadas a circuitos externos diversos daquele da rede de alimentação elétrica. Deve ser colocado em posição tal que to da pessoa que venha a ter acesso a essas partes sob tensão fique advertida da necessidade de separar o equipamento das diversas redes de alimentação. Al ternativamente, um dispositivo de intertravamento pode ser fornecido para assegurar que todos os cir cuitos estão separados.

- aplicações típicas.

As instruções para utilização e a descrição técnica devem incluir as possíveis classificações do equipamento, rela tivamente aos seguintes aspectos:

- tipo de proteção contra choque elétrico (classe de segurança).

- grau de proteção contra choque elétrico.

- grau de proteção contra entrada de 1íquidos.

- método de esterilização ou desinfecção permitido pelo fabricante.

- grau de segurança de utilização na presença de at mosfera inflamável ou mistura inflamâvel.

- modo de operação (em serviço).

- grau de conexões elétricas entre o equipamento e o paciente. 
A documentação também deve reproduzir integralmente as marcações (figuras, símbolos, declarações de advertência e abreviações) afixadas externa e internamente no equipamento, es clarecendo os seus significados. Se algumas marcações não essenciais deixaram de ser afixadas no equipamento por qualquer motivo, devem ser registradas por completo nos documentos acom panhantes. Essas marcações devem indicar de modo inequívoco in formações relativas aos seguintes aspectos:

- indicaçāo de origem, referência de modelo ou tipo e nümero de sërie.

- tipo de alimentação do equipamento, ou seja, ali mentado pela rede, internamente ou por uma fonte de alimentação específicada.

- conexão à fonte de alimentação e terminais de ater ramento.

- frequência da alimentação.

- valor da energia ou da potência de entrada para o equipamento.

- valor de saída de energia ou de potência em tomadas auxiliares de rede instaladas no equipamento.

- classificações.

- especificações de fusíveis e lâmpadas de sinalização, bem como indicações de comandos e mostradores luminosos existentes no painel.

- caracterização da saída. 
- efeitos fisiológicos . Aecorrentes da aplicação.

- indicações de "ALTA TENSAO" junto a dispositivos terminais de alta tensão.

- condições de resfriamento.

- estabilidade mecânica.

- embalagem de proteção.

- meios de proteção removíveis.

- indicações de cilindros de gás medicinal e de suas conexões.

Internamente ao equipamento, outras marcações podem ser necessárias, tais como:

- potência mäxima de elementos aquecedores ou soquetes de 1âmpadas para aquecimento.

- partes sob tensão.

- tipo de bateria e o modo de inserção da mesma.

- fusiveis sem acesso pelo lado externo.

- terminais de aterramento funcional e para proteção.

- terminal para conexão do condutor de alimentaçāo neutro.

- indicação de regiōes com temperaturas elevadas ou de partes em movimento existentes dentro do equipa mento e que acarretem riscos de segurança.

A descrição técnica deve conter todas as informações sobre diagramas de blocos e esquemas de circuitos, diagramas de 
posicionamento e interligação além de listagens e característị cas de peças componentes, descriçōes em gera1, tipos e condições de ensaios, instruções para calibração e aferição ou quais quer outras informações que proporcionem assistência ao pes soal técnico devidamente qualificado do usuário, na reparação da quelas partes do equipamento que são classificadas pelo fabr $\underline{\mathbf{i}}$ cante como reparáveis. Todas as informaçōes que possam ser con sideradas essenciais para uma operação segura devem ser fornecidas e, tanto quanto possível, de acordo com as normas de do cumentação existentes. Eventualmente, a descrição técnica pode conter apenas uma declaração estabelecendo que o fornecedor co locará à disposição do usuário, a pedido, as informações técni cas necessārias, conforme explícita discriminação em contrato de compra e venda.

A descrição técnica deve fornecer dados sobre tipo e caracteristicas de partes eventualmente mencionadas nas instru ções para utilização, tais como fusíveis, lâmpadas, partes in tercambiāveis e/ou destacáveis e acessōrios que fiquem sujeitos a degradação durante uso normal, desde que as informações técnicas adicionais complementem os dados meramente de utilização e op̣eração do equipamento fornecidos anteriormente.

Alẻm dos detalhes incluídos nas instruções para uti 1ização, a descrição técnica deve declarar se hả providências especiais ou condições particulares a serem observadas para a instalação do equipamento e sua posterior colocação em serviço, bem como sobre condições ambientais restritivas para uso, tran $\underline{s}$ porte e armazenamento. As condições a serem consideradas devem ser correspondentes ao uso normal e de primeira falha. 
Uma orientação sobre manutenção e inspecção preventí vas, a serem efetuadas pelo usuário, deve ser incluída nas ins truções para utilização a fim de garantir a segurança, a confia bilidade e o desempenho apropriado do equipamento. A descrição deve conter detalhes suficientes inclusive quanto à frequência dos procedimentos e menção das partes nas quais a inspecção e a manutenção preventivas devem ser efetuadas por outras pes soas. Os detalhes sobre o procedimento efetivo da manutenção preventiva e das inspeções com informações pormenorizadas não necessitam constar nas instruções para utilização mas apenas na descrição técnica. Essas instruções devem fornecer informa ções para efetuar sem risco a manutenção de rotina. Todos os ensaios, bem como a sequência desses ensaios, devem estar deta 1hadamente descritos nos documentos acompanhantes.

Finalmente, as instruções para utilização devem con ter uma declaração estabelecendo que o fabricante, o montador, o instalador ou o importador se considera responsável por efe tos sobre a segurança, a confiabilidade e o desempenho do equi pamento, desde que satisfeitas as seguintes condições:

- operações de montagem, extensões, reajustes, modi. ficações ou reparos são executados por pessoal por ele autorizado.

- a instalação elétrica ligada ao equipamento. está em conformidade com as prescrições de Normas nacio nais e internacionais, tais como Projeto de Norma 3:01.62.1-01 da ABNT e Documento 62A (Secreta 
riat) 55 da IEC.

- o equipamento ê empregado em concordância com os documentos acompanhantes e o código de aplicação.

o Código de Aplicação complementa as instruções para utilização e a descrição tẻcnica, fornecendo com destaque informações sobre uma sērie de assuntos técnicos, administrativos e organizacionais concernentes ao equipamento, tanto em rela ção a seu uso como ao seu ambiente e às instalações (ABNT, NB 961). O Código deve incluir, ao menos, os seguintes tópicos:

- significado das värias classificações de equipamentos eletro-médicos.

- orientação para escolha da utilização adequada de equipamen to eletro-mëdico.

- itens de segurança a serem verificados no ato de recebimento de equipamento novo.

- recomendação de equipamento a ser ligado à fonte de alimentação de emergência, sem interrupção:

- providências de segurança a tomar, sob condições de emergência, durante procedimentos normais.

- modos de evitar queimaduras causadas por radiações de alta-frequência em procedimentos cirürgicos.

- uso de gases anestésicos explosivos em combinação com equipamento eletro-mëdico.

- providências a tomar na eventualidade da presença de interferência de alta-frequência. 
- modo de evitar que fenômenos transitórios se tor nem perigosos.

- modo de usar instrumentos de maior risco, e usualmente utilizados conjuntamente com outros, por exemplo, um desfibrilador .

- lista de ensaios de segurança para procedimentos normais.

- ensaio de rotina de correntes de fuga.

- avaliação da corrente de fuga atravês do paciente causada por diferentes unidades do equipamento $1 \underline{i}$ gadas ao paciente.

- medição correta por meio de dosímetros de Raios-X.

- modos de verificação de equipotencialidade.

- modos de interligação em associações de aparelhos.

- modos de evitar elos de retorno para terra, interferência, etc.

- modos de contornar os problemas ocasionados por campo magnético interferente muito forte, produzi do pela rede elétrica.

- possibilidade de o equipamento ficar exposto ao sol.

- calendārio de manutenção preventiva.

E evidente que a aplicação segura do equipamento re que r boa organização, conhecimento sólido e disciplina quanto à inspeção regular. Consequentemente, o Código de Aplicação de 
ve dar informações às autoridades responsäveis sobre medidas de organização e programas de instrução e de inspeção, devendo ne cessariamente incluir os seguintes tópicos:

- estabelecimento de respoonsabilidades quanto à segu rança do equipamento, à partir de sua compra e da aquisição de suprimentos elétricos para a instalação e utilização.

- estabelecimento de um sistema de arquivos de dados técnicos, incluindo instruções de montagem, manual de manutenção, instruções para utilização, descrição técnica, livro de registro de ocorrēncias e o próprio Código de Aplicação.

- organização do ambiente hospitalar segundo "graus de segurança" e da alocação do equipamento corres pondente a esse ambiente.

- organização de um fichário central de endereços de contactos, para se recorrer na eventualidade de de feitos no equipamento e/ou nas instalações.

- organização de programas de inspeção para verifica ção de recebimento de equipamento novo, revisado, reparado ou modificado, bem como para inspeção pe riódica do equipamento e das instalaçōes, arquivan do-se os relatórios e mantendo-se contactos com os fornecedores. Deve haver um controle periódico pa ra verificar se as instruções dadas com referência a segurança e à operação continuam sendo observa das. 
- organização de treinamento das equipes e de pessoal médico, para-médico e técnico. Os programas de tre $\underline{\mathbf{i}}$ namento e instrução devem conter matérias específicas e diferentes para instrução de pessoal médico e para médico, em relação àquelas destinadas ao pes soal técnico e ao paciente tratado em casa, ou para sua família.

Vários textos normativos nacionais e internacionais contendo informações detalhadas sobre documentos acompanhantes e cỏdigo de aplicação são incluídos nas referências bibliográfi cas. Seus conteúdos devem necessariamente ser considerados na elaboração da documentação de um equipamento utilizado na prāti ca médica. Outras referências relacionadas com a ārea de Enge nharia Clínica e/ou Médica contém informaçōes adicionais que po dem auxiliar e complementar um dado Código de Aplicação, servin do eventualmente como leituras complementares deste Cödigo. 


\section{REFERENCIAS BIBLIOGRÄFICAS}

AIKEN, D.W., 1961. A method of securing tubing conections in cardiopulmonary by pass equipment, J. Thor. Card. Surg. 41, pgs. $272-3$.

ALEXANDER, B.; READ, R. and GAINS, E., 1982. A simple device for blond-flow control in extracorporeal circuits, Journal of Me dical Engineering and Technology, vol. 6, N 1, pp. 28-31, $\mathrm{Jan} / \mathrm{Feb}$.

ALLEN, J. GARROTT, 1958. Extracorporeal Circulation, Charles Thomas Publisher.

AMBRUS, J.L., 1955. A simple heart-lung apparatus, not inju rious to white cells and thrombocytos, Trans. Amer. Soc. Art. Intern. Organs, 1, pgs. 98-101.

AMSDEN, D.M. e AMSDEN, R.T., 1976. Quality Control Circles: Applications, Tools and Theory. American Society for Quality Control, wisconsin.

ANALOG DEVICES, 1978. Data acquisition products catalog, Ana $\log$ Devices, Inc.

ANDLRSAN, R.G., 1980. Organisation and Methods, Macdonald and Evans, New York, 2- - Edition.

ANDREASEN, A.T. \& WATSON, F., 1952. Experimental cardiovascular surgery. Brit. J. Surgery, 39:548.

ASSOCIAÇAO BRASILEIRA DE NORMAS TECNICAS, 1981. Planos de amos tragem e procedimento para qualificação de componentes, ba seados na taxa de falhas, Norma de Procedimento NBR 6534.

ASSOCIAÇĀO BRASILEIRA DE NORMAS TECNICAS, 1981. Confiabilida de, Norma Brasileira NBR 5462. 
ASSOCIAÇÃO BRASILEIRA DE NORMAS TECNICAS, 1983. Símbolos grạ ficos para uso em equipamentos, Projeto de Norma 3:06.3.2-011.

ASSOCIAÇÃO BRASILEIRA DE NORMAS TECNICAS, 1984. Coletânea de Normas: Programas de Qualidade. Publicação do Comitē Brasi leiro de Eletricidade.

ASSOCIAÇAO BRASILEIRA DE NORMAS TECNICAS, 1985. Coletânea de Normas: Planos de Amostragem I e II. Publicação do Comitê Brasileiro de Eletricidade.

ASSOCIAÇĀO BRASILEIRA DE NORMAS TECNICAS, 1986. Aspectos Básicos da Conceituação e das Diretrizes de Segurança de Equipamonto Líctrico Utilizado na Prática Médica, Norma Brasileira NBR 9153 .

ASSOCIAŢION FOR THE ADVANCED OF MEDICAL INSTRUMENTATION, 1978. Safe current limits for electromedical apparatus, ANSI/AAMI, SCL $12 / 78$.

BAHILL, A.T., 1981. Bioengineering-Biomedical, Medical and Clinical Engineering, Prentice-Hall, Englewood Cliffs.

BALDERMAN, S.C., BINETTE, J., ChAN, A.W.K., GAGE, A.A., 1983. The optimal temperature for preservation of the myocardium du ring global ischemia, Ann. Thorac. Surg. 35: 605-14.

BARTHELEMY, R.; VIVES, M.; COUZY, H.; MNRUCCI, J.P. , PUEL, P. e ENJALBERT, A., 1978. Dispositif de controle automatique des aspirations chirurgicales en chirurgie cardiaque, Medi cal 'E Biological Engineering \& Computing, March.

BEALL, A.C. Jr.; SALIS, R.T.; KAKVAN, M.; MORRIS, G.C.Jr. ; NOON, G.P. and DE BAKEY, M.E., 1976. Clinical experience with the Teflo disposable membrane oxygenator, Ann.Thorac. Surg., vol. 21, No 2, pp 144-50, February. 
BERNE, R.M. G LEVY, M.N., 1981. Cardiovascular Physiology, C. $V$. Mosby Co, Fourth Edition, St. Louis.

BERRY, W.B.; DAVIS, L. and DANIELL, M.B., 1976. Clinical trial with a disposable membrane oxygenator, from the Division of Cardiovascular and Thoracic Surgery, Memorial Hospital, Cha ttanooga, Tennessee.

BEST, R.E., 1984. Phase Locked Loops, McGraw-Hi11, New York.

BIDDER, 1862, in Conceição, D.S. e Gomes, O.M., 1973. "Circula ção extracorpōrea". Ed. Jarvier, Editora de Livros Mëdicos Ltda.

BJORK, V.O., 1948. Brain perfusionir dogs with artificially oxigenated blood. Acta Chir. Scand. 96:1.

BJORK, V.O. 1960. An effective blood heart exchanger for deep hypothermia in association with extracorporeal circulation, but excludind the oxygenation. J. Thoraco Cardiov. Surg. 40: 2437 .

BLUEMLE, L.W.Jr., 1958. Discussion on blood.pumps, Trans. Amer. Soc. Art. Intern. Organs, 4, pg. 80.

BOMMER, J., PERNCKA, E., KESSLER, J., RITZ, E.,1983a. Reduction of silicone particle load during haemodialysis, Amer. Soc.of Nephro1. Abst., 45 A.

BOMMER, J., WALDHERR, R., RITZ, E., 1983b. Silicone disease in long term haemodialysis patients. Cartr. Nephro1., 36, 11526.

BRITISH STANDARD BS5724, 1979. Specification for Safety of Medical Electrical Equipment. Part I: General Requirements. 
BROLIE, 1903, in Conceição; D.S. e Gomes, O.M., 1973. "Circula ção extracorpórea". Ed. Jarvier, Editora de Livros Médicos Ltda.

BRONZINO. J.D., 1982. Computer Applications of Patient Care, Addison-Wesley, London.

BROWN, F., 1961: Hemolysis caused by pumps, Trans. Amer. Soc. Art. Intern. Organs, 7 , pgs. 350-4.

BROWN-SEQUARD, 1858, in Conceição, D.S. e Gomes, O.M., 1973. "Circulação extracorpörea". Ed. Jarvier, Editora de Livros Mé dicos Ltda.

BUCKLEY, D.E., 1984. Investigation of wear phenomena by microscopy, J.Microscop., 135, $119-38$.

Bunge \& SCHMIEDBERgEN, 1876, in Conceição, D.S. e Gomes, O.M. , 1973. "Circulação extracorpörea". Ed, Jarvier, Editora de Li vros Médicos Ltda.

CALEGARE, A.J.A., 1985. Técnicas de garantia de qualidade, Li vros Técnicos e Científicos. Editora SA., Rio de Janeiro.

CANADIAN STANDARDS ASSOCIATION, 1973. Electro-medical equip ment, CSA Standard C22.2 No 125. Forming part of Canadian Electrical Code, Part II, Safety Standards for Electrical Equipment.

CARMICHAEL, D.B., 1959. Development of a heart-1ung machine, Journal Amer. Med. Wom. Assn. 14, pgs. 502-4.

CLARK, S.C.; GOLLAN, F. \& GUPTA,V.P., 1950. Oxygenation of blood by gas dispersion. Science. 111:85.

CLOWES Jr., G.H.A.; HOPKINS, A.L. \& NEVILLE, W.E., 1956a. An artificial lung dependent upon diffusion of oxygen and car bon dioxide through plastic membranes. J. Thoracic Surg. 32: 630 . 
CLOWES Jr., G.H.A.; HOPKINS, A., 1956b. Further studies with plastic filmes and their use in oxygenating blood. Trans. Am. Soc. Artif. Int. Organs, $1: 6$.

CLOWES Jr., G.H.A. \& NEVILLE, W.E., 1958. The membrana oxygena tor. In Allen, J.C. Editor: Extracorporeal circulation. Char les C. Thomas Publisher-Springfield . 111.

CLOWES JR., G.H.A., 1969. Bypass of the heart and lungs with an extracorporeal circulation. In: Gibbon Jr., J.H. SABISTON Jr., D.C. \& SPENCER, F.C., eds: Surgery of Chest. $2 \frac{\text { nd }}{\text { ed. }}$ Philadelphia, W.B. Saunders Company. p. 610-42.

CONCEIÇÃO, D.S. e GOMES, O.M., 1973. "Circulação extracorpō rea". Ed. Jarvier, Editora de Livros Médicos Ltda.

CONSELHO NACIONAL DE PESQUISAS E DESENVOLVIMENTO; CTI, SBA, 1985 "Relatório de Programa Nacional de Automação - Pesquisa e De senvolvimento em Universidades e Centros Tecnológicos e de Pesquisa", Editado pelo Centro Tecnológico para Informätica, (CTI) .

CONSELHO NACIONAL DE -PESQUISAS E DESENVOLVIMENTO, 1981, "Protó tipos de Instrumentos desenvolvidos em centros de pesquisas e Universidades do Brasil", Programa de Instrumentação, Imp. na Gräfica do CNPq.

COWAN, R., 1952. Physiological perfusion pump, J. Appl. Physiol. 4, pgs. 695-7.

CROMWELL, L., WEIBELL, F.J., PFEIFFER, E.A., e USSELMAN, L.B. , 1980. Instrumentacion y Medidas Biomédicas, Marcombo, Boixa reau Editores, Barcelona.

CROSS,F.S.,KAY,E.B.; BERNE, E.S., HTROSE, R.M., e JONES, R.D., 1956. Evaluation of a rotating disc type reservoir-oxygenator.Proc. Soc. Exper. Bio1. \& Med 93:210. 
DALZIEL, C.F., 1972. Electric shock hazard, IEEE Spectrum, Fe bruary, pgs. $41-50$.

DEBAKEY, M.E., 1934. Simple continuous f1ow blood transfusion instrument. Med. Surg. J. 87:386. New Orleans.

DE MARRE, P.A. e MICHAEL, D., 1983. Bioelectronic Measurements, Prentice Hall, Englewood Cliffs.

DE NORAIS, D.J., LEITE, C.S.; JASBIK, W. e FRANCO, S., 1960. Estudo metabôlico e hemodinâmico na circulação extracorpórea com exclusão cardio-vascular, Hospital, Rio de Janeiro, n:57, pgs. $201-23$.

DENNIS. C. SPRENG, D.S.; NELSON, G.E., KARLSON, K.E.; NELSON , R.S.; THOMAS, J.V., EDER, W.P. \& VARCO, R.L., 1951. Development of a pump-oxigenator to replace the heart and lungs: an apparatus applicable to human patients and application to one case. Ann. Surg, 134:709.

DEPARTMENT OF HEALTH AND SOCIAL SECURITY, 1976. Safety code for electro-medical apparatus, Hospital Technical Memorandum No 8 , London.

DE WALL. R.A.; LONG JR., D.M.; GEMMILL, S.J. \& LELLEHEI, C.W., 1959. Certain blood changes in patients undergoing extracor poreal circulation. J. Thorac. Surg. 37:325.

DE WALL, R.A.; GRACE, T.B., MCFEE, A.S. \& CHIECHI, M.A., 1961. Theme and variations on blood oxygenators. I. Buble oxygenators. Surgery, 50:931.

DE WALL, R.A. \& LILLEHEI, C.W., 1962. Simplified total body perfusion: Reduced flows, moderate hipothermia and hemodilution. J.A.M.A. 179:430.

DE WALL, R.A.; WARDEN, H.E.; VARCO, R.L. \& LILLEHEI, C.W., 1956 . Total body perfusion for open cardiotomy utilizing the bub 
ble oxygenator: Physiologic responses in man. J. Thoracic. Surg., $32: 591$.

DE WALL, R.A.; WARDEN, H.E. VARCO, R.L. \& LILLEHEI, C.W., 1957. The helix reservoir pump oxygenator. Surg., Gynec $\&$ Obstetr. $104: 699-710$.

DUBOVY, J., 1978. Introduction to Biomedical Electronics, McGraw-Hil1, New York.

EDMONDS, I.R., 1981, Critical comment on the thermal entrain ment of blood flow, Journal of Medical Engineering and Technology, vol. 5, No 4, pp. 186-8, July.

ELECTRO-CRAFT CORPORATION, 1977. DC. Motors Speed Controls Servo Systems, $3 \stackrel{\text { rd }}{-}$ Edition, Pergamo, New York.

ERHART, E.A., 1969. Elementos de Anatomia Humana, Atheneu Ed. São Paulo, S.A., pgs. 173 a 226, 3. Edição.

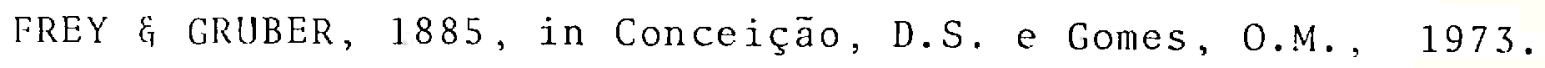
"Circulação extracorpôrea". Ed. Jarvier, Editora de Livros Mẹ dicos Ltda.

GALLETI, P.M. e BRECHER, G.A., 1962. Heart-1ung bypass-Principles and Techniques of extracorporeal circulation, Grun $\xi$ Stratton Inc., New York.

GANONG, W.F., 1972. Fisiologia Mëdica, Atheneu Editora São Pau 10 S/A/MEC, 2a Edição, pgs. 444-469.

GIBBON, J.H.JR., 1937. Artificial maintenance of circulation during experimenta1 occlusion of pulmonary artery. Arch Surg. $34: 1105$.

GIBBON, J.H.JR., 1939. The maintenance of life during experimental occlusion of the pulmonary artery followed by survival. Surg. Gynec. Obstet., 69:602. 
GIBBON, J.H.JR., 1954. Application of a mechanical heart and lung apparatus to cardiac surgery. Minn. Med., 37:371.

GIBBON, J.H.JR.; MILLER, B.J.; FINEBERG, C., 1953. An improved mechanical heart-lung apparatus. Med. Clin. N. Amer., 37:1603.

GOLLAN, F. BLOS; P. \& SHUMAN, H., 1952. Exclusion of heart and lungs from the circulation in the hypothermic, closed chest dog by means of a pump-oxigenator. J. Appl. Physiol. 5:180.

GONSER, D.I. \& KRAFT, O.F., 1976. Design hazards of electrosurgical devices, Medical Instrumentation, vol, 10, No 2 , March-April, pgs. 130-7.

GOMES, O.M.; CONCEIÇÃO, D.S.; LANGER, B.; STOLF, N.A.G.; WOLOS KER, M.; BITTENCOURT, D.; VERGINELIT, G.; OLIVEIRA, S.A. \& ZERBINI, E.J., 1970. Estudo da heparina em circulação extracorpórea. Apresentado ao XXVI Congresso Brasileiro de Cardio logia, Belèm, Brasil.

GOMES, O.M., 1971. Oxigenador de bolhas de coluna variäve1.Te se de doutorado apresentada à Faculdade de Medicina da Uni versidade de São Paulo.

GOTT, V.L.; DE WALL, R.A.; PANETH, M.; ZUHDI, N.; WELRICH, W.; VARCO, R.L. \& LILLEHEI, C.W., 1957. A self-contained, dis posable oxygenator of plastic sheet for intracardiac surgery. Experimental development and clinical application. Thorax, 12:1.

GRANT, E.L., 1952. Statistical Quality Control, McGraw-Hill, New York, 2-ind ed.

GRANT, E.I.,, e LEAVEWORTH, R.S., 1985. Statistical Quality Con trol, 5-h Edition, McGraw Hill, International Student Edition, New York. 
GROSSI, E.A. and BAUMANN, F.G., 1985. Pulsatile flow. The Annals of Thoracic Surgery, vol. 40, No 6, December, pg. 368 .

GROSSI,E.A., CONNOLLY, M.W., KRIEGER, K.H., 1985. Quantification of pulsatile flow during cardiopulmonary bypass to permit direct comparison of the effectiveness of various types of "pul satile" and "nonpulsatile" flow-Surgery, 98:547.

HEAD, L.R.; COENEN, I.P., ANGOLA, E. ; NOGUEIRA, C. ; MENDELSOHN, D. e KAY, E.B., 1960. Operation of the roller pump for ex tracorporeal circulation, The Journal of Thoracic and Cardio vascular Surgery, vol. 39, N:2, Feb.

HEIMBECKER , R.O.; MCKENZIE, F.N.; WALL, W.; ROBERT, A.; BARNICOAT. K.'l. and GERGELY, N., 1976. Bloodless open heart sur gery-the blood sparing effect of a membrana oxygenator and an atraumatic circuit. Abstract of paper submitted to the Society of Thoracic Surgeous.

HEWLETT PACKARD, 1971. Patient Safety, Application Note AN718, Medical Electronics Division, Waltham, Massachusetts.

HOWELL, W.H. E HOLT, E., 1918. Two new factors in blood coagu lation - heparin and proautithrombin. Amer. J. Physiol, 47: 328 .

IUURST, J.W.; LOGUE, R.B.; SCHLANT, R.C.; WENGER, N.K., 1977 . o Coração-Artérias e Veias, Ed. Guanabara Koogan, 2 Vols. 3. edição.

INTERNATIONAL, ELECTROTECHNICAL COMMISSION, 1977. Safety of medi cal electrical equipment. Part 1: General Requirements, Publication 601-1.

INSTITUTE OF ELECTRICAL AND ELECTRONICS ENGINEERS, 1980. Recom mended Practice for Emergency and Standby Power for Industrial and Commercial Applications, IEEE Color Book Series, ANSI/IEEE Std 446-1980. IEEE Orange Book, New York. 
INTERNATIONAL ELECTROTECHNICAL COMMISSION, 1976. Basic aspects of the safety philosophy of electrical equioment used in me dical practice, Publication 513.

INTERNATIONAL ELECTROTECHNICAL COMMISSION, 1981. Collective standard on graphical symbols for electrical equipment in medical practice, Document 62A (Secretariat) 52 .

INTERNATIONAL ELECTROTECHNICAL COMMISSION, 1982 . Requirements for electrical installations in medical establishments, Docu ment $62 \mathrm{~A}$ (Secretariat) 55 .

INTERNATIONAL ELECTROTECHNICAL COMMISSION, 1982. Graphical sym bols for electrical equipment in medical practice, Document 3C (Central office) 94 .

INTERNATIONAL ELECTROTECHNICAL COMMISSION, 1984. Guidelines for administrative, medical, and nursing staff concerned with the safe use of medical electrical equipment, Document 62A (Central office) 22 .

INTERNATIONAL ELECTROTECHNICAL COMMISSION, 1985, General guide lines for the safe application of medical electrical equipment ('hechnical application code), Document 62A (Secretariat) 74 .

INTERNATIONAL ELECTROTECHNICAL COMMISSION, 1985, 1986. Medica1 Electrical Equipment, Sections 1 through 10, Documents 62A (Central office) $24-\mathrm{I}$ through $\mathrm{x}$.

IONESCU, M.I. \& WOOLER, G.H. 1976. Current Techniques in Extracorporeal Circulation, Butterworth $\xi_{G}$ Co (Publishers) Ltd, London.

ISSE KUTZ, B., 1927. Beitrage zur Wirkun des Insulines Bio chem Z. 183:283-297.

JACKMAN, W.S., LONG HEED, W., MARLISS, E.B., ZINMAN, B., ALBHISSER, A.M., 1980. For insulin infusion: a miniature pre cision peristaltic pump and silicone rubber reservoirs. Dia betes Care, 3, 322-31. 
JACOBSON, J.; \& WEBSTER, J.G., 1977. Medicine and Clinical En gineering, Prentice Hall, Englewood-Cliffs.

JACOBY, 1890, in Conceição, D.S. e Gomes, O.M., 1973. "Circula ção extracorpōrea". Ed. Jarvier, Editora de Livros Médicos Ltda .

JAZBIK, W. ; MEIER, M. ; JAZBIK, A.; PERNAMBUCO, P. \& MORAIS, D. J., 1967. Modelo aperfeiçoado de coração-pulmão artificiàl compacto para perfusões com hemodiluição, normotermia e hipo. termia. Arq. Bras. Cardiol. 20 (supl. 1):112.

JORDAN, R.C. e PRIESTER, G., 1976. Refrigeration and air con

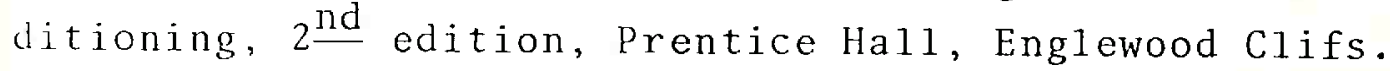

JUNQUEIRA, L.C. e CARNEIRO, J., 1971. Histologia Bäsica, Editora Guanabara Koogan SA, 2 a Edição.

JURAN, J.M.; GRYNA JR., F.M. e BINGHAM JR., R.S., 1979. Quali ty Control Handbook, 3르 Edition, McGraw-Hill, New York.

JUTTA, S., WALTER, P., SCHELD, H. and HEHRLEIN, F., 1985. The effects of retrograde perfusion of cardioplegic solution in cardiac operations. The Journal of Thoracic and Cardiovascular Surgery, $90: 882-7$.

KAIJSER, L., JANSSON, E., SCHMIDT, W., and BONFIM, W. , 1985 . Myocardical energy depletion during profound hypothermic car dioplagia for cardiac operations, The Journal of Thoracic and Cardiovascular Surgery, 90:896-900.

KANTER, E.S., 1974. Servicing Biomedical Equipment, Howard W. Sams \& Co, Indianopolis.

KAPUR, K.C. ६ LAMBERSON, L.R., 1977. Reliability in engineering design, John Wiley $\xi$ Sons, New York. 
KATZ, A.M., 1977. Physiology of the Heart, Raven Press, New York.

KAY, E.B., CROSS, F.S., BERNE, R.M., HIROSE, Y. \& JONES, R.D. , 1956. Description and evaluation of a rotating disc type re servoir oxygenator. Proc. Soc. Exper. Bio1. Me1. 93:210.

KAY, E.B., ZIMMERMAN, H.A., BERNE, R.M., HIROSE, Y., JONES, R. I. and CROSS, F.S., 1956. Certain clinical aspects of the use of a purp oxygenator. J.A.M.A., 162:639.

KIMMICH, H.P., 1981. Monitoring of Vital Parameters during Ex tracorporeal Circulation, S. Karger AG, Basel, Switzerland.

KIVENSON, G., 1971. Durability and Reliability in Engineering Design, Hayden Book Comnany, Inc., New York.

KRESTEL, E., 1973. Safety of electromedical equipment, Electromedica 3 , pgs. $120-5$.

KURUSZ, M., CHRISTMAN, E.W., WILLIAMS, E.H., TYERS, G.F.o. 1980. Roller pump induced tubing wear. Another argument in favour of arterial line filtration. J. Extra-corp. Tech., 12 , $49-59$.

LAOHAPAND, T.T., OSMAN, E., MORLEY, A.R., WARD, M.K., KERR, D. N.S., 1982. Accumulation of silicone elastomer in regular dialysis, Proc. EDTA, 19, 143-52.

LEFRAK, E.A.; STEVENS, P.M.; NOON, G.P.; DEBAKEY, M.E., 1973 , Current status of prolonged extracorporeal membrane oxygenation for acute respiratory failure, Chest, vol.63, May, pgs. $773-82$.

LEGALLOIS, J.J.C., 1813. Experiments on the principle of life. Translated by N.C. and J.C. Naucrede. Philadelphia. 
LEMISKI, M.J., 1980. The deterioration of silicone-rubber tu bes as a peristaltic pump for insulin delivery. Thesis University of Toronto, 1980 .

LEONG, A.S.Y., DISNEY, A.P.S., GOVE, D.W., 1981. Refractile particles in liver of haemodialysis patients, Lancet, i, 889 .

LEVY, M.N., 1954. The relationship between pressure and flow in the systemic circulation of the dog. Circulation Res. 2:372.

LIDDICOAT, J.E., BEKASSY, S.M.; BEALL, A.C. JR., GLAESER, D.H. and DE BAKEY, M.E., 1975. Membrane vs bubble oxygenator:cli nical comparison, Ann. Surg., vol. 181, N 5, pp 747-53, May.

LILLEHEI, C.W. ; WARDEN, H.E.; VARCO, R.L. ; STANLEY, P. \& -DEWALL, R.A., 1957. Use of cardiopulmonary bypass in surgical treatment of 305 patients with congenital or acquired cardiac cardiac disease - Archives of Surgery.

LOEBELL, 1845, in Conceição, D.S. e Gomes, O.M., 1973. "Circulação extracorporea". Ed. Jarvier, Editora de Livros Médicos Ltda:

LOURENÇO FILHO, R.C.B., 1984, Controle Estatístico de Qualidą de, Livros Técnicos e Científicos Editora S.A., Rio de Janeiro.

LUDWIG, 1865, in Conceição, D.S. e Gomes, O.M., 1973. "Circula ção extracorpoorea". Ed. Jarvier, Editora de Livros Médicos Ltda .

LUNDAR, T., LINDEGAARD, K.F., FRYSAKER, T., AASLIDE, R. , GRIP , A. and NORNES, H., 1985. Dissociation between cerebral auto regulation and carbon dioxide reactivity during nonpulsatile cardiopulmonary bypass. The Annals of Thoracic Surgery, December, pp. $582-7$. 
LUNT, M.J., 1983. Electrical safety, Journal of Medical Engi neering and Technology, vol. 7, No 5, pp. 251, September/October.

MACINTYRE, A.J., 1980. Bombas e Instalações de Bombeamento, Ed. Guanabara Dois S.A., Rio de Janeiro.

MAGALHAES, H.P.; SOUZA, L.C.B.; KORMANN, D.S.; AQUINO, M.M. ; LINO, G.V. \& JATENE, A.D., 1966. Oxigenador de bolhas com permutador de calor: novo modelo compacto sem hëlice. Arq. Bras. Cardiol. $19(\sup 1.1): 63$.

MC DICKEN , W.N., 1981. Diagnostic Ultrasonics - Principles and Use of Instruments - 2으 Edition. John Willey, New York.

MCPHUN, M.K., 1981. Engineering design and appropriate technology, Journal of Medical Engineering and Technology, vol. 5, $N^{\circ}$ 2, pp. 80-3, March.

MORAES, J.C.T.B. e BARROS MORAES, N.L.T., 1979a. "Patente P. P. No 7908096 de 10/12/79 para PI - "Aperfeiçoamento em Bom bas" - Garantia de Prioridade, publicada na Revista de Pro priedade Industrial no 556 de 16/06/81, pg. 42 - Jolui Engenharia Biomédica Eletro-Eletrônica Ltda.

MORAES, J.C.T.B. e BARROS MORAES, N.L.T., 1979b. "Patente P. P. No 7908705 de 11/12/79 para PI - "Refrigerador" - Garantia de Prioridade, publicada na Revista da Propriedade Indus trial no 558 de 30/06/81, pg. 32 - Jolui Engenharia Biomédica Eletro-Eletrônica Ltda.

MORAES, J.C.T.B. e VITA, G.M., 1981. "Desafios de problemas da saüde no Brasil à Engenharia Biomédica", Anais do VII Con gresso Brasileiro de Engenharia Biomédica, Petrópolis - R. J., páginas 131-137.

MORAES, J.C.T.B. e BARROS MORAES, N.L.T., 1981. "Novo Sistema de Circulação Extracorpórea" Resumos do VII Congresso Brasileiro de Engenharia Biomédica, Petrópolis - R. J., pg. 65. 
MORAES, J.C.T.B., 1983. "Engenharia Biomëdica", Palestra pro ferida no 2 ㅇ Seminário e Feira de Eletrônica da Baixada San tista, patrocinado pela Escola Treinasse, Santos - S.P.

MORAES, J.C.T.B., 1985. "Instrumentação Biomédica e Insta1a çōes Elëtricas para fins mëdicos: um curso fundamental" , Anais do IX Congresso Brasileiro de Engenharia Biomëdica, Cam pinas - S.P., pgs. 215 a 219.

MORAES, J.C.T.B., 1986. "Equipamento Eletro-Médico e Instalações Elētricas para fins médicos-Normalização e Padronização", Seminário Especial oferecido pelo Centro Latino Americano de Capacitacion y Desarrollo de Empresas (CELACADE) em 21-22 de março de 1986 - São Paulo, S.P.

MORLEY, A.R:, BARRON, D., THOMPSON, P., HOENICK, N.A., HARBOT TLE, S. and KERR, D.N.S., 1986. Surface alterations in dia lysis roller pump inserts: A scanning electron microscopy study, Journal of Biomedical Engineering, vol. 8, No 3, pp. 255-61, July, Butterworths.

NATIONAL FIRE PROTECTION ASSOCIATION, 1975. National Electrical Code, Publicação No 70-1975.

NETTER, F.H., 1971. Heart. The Ciba Collection of Medical I1lustrations, Vol. 5, Edited by Frederick F. Youkman, CIBA.

NEWBAUER, O. E GROSS, W., 1910. Zur Kenntniss des Tyrosinabbaus in der kunstlich curchbluteten Leber. Happe-Seyler's z. Physiol. Chem. 67:212-29.

OCCUPATIONAL SAFETY AND HEALTH ADMINISTRATION, 1983-Revised. An Illustrated Guide to Electrical Safety, U.S. Department of Labor, OSHA 3073 .

O'CONNOR. P.D.T., 1985. Practical Reliability Engineering, $2^{\text {nd }}$ Edition, John Wiley $\&$ Sons, New York. 
PALMER, C.F., 1974. Controle total de qualidade, Ed. Edgard Blücher Ltda./Editora da Universidade de São Paulo.

PANERAI, R.B., 1985. "Prioridades da pesquisa em Engenharia Bio médica - Brasil, 1985", Anais do IX Congresso Brasileiro de Engenharia Biomédica, Campinas - S.P., pgs. 207 a 213.

PANETH, M. , SELLERS, R., GOTT, V.L., WEIRICH, W.L., ALLEN, P., READ, R.C. \& LILLEHEI, C.W., 1957. Physiologic studies upon prolonged cardiopulmonary by-pass. J. Thoracic Surg. 34:570.

PHYSIOLOGICAL MEASUREMENT TOPIC GROUP, 1983. Safe Design and Construction of Electromedical Equipment, Hospital Physicists' Association, London.

RICHARDSON, D.R., 1976. Basic Circulatory Physiology. Little, Brown and Company, Boston.

ROBERTS, V.C., 1982. Design excellence in medical engineering -luxury or necessity?, Journal of Medical Engineering and Technology, vol. 6, No 1, pp. 8-11, Jan/Feb.

ROLFE, P., 1982. Monitoring of vital parameters during extracorporeal circulation, Journal of Medical Engineering and Technology, vol. 6, No 4, pg. 164, Jul/Aug.

ROTH, H.H.; TELTSCHER, E.S. e KANE, I.M.. 1975. Electrical Sa fety in Health Care Facilities, Academic Press, New York.

RUSHMER, R.F., 1976. Cardiovascular Dynamics, W.B. Saunders Company, 4-th Edition.

SALTZMANN, 1949, in Conceição, D.S. e Gomes, O.M., 1973. "Circu lação cxtracorpörea". Ed. Jarvier, Editora de Livros Médicos Ltda.

SCHRONLR, W. 1882 , Iber die bildungstatte des harnstoffs. Arch. Exper. Path. Pharmako1. 15: 364-402. 
SCOTT, R.N. and PAASCHE, P.E., 1986. Safety considerations in clinical engineering, CRC Critical Reviews in Biomedical Engineering, volume 13 , issue 3 .

SECRETARIA ESPECIAL DE INFORMĀTICA (SEI)/PR/CSN, 1983a, Seminārio de Instrumentação Biomëdica (Médico-Hospitalar), Reco mendações GF-01: Demanda, Recomendações GT-02: Oferta, Recó mendaçōes GT-03: Pesquisa e Desenvolvimento, Classificação de Instrumentos Médico-Hospitalares.

SECRETARIA ESPECIAL DA INFORMÁTICA/C.S.N., 1983b. A to Normati vo n: 024/83 - Dispōe sobre as condições prëvias para a anáa 1 ise de projetos de fabricação de sistemas, equipamentos e dispositivos digitais de tratamento de informações referen tes às grandezas físicas que menciona - publicado no Diārió Oficial de 31 de março de 1983. Seção 1 pg. 9205.

SECRETARIA DO PLANEJAMENTO/CNPq, 1983. "Avaliação e Perspectị. vas - 1982 - Engenharias - al. Engenharia Biomēdica", Secré taria de Planejamento - Conselho Nacional de Desenvolvimento Científico e Tecnológico - Coordenação Editorial Brasília Redator: Wang Binseng (Unicamp - Faculdade de Engenharia):

SECRETARIA DO PLANEJAMENTO/CNPq, 1985. "A instrumentação biomëdica e o problema da engenharia de manutenção nos hospitais brasileiros", Secretaria de Planejamento - Conselho Na cional de Desenvolvimento Científico e Tecnológico - Coordenação Editorial Brasília - Coordenadores da Edição: João Augusto Costa Lima e Lygia Donadio.

SHAMES, I.H., 1962, Mechanics of Fluids, McGraw Hill Book Co., New York.

SHAW, A. and LEWIS, R.B., 1981. Methods of measuring blood loss during surgery, Journal of Medical Engineering and Tech nology, vol. 5, No 4, pp. 196-7, July. 
SIEMENS AKTIENGESELLSCHAFT, 1973. Medida de la resistência de conductores de protección para anaratos y equipos electromédicos, Publicação PT 01/1-002, R1.0922.41.08.01.

SMITH, C.O., 1976. Introduction to realibility in design. MC Graw-Hill Kogakusha, Ltd., Tóquio.

SOCIEDADE BRASILEIRA DE ENGENHARIA BIOMEDICA. Anais de Congressos Brasileiros de Engenharia Biomédica.

SOLIS, R.T.; KENNEDY, P.S.; BEAL, A.C.., JR.; NOON, G.P.; and DE BAKEY:, M.E., 1975. Cardionulmonary bypass-microembolization and platelet aggregation, Circulation, vol. 52, pp $103-8$, Ju1y.

STILLMAN, R., 1983. Safe design and construction of electromedical equipment, Journal of Medical Engineering and Techno logy, vol. 7, No6, pg. 314, Nov/Dec.

STONER, D.L., SMATHERS, J.B., HYMAN, W.A., CLAPP, D.E. and DUN CAN, D.D., 1982. Engineering a Safe Hospital Environment, in the Wiley-Interscience Series on "Biomedical Engineering and Health Systems, edited by J.H. Milsum, John Wiley \& Sons, Chi chester and New York.

TAYLOR, J.D., 1957. A mechanica1 heart-lung apparatus, I BM Journal Research Development, 1, pgs. 330-340.

THOMAS, H.E., 1979. Handbook of Automated Electronic Clinical Analysis, Reston Publishing Co, Reston, Virginia.

TISCHLER, M., 1981. Experiments in General and Biomedical In trumentation, McGraw-Hi11, New York.

TOMPKINS, W.J. F WEBSTER, J.G., 1981. Design of Microcomputer Based on Medical Instrumentation, Prentice Hall, Englewood Cliffs. 
TRAISTER, R.J., 1981. Principles of Biomedical Instrumentation an Monitoring, Reston Publishing Co, Reston, Virginia.

TRUDELL, L.A.; FRIEDMAN, L.I.; KAKVAN, M. ; GALLETTI, P.M. and RICHARDSON: P.D., 1972. Evaluation of a disposable membrane oxygenator. Trans. Amer. Soc. Artif. Int. Organs, vol. XVIII, pgs. $538-44$.

VIEIRA, R.C.C., 1971. Atlas de Mecânica dos Fluídos. Vol. 1: Cinemätica: vol. 2: Estâtica; vol. 3: Fluídodinâmica, Ed. Edgard Blucher Ltda/Ed. da Universidade de São Paulo. São Pau 10 .

VITA, G.M., 1982. "Relacionamento Governo X ABNT nas atividades de normalização e qualificação". Trabalho apresentado na Reunião Geral da ABNT - 1982 perante a 2a Comissão: Participação do Governo, SINMETRO, Orgãos e Empresas Estatais.

VON EULER, 1932, in Conceição, D.S. e Gomes, O.M., 1973. "Circu lação extracorpörea". Ed. Jarvier, Editora de Livros Médicos Ltda.

WAENY, J.C.C., 1980. Noções bāsicas de confiabilidades metrológica, Instituto de Pesquisas Tecnológicas de São Paulo.

WAENY, J.C.C., 1982. Confiabilidade metrológica: Conceitos báa sicos para um Sistema de Medições. Instituto de Pesquisas Tec nológicas de São Paulo.

WEBSTER, J.G., 1978. Medical Instrumentation - Application and Design, Houghton, Mifflin .

WEBSTER, J.G. e COOK, A.M., 1979. Clinical Engineering-Princ $\underline{i}$ ples and Practices, Prentice Hall, Englewood Cliffs.

WESTINGHOUSE, ELECTRIC CORPORATION, 1984. Electrical Maintenan ce Hints, volume 1 - General Maintenance, Printing Division, rorbes Road, Trafford. 
WESTINGHOUSE, 1984. Electrical Maintenance Hints, volume 2 Industrial Equipment Maintenance.

WESTINGHOUSE, 1984. Electrical Maintenance Hints, volume 3 Power Apparatus.

WESTINGHOUSE, 1984. Reference Material, Tables and Formulas, 4 volumes + Index.

WILL, D.W. \& DOLAN, A.M., 1976. Intensive Care Instrumentation, Academic Press Inc., London.

IVRIGHT, G., FURNESS, A., 1985. What is pulsatile flow? Ann. Tho rac. Surg., 39: 401 .

:INTON, F.R. e LIPPOLD, O.C.I., 1970. Fisiologia Humana, Ed. Cultura Médica, pgs. 33-55, 6? Ed. Inglesa, 4? Ed. Brasileira.

ZUANElla, V.M. e PEREz, V.R.A., 1986. Projeto de resfriamento

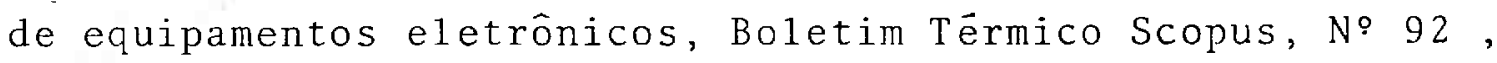
Fev̄/86, Ano 8.

ZUHDI, N.; KIMMELL, G.; CAREY, J. \& GREER, A., 1952. Experimen tal Maintenance of the circulation by mechanical pumps-Surge ry. 31: 769 .

ZUHDI, N.; KIMMELL, G.; MONTROY, Y. ; CAREY, J. ; GREER, A. , 1960. A system for hypothermic perfusion. J. Thorac. Cardiov. Surg. $39: 629$.

ZUHDI, N.; MC COLlOUGH, B.; CAREY, J. \& GREER, A., 1961. Dou ble helical reservoir heart lung machine designed for hypother mic perfusion. Arch Surg. Chicago. 82:320..

ZUHDI, N., 1962. Hemodilution and coagulation factor in extracorporeal circulation. J. Thorac. Cardiov. Surg. 43:816. 